\title{
Contemporary Developments in Child Protection
}

\section{Volume 2: Issues in Child Welfare}

Edited by

Nigel Parton

Printed Edition of the Special Issue Published in Social Sciences

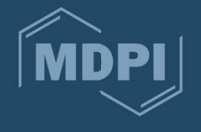


Nigel Parton (Ed.)

Contemporary Developments in Child Protection

\section{Volume 2}

Issues in Child Welfare<smiles>[194In]</smiles> 
This book is a reprint of the special issue that appeared in the online open access journal Social Sciences (ISSN 2076-0760) in 2014 (available at:

http://www.mdpi.com/journal/socsci/special_issues/child_protection).

\section{Guest Editor}

Nigel Parton

University of Huddersfield, Queensgate,

Huddersfield, HD1 3DH

UK

\section{Editorial Office}

MDPI AG

Klybeckstrasse 64

Basel, Switzerland

Publisher

Shu-Kun Lin

Editorial Manager

Alistair Freeland

\section{Edition 2015}

MDPI • Basel • Beijing • Wuhan

ISBN 978-3-03842-086-6 (PDF) Volume 1 - 3

ISBN 978-3-03842-087-3 (PDF) Volume 1

ISBN 978-3-03842-088-0 (PDF) Volume 2

ISBN 978-3-03842-089-7 (PDF) Volume 3

(C) 2015 by the authors; licensee MDPI, Basel, Switzerland. All articles in this volume are Open Access distributed under the Creative Commons Attribution 3.0 license (http://creativecommons.org/licenses/by/3.0/), which allows users to download, copy and build upon published articles even for commercial purposes, as long as the author and publisher are properly credited, which ensures maximum dissemination and a wider impact of our publications. However, the dissemination and distribution of copies of this book as a whole is restricted to MDPI, Basel, Switzerland. 


\section{Table of Contents}

List of Contributors $\mathrm{V}$

About the Guest Editor VII

Preface

IX

Susan Young, Margaret McKenzie, Cecilie Omre, Liv Schjelderup and Shayne Walker

Practicing from Theory: Thinking and Knowing to "Do" Child Protection Work

Reprinted from: Soc. Sci. 2014, 3(4), 893-915

http://www.mdpi.com/2076-0760/3/4/893

\section{Elizabeth Fernandez}

Child Protection and Vulnerable Families: Trends and Issues in the Australian Context

Reprinted from: Soc. Sci. 2014, 3(4), 785-808

http://www.mdpi.com/2076-0760/3/4/785

\section{Eline Vyvey, Rudi Roose, Lieselot De Wilde and Griet Roets}

Dealing with Risk in Child and Family Social Work: From an Anxious to a

Reflexive Professional?

Reprinted from: Soc. Sci. 2014, 3(4), 758-770

http://www.mdpi.com/2076-0760/3/4/758

\section{Carme Montserrat}

The Child Protection System from the Perspective of Young People: Messages from 3 Studies Reprinted from: Soc. Sci. 2014, 3(4), 687-704

http://www.mdpi.com/2076-0760/3/4/687

\section{Shanti Raman, Michelle Maiese, Katrina Hurley and David Greenfield}

Addressing the Clinical Burden of Child Physical Abuse and Neglect in a Large

Metropolitan Region: Improving the Evidence-Base

Reprinted from: Soc. Sci. 2014, 3(4), 771-784

http://www.mdpi.com/2076-0760/3/4/771 
M. Angeles Balsells, Crescencia Pastor, Pere Amorós, Ainoa Mateos, Carmen Ponce and Alicia Navajas

Child Welfare and Successful Reunification through the Socio-Educative Process:

Training Needs among Biological Families in Spain

Reprinted from: Soc. Sci. 2014, 3(4), 809-826

http://www.mdpi.com/2076-0760/3/4/809

\section{Nuria Fuentes-Peláez, Pere Amorós, Crescencia Pastor, María Cruz Molina and}

\section{Maribel Mateo}

Assessment in Kinship Foster Care: A New Tool to Evaluate the Strengths and Weaknesses

Reprinted from: Soc. Sci. 2015, 4(1), 1-17

http://www.mdpi.com/2076-0760/4/1/1

Joanna Alexander, Shanti Raman, Terence Yoong and Belinda Mawhinney

Improving Pathways to Assessment and Care for Infants of Substance Abusing Mothers:

Are We Getting It Right?

Reprinted from: Soc. Sci. 2015, 4(1), 192-204

http://www.mdpi.com/2076-0760/4/1/192

\section{Emily Keddell}

Current Debates on Variability in Child Welfare Decision-Making:

A Selected Literature Review

Reprinted from: Soc. Sci. 2014, 3(4), 916-940

http://www.mdpi.com/2076-0760/3/4/916

\section{Doug Magnuson}

The Productive Uses of Conflict in Child Protection

Reprinted from: Soc. Sci. 2014, 3(4), 672-686

http://www.mdpi.com/2076-0760/3/4/672 


\section{List of Contributors}

Joanna Alexander: Liverpool Community Health, Health Services Building Level 3, Corner Campbell \& Goulburn St., Liverpool, NSW 2170, Australia

Pere Amorós: Department of Educational Methods and Diagnostics, School of Education, University of Barcelona, 08035 Barcelona, Spain; Department of Methods of Research and Diagnosis in Education, University of Barcelona, Passeig de la Vall d'Hebron 171, Edifici Llevant, Barcelona 08035, Spain M. Angeles Balsells: Department of Pedagogy and Psychology, School of Educational Sciences, University of Lleida, 25001 Lleida, Spain

María Cruz Molina: Department of Methods of Research and Diagnosis in Education, University of Barcelona, Passeig de la Vall d'Hebron 171, Edifici Llevant, Barcelona 08035, Spain Lieselot De Wilde: Department of Social Welfare Studies, Ghent University, Henri Dunantlaan 2, Ghent 9000, Belgium

Elizabeth Fernandez: School of Social Sciences, The University of New South Wales, Sydney NSW 2052, Australia

Nuria Fuentes-Peláez: Department of Methods of Research and Diagnosis in Education, University of Barcelona, Passeig de la Vall d'Hebron 171, Edifici Llevant, Barcelona 08035, Spain David Greenfield: Australian Institute of Health Innovation, University of New South Wales, Sydney, NSW 2052, Australia

Katrina Hurley: Child, Youth, Women and Families Health, South Eastern Sydney Local Health District, GPO Box 1614, Sydney, NSW 2001, Australia

Emily Keddell: Department of Sociology, Gender and Social Work, University of Otago, PO Box 56, Dunedin 9054, Aotearoa, New Zealand

Doug Magnuson: School of Child and Youth Care, University of Victoria, Box 1700 STN CSC, Victoria, BC V8W 2Y2, Canada

Michelle Maiese: Child Protection, Sydney Local Health District, Croydon Health Centre, 24 Liverpool Road, Croydon, NSW 2132, Australia

Maribel Mateo: Department of Methods of Research and Diagnosis in Education, University of Barcelona, Passeig de la Vall d'Hebron 171, Edifici Llevant, Barcelona 08035, Spain

Ainoa Mateos: Department of Educational Methods and Diagnostics, School of Education, University of Barcelona, 08035 Barcelona, Spain

Belinda Mawhinney: Sydney Local Health District, Croydon Health Service, 24 Liverpool Road, Croydon, NSW 2132, Australia

Margaret McKenzie: School of Social Services, Otago Polytechnic, Dunedin 9054, New Zealand Carme Montserrat: University of Girona, Plaça Sant Domènec, 9, 17071 Girona, Spain

Alicia Navajas: Department of Pedagogy and Psychology, School of Educational Sciences, University of Lleida, 25001 Lleida, Spain

Cecilie Omre: Department of Social Studies, University of Stavanger, Stavanger 4036, Norway 
Crescencia Pastor: Department of Educational Methods and Diagnostics, School of Education, University of Barcelona, 08035 Barcelona, Spain; Department of Methods of Research and Diagnosis in Education, University of Barcelona, Passeig de la Vall d'Hebron 171, Edifici Llevant, Barcelona 08035, Spain

Carmen Ponce: Department of Pedagogy, School of Educational Sciences and Psychology, Rovira i Virgili University, 43003 Tarragona, Spain

Shanti Raman: Liverpool Community Health, Health Services Building Level 3, Corner Campbell \& Goulburn St., Liverpool, NSW 2170, Australia

Griet Roets: Department of Social Welfare Studies, Ghent University, Henri Dunantlaan 2, Ghent 9000, Belgium

Rudi Roose: Department of Social Welfare Studies, Ghent University, Henri Dunantlaan 2, Ghent 9000, Belgium

Liv Schjelderup: Department of Social Studies, University of Stavanger, Stavanger 4036, Norway Eline Vyvey: Department of Social Welfare Studies, Ghent University, Henri Dunantlaan 2, Ghent 9000, Belgium

Shayne Walker: Department of Sociology, Gender and Social Work, University of Otago, Dunedin 9016, New Zealand

Terence Yoong: Sydney Local Health District, Croydon Health Service, 24 Liverpool Road, Croydon, NSW 2132, Australia

Susan Young: Social Work and Social Policy, University of Western Australia, 35 Stirling Highway, Crawley 6009, Australia 


\section{About the Guest Editor}

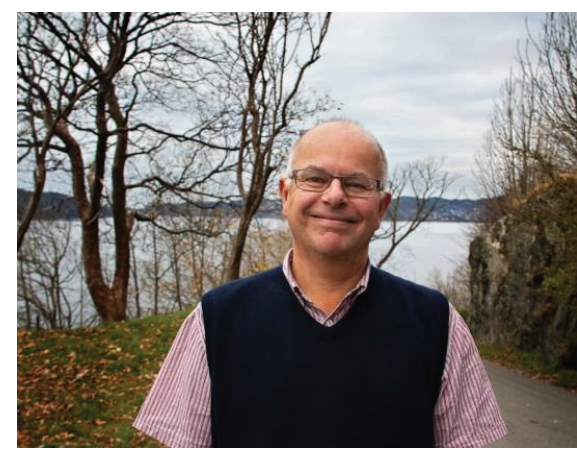

Nigel Parton is Professor in Applied Childhood Studies at the University of Huddersfield, England where he has worked for most of the last forty years. A social worker by background he has written and edited over twenty books and a hundred articles and chapters on the broad areas of child protection, child welfare and social work and in recent years has developed a particular interest in studying and comparing child protection policies and systems in different jurisdictions. Recent books include 'Child Protection: International Trends and Orientations' (edited with N Gilbert and M Skivenes. New York: Oxford University Press, 2011) and 'The Politics of Child Protection: Contemporary Developments and Future Directions' (Basingstoke; Palgrave/Macmillan, 2014). 



\section{Preface}

\section{Developments in Child Protection: Foreword(s) for Three Book Volumes}

The last forty years has witnessed increasing public, political and media concern about the problem of child maltreatment and what to do about it. This is now evident in most jurisdictions and is receiving serious attention from many international and trans-national organisations. While the '(re)discovery' of the problem in the USA was particularly associated with the 'battered baby syndrome' this has now broadened to include: physical abuse, sexual abuse, neglect, emotional abuse, abuse on the internet, child trafficking, female genital mutilation, sexual exploitation and refers to all children and young people, not just babies. Similarly, the focus of attention has broadened from intra-familial abuse to abuse in a whole variety of settings including schools, day care centres, churches, youth and sports clubs and the wider community more generally. There has also been a broadening of concern from not simply protecting children and young people from serious harm to also attempting to prevent the impairment of their health and development and to ensure that they are able to grow up in circumstances which are consistent with the provision of safe and effective care so that all children can achieve the best outcomes.

In the process, the laws, policies, practices and systems which have been developed to try to identify and prevent child maltreatment have become much more wide-ranging and complex and have themselves been subject to continual criticism and review. A wide range of professionals and members of the community are all seen to have key roles to play in both protecting children and young people and also assessing and monitoring actual and potential perpetrators.

However, while these issues have been subject to often heated and high profile media and political debate, rarely have they received sustained analytic and research attention in the social sciences. It was in this context that the internet journal Social Sciences, in 2013, invited papers for publication in a Special Issue dedicated to the topic and these were published from July 2014 onwards. In the event thirty papers were accepted for publication - far and away the highest number of papers submitted and accepted previously for a Special Issue in the journal. Authors came from a range of countries including: Australia, Belgium, Canada, England, Ethiopia, France, Netherlands, New Zealand, Scotland, South Africa, Spain, and the USA. Sixteen of the thirty papers were based on original research, ten provided a policy analysis, two were based on particular practice developments, one was a literature review, and one provided a more theoretical/conceptual piece. Authors came from a wide range of disciplinary backgrounds including: sociology, history, social policy, sports science, psychology, social work, education, law and various branches of health and medicine. The focus of the papers was diverse, though they did tend to cluster around a number of themes and it is these that have provided the rationale for the organisation of the papers into the three published volumes; however, the process of organising and ordering the papers proved a particular challenge. There are ten papers in each volume. 


\section{Volume 1: Policy Changes and Challenges}

Volume 1 takes as its central theme the ongoing and challenging issues which child protection agencies have to address and the policy and practice initiatives that are developed to try and address these. The volume includes papers on: the relationship between the decline in the rate of 'unnatural' deaths and the growth of concern about child abuse in the USA between 1940 and 2005; mandatory reporting; the balance between providing urgent intervention and meeting chronic need; risk and the Public Law Outline in England; the nature and implications of 'child centred' policies; the impact of intimate partner and family violence; the intended and unintended consequences of high profile child abuse scandals; developing multi-disciplinary team work in a health setting; and the possibilities of technology-based innovations in prevention programmes.

\section{Volume 2: Issues in Child Welfare}

Volume 2 is primarily concerned with how best to respond to maltreatment 'within' the family and hence has a range of papers which are much more concerned with the area of policy and practice more traditionally framed in terms of 'child welfare' and social work with children and families. It also includes a paper on how to respond to child maltreatment and neglect in a large hospital context.

\section{Volume 3: Broadening Challenges in Child Protection}

Volume 3 takes a somewhat broader brief and reflects many of the changes over the past twenty five years in terms of the broadening of concerns from maltreatment within the family to maltreatment in a variety of extra-familial contexts, including: sport, the internet, various institutional settings and is much more concerned with sexual abuse and the challenges for criminal justice and public protection.

Nigel Parton

Guest Editor 


\title{
Practicing from Theory: Thinking and Knowing to "Do" Child Protection Work
}

\section{Susan Young, Margaret McKenzie, Cecilie Omre, Liv Schjelderup and Shayne Walker}

\begin{abstract}
Child protection practice in much of the Western world is performed using some specific models with limited attention paid to the underpinning of informing worldviews, theories for practice (explanatory theories) and theories of practice (intervention theories). Over the past few years we have explored how child protection practice may be undertaken using a child rights perspective and community development principles and practices. From this we have developed a model which we here seek to support with worldviews, explanatory and intervention theories. We hope this theoretical framework answers some of the complexity found in the "wicked problem" of child abuse and provides guidance to the practice of protecting children.
\end{abstract}

Reprinted from Soc. Sci. Cite as: Young, S.; McKenzie, M.; Omre, C.; Schjelderup, L.; Walker, S. Practicing from Theory: Thinking and Knowing to "Do" Child Protection Work. Soc. Sci. 2014, 3, 893-915.

\section{Introduction}

We are social work educators in Aotearoa New Zealand, Norway and Western Australia (WA) ${ }^{1}$ and, concerned that our child protection systems have tended towards investigatory rather than supportive strategies [1] to deal with what has become a "wicked problem" [2], have been exploring the development of alternate approaches. Seeking good practice examples from child protection practitioners we have been encouraged by the efforts practitioners have made to understand the circumstances of the families they work with and design appropriate and diverse interventions to keeping children safe. From these examples we have developed a framework for practice that is informed by child rights perspectives, community development and strengths based principles and practices $[3,4]$. We advocate for a more nuanced approach than we find exists in the countries in which we work. Importantly, through this framework is interwoven an Indigenous perspective, specifically calling on Maori knowledges, as one of our group is Maori, to reassert the epistemological equality [5] to which we subscribe as educators and practitioners. While our orientation is with Maori worldviews, we maintain that Indigenous worldviews from the places in which social work is practiced are similarly necessary to include. As Russell ([6], p. 10) notes, Native Theory maintains "the right of Indigenous people to make sense of their time and place in this world". Social work theory and practice continues to be culturally invigorated and challenged by Indigenous peoples globally and locally [7-19]. Indigenous knowledges are particularly important in relation to child protection, for in many jurisdictions, Indigenous children and families, as well as children and families from many immigrant minority groups, are the most affected by child protection policy and

1 While WA is not an autonomous nation, it is the jurisdiction within Australia with responsibility for child protection for that State under the country's federal system. 
practice, with, often, minimal attention paid to Indigenous knowledges and practices for protecting children. In seeking to be culturally robust we wholeheartedly accept that theory and practice are not a-cultural and should enhance and support "other" ways of knowing rather than relegating them to being an add-on, exotic or alternative.

\section{Background}

Contrary to the policy and societal inclination towards a single solution to child abuse, a contradiction in terms of the nature of "wicked problems", the practitioners whose examples have led to this framework have sought to apply complex thinking, and thus accept the possibility of complex solutions, to the questions of "what is happening, why, and what can/should be done?" in relation to each individual situation. If the "what should be done?" is answered by the decision to remove the child to a place of safety then that is what is done. But in many cases we maintain that the answer can be to co-arrange or co-construct different supports with the family, to engage with families so that they can participate productively in creating safety for their children, to assist families develop missing skills and so on. For it is now well established that, even with the best intentions, there is a limit to how well and for how long the State can be a parent [20] to a child who is removed from his/her family. The long-term intent for social work practice, and indeed society, is to assist families who are currently not looking after their children well enough to do so and to help those children grow into stable and productive adults. However, despite decades of targeted policy and practice, current systems are still characterised by growing numbers of children taken into care, increasing numbers of care placements breaking down with consequent instability for children, fewer families being supported to care for their children and fewer families being willing to care for others' children with resultant institutional care. It is not a system which serves societal stability well. How to address the complex and varied needs of this "wicked problem" requires complex and varied solutions, not merely more of the same.

The other side of the equation, the preparation of social workers to work in this complex area, also demonstrates challenges. De-professionalisation, new public management technologies distancing decisions and policy from the lived experiences of both clients and workers, and the increasing use of standardising and quantifying tools for information management in child protection have all affected the practice of social work with child protection. As Bay states: "One of the concerns is that what newer practitioners learn is how to become good at ticking boxes rather than critically thinking about their practice" ([21], p. 94). Bay posits that technologies of the state are replacing critical engagement with the very precarious area of keeping children safe, echoing Arendt's critique of administrative systems in which "nobody rules" ([21], p. 95).

In this article, in suggesting a different way of considering these dual challenges of the lack of complex responses and of practitioners restricted by systems, we return to the definition of social work to reinforce our view of the necessity of theory for practice [22] by maintaining the inseparability of theory and practice. We find it important to counter the view that theory is irrelevant or overused in practice, as suggested in the headline accompanying the release of the Narey report in the UK [23], a debate which has coincided with this, our fourth paper on these matters, and which has particular relevance to the training of social workers. 
A further complication is a trend found in new public management which locates thinking with managers and doing with service deliverers ([21], p. 8) supporting the, to us, quaint, idea that a-theoretical practice is to be more valued. In contrast we are strongly of the view, following Lewin, that there is nothing more practical than a good theory ([24], p. 169). Vankeenstiste \& Sheldon [25] summarise Lewin's work in which he maintained there was a joint role to be played by theorists and researchers in trying to ensure that particularly problematic situations are addressed using new ideas or conceptualisations of those problems derived from and tested in practice. In turn, then, theorists should develop "practical" theories, or theories which can be applied in practice. Had Lewin lived beyond 1947 he may well have considered the challenge of addressing the "wicked problem" of child abuse an essential focus for the theory-practice cycle.

In earlier papers $[3,4]$ we have proposed the requirement to build practice upon solid theoretical foundations $[3,4]$ and advocated for child protection practice to incorporate community development approaches which are informed by the rights of the child. In those papers we began to articulate detailed practice principles, developed from practice examples to demonstrate the value of these approaches. The Key Elements developed in the latest work [4] formed the beginnings of a model for practice. However, as mentioned above, we recognise the need to have practice specifically connected to theory so that practitioners are able to provide clear explanations of why they choose the actions they do and what they hope to achieve by them. Theory of practice (explanatory theory) and theory for practice (intervention theory) become central to the practitioners' ability to articulate their decisions and aims. Thus we turn now, in this piece, to further provide underpinning theory for these Elements for practice.

\section{A Model for Practice}

In our most recent work [4], we proposed five Key Elements for child protection practice underpinned by child rights and using community approaches. These elements are: child-centred, contextual, collective action, reciprocity, and family capital and they form what may be considered a "model for practice", which we are describing as "co-constructing social work" and are represented in Table 1. While we acknowledge that the idea of "constructing" social work appears readily in the literature, especially in those forms which employ social construction as a theoretical base and the notion of "co-constructing" reality is a feature of a social constructivist approach [26], we apply this term here to describe the processes employed between workers, families, children, communities, other professionals using these key elements for change. From this short overview of this model, it is clear that a theoretical positioning relies heavily on a constructivist interpretation of the social world. Greene \& Lee's ([26], p. 13) description of social constructivism, derived from Gergen, provides a useful summary: "Social constructivism takes a view that both individual and social processes are involved in the social construction of reality; thus it is not a matter of 'either/or' but rather 'both/and'." Greene \& Lee go on to state that, therefore, social constructivism is a natural fit for social work employing as it does an extensive use of an ecological theory. We are therefore positioning this model as both constructivist in its epistemology and as a process involving equal participation by relevant people. 
Table 1. Key elements for community development and child rights informed child protection practice ([4], p. 149).

\begin{tabular}{lll}
\hline Key Elements & Description/Skills and Process & Theoretical Perspective/Knowledge \\
\hline Child centred & $\begin{array}{l}\text { Seeking, listening to and acting on the child's } \\
\text { definition of his/her daily life }\end{array}$ & $\begin{array}{l}\text { Children as competent agents } \\
\text { Resilience }\end{array}$ \\
Contextual & Situatedness (time, place, history, culture) & $\begin{array}{l}\text { Human/children's rights } \\
\text { Social constructivism }\end{array}$ \\
Family capital & Family knowledge, history, capability, contacts & $\begin{array}{l}\text { Symbolic interaction } \\
\text { Social capital }\end{array}$ \\
& & Social network \\
Collective & & Strengths \\
action & The whole is more than the sum of the parts & Family definition \\
& The whole has greater longevity & Power \\
& & Community development \\
& Distributed leadership & Participative democracy \\
Reciprocity & The family as theorist & Social justice \\
& Shared responsibility & Learning \\
& Trustworthiness & Anti-oppression \\
& & Cross-cultural \\
\hline
\end{tabular}

Although the purpose of social work practice in child protection is uniformly to protect children from (further) abuse, there are different practices (models) used by different social workers, employing different processes. We do not intend expanding on the elements we previously articulated here-initial descriptions of both how we arrived at these and some examples where they may be seen in practice formed the major part of the previous paper [4]. However we do acknowledge the difficulties present in taking a "child-centred" approach where competence and agency for very young children, including babies, for example, must be conceptualised very differently from those of older children. The United Nations Convention on the Rights of the Child does not specify a lower age limit of competency and in some jurisdictions, Norway, for example, states that children from the age of 7 and younger who are capable of forming their own views should be given the opportunity of expressing them. While this still leaves adults in the position of assessing capability it reminds adults to include children in the consultation and decision making process according to agency and competency rather than age. This is an area for ongoing development, particularly for those social work practitioners who tend to interpret their concern for children as "child-centred" rather than engaging with children in an attempt to include them in the decision-making process. Greater attention needs to be paid in training for practice into ensuring adults develop fuller understanding of children as on a spectrum of "being" and "becoming" competent agents and what that might mean for inclusive practice.

These brief theoretical considerations, while familiar to our thinking, do both require more explanation and discussion as well as acknowledging other, equally valid, ways of explaining the "why" of the choices made to act in certain ways. For this we use and expand the framework developed by Pat Shannon [27]. Figure 1 presents our theorising using this framework. 
Figure 1. Theory for practice. Adapted from Shannon \& Young ([27], p. 27).

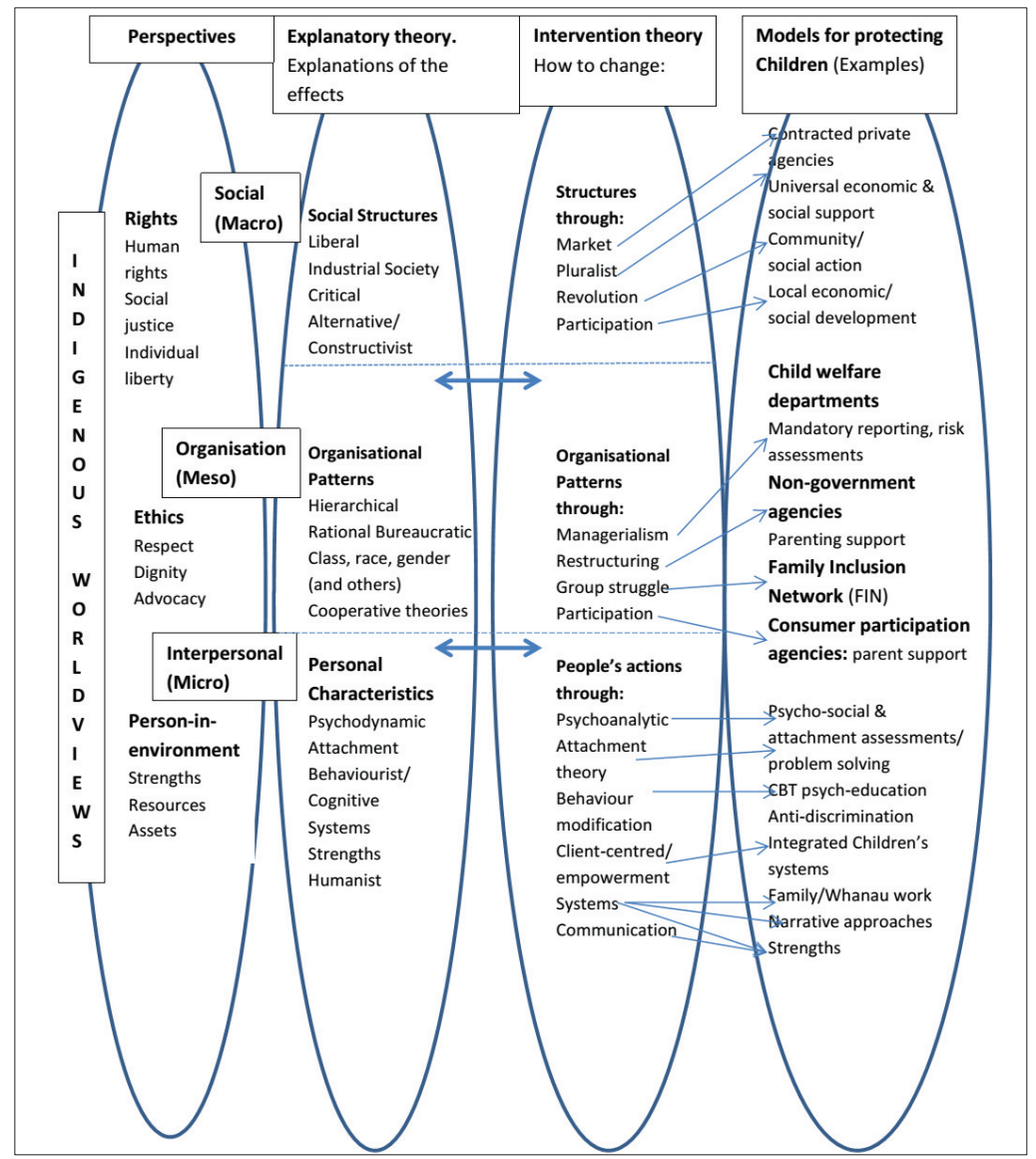

\section{A Theoretical Framework}

We find the theoretical framework provided in Shannon \& Young [27] useful to detail our ideas. A pictorial "eggs" diagram ([27], p. 24) is used in their work to demonstrate the connection between worldviews or perspectives and the models for practice which can be traced back to the worldviews through explanatory and intervention theories. In Shannon \& Young's work, the focus is on social problems and social policy with the main attention being on the structural setting. Hence "grand" theories and how they shape responses to social problems comprise the majority of the discussion. While not discussing child protection among these problems, child abuse constitutes one of the additional "wicked" and social problems.

The far left (in non-political terms) "egg" contains the values and beliefs a worker brings to his/her work: the lenses through which to view the world and what sort of change is desired. What is placed in this location will vary from worker to worker but be fundamental in guiding choices of what to do and how, but more importantly why, as these positions are starting points for the work. The next "egg" contains the theories which seek to explain the world that is seen and experienced, 
known as "theories for practice". Despite the caution of conflating "explanatory" theories with a positivist position [28], we take explanation as one of a sequence of steps to identify what is happening and posit why that might be before seeking to apply some predictive elements to create change. Payne and others [29,30], for example, reinforce the value of explanation emerging from a value base about how the world is or should be and leading to a set of practices designed to create that change.

In Shannon \& Young's ([27], pp. 28-33) work four "grand" theories are identified as being Classical Liberal, Industrial Society, Socialist and Alternative: theoretical positions which have variations elsewhere, but are claimed here to incorporate four basic and widespread approaches to understanding the social world. For our current purposes we are less concerned with theories at the Macro level, except inasmuch as they provide for the policy setting within which child protection practice occurs, than those at the interpersonal level. However, the "grand" theories of Classical Liberalism, associated with the "free-market, individualism and the invisible hand"; Industrial Society with "state-guided technological change"; Socialism with the allocation of resources according to needs and ability; and Alternative/Constructivism to include the relatively newly emerging theoretical explanations which uphold the local, contingent, contextual and diverse differentially give rise to different policy formulations. It must be stressed that even though these theoretical positions are "ideal types" they do offer distinct starting points from which to analyse and work in the social world. They differ according to the "foundational unit of society, and the mechanism through which people interact in society" ([27], p. 28). As such they can provide both analyses of what is currently happening in society and what changes may be desirable.

Intervention theories, or practice theories, emerge from or are the same as the explanatory theories. So, for example, a Classical Liberal explanation of the structural world would lead to using market forces to create change in the policy context. This may involve the private sector being contracted to provide child protection services on the premise that efficiencies and better effectiveness may be guaranteed. The models which are then designed and applied put into action the principles of the perspective (valorising individual autonomy and his/her choices and condemning poor choices) mediated through the explanation of individual failure and the need for correction through coercion and application of a market approach to the delivery of social service. Individual failure assessed through non-attached or inadequately attached children, for example, could then lead to a model to protect those children through contracting a private agency to manage the adoption of those children. For meso practice an Industrial Society theoretical position has led to parenting support programmes for example in the belief that parents can learn alternate strategies of disciplining their children, with the help of expert advice.

The Micro section includes some generic illustrations of the explanatory and intervention theories that relate to the "grand" theories. So for example, an explanatory theory at the micro level which could relate naturally to both Classical Liberal and Industrial Society theories is one of what Healy [29] refers to as the "psy" theories: psychodynamic theories which operate on the premise that the mind stimulates behaviour ([31], p. 72). Intervention theory could employ ego psychology or a psychosocial study which then leads to the particular form of casework method promoted by Florence Hollis. Problem solving as a social work method can be directly related back through these 
intervention and explanatory theories. Explaining the world may be here through individual predispositions which lead to inadequate social performance (a premise of Classical Liberal grand theory) or failure to adapt the individual responses to a changing environment (a premise of Industrial Society grand theory). Having these positions to explain the world leads to particular forms of social policies and institutional structures, policies and operations: through private or funded agencies contracted to provide appropriate and expert services with coercive or therapeutic aims.

The models which derive from these are directly informed by the way in which problems are explained and the choices which are made as appropriate interactions. There are a range of possibilities, but it is important to reiterate that there are some direct connections and congruence between how the situation is explained and the choice of model to apply. The converse applies also. Some models cannot be used with certain explanations. For example CBT would likely be ineffective as a model of practice with a discriminatory situation/explanation.

\subsection{Worldviews for Community Based Child Protection Work}

The first "egg" deals with worldviews, and here we present the underpinning values and perspectives we take to inform the approach we recommend. We will focus most of our paper on this section as we find it important to tease out and be clear about what worldviews mean for our practice. It would be easy to rely on the "taken-for-granted" tenets of social work in the expectation that "we all know" what is meant.

We have developed our "model" from the following understandings of the world. First, people have the capacity and potential to be active and competent agents in their own lives and those of their families; second, the social nature of humans means that collective activity can make a positive contribution to keeping children safe; and third, humans interact with each other and their environment in ways that can be both positive and negative-a rights perspective enables a complex response to assist in change. Rights, Ethics and Person-in-Environment describe our worldviews. While these are no strangers to social work, we find it important to re-emphasise their value in the ways they give rise to how we work with the "wicked problem" of child abuse. These dimensions must be set in relation to Indigenous worldviews.

\subsubsection{Rights}

Our particular elements for Rights focus on Human Rights, Social Justice, and Individual Liberty.

Promoting and upholding Human Rights is one of the foundations of the social work profession, and increasingly practitioners are being required to articulate more explicitly how the work they do fulfils this mission. The framework for social work's use of Human Rights derives predominantly from the various UN Conventions, the articles of which provide for protective, provision and participatory interventions as referred to in our previous work [4]. And here, as elsewhere, we maintain that the practice of Human Rights must, by its very nature, specify that children's rights are also included in social workers' practices.

We have argued previously [4] that a much more nuanced approach to how social work practice engages with understandings of Rights is necessary to enable child protection to be expansive and 
not reductionist in its application. By this we mean that a "best interests" approach to child protection would incorporate provisions of: sufficient state resources to ensure the child's development (Articles 18, 19 \& 27); parental participation in decision making (Article 9); family care (Article 7); retaining cultural identity (Articles $8 \& 30$ ); instead of, as a first response, removing a child from a situation assessed as presenting a risk and later seeing what reparative resources may be provided. The rights for children contained in the United Nations Convention on the Rights of the Child specify many more than these (54 in all) but it seems apparent that "best interests" (Article 3) has almost monopolised the attention of policy makers and practitioners alike. Further, we take the Rights framework in its entirety to refer to more than the individual as specified in Article 5, and so invoke the notion of collective responsibility. This not only refers to the collective nature of Indigenous communities at the micro level but also at meso and macro levels where it is necessary that governments ensure the provision of those goods and resources which are considered necessary within Western welfare states for the adequate development of the individual through health, education and housing.

Many of the above human rights are also recognised within the 46 articles of the 2007 United Nations Declaration on the Rights of Indigenous Peoples, for example: Article 1, the right of Indigenous peoples to all human rights individually and collectively and Article 2- to be free from discrimination in the exercise of those rights. If we are not able to use theory that derives from Indigenous peoples' world views unintentional discrimination can be an outcome of child protection theory and practice. Article 3 specifies the right to self-determination economically, socially and culturally. Article 5 refers to the right to maintain and strengthen their cultural and social institutions. Article 7 mentions rights to physical and mental integrity and not removing children forcibly to another group. Article 8 emphasises the right to not be subject to forced assimilation and destruction of their culture, and Article 11 specifies the right to practise and revitalise their cultural traditions and customs. Child protection processes, theory and practice must respect Indigenous peoples' integrity as distinct peoples and their cultural values and ethnic identities.

All of these provisions and protections fall within the broad spectrum of a Social Justice perspective to provide the environment in which humans, including children, may grow and develop. Where these provisions and protections are not present, it is incumbent on signatories (governments) to provide restitution, recompense or rehabilitation. Further, if the social work profession is committed to social justice its practitioners are required to ensure through their actions that they both contribute directly to provisions and protections, and where they are missing advocate for their provision. Social Justice as a concept is not subject to codified definition as in the UN Conventions, nor do many of the professional Associations specifically define it. One exception is the NASW which states: "Social justice is the view that everyone deserves equal economic, political and social rights and opportunities" [32]. An examination of social justice published immediately prior to a Social Work International Conference dealing specifically with Human Rights, in Stockholm in 2012, presented a much more complex view of Social Justice. Payne [33] wrote that three aspects of the work of social workers contribute to it being considered a Social Justice profession: it deals with the "social" as distinct but also inclusive of the individual; it focuses on those people who "miss out" on provisions or resources; and social workers do not hesitate to intervene in social relations, even 
when it makes them unpopular. While still potentially a reductive definition, Payne's presentation allows for a more multi-faceted understanding of, and ability to "do" Social Justice.

An examination of Social Justice also necessitates considerations of Justice. A major contributor to understandings of Justice in social work has been John Rawls whose notion of the social contract was mediated through the two principles: (1) equal liberty; and (2) equality of fair opportunity and the difference principle. Arguing that fundamental basic liberties should be equally distributed, Rawls also maintained that if there were to be inequalities in how goods and resources were to be distributed they must advantage the least advantaged people in society. It is not just to have "those who are better off have a veto over the benefits available for the least favoured" ([34], p. 80). Not only, then, should equality be upheld as a principle, but equity or fairness must be as readily upheld. Social Justice, according to a Rawlsian interpretation, emphasises both equality and fairness: that is, unequal treatment in the form of greater provision of the already disadvantaged is just. Social justice in the setting of child protection invokes the provisions, as well as the protections, of a rights perspective as noted above. A recent snapshot of comparative costs of undertaking the investigatory and placement of children at risk compared to intensive family support for children at risk in Australia found disproportionate spending with only $12 \%$ of total expenditure on family support services indicating the continuing disparity between provision and protection. Social justice for these children in care is therefore questionable.

Individual liberty forms the third of our elements under the Human Rights dimension. Much of the focus of the Convention is on the protection from offences against the person, such as freedom from torture, and the ability of the person to engage with societally provided goods, such as the freedom to choose a political representative. These "freedoms from" and "freedoms to" signal the importance placed on the person as an individual while also noting that "Human" of course is a collective. Our emphasis here is on what having rights as an individual who is considered to be free and equal means for the notion of equality as proposed by Rawls in the two principles mentioned above. If the individual is both free and equal and participates in society according to these principles, then Rawls considers that the idea of the free and equal individual as a co-operator is bound by the practice of reciprocity ([35], p. 49). This idea of reciprocity can be extended by Levinas' notion of responsibility to the other [36], for acting in recognition that the difference principle requires differential treatment in certain circumstances necessitates the individual to regulate self-interest in the interests of others. Contrary to the individualistic ideology so characteristic in western democracies in which the individual is all that matters, this position brings us closer to the mission of social work practice of social justice informed by human rights in which the individual is recognised as the most important person to attend to in relation to other individuals. This has long been recognised in Indigenous societies and it is to Aotearoa New Zealand's credit that such acknowledgement was enshrined in law in 1989 with the Children, Young Persons and their Families Act. As Ife signals it is how the "links between the individual and the collective, or the personal and the political, across all social work, and an integration of the 'macro' and the 'micro' approaches to social work practice" ([37], p. 60) that is central to social work human rights practice. This is particularly important in child protection practice where the tendency has been, as we have 
discussed, to isolate the child, as individual, for attention thereby restricting the possibility for cooperative and reciprocal work.

For social workers, along with others of the "caring professions" [38], justice, or what is just, is inseparable from what can be judged to "good" or "bad". Having an ethical perspective is the way workers assess the morality of what to do and how to do it. Ethics thus constitutes the next dimension in our worldview.

\subsubsection{Ethics}

Social workers subscribe to the idea of having an ethical grounding and to be bound to codes specifying ethical practice. Yet all social workers know that maintaining adherence to the codes or even to "being" ethical in their practice is far from the seemingly simple practice suggested in the first sentence. Procedural or prescriptive ethics, as are found in Codes, offer only scant direction when faced with having to make decisions involving value conflicts, as are commonly found in ethical dilemmas. Not only is the daily world of social work practice one in which arise dilemmas begging ethical decision making, there are no hard and fast rules to assist with those decisions: social workers will have no certainty in their decisions. The legacy of ethical traditions and their divergences, for example, deontology and utilitarianism; the postmodern "turn" giving rise to alternate ethics, "of care", "of life", "of love" for example; and, for our purposes here, the potential incommensurability of ethics and some social work theories [39] to say nothing of an Indigenous ethics, produce an ethical impossibility. This emerges in several ways. Some value bases of social work such as self-determination find themselves contradicted by some of the underlying assumptions about the human condition of particular theoretical positions, psychodynamic theory, for example ([39], p. 77). A postmodern notion of ethical subjectivity challenges the idea that workers can make ethical decisions which call on an idea of a moral universe ([21], p. 40). Conflicting principles in codes or standards render prescriptive ethics meaningless ([40], p. 31). Adhering to the "social mandate" of social work almost certainly will contravene one or more organisational and political policy directives and bring into question the professional role ([38], p. 46), and so on. Ethics, therefore, as a worldview, is immediately confronted by this impossibility. How to provide an Ethics worldview requires making theoretical and value-based choices which can disenfranchise other positions.

We do not seek to provide a theory of ethics, although in the very stating of that, this becomes a theory for ethics. Unremarkably, the elements to be included here are Dignity, Respect and Advocacy, mirroring, in part, most other social work ethics frameworks. The provisions of the Human Rights Convention emphasise that all persons have rights irrespective of the various distinctions which are found within the human collective. Respect for those distinctions is at the centre of the consequent anti-discrimination legislation of signatory nations. Respect forms a central part in common frameworks for moral thinking and depending on the proponent can be found to lead to the value positions upheld by the social work profession of non-judgementalism, the promotion of user's welfare and challenging inequalities and working for social change ([39], p. 60). A Human Rights practice, then, is an ethical practice which recognises the individual to have the right to be distinct, not to be judged, to be self-determining and to attract support and resources for his/her welfare. Complicating this in child protection practice is weighing up the (usually) child's right to 
protection from any harms that might emerge from an (usually) adult's exercise of self-determination and so on. Here the additional provisions of the Human Rights convention as argued above come into play where a complex interweave of the child's rights to family, culture, and government supportive resources are invoked to ensure that the "best interests" of the child are met. Challenging and changing damaging behaviour should be conducted through this prism. And while overt discriminatory behaviour may attract sanctions, the tendency to collapse normative expectations of family systems, child rearing practices, and so on continues. Respect due to the human person in circumstances of wilful harms to children is more difficult to defend. For the majority of situations, however, irrespective of the behaviour, the person who offends through his/her behaviour is still in relation to the child. There should be little to explain here or attract argument from others, unless they would seek to expand this list. We maintain, however, that Dignity and Respect and Advocacy, encompass necessary value positions for practice, irrespective, and possibly because of, the cautions identified above. Embedded in these cautions is the impossibility of the "generalised" moral world in which, irrespective of value positions, all people embody the same ethical position. Such is the reason for Critchley's [41] argument for an ethical subjectivity in which ethical experience is at the heart of ethical actions, or to put it another way-ethics requires an acting ethical subject. However, Dignity and Respect and Advocacy are themselves embedded in the Human Rights Convention, whether directly stated (Article 1), implied (e.g., Article 2 requiring respect for difference) or as a necessary activity for participation (e.g., Article 29 in relation to duties to the community). Ife's [37] discussion of the three generations of human rights which include additional declarations, treaties and other conventions make clear that these three are central to how people's rights should be upheld, with advocacy being a central and driving activity for social workers.

Advocacy is a central factor of ethical practice as illustrated in various social work codes, for example that of Aotearoa New Zealand ([42], para. 1.6) which states:

Members actively promote the rights of Tangata Whenua to utilise Tangata Whenua social work models of practice and ensure the protection of the integrity of Tangata Whenua in a manner which is culturally appropriate.

Not only here is the requirement to act for rights but to respect the particular Indigenous models of work which are culturally appropriate. For example, working in Aotearoa New Zealand is always informed by core concepts of Maori care and protection social work practice: restoration of tapu (being, restriction and sacredness) ([43], p. 287) is central and mana (spiritual power and authority, influence, control, prestige and status) ([43], p. 283) of the children and families. Therefore, in Maori social work practice and theory there are three guiding ethical principles for this work. Pono is seen as social workers being true, genuine, unfeigned, honest, integrity and faithful ([43], p. 285). Tika is understood as being right, correct, appropriate, proper, just, straight and direct, and is a societally agreed value or action ([43], p. 288). Aroha requires workers to be people who act with and are motivated by affection, love, compassion, mercy, empathy ([43], p. 281). Aroha recalls us to the Rogerian "unconditional positive regard", noted by Banks ([39], p. 37) in her justification for subsuming "respect for persons", a core belief in social work, into any precondition for ethical acts. Generalised "love" (agape), or, here, aroha, require these ethical principles be indivisible from practice. 
For many Indigenous peoples protection of integrity is indissoluble from the natural and spiritual environment and so an ethics for practice is inclusive of the wider ecological system [44]. While social work internationally is starting to explore what the relatively newly emerging eco-social work practice might include and within that attention is being paid to Indigenous models [45], the extent of an ethics of and for practice which is informed by Indigenous worldviews is yet to be established.

\subsubsection{Person-in-Environment}

The Person-in-environment is the third of the principles which comprise our worldview and succinctly incorporates and represents much of what we have proposed in the previous sections. While this is a taken-for-granted maxim of social work, it bears a little reaffirmation here of its intrinsic meaning, especially in relation to who constitutes the "person" and what constitutes the "environment". Early social work theorists, such as Mary Richmond, emphasised that worker responses to the problems confronting clients needed to not only focus on individual issues but also on the contributing factors in the environment. Greene \& Lee ([26], p. 9) note that Mary Richmond's diagnostic work included identifying "strengths, resources and assets of clients and their environment", even though the social work adoption of the medical model is often credited to Richmond. Possibly the most common representation of a model to describe the interaction between person and environment has been Bronfennbrenner's [46] bioecological systems theory particularly in relation to child protection [47]. However useful this has been we propose that an additional essential aspect to the systems approach to understanding the relationship between the individual and the environment is the necessity to invoke a cultural perspective. This may be done using Congress' [48] Culturagram. In the Aotearoa New Zealand setting, as in many Indigenous systems, the person is considered holistically alongside his/her relational responsibilities and the environment inclusive of the natural and spiritual world, and here an appropriate systems model may be Mason Durie's [49] Te whare tapa whā model.

Again from the Aotearoa New Zealand setting is Leland Ruwhiu's [13,14] model, Te Mahi Whakamana (a mana enhancing social and community work practice indigenous theoretical framework) in which there are three central recognition points: Maori understandings of well-being; historical developments; and the role of narratives. Te Mahi Whakamana draws upon the cultural metaphor of "he Ngakau Maori" (a Maori heart). Six key thematic concepts are used to examine wellbeing among Maori families and their relational and environmental circumstances. These are: wairuatanga (ideology, philosophy, paradigms, theoretical conceptualisations); whanau (relational development); tikanga matauranga (protocols of engagement); hauora, renamed mauri ora (levels of well-being); mana (respect); and ko au (identity and interconnectedness). Te Mahi Whakamana-mana enhancing theory and practice are premised on tangata whenua (people of the land, indigenous, native) epistimologies and ways of viewing the world. Tangata whenua inherantly "recognise the human (he tangata), natural (te ao turoa) and the ideological (wairuatanga) dimensions of their worldview as being held together by the "cultural adhesive of mana"” ([13], p. 134). Briefly, Te Mahi Whakamana practice is restorative and seeks to: build on inherent strengths, facilitate emancipatory strategies, enhance positive self-worth, demystify and deconstruct oppression, promote wellness, service and love for others [13]. 
Social work has always operated between the terrain occupied by the individual in the private world and the social, or external, world in which the state intervened to a greater or lesser degree, depending on particular ideological positionings in different locations, to ameliorate the circumstances affecting people's lives. Strengths, resources and assets of both the individual and her/his environment, then, characterise this worldview as presented here.

\subsection{A Rights, Ethics and Person-in-Environment World View for Child Protection Practice}

If we take these three elements together-rights, ethics and person-in-environment - our worldview can be summed up thus: the human condition is one of hope and potential even in the face of individual and environmental, or situational, adversity. A Human Rights perspective maintains that people (generally) and children (in particular) by the very nature of being human have recourse to the privilege of being regarded as capable, autonomous, and self-directing agents in their own right. It is the natural inclination of humans to be able to manage themselves and arrange their affairs in ways that are productive and contributive to the wellbeing of others. The social nature of the human environment provides the often realised opportunity to use their social interactions to the benefit of each other. This view of the human condition is tempered by deficits present in the environments around them and by individual and collective failures, all of which can affect people's ability to meet their potential. A Rights perspective assumes active and productive participation along with responsibilities to meet societal obligations. An Ethics perspective requires that people are to be treated with dignity, fairness, and respect, and that ethical practice demands workers advocate for these when they are absent or denied. And a Person-in-environment perspective assumes people have the capacity for positive growth and development to contribute productively to their own and their families' lives, and they have resources which they can use to this end.

\section{Explanatory Theory for Child Protection Practice}

The way workers seek to explain the circumstances and situations of those people with whom they work and then how they respond, using what methods, need to have substantial and well-articulated rationales. This is the role of theory of practice or explanatory theory. There are several writers of social work theory who have long made the distinction between explanatory theory and models of social work practice. Malcolm Payne ([28], p. 23), for example, at the same time as he explicitly takes a social construction approach to social work theory, also states that "a major feature of any acceptable model of social work 'theory' is the extent to which it can offer explanations of and guidance" and David Howe ([30], p. 10), characterises social work theory as needing to "explain [and] predict". Explanatory and intervention theories are closely linked, to the extent that there seems sometimes no need to differentiate between them. For example Attachment Theory, as deriving from ethology or survival mechanisms in the animal world [50], is both an explanation of why secure attachments for young children (or goslings from whence came Bowlby's insights) are essential for survival as well as providing guidance for how to both recognise insecure or faulty attachments and how to restore them through programmes or processes employed with the birth parents or alternate care givers. The distinction drawn here between Explanatory theory and Intervention Theory is 
perhaps unique to those seeking to not only explain why problems occur but also to seek ways to theorise congruent interventions which can lead to the development of on-the-ground practice models required for the day-to-day practice.

It will be evident from our previous discussion where in this framework our theoretical sympathies lie, and we will expand on these in this section. However, it is also evident that Classical Liberal, Industrial Society theoretical explanations of the social world are used, quite effectively, to explain child abuse, and, leading into Intervention theories provide directions as to what sort of change is required and how to try to effect that change. So, for example, child abuse may be explained by the failure of parents and the family to provide adequate care such that children fail to thrive and, in some cases, families employ deliberate actions to damage children. These children must be removed to places of safety and their parents punished for their acts. Investigative measures are usually taken by governmental authorities in most Western jurisdictions, but consequent actions, such as supervisory and other treatment programmes may be undertaken by the private sector, funded for those purposes by the State. Taking a Classical Liberal explanation of failure and deficit, the State seeks to change behaviour through punishment or coercive means and contracts private agencies to assist. Or, taking an Industrial Society theory position which explains "failure" through lack of knowledge or skills, would look to such theories for practice as Attachment and those emerging from the Neurosciences, such as the importance placed on early brain development [51] which identify the early years of brain development as crucial for stable and productive adulthood. These theoretical positions are used widely in child protection policy and practice, albeit with others, to assess whether or not children should remain with their parents.

We have further refined the Socialist form of explanatory theory to one using Critical Theory on the grounds that this enables a much wider inclusion of approaches than the traditional class-based explanation, and one which we believe is much more applicable to the issue of child protection. So, in seeking to explain the phenomenon of child abuse, using a Critical Theory approach can argue that the widespread over-representation of minority (predominantly black but also inclusive of other minorities) children in Western child protection systems (see [52]) can be explained by racism, oppression and discrimination, for example [53-55], while still being congruent with the earlier positions of the perspective. While focusing on minority difference may leave relatively unscrutinised the protection needs of children from majority settings, the concern of this theoretical approach is of the tendency to increase surveillance on the "other" [4]. Strategies, or models to redress this, focus largely on organisational and structural change as well as child placement principles in force in some jurisdictions which specify that children removed from families should be placed, wherever possible, within their own cultural milieu [56]. Here we see the intersection of the principles from the United Nations Convention on the Rights of the Child (UNCRoC), in which Article 8 specifically refers to the child's right to cultural identity.

Our perspective for understanding child protection leans more towards what Shannon \& Young [27] have identified as the Alternative group of theories, which they also note is "constructivist" ([27], p. 33). In this interpretation we do not deny the existence of deliberate or willful damage to children by their parents, nor the prevalence of negative socio-economic indicators which often lead to allegations of neglect [57]. Taking our lead from Gergen [58] we understand social constructivism to be the 
interaction between the knowing subject and the external environment. Parton \& O'Byrne ([59], p. 14) expand by illustrating what is distinctive in constructionist thought: audience ascription. Accordingly, not only does a problem not exist until the audience, or the claims-maker, assert it to be so, the type or characteristics of the problem become those which are asserted in the claims that are made about it. Parton \& O'Byrne are not alone in the social work world in believing that social work has an affinity for a constructionist perspective because of its change-oriented ethic and purpose. If social work seeks change, whether that of individuals, families or communities, then there must be an inherent belief in the possibility of change rather than the inevitability of a taken-for-granted consequence to a specific set of circumstances. They sum up their view of social constructionist social work as being one which centralises the problematising and criticising the social with a view to change and transform ([59], p. 26). Hence constructivism "emphasises process, plurality of both knowledge and voice, possibility and the relational quality of knowledge" ([59], p. 2).

It will be seen here that constructionist and constructivist have been used interchangeably, despite Gergen differentiating on the basis of the individual and the social constructions of reality. For Gergen ([60], p. 60) social constructivism advances the view that "while the mind constructs reality in the relationship to the world, this mental process is significantly informed by influences from social relationships". It is this emphasis on the person in environment that makes a social constructivist approach so appealing to social work.

Yet, despite the evident rejection of a realist or even subjectivist [59] position in social constructivism, this does not mean eclecticism should go unchallenged. While Gergen ([58], p. 26) contends: "constructionists establish no transcendent grounds for eliminating any theoretical formulation [and so] there is implicit in constructionism a strong pluralist ethic", this plurality is less about opposing theoretical explanations than it is about different interpretations of reality. A constructivist standpoint, therefore, accepts people in their environment will construct their own realities and social workers can engage with them about those realities. Nevertheless it is still incumbent on the worker to have ways to explain his/her own constructions of what $\mathrm{s} /$ he does and why without collapsing into an unexamined and eclectic selection of disparate and possibly opposing models.

An additional challenge arises here which demands attention. Rather than eclecticism, relativism may be a greater danger as one outcome of a constructivist position in which the end point may be "anything goes". In developing a proposed framework for practice we maintain that inclusion of all the key elements, with all their internal features, provides an opportunity to explore a range of opportunities and possibilities in working with the complexities of protecting children. While inevitably there are likely to be different interpretations, some of our previously cited examples [3,4] show that hearing the explanations that families have of their world; with shared responsibilities (Reciprocity) with their knowledges and capabilities (Family capital) alongside the distributed leadership of Collective action may assist in the arriving at solutions which do not descend into binary positionings.

It should be apparent now why the term Co-Constructing Social Work is the preferred description of our emerging model. We will elaborate on this in a later section, but the social constructivist definition offered above locates worker, client and the social environment in a triad of relational exploration, meaning-making and dialogue to arrive at co-constructed and collaborative actions and 
processes. This, we propose, is informed by the congruence between Explanatory Theory and practice approaches which are co-constructed and collaboratively employed with clients and their support systems to be useful in the business of keeping children safe from harm.

\section{Intervention Theories, or Theories for Child Protection Practice}

Writing in social work for child protection practice is prolific, with much offering particular practice guidance, or in other words, models for practice rather than intervention theory for practice, for example [61,62]. Among the most common theoretical perspectives presented however, where they do appear, are Attachment Theory and Ecological Theory which are used extensively in child protection practice. With their emphasis on the importance of relationships, either between intimates or between the parts of the environment in which children live, these two theories are found to be explanatorily useful as well as providing guidance for practice. While deriving from different foundations, with Attachment Theory located in what Healy ([29], p. 47) calls the "psy" disciplines and Ecological Theory in the biological sciences ([31], p. 137), these two theoretical positions occupy a significant role in social work generally and in child protection practice specifically [50,63-65].

However, we maintain that the practice of child protection informed by child rights and using community development principles requires different Intervention theories to assist in the work. Community development is perhaps the most obvious, given its location in the overall aim of our work. In Figure 1, we provide a selection of Intervention theories relevant to the work inclusive of some Indigenous approaches, such as Te whare tapa wha [49] from Aotearoa New Zealand and Raising our heads above the mountains [66] from WA. There are of course others, and the suggestion here is for practitioners to engage with local Indigenous people to explore with them their Intervention theories, and asking permission for their use.

\section{Model to Theory: Co-Constructing Social Work}

In our present work, we are interested in how the worldviews and their corresponding explanatory and intervention theories can be applied to child protection practice using community development approaches. This means adapting somewhat the "eggs" and their contents for this purpose, and in particular paying more attention than those authors acknowledge they do to the Interpersonal ([27], p. 28).

We do this by taking our model [3,4] developed for practice with child protection using community development principles and practices framed within a child rights perspective and populate the micro section of the "Eggs" with the connections between the model, intervention theory and explanatory theory. We also reiterate that for us, these particular theories emanate from an Alternative or Constructivist "grand" theory. As such our presentation does not attempt to make similar connections to Industrial Society Theory, or Classical Liberal Theory, although it will be seen in Figure 2 that these connections are made between some models for practice and intervention and explanation in these theoretical positions. For example a managerialist (connected to hierarchical explanation) intervention leads to risk assessments as a model in child protection. 
Figure 2. Perspectives, explanatory and intervention theories and models for child protection practice at the interpersonal level.

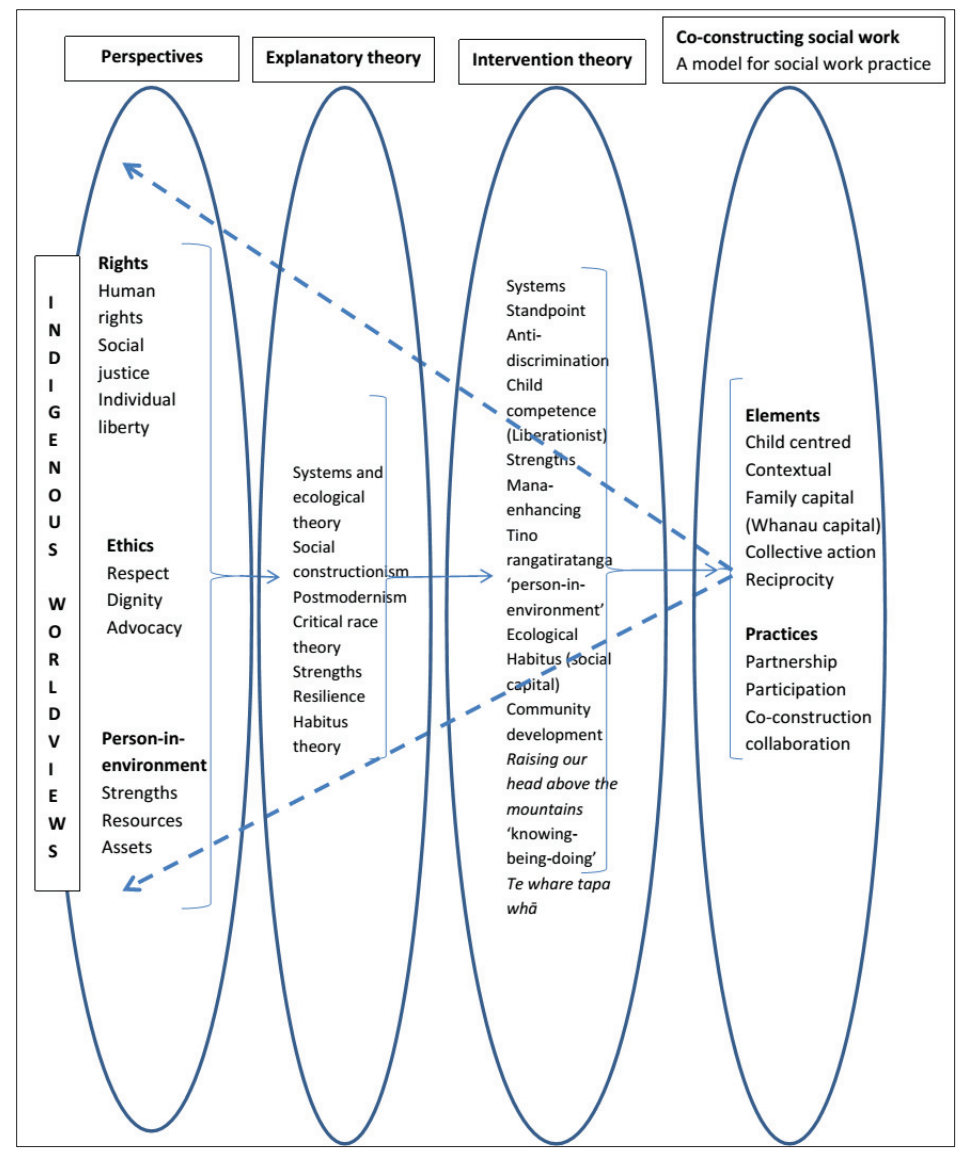

The key elements of the model we propose as Co-constructing social work are child-centred, contextual, family capital, collective action and reciprocity. How these arose as elements and some examples of how they operate in practice are described in the previous two articles [3,4]. In this article we are interested in linking the practices with their theoretical underpinnings. In Figure 2 we identify a range of intervention theories which contribute to the particular practices. These are not exclusive but include: Systems, Standpoint, Mana-enhancing, Anti-discrimination, Child competence (liberationist theory), Strengths, "Person-in-environment" ecological, Te whare tapa wha , Habitus (social capital), Community development, Raising our head above the mountains, and Social network theories. While discussing these in detail would take at least a separate article, the common explanatory theories which link these are what Healy ([29], p. 197) refers to as the "post" theories. As well as critiquing "grand" theories and some of the previous ways of understanding the world as having uniform or universal application, "post" theories offer the opportunity for an interpretation of the human environment and its inhabitants which emphasises the contingent, contextual, multiple and diverse dimensions which may assist in uncovering or displaying alternate "truths" or discourses 
which, often unseen, affect the social world. All of the intervention theories named above allow for alternate from "mainstream" interpretations of the social worlds of those people with whom social workers work, and, importantly, the possibility of alternate strategies. We find this important, as, in concert with other writers such as $[62,67,68]$ we believe the established child protection models as they are currently used in our settings to be insufficiently nuanced, targeted or effective.

This paper acknowledges and seeks to bring together the "colours and humanness" of social work practice and theory. Our working together on this paper is a combination of our different starting points regarding child protection theory and practice. The "Eggs" diagram (Figure 2) which we have further refined is not exclusive or complete. They do however combine our understandings of what is needed to develop good child protection outcomes. This paper encourages us to be "open to learning" and have conversations with those we work with in order to co-construct the social work narrative, practice and outcome. We are privileging particular knowledges in this paper that between the five of us, in our separate countries, agree on. But we believe you will have your own eclectic nuances and your "Eggs" may be different. Useful child protection outcomes require an integrated approach: it is our belief that this starts with you and I.

When you are standing there about to undertake a piece of social work with another human being:

- What is your puku (stomach) saying to you? (Physical response).

- What is your ngakau (heart) saying to you? How have you connected with them and what they are saying and doing? (Felt response).

- What is your wairua (spirit) saying to you? (Sensed response).

- What does Te Ao Maori/Pakeha matauranga (mind) theory say to you? (Thought response).

- What are the whanaungatanga (family making) issues that resonate here? (Relational response).

- What kind of fabric is being woven? It includes distinctiveness that comes from a number of variants in this cultural context. (Integration response) ([69], p. 26).

Perhaps some of these questions may not seem to have any relevance for you as an educator, manager, policy writer or practitioner but they may be relevant for the worldview and meaning making frameworks of your audience. A co-constructing social work practice such as we propose relies upon our ability to incorporate viewings other than our own.

We are human beings who want to treat other human beings as fully human. Mauri ora!

\section{Conclusions}

Whakawhanaungatanga (family making) in the social work context refers to relationship making, which is standard social work practice in terms of the planned change process i.e., engagement, assessment, intervention and evaluation. But is it valued in child protection social work in 2014. Robinson, Hohepa \& Lloyd [70] use the term "open-to-learning" conversations when we are thinking about the quality of the thinking and information we use when making judgements about what is happening and what we are going to do about it. Are we only interested in the validity of our views and imposing them or are we searching for "other" viewpoints that may improve our thinking and practice. The real test is in the co-construction of the social work narrative (in both explanatory 
and intervention theory) and in the models for practice. The people we work with do have ideas about protecting their children and improving their lives. The outworking of our sometimes eclectic and sophisticated perspectives, explanatory and intervention theories and models of practice should reflect these lived experiences and worldviews. Otherwise we are repeating what Freire ([71], p. 21) would refer to as "false generosity", in that "any attempt to soften the power of the oppressor in deference to the weakness of the oppressed almost always manifests itself in the form of false generosity; indeed the attempt never goes beyond this. In order to have the continued opportunity to express their generosity the oppressors must perpetuate injustice as well"' The path forward in a child protection case must come out of the heart of the oppressed; anything else is just false generosity, and perpetuates the myth of equality. Young [72] when discussing "whiteness theory" would see this as an insidious form of white power and privilege under the guise of child protection of the "other". If the aim of a child protection intervention is to protect children and families long term it must be undertaken within their meaning making frameworks (perspectives, theories and practice) which are grounded in their own pukorero (real narratives from within) $[9,17]$.

\section{Acknowledgments}

We acknowledge the practitioners in the field who have assisted us to develop these ideas from sharing their work practices with us.

\section{Author Contributions}

All contributors were responsible for the design and content of the paper, workshopping the ideas and theory in July 2013 and February 2014 which brought together each person's stories, experiences and knowledge. Susan Young was responsible for preparing and submitting the paper, with Margaret McKenzie writing sections, providing some of the Aotearoa New Zealand material and editing. Liv Schjelderup and Cecilie Omre provided the Norwegian material and reviewed and amended the draft document. Shayne Walker provided the Maori material and reviewed and amended the paper. All contributors reviewed and made suggestions to the final document.

\section{Conflicts of Interest}

The authors declare no conflict of interest.

\section{References}

1. Waldegrave, Charles. "Contrasting national jurisdictional and welfare responses to violence to children.” Social Policy Journal of New Zealand 27 (2006): 57-76.

2. Devaney, John, and Trevor Spratt. "Child abuse as a complex and wicked problem: Reflecting on policy developments in the United Kingdom in working with children and families with multiple problems." Children and Youth Services Review 31 (2009): 635-41. 
3. Young, Susan, Margaret McKenzie, Cecilie Omre, and Liv Schjelderup. "The rights of the child enabling community development to contribute to a valid social work practice with children at risk." European Journal of Social Work 15 (2012): 169-84.

4. Young, Susan, Margaret McKenzie, Cecilie Omre, Liv Schjelderup, and Shayne Walker. "What can we do to bring the sparkle back into this childs' eyes? Child Rights/Community Development Principles: Key elements for a strengths based child protection practice." Child Care in Practice 20 (2014): 135-54.

5. Young, Susan, Joanna Zubrzycki, Dawn Bessarab, Sue Green, Victoria Jones, and Katrina Stratton. "Getting it Right: Creating partnerships for change: Developing a framework for integrating Aboriginal and Torres Strait Islander knowledges in Australian social work education." Journal of Ethnic And Cultural Diversity in Social Work 22 (2013): 179-97.

6. Russell, Kayla J. Landscape: Perceptions of Kai Tahu 2000. Dunedin: University of Otago, 2000.

7. Eketone, Anaru, and Walker Shayne. "Kaupapa Social Work Research.” In Decolonizing Social Work. Edited by Gray Mel, John Coates, Michael Yellowbird and Tiani Hetherington. London: Ashgate Publishing, 2013, pp. 259-70.

8. Eruera, Moana. "He Korari, He kete, He Korero." Te Komako, Aotearoa New Zealand Social Work 24 (2012): 12-19.

9. Eruera, Moana. "An Indigenous Social Work Experience in Aotearoa New Zealand." In Becoming a Social Worker: Global Narratives, 2nd ed. London \& New York: Routledge, 2013.

10. Kee, Ling How, Jennifer Martin, and Ow Rosaleen. Cross-Cultural Social Work. South Yarra: Palgrave Macmillan, 2013.

11. Mafile'o, Tracey. "Pasifikan social work theory." Social Work Review 13 (2001): 10-13.

12. Pohatu, Taina Whakaatere. "Takepu: Principled approaches to health relationships." In Traditional Knowledge Conference 2008: Te Tatau Pounamu: The Greenstone Door. Hamilton: Te Wananga o Aotearoa, 2008.

13. Ruwhiu, Leland. "Home fires burn so brightly with theoretical flames." Te Komako Social Work Review 7 (1995): 21-25.

14. Ruwhiu, Leland. "Bicultural issues in Aotearoa New Zealand social work." In New Zealand Social Work: Contexts and Practice. Edited by Marie Connolly. Oxford: Oxford University Press, 2001, pp. 54-71.

15. Ruwhiu, Leland, Witi Ashby, Heta Erueti, Allan Halliday, Hemi Horne, and Phil Paikea. $A$ Mana Tane Echo of Hope: Dispelling the Illusion of Whànau Violence-Taitokerau Tāne Mãori Speak Out. Amokura: Family Violence Prevention Consortium, 2009.

16. Ruwhiu, Leland, and Moana Eruera. "Ngā karangaranga maha o te ngākau o ngā tūpuna. Tiaki Mokopuna. Ancestral heartfelt echoes of care for children." In Indigenous Knowledges: Resurgence, Implementation and Collaboration. Winnipeg: Cambridge Scholars Publishing, 2013.

17. Walker, Shayne. "The teaching of Maori social work practice and theory to a predominantly Pakeha audience." Aotearoa New Zealand Social Work 24 (2012): 65-74.

18. Walker, Shayne. "Tamariki and Whanau in the Milieu of Child Protection Decision-Making." In Hui Poutama Maori Research Symposium Ka Haere Whakamua, Ki Titiro Whakamuri. New Zealand: University of Otago, 2012. 
19. Walker, Shayne. "Seeds of illumination in a sometimes dry landscape." Aotearoa New Zealand Social Work 24 (2012): 1-2.

20. Diamond, Susan C. R. “The State as parent: Metamorphosis from 'wire-monkey' parent to benefactor?" In Social Work and Social Policy. Perth: University of Western Australia, 2009.

21. Bay, Uschi. Social Work Practice: A Conceptual Framework. Melbourne: Palgrave Macmillan, 2014.

22. Australian Association of Social Workers. Code of Ethics. Canberra: Australian Association of Social Workers, 2010.

23. Butler, Patrick. "Trainee social workers taught too much theory, says report." The Guardian, 13 February 2014, p. 9.

24. Lewin, Kurt, and Dorwin Cartwright. Field Theory in Social Science: Selected Theoretical Papers by Kurt Lewin. London: Tavistock, 1952.

25. Vansteenkiste, Maarten, and Kennon M. Sheldon. "There's nothing more practical than a good theory: Integrating motivational interviewing and self-determination theory." British Journal of Clinical Psychology 45 (2006): 63-82.

26. Greene, Gilbert J., and Mo Yee Lee. Solution-Oriented Social Work Practice. New York: Oxford University Press, 2011.

27. Shannon, Pat, and Susan Young. Solving Social Problems: Southern Perspectives. Palmerston North: Dunmore Press, 2004, p. 319.

28. Payne, Malcolm. Modern Social Work Theory, 2nd ed. Houndmills: Macmillan, 1997.

29. Healy, Karen. Social Work Theories in Context: Creating Frameworks for Practice. Houndsmill: Palgrave Macmillan, 2005, p. 238.

30. Howe, David. An Introduction to Social Work Theory: Making Sense in Practice (Community Care Practice Handbooks). Aldershot: Wildwood House; 1987, vol. 24, p. 182.

31. Payne, Malcolm. Modern Social Work Theory, 3rd ed. Houndsmill: Macmillan, 2005.

32. National Association of Social Workers (NASW). Social Justice. Washington, D.C.: NASW Pressroom, 2014.

33. Payne, Malcolm. "What's so special about social work and social justice?" The Guardian, 10 July 2012.

34. Rawls, John. A Theory of Justice. Oxford: Clarendon Press, 1972.

35. Rawls, John. Justice as Fairness. A Restatement. Cambridge, MA: Belknap Press of Harvard University Press, 2001.

36. Levinas, Emmanuel. Entre Nous: Thinking-of-the-Other. London: The Athlone Press, 1998, p. 256.

37. Ife, Jim. Human Rights and Social Work: Towards Rights-Based Practice. Cambridge, UK: Cambridge University Press, 2001, p. 228.

38. Hugman, Richard. New Approaches in Ethics for the Caring Professions. Houndmills: Palgrave Macmillan, 2005.

39. Banks, Sarah. Ethics and Values in Social Work. Houndmills: Palgrave, 2001.

40. Pullen-Sansfaçon, Annie, and Stephen Cowden. The Ethical Foundations of Social Work. Harrow: Pearson, 2012. 
41. Critchley, Simon. Infinitely Demanding: Ethics of Commitment, Politics of Resistance. London: Verso, 2007.

42. Aotearoa New Zealand Association of Social Workers (ANZASW). Code of Ethics. Christchurch: ANZASW, 2008.

43. Tate, Henare Arekatera. "Towards Some Foundations of a Systematic Maori Theology (He Tirohanga Anganui Ki Etahi Kaupapa Hohono Mo Te Whakapono Maori).” Ph.D. Thesis, Melbourne College of Divinity, Melbourne, Australia, 2010.

44. Ungar, Michael. “A Deeper, More Social Ecological Social Work Practice.” Social Service Review 76 (2002): 480-97.

45. Weaver, Hilary, and Elaine Congress. "Indigenous People in a Landscape of Risk: Teaching Social Work Students About Socially Just Social Work Responses.” Journal of Ethnic And Cultural Diversity in Social Work 18 (2009): 166-79.

46. Bronfenbrenner, Urie, and Stephen J. Ceci. "Nature-Nuture Reconceptualized in Developmental Perspective: A Bioecological Model." Psychological Review 101 (1994): 568-86.

47. Scott, Dorothy. "Embracing what works: Building communities that strengthen families." Children Australia 25 (2000): 4-9.

48. Congress, Elaine P. "Cultural and Ethical Issues in Working with Culturally Diverse Patients and Their Families." Social Work in Health Care 39 (2005): 249-62.

49. Durie, Mason. Whaiora: Maori Health Development 1998. Auckland: Oxford University Press, 1998.

50. Kufeldt, Kathleen, and Brad McKenzie. "The policy, practice and research connection: Are we there yet?" In Child Welfare: Connecting Research, Policy and Practice. Edited by Kathleen Kufeldt and Brad McKenzie. Waterloo: Wilfrid Laurier University Press, 2011, pp. 569-88.

51. Mustard, J. Fraser. "Experience-based brain development: Scientific underpinnings of the importance of early child development in a global world." Paediatrics \& Child Health 11 (2006): 571-72.

52. Kaur, Jatinder. Cultural Diversity and Child Protection. A Review of the Australian Research on the Needs of Culturally and Linguistically Diverse (CALD) and Refugee Children and Families. Queensland: Diversity Consultants, 2012.

53. Bernard, Claudia, and Anna Gupta. "Black African Children and the Child Protection System." British Journal of Social Work 38 (2008): 476-92.

54. Chand, Ashok. "The over-representation of Black children in the child protection system: Possible causes, consequences and solutions." Child \& Family Social Work 5 (2000): 67-77.

55. Rodenborg, Nancy A. "Services to African American Children in Poverty: Institutional Discriminiation in Child Welfare?" Journal of Poverty 8 (2004): 109-30.

56. Miller, Robyn Maree. Best Interests Principles: A Conceptual Overview. Melbourne: Department of Human Services, 2007.

57. Mennen, Ferol E., Kihyun Kim, Jina Sang, and Penelope K. Trickett. "Child Neglect: Definition and Identification of Youth's Experiences in Official Reports of Maltreatment." Child Abuse \& Neglect 34 (2010): 647-58. 
58. Gergen, Kenneth J. Social Construction in Context. London: SAGE, 2001.

59. Parton, Nigel, and Patrick O'Byrne. Constructive Social Work: Towards A New Practice. Basingstoke: Macmillan, 2000, 246.

60. Gergen, Kenneth J. An Invitation to Social Construction. Thousand Oaks: Sage Publications, 1999.

61. Davies, Liz, and Nora Duckett. Proactive Child Protection in Social Work. Exeter: Learning Matters, 2008.

62. Ferguson, Harry. Child Protection Practice. Houndmills: Palgrave Macmillan, 2011.

63. Connolly, Marie, and Kate Morris. Understanding Child and Family Welfare: Statutory Responses to Children at Risk. Houndmills: Palgrave Macmillan, 2012.

64. Howe, David. Attachment Theory for Social Work Practice. Basingstoke: Macmillan, 1995.

65. Howe, David. Child Abuse and Neglect: Attachment, Development, and Intervention. Basingstoke: Palgrave Macmillan, 2005.

66. Bacon, Violet. "Yarning and Listening: Yarning and Learning Through Stories." In Our Voices: Aboriginal and Torres Strait Islander Social Work. Edited by Bindi Bennett, Sue Green, Stephanie Gilbert and Bessarab Dawn. Melbourne: Palgrave Macmillan, 2013, pp. 136-65.

67. Berg Insoo, Kim, and Susan Kelly. Building Solutions in Child Protective Services. New York: W.W. Norton \& Company, 2000.

68. Lonne, Robert L., Nigel Parton, Jane Thomson, and Harries Maria. Reforming Child Protection. London: Routledge, 2008.

69. Durie, Mason. Maori Concepts of Wellbeing. Intervening with Maori Children, Young People \& Families. Invercargill: Compass Seminars, 2012.

70. Robinson, Tracy L. "The intersections of dominant discourses across race, gender and other identities." Journal of Counselling and Development 77 (1999): 73-79.

71. Freire, Paulo. Pedagogy of the Oppressed. Harmondsworth: Penguin Books, 1972, p. 153.

72. Young, Susan. "Social work theory and practice: The invisibility of whiteness." In Whitening Race: Essays in Social and Cultural Criticism. Edited by Aileen Moreton-Robinson. Canberra: Aboriginal Studies Press, 2004, pp. 104-18. 


\title{
Child Protection and Vulnerable Families: Trends and Issues in the Australian Context
}

\section{Elizabeth Fernandez}

\begin{abstract}
This paper will provide an overview and analysis of developments in child protection and out of home care in Australia. It will outline early responses to perceived inadequate parenting to provide the historical and policy contexts of contemporary debates on, and responses to, the care and protection of children and young people. Child maltreatment affects a large number of children across Australia. The statistics of reported maltreatment reflect striking increases over time. Over the last decade, several public inquiries into the operation of child protection have been undertaken in a number of state jurisdictions following which some states have embarked on large scale reform of legislation and policy, to either strengthen the child protection mandate, or refocus services. Some exemplars of significant reform in selected states will be cited. Some of the themes that will be explored in the paper will include the impact of major state based public inquiries, overseas reviews and research on child protection policy and practice; the changing balance between orientations to child protection and family support, the parameters of out of home care, the high levels of governmental intervention experienced by Aboriginal and Torres Strait Islander families, and a critical appraisal of major transformations in protective care.
\end{abstract}

Reprinted from Soc. Sci. Cite as: Fernandez, E. Child Protection and Vulnerable Families: Trends and Issues in the Australian Context. Soc. Sci. 2014, 3, 785-808.

\section{Introduction}

Responding to vulnerable children who are neglected or maltreated is an integral focus of child welfare practice in Australia. This article presents an overview of the care and protection system and its components, including the development of child protection policies, their interface with family based services and the nature of out of home care (OOHC). It discusses each of these intervention strategies, traces their historical context, the policies underpinning them, the practice challenges encountered and ongoing responses. Australia has a highly urbanised population with approximately $86 \%$ of the population living in urban areas [1]. As of the end of December 2012, the Australian population stands at just over 22.9 million people. The bulk of the population resides in the eastern states, with approximately 7.3 million in New South Wales, 5.7 million in Victoria and 4.6 million living in Queensland. Western Australia's population was approximately 2.5 million, South Australia approximately 1.7 million, with Tasmania, The Australian Capital Territory and the Northern Territory having approximately $512,000,379,000$ and 237,000 , respectively. With respect to the distribution of the child/youth populations, $25.32 \%$ of the Australian population are under 19 years, $18 \%$ are 14 or younger and $7 \%$ under 4 years of age [2].

Approximately $3 \%$ of the population identifies as being Aboriginal and Torres Strait Islanders (ATSI). In total, the largest ATSI (Indigenous Australians) population resides within New South 
Wales (208,364 people), while the Northern Territory (despite the lowest total population) has by far the largest percentage of population identifying as ATSI, at $29.78 \%$. Victoria, in contrast, has the lowest percentage with $0.86 \%$ [2]. The age structure of the ATSI population is very different, with $57 \%$ of the population aged under 25 years, compared to $34 \%$ of the general population.

Protecting children who are maltreated and providing $\mathrm{OOHC}$ assumes a major focus in Australian child welfare. The definition and scope of maltreatment, its causes, and how it should be responded to are the subject of continuing international and national debate. Central to this debate is the nature of the relationship between the state and family, wherein parents' perceived right to raise their children autonomously is mediated by the obligation of the state to intervene when families fail, due to lack of resources or parental dysfunction, to meet minimal standards of care as in the case of abuse and neglect $[3,4]$.

Determinations about child protection involve deciding a threshold, or a point at which parent behaviour constitutes abuse. The setting of thresholds of intervention is influenced by moral and legal questions, theoretical orientations, knowledge of the impact of maltreatment, as well as resource constraints [5]. The thresholds for child protection intervention have lowered with the increased awareness of the impact of abuse on children's developmental outcomes and the increasing emphasis on children's rights. However, some researchers have argued that the definitions of abuse applied to families are too broad, exposing families to unwarranted intrusion and investigative processes [6]. These dilemmas confront child protection systems internationally and are equally relevant to child protection policy and practice in Australia. Responses to abuse and neglect in Australia will be reviewed to provide a historical context to the current profile of national efforts in child protection policy and practice.

\section{Early Child Welfare Developments}

As early as the mid nineteenth century, state involvement in children and families is evident through the establishment of universal schooling, industrial schools and boarding out systems [7]. Australia's child welfare system can be traced to the early period of white settlement. Significant child welfare problems emerged in this phase when mortality rates, illegitimacy issues and levels of neglect and deprivation were high [8]. The nineteenth century also witnessed the advent of child migration, the importation of large groups of neglected children from Britain [9]. A reliance on institutional care was a key feature of the state's response to children of the working classes in the 1800s. The conditions in institutions under which children lived were harsh. Orphaned, destitute, transported and offending children were placed in similar institutions. Alternative ideas to residential care emerged around the 1860 s as a result of critiques of institutions and reformatory schools, and emergence of "family principle" arguments, leading to the development of "boarding out" of children to "respectable" working class families [10].

Through the 1800s, neglected children were cared for in institutions and forms of family based care. Evidence of abuse and neglect of children in institutions and a growing consciousness of the significance of family life for children gave impetus to the development of foster care as the dominant form of alternative care. During the 1960s and 1970s, arguments for de-institutionalisation of care gained support, resulting in foster family care being largely accepted by policy makers and 
practitioners as best practice. By the late nineties, most states enacted legislation to protect children and established children's courts with care and crime jurisdictions. A number of societies for the protection and rescue of children emerged, such as the Victorian Society for the Prevention of Cruelty to Children (1894) laying the foundation for developing the non-government sector in child welfare. This period also witnessed the antecedents of family support services [8].

The state adopted a highly interventionist approach in its treatment of ATSI children and families. ATSI children were forcibly removed from their parents to be raised in white families or white institutions, and apprenticed to white employers [7,11,12].

The prevalence of abuse and neglect has been noted over time. Several writers have documented the maltreatment of children throughout Australia's history. Gandevia's review of child deaths in Melbourne in 1863 identifies neglect and maltreatment as causes of such deaths in 255 inquests. In the mid-seventies, there was a re-emergence of interest by the State and media in the incidence and severity of maltreatment. Identifying and responding to children who were abused or at risk of abuse became a major focus of the relevant State Departments in Australia. With increased identification of child abuse and highly publicised inquiries into the deaths of children overseas and in Australia, proactive intervention by the state to monitor and protect children became established.

\section{The Australian Child Protection System}

Since the 1970s, the most significant change in the child welfare system has been the concern with children "at risk" which has acquired an increasing prominence on an unprecedented scale. During this period, Australian state government child protection authorities have assumed responsibility for responding to maltreatment concerns. The responsibility for delivering statutory child protection services, enacting child welfare legislation and administering children's courts rests with individual Australian state and territory governments. Inevitably, there are variations in legislation governing children in need of care and protection and processes for investigating protection cases. The legislative framework and policies underpinning child protection systems is different in each state. Reports or notifications of alleged abuse or neglect may be made to the respective State Department by professionals, members of the community, organizations, parents, relatives or children themselves. Such notifications are assessed to determine the degree of harm and the child's protective needs. "Substantiation" of notifications is established when there is "reasonable" cause to believe that the child has been, is being, or is likely to be abused, neglected, or otherwise harmed [13]. The threshold for intervention varies across state jurisdictions, reflecting varying patterns of responding to reports and differing thresholds for what is substantiated. All jurisdictions have introduced "mandatory reporting" or the legal requirement to report suspected child abuse. Selected professionals are mandated to report in some jurisdictions, whereas in others anyone who suspects child abuse or neglect is obliged to report it to the statutory authority $[14,15]$.

An overarching child protection national policy is encapsulated in a National Framework for Protecting Australia's Children 2009-2020 developed through a consultative process with states and territories and significant stakeholders including children and young people. This framework is grounded in the principles of the UN Convention on Rights of the Child and endorsed by the Council of Australian Governments [13,16]. 
The pattern of reporting of maltreatment shows striking increases over time. Across Australia over a 12 month period 2012-2013, 272,980 notifications or reports of child abuse were recorded ([17], p. 16). This represents a $98 \%$ increase in notifications over a decade (i.e., 137,938 in 2001-2002) but showing a decline against a peak of 339,454 in 2008-2009 [13]. An estimated 184,216 children were the subject of these notifications in 2012-2013, reflecting a rate of 35.5 per 1000 children in Australia. Of the total notifications, $45 \%$ were investigated progressing to 53,660 substantiations following investigation, relating to 40,571 children and constituting a rate of 7.4 per 1000 children nationally ([17], p. 16). There were increasing numbers of children in substantiations, on care and protection orders, and in $\mathrm{OOHC}$. There was a $29 \%$ increase in the number of children who were the subject of substantiations, rising from 31,527 in 2010-2011 to 40,571 in 2012-2013 ([17], p. viii). Forty-two per cent of children who were the subject of substantiations were from areas of lowest socioeconomic status ([17], p. viii). The proportion of "substantiated" cases varied across individual states from 31\% in Western Australia to 68\% in Tasmania [17].

The most commonly substantiated forms of maltreatment were emotional abuse (38\%), neglect (28\%) and physical abuse (21\%). With respect to sexual abuse there is a substantiation rate of $13 \%$ ranging from $1 \%$ in the Northern territory to $20 \%$ in Western Australia. Similarly, variations are evident in the substantiation of physical abuse ranging from $8 \%$ in the ACT to $27 \%$ in Victoria. Neglect was the most common category of abuse for children in the states of New South Wales (32\%), Queensland (42\%), South Australia (47\%) and the Northern Territory (47\%). Differential policies on mandatory notification across states are perceived to account for these variations ([17], pp. 19-20). In addition to the identification of the primary abuse type placing the child at risk, the co-occurrence of primary and other types of abuse are recorded. For instance, where emotional abuse was the primary abuse type substantiated neglected co occurred in $32 \%$ of cases. Similarly, co-occurrences of emotional abuse and neglect (37\% and 26\%, respectively) were noted in cases of substantiated physical abuse ([17], p. 20).

In terms of children involved in substantiated reports, children aged under 1 year were more likely (14.4 per 1000 children) and those aged 15-17 years ( 3.5 per 1000 children) were less likely to be the subject of substantiations - a consistent pattern across all states. Accordingly, most jurisdictions have specific policies in place to monitor younger children. In relation to a gender distribution, 51\% of the children who were subject of substantiation were girls. In all states, girls are more likely to be subject of a substantiation of sexual abuse than boys (17\% and $9 \%$, respectively) ([17], p. 22). Overall, while these data trends might point to a perceived escalation in the incidence of maltreatment, they are reflective of an increasing professional and community awareness of the vulnerabilities and rights of children, and increased willingness to act on this awareness to protect children.

There is an over representation of ATSI children in child protection notifications and substantiations. ATSI children were eight times as likely to be the subject of a child protection substantiation (45.3 per 1000 ATSI children compared with 5.7 per 1000 non ATSI children) ([17], p. 25). This disproportionality is explained in terms of the legacy of past highly interventionist policies of forced removal, the continuous erosion of ATSI communities, high levels of socio-economic disadvantage and Eurocentric perceptions of child rearing practices [18-20]. 
In Australia, as is the case overseas, child protection systems are reviewed periodically. A major driver of policy change has been a series of child abuse tragedies and alleged negligent practice. During the 1980s and 1990s, highly publicised inquiries into the deaths of children heightened concern about the consequences of child maltreatment and the shortcomings of child protection systems. In Australia, state level inquiries into deaths from child abuse of Paul Montcalm [20] Daniel Valerio [21] Jordan Dwyer, and Ben [22,23] drew attention to organisational, procedural and individual contributory factors involved, and galvanised political support for strengthening child protection intervention. Statutory reports and media archives document scandals and errors in judgement and management that have exposed vulnerable children to extreme maltreatment and even child death [24]. Evidence of community outrage at media accounts of children and young people who have been abused physically, emotionally and sexually, or neglected to the point of serious impairment, and the apparent inability of the child protection system to prevent maltreatment or protect children either in their own families or in $\mathrm{OOHC}$ have influenced directions in child protection policy. Some commentators have characterised the policy change driven by media and community reaction to the 'worst' scenarios as 'quick fixes' that have the potential to lead the system into further crises [25]. Other commentators have affirmed the contribution of the media in effecting significant policy change [26].

While the development and refinement of child protection systems have brought greater numbers of children and families to the attention of child protection authorities, there is a trend of ignoring vulnerable families of children in need, until there is demonstrated risk. There have been portrayals of the child protection system as being either under protective or overly intrusive [27,28]. The gap between notifications and substantiations is large. The issue of what services families receive beyond an investigation of abuse, and whether these services are experienced as punitive and controlling is raised. Other commentators have drawn attention to the forensically driven responses to child protection in recent years, where monitoring and surveillance have dominated and social work with children and families is increasingly expressed in legal and procedural terms. The emphasis on risk and culpability and the interactions between child welfare workers, police and legal practitioners have transformed the discourse into a socio legal one [29,30].

The preoccupation with a child protection focus has had wide ranging impacts on service delivery to families. The systems and practices developed to respond to the escalating notifications of abuse have had implications for responses to children and families generally, not only those who were abused or at risk of abuse. Many who met the threshold did not receive the appropriate service, or no service at all. Preventative and supportive services for all children and families received lower priority. Vulnerable families in need of services were likely to be caught in the net of child protection in order to access services. The preoccupation with investigation and validation, and failure to engage with families to address their needs have the effect of alienating and deterring families from approaching welfare services [4,28,31].

\subsection{Enhancing System Responses}

Since the mid-nineties, individual states have implemented several system level reforms to achieve better child and family outcomes. Some significant components of Australian child protection 
systems that have developed over the last two decades include central intake systems, differential response models, introduction of risk assessment tools and the operation of interdisciplinary and interagency collaborative mechanisms. As a means of monitoring and standardising responses central intake systems designed to serve as sole points of access for receiving reports of maltreatment have been introduced in selected states. Such systems have been implemented to reduce the impact of inter office, and inter worker variations in assessing thresholds for intervention. The merits of this approach in South Australia is documented in Hetherington [32].

Technologies of risk assessment have been another development in Australia with the introduction in the nineties of child protection structured risk assessment measures to improve consistency of child protection practitioners' assessments at intake and subsequent case management. Individual states have adapted measures from the U.S. or developed frameworks to meet the needs of their local context. While the potential benefits of risk assessment tools are acknowledged [33,34], a review of the research literature on risk assessment instruments raise caution about the limited number of studies examining the properties of these tools, the variability in definitions and measures [35], the lack of unanimity in defining concepts of "risk" and "maltreatment" [27,36] and the inherent ethical dilemmas in the use of such tools [37]. Other commentators draw attention to the importance of distinguishing between risk assessment (estimation of likelihood of recurrence of maltreatment) and family assessment (identifying the unique constellation of developmental and ecological factors that trigger or inhibit maltreatment $[38,39]$ ). Importantly, the essential role of risk assessment measures as aids to decision making designed to complement practitioner clinical judgement is emphasised [40,41].

Another service response evident in a number of states (South Australia, Western Australia and Victoria) has been the development of differential response models, designed to offer multiple pathways for addressing the needs of children and families. In principle, under differential response models families reported and identified as being at low to moderate risk are offered an assessment rather than investigation, a non-adversarial response promoting voluntary engagement of families without coercive state intervention [42]. In the Western Australian differential response model, cases are classified as either a generic child concern report (currently defined as "concerns for child welfare"). All reports benefit from a full assessment of risk and need, incidents of severe and persistent harm being referred to the child protection team, and other child concerns differentiated as requiring family support or no further action. An evaluation of the system concluded it enabled focused targeting of severe cases and prioritising of resources [43].

The Enhanced Client Outcomes implemented in Victoria represents another model providing practitioners with multiple differentiated response options grounded in child-centred family-focused practice. The potential of the differentiated response system to facilitate family engagement, and interagency collaboration, and promote scope for professional judgement at intake is acknowledged [25]. Evaluations of such systems operating in the U.S. note positive impacts in terms of maintenance of family safety, reduced child removals, increased access to services and family satisfaction [44]. 


\subsection{Public Inquiries into Child Protection Systems}

Strong public interest in child protection outcomes for children has continued into the 21 st century. Over the past 15 years, several public inquiries into the operation of child protection systems have been undertaken in a number of jurisdictions [45-53]. Advocating further reforms in the operation of child protection systems these inquiries have triggered major changes in policy and practice in the respective jurisdictions. Individual states have responded to the acknowledged need for major system-wide reform in different ways. Some states have embarked on large-scale reform of legislation and policy following major inquiries, in order to strengthen child protection and/or strengthen family support programs. The emphasis is on promoting safe and stable environments for children exposed to parental drug and alcohol misuse, domestic violence, mental health concerns, and who are vulnerable to abuse and neglect. Preventive and supportive interventions to enhance family and child wellbeing and minimise removal to protective care are revisited in these reforms. Some examples of recent programs of significant reform in selected states are cited.

In the State of New South Wales, the Care and Protection jurisdiction experienced procedural and organizational changes following the Wood Special Commission of Inquiry (2008) [46]. The so-called "Wood Report" on child protection proposed amendments to the Children's and Young Person's Care and Protection Act 1998, to reduce the numbers of children entering care, increase the use of Alternative Dispute Resolution, limit the power of the Children's Court to make contact or parental visitation orders, and enhance the status of the Children's Court by appointment of a District Court Judge as the head of the Children's Court. In New South Wales, the "risk of harm" reporting threshold was amended to "risk of significant harm" as part of the New South Wales "Keep Them Safe" reforms. Child Wellbeing Units (CWUs) were established in major government reporting agencies of Health, Education, Family and Community Services and Police in accordance with attempts to reshape responses to child protection concerns and provide guidance to staff in determining the new threshold of "significant harm". The newly formed CWUs are intended to facilitate agency responses to less serious cases through referral to service systems. These changes have implied a greater focus on preventative and early intervention services to address concerns earlier, and reduce the number of reports of children at risk. In this context, the "Brighter Futures Program", an early intervention program to support vulnerable families with children 0-8 years (by providing a suite of services including child care, parenting programs, home visits, family day care and specific support such as brokerage funds to purchase goods and services), received further impetus under the 'Keep Them Safe' emphasis on shared community responsibility for child wellbeing and child protection. Also included are case management services to address vulnerabilities such as domestic violence, mental health needs and substance misuse [54].

In the State of Queensland, in 2004 the 'Crime and Misconduct Commission of Inquiry in the Abuse of Children in Foster Care' identified serious failures in the child protection system and recommended major reforms, including the creation of a new department (Department of Child Safety) focused exclusively on child protection. It also instituted legislative changes requiring that case plans be submitted to the Children's Court as a pre-requisite to the Granting of Care Orders. The over-representation of ATSI children and their families in the child protection system received 
attention through a re-focusing of intensive resources to enhance early intervention and family support programs to address risks and challenges confronting ATSI families [55].

In Victoria, the legislation (Child Wellbeing and Safety Act, 2005) was amended in 2009 to extend the scope of Child Death Inquiries and significant funds were invested in increasing service system capacity. In addition to the focus on front end child protection demand, there has been enhanced provision of diversionary services through referrals to "Child FIRST" (Child and Family Information, Referral and Support Teams) contributing to reduction in numbers of children entering care. In 2012, the Protecting Victoria's Vulnerable Children Inquiry, which had been commissioned to investigate systemic problems in the child protection system, initiated an extensive reform agenda including child protection, workforce reform, establishment of a child friendly legal system and a Commissioner for Children and Young People, and expanded use of Family Group Conferencing and ATSI family decision making. In terms of prevention and early intervention, specialist programs were initiated to deliver intensive antenatal and postnatal support for vulnerable expectant mothers and parenting education, and skill building in parents to prevent the need for statutory child protection involvement.

This overview of child protection in Australia provides insight into the scope of maltreatment and evolving statutory responses to the issues. While significant practice reforms have been implemented there remain systemic concerns that organisational capacity to carry forward and sustain new practice directions is constrained by high caseloads, staff shortages, inadequate staff training and supervision and a culture that does not promote autonomy and critical thinking. Whether the incidence of child abuse is on the increase or whether there is a greater awareness of maltreatment is debated. However, in serious and fatal incidents of abuse there is less doubt that such an event has a profound impact on the community at large and the morale of practitioners and their organisations as political and public outrage forces reviews of policies and procedures. In such contexts, there has tended to be a diversion of resources and worker skills and time to child protection work at the expense of a relational and supportive orientation to families. Clearly, in such vital circumstances there should be strenuous efforts to avert such occurrences by addressing the implications and messages from published reports which have investigated serious cases [24].

The discourse of child protection has retained a tenacious hold over child welfare policy constraining the development of proactive work with families and children through what Holman (1988) refers to as a "family resource model" which encapsulates a range of services including day care, respite care, family aides, shared care and income and housing support to be made available to all families, not merely the "stigmatised exceptions" [56]. It also stands to reason that the curriculum that prepares practitioners for practice with children and families should lay the foundation for more effective intervention in this area of practice by addressing models that incorporate a collaborative approach between relevant disciplines, that emphasise participatory and empowerment oriented approaches to working with children and families, and encourage critical thinking about the knowledge base and theoretical orientations used to underpin child protection assessments and interventions [57].

There is increasing support for a public health response with emphasis on primary prevention. To reduce risk and optimise children's developmental outcomes and safety universal primary preventative 
services need to be available to all families with additional services targeted to those in special need $[55,58]$.

\section{Out of Home Care}

Integral to Australian child protection is its current out-of-home care (OOHC) provisions for children where reports of abuse and neglect are substantiated and who are not able to live at home safely. Where child protection concerns and risk to the child are substantiated the relevant Statutory Department responds to the child and family with appropriate support services. Regardless of jurisdictional differences between the states, in general, in situations where the harm, or the risk of harm, is serious or when parents need relief for a period of time, the statutory authorities may apply to the Children's Court for Care and Protection Orders. An overview of the structure and decision making processes of Children's Courts in different states is available in Sheehan and Borowski [59]. Care and Protection Orders may vary from highly interventionist orders involving transfer of legal guardianship to the State Department; to Third Party Parental Responsibility Orders involving transfer of guardianship to a relative or carer; to less interventionist orders such as supervisory orders where children continue to be under the custody and responsibility of parents with the State Department supervising and monitoring the quality of care [17]. Placement in OOHC is considered as an intervention of last resort. When children are placed in care the policy emphasis is on reunification.

At 30 June 2013, there were 43,136 children on Care and Protection Orders, a rate of 8.2 per 1000 Australian children. Seventy-one per cent of these children were on Guardianship or Custody Orders ([17], p. 33). The rate of ATSI children on orders was 59.2 per 1000 children ([17], p. 43). A review of the in care population indicates that at June 2013 there were 40,549 children in OOHC. Between 2012 and 2013, 11,341 children entered care, the rate of entry being 7.8 per 1000. Across all jurisdictions the rate of children in OOHC at June 2013 ranged from 5.2 per 1000 in Victoria to 11.7 in Northern Territory ([17], p. 47). The rate of children in OOHC increased between 2009 and 2013 from 6.8-7.8 per 1000. ([17], p. 55) Of those children admitted to OOHC in 2012-2013, 43\% were aged under 5 years, 24\% 5-9 years, 23\% between 10 and 14 years and $11 \%$ aged $15-17$ years ([17], p. 47). The growth in numbers of children and young people in OOHC is explained in terms of increasing drug and alcohol use by parents, increasing exposure of children to domestic violence and abuse, implementation of policies of mandatory notification, and increase in levels of poverty and deprivation in families [13]. The age distribution of children discharged from care is older than that of children entering care - a median age of 11 years at discharge against the median age at entering care of 6 years. The pattern of discharge reflects children being admitted to care at a younger age and remaining there for longer periods ([17], p. 47).

\subsection{Out of Home Placement}

A range of options are available for children who are unable to be cared for by their parents temporarily or permanently. These include formal and informal care arrangements. Formal care options include foster care with non-relatives, kinship care, adoption, and residential care, the latter comprising institutions, boarding schools, small group homes, and youth hostels and shelters. These 
formal care arrangements are usually authorised and financed by the state and frequently involve Children's Court interventions. The informal care arrangements comprise care by relatives and extended family and may be informally negotiated by parents, or formalised by state intervention. Such arrangements are frequently referred to as "kinship care".

In terms of types of $\mathrm{OOHC}$ there has been a substantial decline in residential care. Nationally, one in 20 children in $\mathrm{OOHC}$ live in residential care, this form of care being used predominately for children and young people who have complex needs. Home based care remains the dominant form of care accounting for $93 \%$ of children in 2011-2012. Of these, $43 \%$ are in foster care, $48 \%$ in relative or kinship care and $3 \%$ in other types of home based care ([17], p. 48). The use of kinship care varied across states from $23 \%$ in the Northern Territory to $56 \%$ in New South Wales. The majority of children were placed in care for over a year. Thirty per cent were in a continuous placement for 2-5 years, a further 39\% for five years while 18\% were in their current placement for less than one year. The majority of children (90\%) were in care on legal orders ([17], p. 49).

\subsection{Aboriginal and Torres Strait Islander (ATSI) Children in Out of Home Care}

The data on ATSI children and young people in care for the same period indicates high levels of disproportionality: namely a rate of 57.1 per 1000 children, and a steady increase since 2009 from 44.8 per 1000 children. These rates vary across states ranging from $20.7 \%$ per 1000 in the Northern Territory to 83.4 per 1000 in New South Wales ([17], p. 51). The legacy of the widespread practice of removing ATSI children from their families and communities, and the consequences of such intervention is reflected in their over-representation in child protection and care systems, a theme to be pursued later in this paper.

\section{Permanency Planning: Reunification and Adoption}

Australian jurisdictions have implemented a permanency framework [60], this emphasis being reflected in growth of early intervention and family support to prevent entry to care and to facilitate reunification with families from care [14]. An exemplar from the State of New South Wales care jurisdiction is cited.

\subsection{Care Plans and Permanency Planning}

Once a care application is established in the Children's Court a care plan is devised by the Statutory Department, as far as possible with agreement of the parents or young person, which must make provision for: allocation of parental responsibility for the duration of care; the placement sought and how it relates to permanency planning; arrangements for contact with parents and significant others; agency designated to supervise the placement; services to be provided for the child; statement of minimum outcomes to be achieved for safe restoration; services to be provided by the State Department, or services that the Court could require other Government Departments or NGO's to provide to the child and family to facilitate restoration; and a statement of the timeframe during which reunification should be actively pursued. If restoration is not considered a viable pathway, a care plan must propose a suitable long term placement. The most recent amendments to 
the Children's and Young Persons Care and Protection Act will bring in significant changes in relation to the use of guardianship orders and the use of adoption as a mechanism to reduce the number of children in OOHC. Parents of babies under two years of age will have only six months from the initial interim orders before the court is able to remove their parental rights by making a finding as to whether there is a realistic possibility of restoration of the children to parents. Parents of older children will have that decision made by the end of 12 months ([54], p. 47). While policies are in place to implement permanency planning, the lack of national level data on patterns of reunification, and effectiveness of family preservation services in diverting families and children from care makes it difficult to assess permanency outcomes. Australian based research into reunification outcomes highlight key issues and trends [61,62] and will be discussed later.

\subsection{Adoption: Local and Intercountry}

As a component of permanency planning, adoption in Australia is not as widespread compared to the United States and the United Kingdom. The first adoption legislation in the Commonwealth of Australia was enacted in WA in 1896, with similar legislation following in other states principally from the 1920s. In the period between 1920 and the mid-1970s, it was common for babies of unmarried mothers to be adopted due to social and religious stigma associated with illegitimate births. Inglis (1984) suggests that more than 250,000 Australian women have relinquished a baby for adoption since the late 1920s. A rise in adoptions from the early 1950s saw a peak in the period between 1970 and 1972 when there were almost 10,000 adoptions in Australia. Since this peak and from the mid-1980s, the rates of adoption have significantly declined and plateaued to a relatively stable rate of around 400-600 children per year. During the period 2011-2012, there were only 333 adoptions representing a $78 \%$ decline in the last 25 years $[52,63]$.

This significant reduction in adoption rates coincided with legislative, social and economic factors such as, greater social acceptance of raising children outside registered marriage, accompanied by an increasing proportion of children being born outside marriage. Increased levels of support made available to single parents (e.g., The Supporting Mother's Benefit introduced in 1973) and the increased availability and effectiveness of birth control also contributed to the declining numbers of children made available for adoption [64]. Of particular significance to relinquishing mothers is the acknowledgement of the disempowerment they experienced in the practice of forced adoptions, and the formal National apology on behalf of the Australian people made by the then Prime Minister Julia Gillard on 21 March 2013, for the removal of children from teenage mothers at birth, referred to as Forced Adoption.

In addition to local adoption, intercountry adoptions are also pursued. The adoption process for intercountry children is strictly controlled, by each state and territory under the relevant state-level adoption legislation and by the Australian Government under various Commonwealth Acts [52]. Australia has intercountry adoption programs with 13 countries: Bolivia, Chile, China, Colombia, Fiji, Hong Kong, India, Lithuania, the Philippines, South Korea, Sri Lanka, Taiwan and Thailand. Private adoption arrangements are not supported by state and territory authorities. There were 149 intercountry adoptions finalised during 2011 and 2012, representing $45 \%$ of all adoptions. This was a decrease of 66 adoptions, or $31 \%$, from 2010 to 2011 [52]. 


\section{Emerging Challenges in Out of Home Care}

The system of OOHC has been subject to research scrutiny to identify outcomes experienced by children, and the practices and policies that underpin its operation. The following review will highlight some significant issues confronting $\mathrm{OOHC}$, some unique to Australia, and many consistent with the experience of other countries. Major concerns identified surround the extended periods of time children spend in unplanned care and the instability they experience through breakdown of placements $[58,65,66]$. A number of studies have demonstrated the low priority child welfare systems give to education and schooling and the barriers to educational attainment that children in care experience as a result of changes of placement, frequent changes of schools, and also low expectations by teachers and carers [67-70]. The evidence of emotional and behavioural problems among children in long term care has been found in a number of research studies with the pattern of disturbance found to be higher than the general population [71-75]. Studies have also identified that young people with an experience of $\mathrm{OOHC}$ are significantly overrepresented in criminal justice proceedings and juvenile detention and prison populations [46,76,77]. There is also evidence that young people leaving the care system are disproportionately likely to experience homelessness, unemployment, develop psychological and social problems and become involved in the criminal justice system [78-80]. In addition to these overarching concerns, there are a unique set of issues that merit specific attention.

\subsection{Abuse in Care}

Of national concern is the long term impacts of living in institutional care $[81,82]$. The Care Leavers Australian Network (surveys of members) refers to harsh punishment and sexual abuse that were reported to be common experiences impacting on their current mental health. Currently, national concern about how children were treated whilst in "care" has culminated in the Australian Government's Royal Commission into Institutional Responses to Child Sexual Abuse particularly in relation to organizations with responsibility for children in their care. While serving as a means of gathering evidence, healing and reconciliation, the hearings provide a voice for those who have suffered maltreatment and victimisation in systems designed for their care and protection. Besides publicly acknowledging errors of the past, the evidence emerging from the hearings should inform policy and practice to enhance the safety of current systems $[83,84]$.

\subsection{Aboriginal and Torres Strait Islander Children}

The continued over-representation of ATSI children at all levels of the child protection process and in the care system is a major challenge and a matter of continued national concern. The need for special attention to policy and practice in relation to these children is reflected in the Aboriginal Child Placement Principle now entrenched in legislation. It emphasises a preference for placement with ATSI people who may include the child's extended family; its ATSI community; or other ATSI people in that order of preference.

Entrenched problems of poverty, racism, social exclusion, lack of resources and reluctance of white welfare authorities to accept differences in family structure and child rearing practices between 
ATSI and non-ATSI societies have contributed to the continuing over-representation of ATSI children in care. There has been slow official recognition of the significance of Aboriginality to ATSI people and the significance of this for child protection and OOHC policy. While principles of self-determination are being acknowledged and policy changes have occurred such reforms are perceived by the ATSI community to go only some of the way towards ATSI self-determination $[18,85]$. A formal apology was made by the then Prime Minister Kevin Rudd on 13 February 2008 for the removal of ATSI children from their birth parents, described as The Stolen Generation. Tilbury et al. [86] argue for a critical review of the professional knowledge underpinning child protection practice with ATSI families and advocate the use of context specific knowledge developed from the diverse perspectives of ATSI families and communities. The "Closing the Gap" targets to address child mortality and enhance early childhood education and educational attainment for older children and reduce the gap in health and employment outcomes for ATSI populations [87] is a pivotal national strategy to address the disadvantage ATSI children and young people experience on a broader front, and minimise their vulnerability to the trauma of involvement in the child protection process.

\subsection{Training and Support for Kin and Non-Kin Carers}

Foster carers are required to fulfil a unique and challenging role in caring for vulnerable children who have been removed from their biological families. They play a pivotal role in the child's ongoing development and long term outcomes. Foster families play a significant role in minimising the harm done to a child by their removal, and in children being reunified with their families of origin, or by establishing a nurturing permanent family. To accomplish these goals the issues of recruitment assessment and training have assumed significant focus [37]. In recent years, there has been an exponential increase in the number of children entering care, and a decline in the availability of carers. This situation has triggered considerable research into the challenges of caregiving and the need for policy that supports better training and support for all carers. There are different types of care that are utilised — short term crisis care, long term care, respite care and kin care - each type requiring different skills and levels of support [88-90].

While caring for children can be rewarding, the stressful nature of caring for foster children who often have behavioural difficulties, the challenges of working closely with biological parents and the potential threat of allegations of abuse must be acknowledged. Ongoing support and appropriate training for carers is crucial in ensuring high standards of care for children [91-93]. Parenting foster children involves challenges that are different from parenting of birth children. There is a need for support and training for carers around issues of managing children's emotional and behavioural problems. Where children have experienced abuse and neglect in their families, foster carers and residential staff can benefit from training to recognise and deal with the effects of such maltreatment on children's relationships with them.

There is increasing use of kinship or relative care as the need for OOHC placements escalate and the pool of available foster carers and residential care placements is stretched. The increase in parents affected by drug use and escalating reports of maltreatment have led to rising numbers of children placed formally or informally within extended family $[15,94,95]$. The perceived benefits are maintaining 
continuity of family relationships and preservation of cultural identity and sense of belonging, greater access to birth parents and promoting attachment and ensuring young people who leave care are not isolated. The Aboriginal Child Placement Principle supporting kinship care enables maintenance of ATSI children within their cultural community networks. Despite the positive benefits of continuity, stability and wellbeing, the potential for continued abuse by parents and family members whilst in kinship care is not to be overlooked. There are further concerns identified in national and international studies. Kin carers, despite becoming part of the child welfare system, are known to receive minimal formal support, preparation and recognition for the challenging caretaking roles from the Statutory Authority [96,97]. A number of studies have shown that kin carers and foster carers in general are poorly supervised, receive fewer support services and little training and preparation [91,98-100]. Berrick [101] draws attention to the fact that kin carers are socioeconomically disadvantaged relative to non kin carers. The children in kinship care are disproportionately from ATSI communities who experience high levels of socioeconomic disadvantage resulting in a two tiered care system, each funded, supervised and supported differentially by state authorities.

\subsection{Listening to Children}

There is increasing recognition of the need to enhance participation of children in the services they receive. Participation by children in matters which affect them is a reflection that children as individuals have views and opinions which cannot be represented by parents or professionals. The past decade has seen changes to legislation which place specific statutory duty on Community Service Departments to ascertain the wishes and feelings of the child, and to take these into account when making decisions. Such legislative provisions are only the first step. The day to day practice of involving children and ensuring their voices are heard and taken seriously will need continuing commitment on the part of practitioners and policy makers to the philosophy of working in partnership with young people.

Children's participatory rights have been enhanced by the establishment in Australia of the CREATE Foundation an advocacy organization that seeks to engage and empower young people in participating actively in decisions which affect their lives. A significant contribution comes from the series of Report Cards of the CREATE Foundation which draw attention to children and young people's experience of multiple placement changes, their marginal educational outcomes and their frequent alienation from birth and extended family networks. The 2013 CREATE Report Card [76] presents the views of 1000 children highlighting their desire to have stability in their care experience, to receive consistent support from care staff and caseworkers, to achieve in education and to participate actively in decisions that affect them. Further impetus for recognition of the voices of children and young people is also seen in expanding research undertaken in Australia and overseas [90,102-105]. 


\subsection{Birth Parents}

When children are taken into care there is little evidence of ongoing work to support birth parents. Several writers have alluded to the marginalisation and disempowerment parents experience when their children enter care. Families who are single parents on low incomes and who experience significant hardships in terms of food and housing insecurity are at high risk for child welfare involvement $[19,101,106]$. There is a view that it is the very poor who are the subject of notifications, surveillance and coercive interventions, essentially the same population strata which historically have been recipients of child welfare services, and that their circumstances derive from inherent inequalities in the social structure [107-109]. Child neglect continues to be the predominant concern and the subject of child protection interventions which in the context of growing inequalities and dilemmas about the nature of state intervention in relation to disadvantaged families, including ATSI families, raises several concerns.

Most parents present with multiple and co-occurring problems that lead to maltreatment of their children. Frequently, precipitating factors include substance abuse, physical and mental illness, domestic violence, financial and housing problems and social isolation. The increasing number of drug using parents poses a major challenge to child protection workers. There is increasing recognition that substance use is associated with other circumstances including mental health problems and domestic violence. This prompts realisation of the need for integrated programs to address substance use and its triggers [110]. Facilitating parents in accessing the full continuum of services and integrating them into the overall case plan is crucial to resolving concerns to ensure safety of the child and eventual reunification.

While children are in care, birth parents require support in maintaining contact with their children in the interests of continuity and fostering the child's identity. The level of contact maintained between children and their birth families and its effect on children's outcomes has been emphasised in research studies [104,111,112]. Research suggests structured contact between the child and their birth family provides ongoing benefits for the child while living away from home. The emphasis is on an "inclusive" approach to maintain children's connectedness to birth and extended families, to foster identity and continuity [111]. Higher levels of identification with birth parents have reinforced foster family attachment and self-esteem. Caseworkers play a major role in supporting all parties concerned in facilitating parental, sibling and extended family contact [111].

A child may remain in long-term care or be adopted and still remain connected to his or her parents through such contact [113]. Birth parents are to be considered an integral part of the care team for many reasons: their involvement helps the child's adjustment; through exposure to parenting approaches of foster carers or care staff they acquire the skills needed to respond to their child's needs; while enabling them to work toward reunification [61]. Based on the international evidence on supporting maintenance of children's links with their birth families, this is an important area of practice to be developed and enhanced. 


\subsection{Reunification}

Child Welfare Services, in addition to providing protective OOHC when a child's safety and wellbeing is threatened, emphasise reducing the length of time children are in care and working towards reunification, or return home to parents [60]. Reunification is posited as an overarching goal of out of home services in state legislation. A body of international and Australian research has identified important predictors indicating reunification to be most probable in the early months after entry to care $[61,62,114]$. Child and family characteristics including age, minority status and family disadvantage and placement type have also been found to influence reunification outcomes [115-118].

The findings from research highlight the need for a prioritisation of resources to support expedient reunification given the potential for children to return in the early months after entry to care. These studies also highlight the need for reunification practice to respond to address the systemic and long term entrenched social and economic disadvantages that many families face through provision of housing, income support, child care and health care. This entails a proactive and planned approach to reunification accompanied by a package of integrated services and comprehensive parenting support.

\subsection{Transitioning out of Care}

The challenges experienced by young people leaving the care system have received wide attention in research and policy. Evidence from research suggests they confront major difficulties in securing educational, vocational, housing, employment and other opportunities integral to their transition out of care. Australian studies have documented their severely reduced life chances noting they are more prone to experiencing substance abuse and mental health problems, marginal educational and employment outcomes, homelessness and becoming parents at an early age [70,76,79,119,120]. There is international consensus that young people from the care system should be supported beyond 18 years of age and have a right to be cared for into their early adulthood [80]. While policies and programs to support leaving care exist in different states, there is concern that they are discretionary and not mandatory, and do not go far enough to respond to this vulnerable group of young people.

\section{Conclusions}

This article has reviewed the nature of child welfare practice and the ways in which the state responds to children and families. Child protection systems and family support practice are constantly evolving and statutory interventions have far reaching consequences for children and families. The expanding concepts of child protection and protective care, and an accompanying body of research have reinforced the recognition of the need for permanency in children's lives through supportive care in the environment of their families or through stable OOHC. Responding to children's needs for safety permanence, and importantly, overall wellbeing entails child welfare systems, partnering with other service delivery systems which are outside the parameters of the child welfare system including physical and mental health, education and early childhood services; advocating for children; and helping families secure the services their children need around specific developmental periods, as Wulczyn et al. (2006) argue that children's wellbeing embraces a broader concept, and is influenced by factors that extend beyond the remit of parents and carers [121]. The reinstatement of a 
push for a family service orientation with greater emphasis on preventative services and early support to families is indicative of a desirable shift from a dominant focus on child protection to promoting children's welfare and wellbeing through family support and a multipronged approach. Drawing on the typology of responses to child maltreatment developed by Gilbert et al. [122], Australia's child protection systems represents a mix of the child protection orientation, the family orientation and the child focus orientation. However, the balance of these individual dimensions and the ascendancy of particular orientations are impacted by political and economic contexts. The balance shifts with legislative amendments often triggered by child death inquiries and associated media coverage, and budgetary constraints.

\section{Abbreviations}

ATSI: Aboriginal and Torres Strait Islanders;

CWUs: Child Wellbeing Units;

OOHC: Out of Home Care.

\section{Conflicts of Interest}

The author declares no conflict of interest.

\section{References}

1. Australian Bureau of Statistics. Family Characteristics and Transitions. Canberra: Australian Bureau of Statistics, 2008.

2. Australian Bureau of Statistics. Australian Demographic Statistics. Canberra: Australian Bureau of Statistics, 2013.

3. Lorraine Fox Harding. Perspectives on Child Care Policy. London: Longman, 1991.

4. Elizabeth Fernandez. "Child protection and child maltreatment." In Social Work: Fields of Practice. Edited by Margaret Alston and Jennifer McKinnon. Oxford: Oxford University Press, 2005, pp. 168-89.

5. Dartington Social Research Unit. Child Protection: Message from Research, Studies in Child Protection. London: Dartington Social Research Unit, 1995.

6. Jane Gibbons, Sue Conroy, and Caroline Bell. Operating the Child Protection System. London: Her Majesty's Stationery Office, 1995.

7. Robert Van Krieken. Children and the State: Social Control and the Formation of Australian Child Welfare. North Sydney: Allen \& Unwin, 1991.

8. Max Liddell. "Child welfare and care in Australia: Understanding the past to influence the future." In Responding to Children: Child Welfare Practice. Edited by Christopher C. Goddard and Robert Carew. Melbourne: Longman Cheshire, 1993, pp. 28-62.

9. Philip Bean, and Joy Melville. Lost Children of the Empire. London: Unwin Hyman, 1989.

10. Cliff Picton, and Peter Boss. Child Welfare in Australia: An Introduction. Sydney: Harcourt Brace Jovanovich, 1981. 
11. Peter Read. The Stolen Generations: The Removal of Aboriginal Children in New South Wales 1883 to 1969. Sydney: Govt. Printer, 1982.

12. Australia Parliament Senate Standing Committee on Social Welfare. Children in Institutional and Other Forms of Care: A National Perspective. Canberra: Australian Government Publishing Service, 1985.

13. Australian Institute of Health and Welfare. Child Protection Australia: 2011-12-Child Welfare Series Number 55. Canberra: Australian Institute of Health and Welfare, 2013.

14. Leah Bromfield, and Prue Holzer. A National Approach for Child Protection. Melbourne: Australian Institute of Family Studies, 2008.

15. Elizabeth Fernandez, and Nicola Atwool. "Child protection and out of home care: Policy, practice, and research connections australia and new zealand." Psychosocial Intervention 22 (2013): 175-84.

16. Council of Australian Governments. Protecting Children is Everyone's Business: National Framework for Protecting Australia's Children 2009-2020. Canberra: Council of Australian Governments, 2009.

17. Australian Institute of Health and Welfare. Child Protection Australia: 2012-13-Child Welfare Serios Number 58. Canberra: Australian Institute of Health and Welfare, 2014.

18. Michael Lavarch. Bringing Them Home: National Inquiry into the Separation of Aboriginal and Torres Strait Islander Children from Their Families. Sydney: Human Rights and Equal Opportunity Commission NSW, 1995.

19. Elizabeth Fernandez. Significant Harm: Unravelling Child Protection Decisions and Substitute Care Careers of Children. Aldershot: Avebury Ashgate Publishing, 1996.

20. Robert John Lawrence Responsibility for Service in Child Abuse and Child Protection. Sydney: Government Printer, 1983.

21. Christopher C. Goddard. Child Abuse and Child Protection. Australia: Pearson, 1996.

22. Community Services Commission. Annual Report. Sydney: CSC, 1997-1998.

23. Community Services Commission. Annual Report. Sydney: CSC, 1998-1999.

24. Department of Family and Community Services. Child Deaths 2011 Annual Report. Sydney: Department of Family and Community Services, Community Services, 2012.

25. Adam M. Tomison. "Child protection and child abuse prevention 'down under'. Key trends in policy and practice." In International Perspectives on Child Protection-Report of A Seminar Held on 20 March 2002 - Part of the Scottish Executive Child Protection Review Protecting Children Today and Tomorrow. Edited by Malcolm Hill, Anne Stafford and Pam Green Lister. Glasgow: Scottish Executive, 2002.

26. Philip Mendes. "Social conservatism vs. social justice: The portrayal of child abuse in the press in victoria, australia." Child Abuse Review 9 (2000): 49-61.

27. Elizabeth D. Hutchinson. "Child maltreatment: Can it be defined." Social Service Review 64 (1990): 60-78.

28. Eileen Munro. "Lesson from research on decision making." In Child Welfare Research: Advances for Practice and Policy. Edited by Duncan Lindsey and Aron Shlonsky. New York: Oxford University Press, 2008, pp. 194-200. 
29. Nigel Parton, David H. Thorpe, and Corinne Wattam. Child Protection: Risk and the Moral Order. Basingstoke: Macmillan Press, 1997.

30. Harry Ferguson. Protecting Children in Time: Child Abuse, Child Protection and the Consequences of Modernity. New York: Palgavre Macmillan, 2004.

31. Jane Waldfogel. "The future of child protection revisited." In Child Welfare Research: Advances for Practice and Policy. Edited by Duncan Lindsey and Aron Shlonsky. New York: Oxford University Press, 2008, pp. 235-41.

32. Tim Hetherington. "Child protection reform in south australia: Initial evaulation." Child Abuse Prevention 6 (1998): 7-10.

33. Diane DePanfilis. "Implementing child mistreatment risk assessment systems: Lessons from theory." Administration in Social Work 20 (1996): 41-59.

34. Diana J. English, and Peter J. Pecora. "Risk assessment as a practice method in child protective services." Child Welfare 73 (1994): 451-73.

35. Michael J. Austin. Evidence for Child Welfare Practice. New York: Routledge, 2010.

36. Nigel Parton. "Social work, risk and the blaming system." In Social Theory, Social Change and Social Work. Edited by Nigel Parton. London: Routledge, 1996, pp. 98-114.

37. Bob Lonne, Nigel Parton, Jane Thomson, and Maria Harries. Reforming Child Protection. London and New York: Routledge, 2009.

38. Judith S. Rycus, and Ronald C. Hughes. Issues in Risk Assessment in Child Protective Services: Policy White Paper. Ohio: Center for Child Welfare Policy, 2003.

39. Peter Lyons, Howard J. Doueck, and John S. Wodarski. "Risk assessment for child protective services: A review of the empirical literature on instrument performance." Social Work Research 20 (1996): 143-55.

40. Eileen Munro. "Common errors of reasoning in child protection work." Child Abuse \& Neglect 23 (1999): 745-58.

41. Howard J. Doueck, Diana J. English, Diane DePanfilis, and Gerald T. Moote. "Decision-making in child protective services: A comparison of selected risk assessment systems." Child Welfare 72 (1993): 441-52.

42. Caren Kaplan, and Lisa Merkel-Holguin. "Another look at the national study on differential response in child welfare." Protecting Children 23 (2008): 5-21.

43. Nigel Parton, and Richard Mathews. "New directions in child protection and family support in western australia: A policy initiative to re-focus child welfare practice." Child \& Family Social Work 6 (2001): 97-113.

44. Institute of Medicine and National Research Council. New Directions in Child Abuse and Neglect Research. Washington: Institute of Medicine and National Research Council, 2014.

45. Northern Territory Government. Growing Them Strong, Together: Promoting the Safety and Wellbeing of the Northern Territory's Children Report of the Board of Inquiry into the Child Protection System in the Northern Territory 2010. Darwin: Northern Territory Government, 2010.

46. James Wood. Report of the Special Commission of Inquiry into Child Protection Services in $N S W$. Sydney: State of New South Wales through the Special Commission of Inquiry into Child Protection Services in NSW, 2008. 
47. Edward Picton Mullighan. Children in State Care: Commission of Inquiry. Adelaide: Office of the Commissioner, 2008.

48. Prudence Ford. Review of the Department for Community Development Review Report. Perth: Department of the Preimer and Cabinet, 2007.

49. Commission for Public Administration. The Territory as a Parent: A Review of the Safety of Children in Care in the Act and of Act Child Protection Management. Canberra: Commissioner for Public Administration, 2004.

50. Commission of Inquiry into Abuse of Children in Queensland. Report of the Commission of Inquiry into Abuse of Children in Queensland Institutions. Brisbane: Commission of Inquiry into Abuse of Children in Queensland, 1999.

51. Crime and Misconduct Commission. Protecting Children: An Inquiry into the Abuse of Children in Foster Care. Brisbane: Crime and Misconduct Commission, 2004.

52. Australian Institute of Health and Welfare. Adoptions Australia 2011-12-Child Welfare Series Number 54. Canberra: Australian Institute of Health and Welfare, 2012.

53. Philip Cummings, Dorothy Scott, and Bill Scales. Protecting Victoria's Vulnerable Children Inquiry. Victoria: Department of Treasury \& Finance, 2012.

54. Elizabeth Fernandez, Jane Bolitho, Patricia Hansen, Myvanwy Hudson, and Sacha Kendall. A Study of the Children's Court of New South Wales. Sydney: University of New South Wales, 2014.

55. Adam Tomison. Current Issues in Child Protection Policy and Practice: Informing the NT Department of Health and Community Services Child Protection Review. Darwin: NT Department of Health and Community Services, 2004.

56. Bob Holman. Putting Families First: Prevention and Child Care. London: Macmillan Education, 1988.

57. Brian Corby. Child Abuse: Toward a Knowledge Base. Maidenhead: Open University Press, 2006.

58. Fred Wulczyn, Joseph Kogan, and Brenda Jones Harden. "Placement stability and movement trajectories." Social Service Review 77 (2003): 212-36.

59. Allan Borowski, and Rosemary Sheehan. "Magistrates' perspectives on the criminal division of the children's court of victoria." Australian Social Work 66 (2013): 375-90.

60. Anthony N. Maluccio, Edith Fein, and Kathleen A. Olmstead. Permanency Planning for Children: Concepts and Methods. New York: Tavistock Publications, 1986.

61. Elizabeth Fernandez. Accomplishing Permanency: Reunification Pathways and Outcomes for Foster Care Children. New York: Springer, 2013.

62. Paul Delfabbro, Elizabeth Fernandez, Jessica McCormick, and Lisa Kettler. "Reunification in a complete entry cohort: A longitudinal study of children entering out-of-home care in tasmania, australia." Children and Youth Services Review 35 (2013): 1592-600.

63. Pauline Kenny, Daryl Higgins, Carol Soloff, and Reem Sweid. Past Adoption Experience: National Research Study on the Service Response to Past Adoption Practices (Research Report no. 21). Melbourne: Australian Institute of Family Studies, 2012.

64. Australian Bureau of Statistics. Australian Social Trends. Canberra: ABS, 1998. 
65. Elizabeth Fernandez, and Paul Delfabbro. "Reunification in australia: Insights from south australia and new south wales." In How Does Foster Care Work? International Evidence on Outcomes. Edited by Elizabeth Fernandez and Richard P. Barth. London: Jessica Kingsley Publisher, 2010, pp. 111-30.

66. Sigrid James. "Why do foster care placements disrupt? An investigation of reasons for placement change in foster care." Social Service Review 78 (2004): 601-27.

67. Fiona Daly, and Robbie Gilligan. Lives in Foster Care: The Educational and Social Support Experiences of Young People Aged 13-14 Years in Long Term Foster Care. Dublin: Trinity College, 2005.

68. Sonia Jackson. "The education of children in care." In Nobody Ever Told Us School Mattered: Raising the Educational Attainment of Children in Public Care. Edited by Sonia Jackson. London: British Association for Adoption and Fostering, 2001.

69. Michelle Townsend. Are we Making the Grade? The Education of Children and Young People in Out of Home Care Research Report 2012. Sydney: Department Family and Community Services, 2012.

70. Philip Mendes, Pamela Snow, and Susan Baidawi. "Young people transitioning from out-of-home care in victoria: Strengthening support services for dual clients of child protection and youth justice." Australian Social Work 67 (2014): 6-23.

71. June M. Clausen, John Landsverk, William Ganger, David Chadwick, and Alan Litrownik. "Mental health problems of children in foster care." Journal of Child and Family Studies 7 (1998): 283-96.

72. Elizabeth Fernandez. "Unravelling emotional, behavioural and educational outcomes in a longitudinal study of children in foster-care." British Journal of Social Work 38 (2008): 1283-301.

73. Elizabeth Fernandez. "Children's wellbeing in care: Evidence from a longitudinal study of outcomes." Children and Youth Services Review 31 (2009): 1092-100.

74. David M. Rubin, Evaline A. Alessandrini, Chris Feudtner, David S. Mandell, A. Russell Localio, and Trevor Hadley. "Placement stability and mental health costs for children in foster care." Pediatrics 113 (2004): 1336-41.

75. Michael Tarren-Sweeney. "Retrospective and concurrent predictors of the mental health of children in care." Children and Youth Services Review 30 (2008): 1-25.

76. Joseph McDowall. Experiencing out of Home Care in Australia: The Views of Children and Young People. Sydney: CREATE Foundation, 2013.

77. Katherine McFarlane. "From care to custody: Young women in out-of-home care in the criminal justice system.” Current Issues in Criminal Justice 22 (2011): 345-53.

78. Mark E. Courtney, and Amy Dworsky. "Early outcomes for young adults transitioning from out of home care in the USA." Child and Family Social Work 11 (2006): 209-19.

79. Judy Cashmore, and Marina Paxman. Longitudinal Study of Wards Leaving Care: Four of Five Years on, Research Project Commissioned by the NSW Department of Community Services. Sydney: Social Policy Research Centre, University of New South Wales, 2007. 
80. Mike Stein. Young People Leaving Care: Supporting Pathways to Adulthood. London: Jessica Kingsley Publishers, 2012.

81. Richard B. McKenzie. "The impact of orphanages on the alumni's lives and assessments of their childhoods." Children and Youth Services Review 25 (2003): 703-53.

82. Joanna Penglase. Orphans of the Living: Growing Up in "Care" in Twentieth-Century Australia. North Fremantle: Fremantle Press, 2005.

83. Care Leavers Australia Network. "Care leavers australia network-A epistemological and methodological tenets." American Journal of Community Psychology 28 (2007): 773-91.

84. Royal Commission into Institutional Responses to Child Sexual Abuse. About the Royal Commission. Sydney: Royal Commission, 2014.

85. Hallahan Sue Gordon, and Darrell Henry. Putting Picture Together, Inquiry into Response by Government Agencies to Complaints of Family Violence and Child Abuse in Aboriginal Communities. Western Australia: Department of Premier and Cabinet, 2002.

86. Clare Tilbury, Rosslyn Aitchison, Lesley Chenoweth, Donna McAuliffe, Daniela Stehlik, and Jennifer Osmond. "Valuing local knowledge in child protection practice." Communities, Children and Families Australia 8 (2014): 5-20.

87. Australian Government. Closing the Gap Prime Minister's Report 2013. Canberra: Australian Government, 2013.

88. Stacy Blythe, Elizabeth Halcomb, Lesley Wilkes, and Debra Jackson. "Caring for vulnerable children: Challenges of mothering in the fostering system." Contemporary Nurse 44 (2013): 87-98.

89. Elaine Farmer, and Sue Moyers. Kinship Care: Fostering Effective Family and Friends Placements. London: Jessica Kingsley Publishers, 2008.

90. Ian Sinclair, Claire Baker, Kate Wilson, and Ian Gibbs. Foster Children Where They Go and How They Get On. London: Jessica Kingsley Publishers, 2005.

91. Marilyn McHugh, Justin McNab, Ciara Smyth, Jenny Chlamers, Peter Siminski, and Peter Saunders. The Availability of Foster Carers. Sydney: Social Policy Research Centre, University of New South Wales, 2004.

92. Jennifer Osmond, Teresa Scott, and Julie Clark. "The knowledge of caring: Revisiting the need for knowledge support of carers." Child \& Family Social Work 13 (2008): 262-73.

93. Amandeep Samrai, Helen Beinart, and Peter Harper. "Exploring foster carer perceptions and experiences of placements and placement support." Adoption \& Fostering Journal 35 (2011): 38-49.

94. Emily Jean McFadden. "Kinship care in the united states." Adoption and Fostering 22 (1998): 7-15.

95. Nigel Parton, and David Berridge. "Child protection in england." In Child Protection Systems: International Trends and Orientations. Edited by Neil Gilbert, Nigel Parton and Marit Skivenes. New York: Oxford University Press, 2011.

96. Jan Mason. Understanding Kinship Care. Sydney: Association of Children's Welfare Agencies, 2002. 
97. Jill Worrall. Grandparents and Other Relatives Raising Kin Children in Aotearoa New Zealand. Auckland: Grandparents Raising Grandchildren Charitable Trust, 2005.

98. Bob Broad. "Kinship care: Enabling and supporting child placements with kin." In Assessment, Preparation and Support: Messages from Research. London: British Agencies for Adoption and Fostering, 1999.

99. Mike Doolan, Paul Nixon, and Patrice Lawrence. Growing Up in the Care of Relatives or Friends: Delivering Best Practice for Children in Family and Friends Care. London: The Stationery Office, 2004.

100. Australian Psychological Society. Inquiry into Grandparents Who Take Primary Responsibility for Raising Their Grandchildren. Melbourne: Australian Psychological Society, 2014.

101. Jill Duerr Berrick. "Trends and issues in the U.S. Child welfare system." In Child Protection Systems: International Trends and Orientations. Eidted by Neil Gilbert, Nigel Parton and Marit Skivenes. New York: Oxford University Press, 2011.

102. Sharon Bessell. "Participation in decision making in out of home care in australia: What do young people say?" Children and Youth Services Review 13 (2011): 496-601.

103. Community Services Commission. Voices of Children and Young People in Foster Care. Sydney: Community Services Commission, 2000.

104. Elizabeth Fernandez. "How children experience fostering outcomes: Participatory research with children." Child and Family Social Work 12 (2007): 349-59.

105. Robbie Gilligan. "The importance of listening to children in foster care." In Issues in Foster Care: Policy Practice and Research. Edited by Greg Kelly and Robbie Gilligan. London: Jessica Kingsley Publishers, 2002.

106. Jane Thomson, and Ros Thorpe. "Powerful partnerships in social work: Group work with parents of children in care." Australian Social Work 57 (2004): 46-56.

107. Robert Dingwall, John Eekelaar, and Topsy Murray. The Protection of Children: State Intervention and Family Life. Oxford:Blackwell Publishing, 1983.

108. David G. Gil. Child Abuse and Violence. New York: AMS Press, 1979.

109. Karen J. Swift. "Canadian child welfare: Child protection and the status quo." In Child Protection Systems: International Trends and Orientations. Edited by Neil Gilbert, Nigel Parton and Marit Skivenes. New York: Oxford University Press, 2011.

110. Jeanne C. Marsh, Joseph P. Ryan, Sam Choi, and Mark F. Testa. "Integrated services for families with multiple problems: Obstacles to family reunification." Children and Youth Services Review 28 (2006): 1074-87.

111. Roger Bullock, Daniel Gooch, and Michael Little. Children Going Home: The Reunification of Families. Aldershot: Ashgate Publishing, 1998.

112. James G. Barber, and Paul Howard Delfabbro. Children in Foster Care. London: Taylor and Francis, 2004.

113. Elizabeth Neil. "The benefits and challenges of direct post-adoption contact: Perspectives from adoptive parents and birth relatives." Aloma 27 (2010): 89-115. 
114. Elaine Farmer, Wendy Sturgess, Teresa O’Neill, and Dinithi Wijedasa. Achieving Successful Returns from Care: What Makes Reunification Work? London: British Association for Adoption and Fostering, 2011.

115. Christian M. Connell, Karol H. Katz, Leon Saunders, and Jacob Kraemer Tebes. "Leaving foster care-The influence of child and case characteristics on foster care exit rates." Children and Youth Services Review 28 (2006): 780-98.

116. Becci A. Akin. "Predictors of foster care exits to permanency: A competing risks analysis of reunification, guardianship, and adoption." Children and Youth Services Review 33 (2011): 999-1011.

117. Katherine Kortenkamp, Rob Geen, and Matthew Stagner. "The role of welfare and work in predicting foster care reunification rates for children of welfare recipients." Children and Youth Services Review 26 (2004): 577-90.

118. Loring Jones. "The social and family correlates of successful reunification of children in foster care." Children and Youth Services Review 20 (1998): 305-23.

119. Phil Crane, Jatinder Kaur, and Judith Burton. Homelessness and Leaving Care: The Experiences of Young Adults in Queensland and Victoria, and Implications for Practice. Brisbane: Queensland University of Technology, 2013.

120. Philip Mendes, Guy Johnson, and Badal Moslehuddin. Young People Leaving State Out-of-Home Care: A Research-Based Study of Australian Policy and Practice. Melbourne: Australian Scholarly Publishing, 2011.

121. Fred Wulczyn, Richard P. Barth, Ying-Ying T. Yuan, Brenda Jones Harden, and John Landsverk. Beyond Common Sense Child Welfare, Child Well-Being, and the Evidence for Policy Reform. Chicago: Chapin Hall Center for Children, 2006.

122. Neil Gilbert, Nigel Parton, and Marit Skivenes. "Changing patterns of response and emerging orientations." In Child Protection Systems: International Trends and Orientations. Edited by Neil Gilbert, Nigel Parton and Marit Skivenes. New York: Oxford University Press, 2011. 


\title{
Dealing with Risk in Child and Family Social Work: From an Anxious to a Reflexive Professional?
}

\author{
Eline Vyvey, Rudi Roose, Lieselot De Wilde and Griet Roets
}

\begin{abstract}
The rhetoric of risk has become a prominent issue in the field of child and family social work. As a consequence, an emerging politics of fear has re-oriented this field towards managing, controlling, and securing social work practice against risk, rather than responding meaningfully to the needs and concerns of children and families. In the available body of research, it is argued that this general tendency creates "anxious" professionals. As a response, different scholars refer to the need to "speak back to fear". In this article, we analyze this claim in the context of a currently ongoing large-scale policy reform, named Integrated Youth Care (IYC), in the field of child welfare and protection in Flanders (the Dutch speaking part of Belgium). The debate on dealing with risk is often limited to an organizational and methodological discussion. We assert that we should reorient this debate and make a plea for a radical approach of applying a welfare perspective in child welfare and protection.
\end{abstract}

Reprinted from Soc. Sci. Cite as: Vyvey, E.; Roose, R.; de Wilde, L.; Roets, G. Dealing with Risk in Child and Family Social Work: From an Anxious to a Reflexive Professional? Soc. Sci. 2014, 3, $758-770$.

\section{Introduction}

The concept of risk recently received a lot of attention in human services management, frontline practice, and the social policy domain of child and family social work [1-4]. There is an emergent consensus in research on child and family social work that there has been a shift in emphasis across the Western world from child welfare to child protection, with a great deal of time being absorbed by the investigation of alleged abuse [5,6]. In different countries, the major impetus for this focus on risk in social work is rooted in political and cultural responses to tragedies (in particular, cases involving extreme negative outcomes for children). Over the last few years, an exponential growth of policy focused on children and young people has emerged. Especially in the UK, a public concern emerged due to the death of Victoria Climbie, an eight-year-old girl who was abused by her guardians despite family contact with a large range of health, welfare, and child protection services. The death of Peter Connely (named "Baby P") is another high profile case [7]. At the time of his death at the age of seventeen months, he had a broken back and some fifty injuries, even though the social worker saw the child on a home visit four days before he died [8]. This preoccupation with risk, however, is not just a "British disease" [7]. Inquiries into the fatal abuse of children have recently also taken place in other European countries, for instance in the Netherlands. In 2004, the three-year-old Savanna died in the Netherlands after a long period of serious abuse mainly by her mother, despite being under the supervision of child protection services. This case led to the prosecution of the frontline social worker who was charged with supervising Savanna. The death of 
Savanna impacted Dutch society deeply, and therefore, referral is made to the "Savanna effect", as several changes in child welfare and protections policy and practice were made with the intention of making earlier interventions by child protection workers possible in families. The responsibility for such cases was not only attributed to the actual abusers, but also to the agencies and professionals who had failed to prevent such outcomes [9]. In some countries, these cases even led to official inquiries into professional practice after child abuse tragedies. The main aim of these inquiries was to improve child protection in order to reduce the risk of more infant casualties $[10,11]$.

As a result, these tragic cases of child abuse and neglect strengthened the idea that risk should be perceived in negative and fearful terms, rather than in positive terms [12]. This solely negative approach to risk can, according to the authors of this article, have a deep impact on professional practices, as the climate of fear affects professionals who work with the children and families that are considered to be at risk $[13,14]$. Consequently, social workers fear for their physical and mental well-being, for being blamed when things go wrong, and for an undermining of the integrity of their profession. In that sense, this culture of fear, as cultivated by society, can drive frontline workers to become anxious professionals [15]. As such, perceiving risk in more positive terms as an impulse for change and opportunities seems to have disappeared in social work. These issues tend to create moral dilemmas, which undermine social work's capacity to respond meaningfully, purposefully, and creatively to risk situations [16]. Fear, panic, and the need to control have overtaken and undermined discussions about the courage and creative thinking necessary to take risks in social work practices [2]. Therefore, it is argued that social work must "speak back" to the culture of fear. Since notions of risk operate as powerful discursive constructs for shaping social work knowledge and practice in child welfare and protection, Stanford [17] suggests that it is necessary to explore the ways in which social workers can "speak back" to the "culture of fear" that is engendered by the rhetoric of risk as an integrated dimension of social work practice. In that vein, social workers need to understand that the profession inherently involves risk-taking, and consequently, there is an urgent need for reflection on the way social workers can act in meaningful ways when attending to risk-related matters during their interventions [17]. In this contribution, we discuss the idea of speaking back to fear in the context of a currently ongoing reform, named Integrated Youth Care, in the field of child welfare and protection in Flanders (the Dutch speaking part of Belgium). Although child and family social work in Flanders still focuses on elements of child welfare, the focus on risk and on elements of child protection, an orientation characterized by a primary concern to protect children from abuse, recently became increasingly dominant. While social workers may support a child welfare orientation in practice [18], this holds the risk of strengthening professional and organizational anxiety in managing child protection risks, whereby bureaucratic and defensive practices prevail [19].

In this contribution, we first look at historical dimensions of risk, and more in particular at the notion of the "child at risk", as an ambiguous social construct, since there are lessons to be learned from the ways in which the notion of the "child at risk" has changed as an ever-evolving concept in child welfare and protection practices. Second, we link the notion of risk to the debate about a child welfare or child protection perspective. Third, we discuss these different approaches in relation to the reform of Flemish practices concerning child welfare and protection, which is called "Integrated 
Youth Care". Although child and family social work is driven by a child welfare approach, Integrated Youth Care also adopts an increasingly prominent protectionist approach. Fourth, we argue that different underlying assumptions are at stake in the policies and practices of Integrated Youth Care in dealing with risk: the logic of risk avoidance and the logic of risk taking. We conclude with some reflections, arguing that the dominant discourse on risk requires reflexive rather than anxious professionals. The anxious professional works according to the logic of risk avoidance, implementing an approach in which social workers try to avoid risks rather than maximizing their engagement towards complex situations, which is typical for the reflexive practitioner, who works in the vein of a logic of risk-taking. Finally, we argue that speaking back to fear demands a radical welfare approach in child and family social work with children, youngsters, and their families.

\section{Risk as an Ambiguous Social Construct}

Child and family social work in Flanders (the Dutch speaking part of Belgium) has recently been reformed into a system of Integrated Youth Care (IYC). In this reform, a stronger attention for risk is coming to the fore. This is in line with development in many Western welfare states, as a much closer concern emerged recently about what causes harm to children, indicating a renewed interest and priority given to social work in the field of child welfare and protection to intervene in alarming situations [20]. The rhetoric of risk, however, is not a new or particularly 21 st century phenomenon, because growing up has historically been linked to the specific dangers and threats that young people could either be subjected to ("being endangered" or "at risk") or pose themselves ("being a danger" or "a risk") [21]. The specific term, "children at risk", pops up for the first time in the first half of the 20th century, although the origin of the discourse is even older. Most authors situate the birth of the "child at risk" at the beginning of the 19th century in the realm of an increasing interest of philanthropists, who paid special attention to the marginal position of the child from lower societal classes. In the spirit of that age, attention went primarily to children who grew up in misery, desolation, and neglect, and who were regarded as morally endangered [22,23]. This kind of upbringing would allegedly provide a so-called breeding ground for socially deviant behavior and juvenile delinquency. As a result, different kinds of solutions were considered to save these so-called "gangs of unsupervised children", such as orphans, foundlings, and abandoned children [23]. As such, a public concern emerged to protect society, as well as these "children at risk". The underlying assumption implied that children at risk needed to be protected against their so-called "dangerous" and "irresponsible" parents, based on a legal ground of "child protection", by removing them (temporarily) from their parents [22]. This tendency to speak of children and families as being "at risk" led to a climate in which the legitimacy of government intervention would be broadly accepted [24].

Despite the widely acclaimed improvement of our standard of living during the last century and countless interventions, we find that the group of "children at risk" has not "resolved" itself. On the contrary, in the present day, we observe a countless number of potential risks that children and young people can pose or be exposed to. In this context, the sociologist Turmel [25] refers to an important shift within the "risk discourse": from the potential delinquent child as the encapsulated form of the "child at risk" towards the "normal child". He argues that this process started at the end of the 19th 
century and entails an intensive search for methods, procedures, and techniques to observe children and to register the collected data, on an increasingly professional and scientific level [26]. Under the influence of two key processes in the domain of education and child rearing, technologization and professionalization, the notion of the "normal child" (as in the average child), became gradually more central in the course of the 20th century. Therefore, the initial hope of reducing the number of at risk children fades away, since the group only grows: the criteria for determining when a child is or is not at risk expands, and new categories leading to new risks and risky situations occur. In international circles, the notion of the "child at risk" is currently considered as a strikingly ambiguous and ever-evolving concept [27]. We see risks and dangers everywhere against which we must protect children and young people. As Dekker ([24], p. 18) asserts, "we can easily speak of 'the century of the child at risk' since 'the history of children at risk is a story of expansion. It is a story of the birth time and again of new categories of children at risk together with new measures and institutions to tackle these new risks"". As a result of these developments within the field of child welfare and protection, the assumption is raised during the 20th century that any problematized deviation from the norm would be a manageable given. The assumption strongly lives that we can and should unravel any risk, which is calculated on the basis of a set of abstract factors [28]. A so-called "control illusion", or what is often called "the scientification of risk" [23], implies that technological advances and the deployment of experts make it feasible to control every risk. The result is an excessive collective astonishment when something goes wrong after all. This urge for risk management seems widespread. As Guldberg ([28], p. 85) writes, "once overworrying is institutionalized, the list of potential problems facing children goes on and on". In that sense, today's prevailing moral panics regarding children and young people have never been so excessive, and several authors emphasize that we currently live in a true "culture of fear". She [28] states in "Reclaiming childhood" that we live in a "safety obsessed culture," in which the "better safe than sorry idea" is ever-present, and prevention and control accordingly are keywords in mitigating all possible risks. Hence, in light of the reform of youth care in Flanders, it is important to keep in mind that the notion of the "child at risk" is extremely complex and ambiguous, since it can be considered and constructed in radically different ways in child welfare and protection practices [20,29,30]. As Parton ([31], p. 855) asserts, "new and sometimes competing ideas about risk to children and the best ways of addressing these" are currently at stake. This construction process might involve major challenges to professional (risk) assessment and intervention [17,30]. As Hood ([30], p. 6) asserts, the current concern that families may be a locus of risks to children "obviously puts great pressure on assessment and decision making; making the wrong prediction about what will happen can have tragic consequences".

\section{A Child Welfare or Child Protection Perspective}

In the field of child welfare and protection, several authors $[18,32,33]$ have identified differences between child protection and child welfare orientations. From a child protection perspective, the focus typically lays on investigative procedures to legitimize rather intrusive interventions, whereas, from a child welfare perspective, problems are located in the broader social context in order to realize child welfare [34]. In relation to the issue of dealing with risk, the child protection perspective gives

priority to protecting children against abuse. The goal is to prevent damage to children, and to reduce 
the risks of harm. Social work practice therefore is defined mainly as an investigation, conducted to detect potential harm in family life situations. By contrast, a child welfare approach is "characteriszd by a tendency to understand acts, or circumstances, thought of as harmful to children, in the context of psychological or social difficulties experienced by families" ([18], p. 934).

In the Belgian context, this child welfare perspective is firmly rooted in social policy, in which child welfare and protection are perceived as a "comprehensive array of policies that form a pyramid" ([35], p. 205). From an organizational perspective, this is manifest in a range of interventions; from a broad array of indirect preventative child welfare services (such as a range of family support oriented services) to, at the top of the pyramid, more specific and reactive child protection services. Hence, a leading principle in child welfare and protection in Belgium is subsidiarity, "which basically refers to the idea that more investments at the base will reduce the need for interventions at the apex" ([35], p. 205). As such, the child welfare perspective in services is strengthened in order to prevent the intake of children and youngsters in the system of child protection services [33]. The rationale is that child protection services and practices are seen as more intrusive and expensive than the services and practices that are underpinned by this child welfare perspective, and therefore should be avoided where possible [34]. In the context of the large-scale social policy reform of Integrated Youth Care, entering child protection services is currently only possible through two specific organizations, which function as gatekeepers (since they have the mandate to intervene in a more mandatory way or to make references youth judges): the Youth Care Offices and the Confidential Centers for Child Abuse and Neglect. The Youth Care Offices provide support to social workers in cases of risk situations and the Confidential Centers for Child Abuse report and investigate particular suspicions of child abuse. In these practices, the concept of "societal necessity" is introduced as an underlying ground that legitimizes intervention. Dealing with societal necessity means coping with alarming risk situations or environments when someone feels the need or formulates the expectation that youth care is exigent for the minor and/or his family [35].

Although one might argue that child and family social work is principally driven by a child welfare logic, it is equally valid to observe that a mainly protectionist approach has been implemented. First, welfare-oriented organizations in the field of child welfare and protection are driven by a logic of prevention, in a sense that these organizations are oriented towards the prevention of the use of social service delivery itself, rather than towards preventing social problems and the broadening of social support (e.g., housing, poverty work). The prevention of child protection interventions in Belgium has been historically a key idea in the development of the child welfare and child protection system and has become more influential during the latter half of the twentieth century, so that scarce welfare state resources could be directed to where, in theory, they were most needed. While hoping to make the child protection system redundant and residual, social policy also aimed to reduce the number of referrals to non-directly accessible child protection services [22]. Hence, although the welfare approach is still very dominant in the policy framework, this welfare approach is very much driven by a logic of protection. Thus, child welfare organizations perform their functions from a negative perspective that prioritizes the prevention of more intrusive interventions, rather than the provision of support [30]. 


\section{Integrated Youth Care}

This preventative rhetoric of risk recently acquired a central role in the framework of Integrated Youth Care. This is a cross-sectorial policy program of the Flemish government, which aims at a coordinated approach for helping troubled children and young people and their families [36,37]. This reform resulted from the activities of a Parliamentary Ad Hoc Commission on Youth Care during 1998. As the result of this think tank, it was stated that the fragmentation of child protection and child welfare services, reflected in the striking gaps and overlaps in the provision of services, was leading to conspicuous ineffectiveness and inefficiency. Launched as a large-scale policy-driven organizational reform of child and family services in the Decree on Integrated Youth Care of 2004, the development of Integrated Youth Care required the inter-sectorial reorganization of a wide diversity of ambulant, as well as residential, welfare services for children and youngsters (0-18 years-old), covering seven different sectors, to improve the effectiveness and efficiency of child and family services [38]. The central aim of Integrated Youth Care was summarized as "rendering an integrated assistance to the minor and/or the minor and his/her relatives to safeguard their scope to develop and to improve their well-being" ([39], p. 11). As such, social policy makers decided to aim at organizing the existing supply of social work services into clear-cut "modules", which define what services and organizations do, how they do it, and for whom [40]. This is directed at the realization of a transparent and inter-sectorial joining-up of networks of social service delivery to serve customers, based on the establishment of a flexible and demand-driven integration of social work modules in service delivery. This organizational reform also stipulates that the activities of different child and family services are geared to each other, in order to cover existing gaps and to prevent overlaps in service provision [41].

In this reform, child welfare organizations are urged to take more responsibility in risk situations. In the social policy framework of Integrated Youth Care, "risk" is "a situation that threatens the development of a minor because his mental, physical or sexual integrity or that of one or more members of his family is affected, or because his emotional, moral, intellectual, and social development opportunities are threatened, which make youth care socially necessary" ([41], p. 133). From this perspective, prevention is likewise focused on the individual child rather than on preventing or tackling broader social problems [42].

\section{Dealing with Risk: The Beginning or the End of Dialogue}

Hence, in the framework of Integrated Youth Care, child welfare and child protection workers are increasingly required to deal with complexity and risk, and are increasingly required to make decisions about potential threats as "risk positions individuals and governments and citizens in relationships dominated by suspicion, and attitudes and moralities of protectionism and responsibilization as an inherent part of their job" ([17], p. 1066). In that light, risk assessment and management have become part of ongoing processes of professionalization in the complex world of child welfare and protection [43]. Given increased demands for public accountability, approaches to risk assessment and management currently vary between standardizations, technical and diagnostic tools, checklists and procedures, and more qualitative, open-ended, and dialogic ways to assess and 
interpret the potentiality of risk [44]. However, as mentioned in the introduction, there is currently no clarity about the question of how social workers can act in meaningful ways when considering and dealing with risk in their interventions, and how they can possibly "speak back to fear". As such, how social work in Integrated Youth Care will deal with risk and which kind of logic will drive them is an important issue: one may adopt either a logic of risk avoidance, where accountability for what social workers are doing is situated outside practice, or of risk taking, where accountability for what social workers are doing is positioned within the practice [45].

\subsection{Risk Avoidance: The End of Dialogue}

It is stated that the contemporary societal obsession with danger and risk minimization [13] has reoriented social work towards managing and securing their practice against risk, instead of responding meaningfully to the needs of children and families [17]. Whilst much of the practice of professionals in child and family social work is necessarily based on the development of a mutual understanding and trust through client contact, the assumption of risk has resulted in an expansion of risk management practices. Management systems develop regulatory systems and routines intended to standardize practice and thereby limit variations in practice [46]. Most of these strategies are based on a restricted approach to risk that emphasizes hazard assessment and safety issues. There is limited evidence of broader integrated approaches to risk management [2]. The practice of risk control changes the type and nature of child and family social work from one of trusting relationship built over time to technological interventions characterized by risk-based classification, assessment, and short-term intervention [14]. The shift towards social work as a possible instrument of surveillance and control can also be situated within a changing discourse on responsibility. In neoliberal contexts, responsibility tends to evolve as a downward spiral [47], as it is increasingly shifted from the state to the individual [48]. In this development, "more responsibility for the individual (citizen)" rather needs to be interpreted in terms of a responsibilization of the individual in which the conditions of being responsible are clearly formulated by the state [49]. The state defines a social problem, and the individual is expected to play a central role in the solution for that socially constructed problem. Who is not willing to be "responsible", will be forced (and even punished); who is not able to be "responsible" will be helped. In this, the state presents itself as a companion of the individual (citizen), but at the same time it defines what needs to be regarded as responsible behavior [50]. The security that risk technology suggests is seductive [44]. However, if we look at risk and danger in such a defensive way [51], accountability for the actions of social workers is placed outside the concrete situation, because these risk assessment instrument reduce decision-making options and minimize discretion [43]. The growing trend to establish tools, procedures, and protocols seem to indicate that social workers can resolve the complexity that is typical for social work and can protect themselves against radical criticism when things go wrong with children in families. Important in this context, however, is the awareness that an anxious professional remains a powerful professional: his fear drives the policy space into a risk avoiding direction [15] and paradoxically, "risk avoidance carries the danger of creating new risks, both by heightening social workers' anxiety and vulnerability, and by prompting them to identify new areas of risk in users' lives, which can lead them to adopt a more controlling approach" ([45], p. 227). 


\subsection{Risk Taking: A Starting Point for Dialogue}

Social workers might also deal with risk more reflexively [30,49,52]. Here, accountability for the ways in which social workers are dealing with risk is judged on the basis of the engagement of social workers in the concrete situations in which they intervene. "Rather than try to calculate the incalculable, social workers need to regain their former status as experts in uncertainty" ([45], p. 228). This implies that social workers do more than implement a strengths-based perspective and organize a dialogical assessment. For instance, to objectify risk situations in Integrated Youth Care in Flanders, a methodology is promoted that aspires to objectify "risk security": Signs of Safety. This so-called "objective" diagnosis is seen as a prerequisite for good care. Nevertheless, this assumption is not necessarily evident. First of all, proper care does not inherently coincide with the quality of the diagnosis, but also depends on the quality of the engagement towards young people and their families [21]. Second, child welfare work is about commitment, being present, and the development of a shared responsibility of social workers and parents [30]. This also involves the engagement to challenge the dominant risk discourse and to question one's own constructions and ideas. According to this approach, risk assessment is viewed as a starting point for dialogue instead of an end of dialogue. According to McLaughlin [13], risk assessment in social work is not a precise actuarial model in which the probability of unwanted outcomes can be precisely determined. It goes beyond that. Each individual is also influenced by their interactions with the organization in which they work and the wider society in which they live [13]. Most risk instruments ignore the importance of moving beyond procedures to examine the detail of how practitioners enact risk technologies [53]. According to Ferguson [8], realizing high quality in child protection involves the skillful management of actively engaging with children and their environment. The relational aspect of practice creates a range of practical and moral dilemmas that are difficult to systematize [48]. Hence, while professionals are concerned about hazard and harm, they also recognize the need for risk-taking [2]. This implies that the possibility of error and mistake, and also of public debate, about the assessment of risk is essential on an organizational as well as on an inter-organizational level in social work services, because even mistakes - which are often kept hidden — can serve as an opportunity to learn. As Roose [54] argues "social workers need space to make mistakes and the opportunity to have open-minded discussions about these mistakes because, paradoxically, in many cases, it is the only way to develop a responsive approach to the client and to enable social workers to find new ways to face the complexity of problems. The irony of situations, and particularly of mistakes, might enable social workers to consider mistakes as a point of departure for further actions" ([54], p. 12).

\subsection{An Example: The Use of Consultation}

As an example of the different perspectives that social workers can develop in dealing with risk, we refer to the role and use of the practice of "consultation", as one of the core missions of the Youth Care Office in Flanders. The main aim of the Youth Care Office is to provide consultation to social workers and youth care services in risk situations, where social workers no longer feel 
comfortable in dealing with situations of risk within their own practice. Hence, they can ask the Youth Care Office for support and advice in dealing with the situation [25].

We notice in practice that social workers make use of this possibility of consultation in different ways. Some use it defensively [51]. This practice is sometimes used, for example, in the hopes of legitimizing the ending of the engagement towards the situation and the passing of the case to other social work services [21]. Thus, accountability is placed outside the concrete situation as the end of dialogue $[43,45]$, as the demand for a consult is mainly used to prevent the possibility of error [55].

Consultation is, however, also used in more reflexive ways, aimed at broadening the engagement in situations of risk $[30,49,53]$. Here, accountability is placed inside the concrete situation and the perception of a situation as risky is viewed as a starting point for dialogue. Social workers accept their responsibility for risk taking and have a great commitment to each specific situation, including the commitment to question their own construction of risk. As such, child and family social work involves travelling into the unknown. Rather than understanding risk in social work as only danger and in terms of fear of blame for things going wrong, the consult might support the social workers to recast notions of risk in more positive terms of opportunity, courage, resilience, skill, and creativity [8].

\section{Concluding Reflections: From an Anxious to a Reflexive Professional?}

In this contribution, we argued that a more protectionist approach, driven by a focus on risk, has become increasingly central in Flemish practices of child welfare and protection. However, we also argued that social workers can deal with this development in diverse ways, be it defensive or reflexive. In that vein, Fargion [32] refers to the features of a child welfare approach, in which professionals are mainly seen as strong and reflexive professionals; whereas a child protection perspective implies that professional discretion is limited and social workers are easily distrusted. We argue that the dominant discourse on risk requires reflexive rather than anxious professionals. Anxious professionals work according to a logic of risk avoidance rather than maximizing their engagement towards complex situations, which is typical for the reflexive practitioner, who works in the vein of a logic of risk taking.

In present-day, this is not the case in Flanders, as the media and the profession seem to respond to tragic incidences in a more serene manner than in other countries, such as the UK and the Netherlands [56]. Nevertheless, social workers in Flanders are in fact influenced by these developments. Albeit, in our view it is deeply problematic that the debate on dealing with risk in Flanders mainly refers to the management of child welfare and protection and to the development of objective and technical methods to deal with risk (such as signs of safety [57]). The attention currently goes to the questions of whether risk can be avoided, how the transition from child welfare to child protection can be prevented, or, if unavoidable, how the transition can be organized [30]. Little or no attention goes to the underlying question from which child welfare and protection are realized: what are our ideas about risk and about good social work? What do we consider to be a strong professional? What kind of responsibilities for whom does this involve, etc.? Hence, a thorough debate on risk-taking stays under the radar. 
Although social workers in reality construct multiple manners to speak back to fear [7], we argue that dealing with risk should not be reduced to a debate about organizational or methodological issues. Therefore, we argue that a child welfare perspective should be implemented as radically as possible. This discussion should go beyond the plea for more child welfare organizations to prevent protectionist interventions. It also goes beyond a focus on individual social workers and organizations. It should include a diversity of questions with respect to the underlying perspective of child welfare and protection practices, and should ultimately refer to questions concerning the kind of society we want to live in and the place of social work in the welfare state.

In our view, social work needs to consider its responsibility to interrupt the conservative ethos of negative constructs of risk, and enable its capacity to take risks in favor of the client, driven by the question of how to deal with risk without answering risk-related dilemmas with fear [17].

\section{Author Contributions}

Eline Vyvey was the primary writer and editor of the paper, together with her supervisor Rudi Roose who participated in the whole process of the literature review, preparing the paper and finishing the manuscript. Lieselot De Wilde and Griet Roets wrote different paragraphs in the paper while strengthening the coherence of the paper and participated in every step of preparing this manuscript.

\section{Conflicts of Interest}

The authors declare no conflict of interest.

\section{References}

1. Barry Goldson. “'Children in Need' or 'Young Offenders'? Hardening ideology, organizational change and new challenges for social work with children in trouble." Child and Family Social Work 5 (2000): 255-65.

2. Andy Alaszewksi, and Helen Alaszewski. "Towards the creative management of risk: Perceptions, practices and policies.” British Journal of Learning Disabilities 30 (2002): 56-62.

3. Derrick Armstrong. "A risky business? Research, Policy, Governmentality and Youth Offending." Youth Justice 4 (2004): 100-17.

4. Hazel Kemshall. "Risks, rights and justice: Understanding and responding to youth at risk." Youth Justice 8 (2008): 21-37.

5. Nigel Parton, David Thorpe, and Corinne Wattam. Child Protection: Risk and the Moral Order. Basingstoke: Macmillan Press, 1997, p. 276.

6. Jonathan Scourfield, and Ian Welsh. "Risk, Reflexivity and Social Control in Child Protection: New Times or Same Old Story?” Critical Social Policy 23 (2003): 98-120.

7. Joanne Warner, and Elaine Sharland. "Editorial." British Journal of Social Work 40 (2010): $1035-45$.

8. Harry Ferguson. "Walks, Home Visits and Atmospheres: Risk and the Everyday Practices and Mobilities of Social Work and Child Protection." British Journal of Social Work 40 (2010): $1100-17$. 
9. Tirza Kuijvenhoven, and Willem J. Kortleven. "Inquiries into Fatal Child Abuse in the Netherlands: A Source of Improvement?” British Journal of Social Work 40 (2010): 1152-73.

10. Nigel Parton. "Risk, Advanced Liberalism and Child Welfare: The Need to Rediscover Uncertainty and Ambiguity." British Journal of Social Work 28 (1998): 5-27.

11. Peter Lachman, and Claudia Bernard. "Moving from blame to quality: How to respond to failures in child protective services." Child Abuse \& Neglect 30 (2006): 963-68.

12. David Denney. "Violence and Social Care Staff: Positive and Negative Approaches to Risk." British Journal of Social Work 40 (2010): 1297-313.

13. Ken McLaughlin. Social Work, Politics and Society: From Radicalism to Orthodoxy. Bristol: Policy Press, 2008, p. 192.

14. Stephen A. Webb. Social Work in a Risk Society: Social and Political Perspectives. Houndsmills: Palgrave Macmillan, 2006, p. 256.

15. Maria Bouverne-De Bie. "Over angstige en sociale professionals." Paper presented at the Association Research Group Pedagogy of Social Work, Ghent University Association, Radboud University and HAN University of Applied Sciences, Ghent University, Ghent, Belgium, 12 December 2008.

16. Mike Titterton. Risk and Risk Taking in Health and Social Welfare. London: Jessica Kingsley Publishers, 2006, p. 160.

17. Sonya Stanford. "'Speaking Back' to Fear: Responding to the Moral Dilemmas of Risk in Social Work Practice.” British Journal of Social Work 40 (2010): 1065-80.

18. Matthew Colton, Charlotte Drury, and Margaret Williams. Children in Need: Family Support under the Children Act 1989. Aldershot: Avebury, 1995, p. 248.

19. Trevor Spratt. "The Influence of Child Protection Orientation on Child Welfare Practice." British Journal of Social Work 31 (2001): 933-54.

20. Ingrid Lohmann, and Christine Mayer. "Lessons from the history of education for a 'century of the child at risk'." Paedagogica Historica: International Journal of the History of Education 45 (2009): 1-16.

21. Cynthia Anne Connolly. Saving Sickly Children: The Tuberculosis Preventorium in American Life, 1909-1970. New Brunswick: Rutgers University Press, 2008, p. 200.

22. Juliane Jacobi. "Between charity and education: Orphans and orphanages in early modern times." Paedagogica Historica: International Journal of the History of Education 45 (2009): 51-66.

23. Paul Smeyers. "Child rearing in the 'risk' society: On the discourse of rights and the best interests of a child." Educational Theory 60 (2010): 271-84.

24. Jeroen J. H. Dekker. "Children at risk in history: A story of expansion." Paedagogica Historica: International Journal of the History of Education 45 (2009): 17-36.

25. André Turmel. A Historical Sociology of Childhood: Developmental Thinking, Categorization and Graphic Visualization. Cambridge, UK: Cambridge University Press, 2008, p. 376.

26. Christine Mayer, Ingrid Lohmann, and Ian Grosvenor. Children and Youth at Risk: Historical and International Perspectives. Frankfurt am Main: Peter Lang, 2009, p. 316. 
27. Robert Castel. "From dangerousness to risk." In The Foucault Effect: Studies in Governmentality. With Two Lectures by and an Interview with Michel Foucault. Edited by Graham Burchell, Colin Fordon and Peter Millger. Chicago: The University of Chicago Press, 1991, pp. 281-98.

28. Helene Guldberg. Reclaiming Childhood: Freedom and Play in an Age of Fear. New York: Routledge, 2009, p. 216.

29. Sylvia Schafer. Children in Moral Danger and the Problem of Government in Third Republic France. Princeton: Princeton University Press, 1999, p. 232.

30. Rick Hood. "Complexity and Integrated Working in Children's Services." British Journal of Social Work 44 (2014): 27-43.

31. Nigel Parton. "Child protection and safeguarding in England: Changing and competing conceptions of risk and their implications for social work." British Journal of Social Work 41 (2011): 854-75.

32. Silvia Fargion. "Synergies and Tensions in Child Protection and Parent Support: Policy Lines and Practitioners' Cultures." Child and Family Social Work 19 (2014): 24-33.

33. Rudi Roose, Griet Roets, and Tineke Schiettecat. "Implementing a strengths perspective in child welfare and protection: A challenge not to be taken lightly." European Journal of Social Work 17 (2014): 3-17.

34. Neil Gilbert. Combating Child Abuse: International Perspectives and Trends. New York: Oxford University Press, 1997, p. 255.

35. Kristof Desair, and Peter Adriaenssens. "Policy toward child abuse and neglect in Belgium: Shared responsibility, differentiated response." In Child Protection Systems. Edited by Neil Gilbert, Nigel Parton and Marit Skivenes. New York: Oxford University Press, 2011, pp. 204-22.

36. Cocops. Available online: http://www.cocops.eu/wpcontent/uploads/2014/02/ Belgium_Health_Integrated_Youth_Care_fin1.pdf (accessed on 1 June 2014).

37. Jean-Pierre Vanhee. Dat verandert de zaak. Een bijdrage tot de articulatie van Integrale jeugdhulp. Brussel: Politeia, 2014, p. 246. (In Dutch)

38. Griet Roets, Rudi Roose, and Tineke Schiettecat. "Reconstructing the foundations of joined-up working." British Journal of Social Work, 2014, in press.

39. Dirk Broos, and Veronigue Grossi. Strategisch Plan Integrale Jeugdhulpverlening. Brussel: Ministerie van de Vlaamse Gemeenschap, Departement Welzijn, Gezondheid en Cultuur, 2000, p. 11. (In Dutch)

40. Ludo Serrien. Modulering is meer dan een wegwijzer. Handboek Integrale jeugdhulp. Brussel: Politeia, 2011, pp. 1-10. (In Dutch)

41. Vlaams Parlement. Decreet integrale jeugdhulp. Brussel: Vlaams Parlement, 2013, pp. 5-227. (In Dutch)

42. Emily Kedell. "The ethics of predictive risk modelling in the Aotearoa/New Zealand child welfare context: Child abuse prevention or neo-liberal tool?" Critical Social Policy, 2014, in press. 
43. Karen Broadhurst, Chris Hall, Dave Wastell, Sue White, and Andy Pithouse. "Risk, Instrumentalism and the Humane Project of Social Work: Identifying the Informal Logics of Risk Management in Children's Statutory Services." British Journal of Social Work 40 (2010): 1046-64.

44. Tom Horlick-Jones. "Informal logics of risk: Contingency and modes of practical reasoning." Journal of Risk Research 8 (2005): 253-72.

45. Kirsten Stalker. "Managing Risk and Uncertainty in Social Work." Journal of Sociaal Work 3 (2003): 211-33.

46. Fran Tonkiss, and Andrew Passey. "Trust, confidence and voluntary organisations: Between values and institutions." Sociology 33 (1999): 257-74.

47. Gerald Cradock. "The responsibility dance: Creating neoliberal children." Childhood 14 (2007): $153-72$.

48. Nina Oelkers. "The redistribution of responsibility between state and parents: Family in the context of post-welfare-state transformation." In The Politicization of Parenthood. Edited by Martina Richter and Sabine Andresen. Heidelberg/London: Springer, 2012, pp. 101-10.

49. Rik Peeters, and Gerard Drosterij. "Verantwoordelijke vrijheid. Responsabilisering van burgers op voorwaarden van de staat." Tijdschrift voor Beleid, Politiek en Maatschappij 38 (2011): 179-99.

50. Michel Foucault. Security, Territory, Population. Lectures at the College de France 1977-1978. New York: Picador, 2007, p. 464.

51. John Harris. The Social Work Business. London: Routledge, 2003, p. 240.

52. Harry Kunneman. Voorbij het dikke-ik. Bouwstenen voor een kritisch humanisme. Amsterdam: SWP, 2005, p. 287. (In Dutch)

53. Rami Benbenishty, Rujla Osmo, and Nora Gold. "Rationales Provided for Risk Assessments and for Recommended Interventions in Child Protection: A Comparison between Canadian and Israeli Professionals.” British Journal of Social Work 33 (2003): 137-55.

54. Rudi Roose, Griet Roets, and Maria Bouverne-De Bie. "Irony and Social Work: In Search of the Happy Sisyphus.” British Journal of Social Work 42 (2012): 1-16.

55. Brian Littlechild. "Child protection social work: Risks of fears and fear of risks-Impossible tasks from impossible goals." Social Policy and Administration 42 (2008): 662-75.

56. Rijksoverheid. Available online: http://www.rijksoverheid.nl/documenten-en-publicaties/ rapporten/2013/11/12/risico-regelreflex-in-de-jeugdzorg.html (accessed on 1 June 2014).

57. Andres Turnell, and Steve Edwards. Signs of Safety: A Safety and Solution Oriented Approach to Child Protection Casework. New York: W. W. Norton, 1999, p. 45. 


\title{
The Child Protection System from the Perspective of Young People: Messages from 3 Studies
}

\section{Carme Montserrat}

\begin{abstract}
This article reports findings and reflections based on the results of three different research projects conducted between 2008 and 2013 and focusing on the perspective of young care leavers in Spain. The overall aim was to examine these young people's perceptions and evaluations of how they were treated while in the public care system, mainly residential care. Reviewing these qualitative studies, the most common and relevant issues highlighted by young people were related to the following themes: (a) entering care; (b) stability and emotional bonds in care; (c) education; (d) friends; (e) labelling, stigmatization, rights and opportunities; (f) autonomy and responsibility versus overprotection; ( $g$ ) contact with parents, siblings and extended family; (h) maltreatment in care; and (i) leaving care. One of the main elements used in their assessments was comparison (i) between their previous situation within their birth family and the quality of care experienced in the residential home; and (ii) between what these young people commonly refer to as "normal children" and children in care. Recommendations deriving from their advice and opinions are also debated.
\end{abstract}

Reprinted from Soc. Sci. Cite as: Montserrat, C. The Child Protection System from the Perspective of Young People: Messages from 3 Studies. Soc. Sci. 2014, 3, 687-704.

\section{Introduction}

"In order to improve, services need consumer feedback, and there are ethical, practical, therapeutic and legal reasons for consulting children and young people as the primary users of foster care" ([1], p. 16).

Since the introduction of a democratic constitution and its recognition of social rights in 1980, Spain has developed a welfare state for the universal provision of education, health care and pensions [2]. Initially classified under the category of conservative-corporative regimes [3], this Mediterranean welfare state has incorporated aspects of different regimes in varying combinations; for example, it has a universal system of health and education but offers weaker provisions for vulnerable and excluded groups [4,5]. Similarly to other countries, in Spain social actors like non-governmental organisations (NGOs) are gradually replacing the state institutions traditionally responsible for protecting individual rights and needs $[6,7]$.

The tradition in Mediterranean states is for the family to play an important role in caring for dependent members such as children. However, families receive little support from the state, and there is low social expenditure on children and families, leaving Spain some distance from countries like Norway, with its strong expansion of the public childcare system. According to this author ([6], p. 19), in Spain it is the family which is the de facto "key welfare provider", with an important share of both material and non-material intra-familial transfers. This strong focus on the importance of the family within the Mediterranean culture does not translate into more provision for families and 
children in the form of state support. The expenditure on family and children in Spain is one of the lowest in the EU-27 [8].

The Spanish welfare model does not include any benefits or financial support for further education or attaining independence for young people from the general population reaching adult age, with the exception of study grants, which are scarce. In 2013 in Spain [9], only 22.1\% of young people under 30 were living outside their family home, this figure being $25.4 \%$ for Catalonia.

Regarding the child protection system, residential care bears a considerable weight and there are great difficulties in placing a child in a non-kinship foster family compared with other Western countries. The figures for Spain are around $45 \%$ for residential settings, $45 \%$ kinship care and $10 \%$ non-kinship foster families [10].

This article focuses on Catalonia, where there is a policy regarding care leavers since 1994, making it almost unique among the Spanish autonomous regions (from 1980 onwards, as a result of the decentralization process, Spain was divided administratively into 17 autonomous regions, each with its own government, parliament and a range of administrative powers, including social services). In May 2010, the Parliament of Catalonia approved the Childhood and Adolescence Rights and Opportunities Act (14/2010). This new Act represented an important step forward for care leavers. Article 146 concerns transition to adulthood, with a set of measures that includes supported housing, financial support, legal guidance and employment for 16 year-olds leaving the care system and who accept support on a voluntary basis [10].

The Care Leavers Department (ASJTET) has entered agreements with several NGOs as providers. Referrals to this service are usually from the child protection team, residential homes or local social services, which compile a written proposal and plan for action and review. This plan must be agreed with the young person and ASJTET, who implement it jointly. The professionals responsible for working directly with the young person are usually social educators. In many cases, professionals who help with labour market integration are also involved, and depending on the request, sometimes also psychologists and social workers. In many situations, a lawyer is also present due to the legal guidance that may be required. For those living in accommodation supported by the Department, the social educator becomes an important person in their life and one of their key means of support, also emotional, in the process of becoming independent.

\section{Positive Parenting: Does It Happen in the Child Protection System?}

In 2006, the Council of Europe published the Recommendation (2006) on policy to support positive parenting and encouraged states to recognize the importance of parental responsibilities and the need to provide parents with sufficient support in bringing up their children. Member states were recommended to take all appropriate legislative, administrative and financial measures to promote this. For this purpose, the Council of Europe defined "Parents" as the persons with parental authority or responsibility; "Parenting" as all the roles falling to parents in order to care for and bring up children, centred on parent-children interaction and entailing rights and duties for the child's development and self-fulfilment; and "Positive parenting": as the parental behaviour based on the best interests of the child that is nurturing, empowering, non-violent and provides recognition and guidance which involves setting of boundaries to enable the full development of the child ([11], p. 2). 
According to this concept of positive parenting, parents should provide children with warmth and support by spending quality time with them; trying to understand their life experience and behaviour; explaining the rules they are expected to follow; praising good behaviour; and avoiding harsh punishment. This also means embedding children's rights within policymaking, such as creating possibilities for children to make their opinions heard and participate in political decision-making on matters concerning them. In Spain, as in other countries, following the campaign launched by the Council of Europe, the Ministry of Health and Social Policy has been publishing documents and guidelines to foster local authorities implementing positive parenting programmes [12].

However, the term is mainly used with regard to parents and how to enhance their role. The question I wish to address here is whether the state is providing positive parenting for children in the care system. Some authors [13] asked whether the corporate state can in fact parent. The interesting aspect of the English term "corporate parenting" is the inclusion and extension of this concept within the role of the state. According to these authors, several factors are required to make the state a better parent. One of these is that the legal and administrative framework has to be appropriate and adapted to children's needs, improving collaboration and coordination among services to provide optimal outcomes for children. Another requirement is to ensure that the care offered by the state is of a high quality: the selection of placements, carers and types of interventions should ensure the child's wellbeing. Another requirement regards support for care leavers, particularly when they are adolescents, and the need for a wide range of post-care services.

\section{Research where Children Give Their Opinion}

What do young people say about the treatment they received while in the protection system? Was it positive parenting? According to the authors [14], the key to protecting and promoting children's well-being is the ability to understand their situation from their point of view. Professionals must be trained and endowed with the skills that parents usually work with to ensure that they know how to talk to children, while taking into account any disabilities and cultural differences that may exist. A first aspect they should take into account is not pathologizing children's situations of living in adverse family contexts. Another author [15] also show that children do not like psychologists concerning themselves with aspects of their health or development while not focusing on being able to help them solve the problem they have at home. Children can present a wide range of physical symptoms and emotional changes. Very often they are treated on the basis of this without addressing the underlying issue, and this does not lead to very good results. We should therefore be striving to avoid their pathologization and work more towards recognizing their resilience, as many of them improve when they are removed from the situation of violence.

Some authors [16] show that children do not always want to talk about what is happening to them with a professional or with their foster carers as they are afraid that their family will find out, or of the negative consequences it might have for their parents or other family members. However, often they also fear not being believed because they have lost trust with others, or even if they do believe them, they will not be able to help. They also fear being labelled, rejected and treated differently, at school for example. They tend to use informal support and talk to extended family, friends and pets. This fact is often overlooked and underestimated by professionals. It is very rare 
that they actually seek the help of professionals: they find many differences in the language they use, and professionals can fail them, or not listen to them or understand them. According to children, there are key problems in their relationships with professionals, who either do not believe them, do not speak to them directly or do not act to give them help when they ask for it. One of the main pleas made by these children is for things to be explained to them, verbally or in writing, in a language appropriate to their age, as well as providing them with security and above all confidentiality. They highly value their experience being respected, acknowledged and valued.

Previous research [15] stated that children who have experienced domestic violence when protected begin to realize what they have lost, but without underestimating the value of feeling secure. They start to think about their home, belongings, toys and collections, their friends, their school, their pets, their extended family, and see that all of these multiple losses were not caused by them. The situation is very different for those who have been able to maintain some parts of their life. Indeed, children's behavior and feelings once they are protected varies widely, from those who are happy and calm, to those who are sad, enraged, violent or fearful. Children want to feel safe and have someone to talk to: professionals can play an important role in both of these areas.

One aspect that stands out in interviews with children is receiving informal help, which is very important to them but unfortunately not valued by professionals. For example, the role of siblings, together with whom they can build helping relationships and coping strategies. If this is maintained and fostered, it is a source of emotional support which does not require substitution. Also the role of friends, who tend to be the people they would rather trust, do not label them and can be someone they can confide in. And finally the role of the extended family, if professionals were aware of the importance of these bonds, they would take them into account in their interventions. Professionals should understand the role of friends, siblings, extended family and community better in the lives of children in order to improve their interventions.

A study on family foster care [17] lists the following key issues from the point of view of children: they like to be heard, both by professionals and by carers; they like to be informed, to choose their foster family, make a prior visit to the foster home; have good relations with carers, be with more children in the same household, have regular interviews with the same social worker, have a say in the contact they have with their family, and stay in the same school. The issue of visits is open to debate, as in many cases children are forced to make visits they do not want to make and are only calm when they know that this will not happen, or contrarily, they would like more contact and cannot have it [15]. Previous research [1] highlight that children, even when they are in foster care, share the same basic needs as other children, in the sense that they want the following: to have a normal family life, a sense of progress and success, respect for their individuality and culture, basic information about their rights, a good education, to be able to express an opinion on their carers, and finally to be able to choose the frequency and type of contact they have with their biological family.

The other issue they highlight is that children do not like there to be uncertainty about their future [18]. They like to be consulted regarding possible decisions in the reviewing of their case and are unhappy when they feel they are not heard. They show concern at having a change of carer without being previously consulted and criticize professionals harshly for not being honest with 
them about the reasons for the change. To this, [19] add the negative perception that children have when they have a change of carer, as it affects their whole personal and family life, school (it often also involves a change of school), there can be a change of doctor, and they lose many of their possessions, all leading to a loss of identity.

Some authors [20] show that the experience of long-term, stable foster care may be very positive and can provide children with emotional security and a sense of permanence. Previous research [21,22] highlight the key factor of stability and underline the importance of children having stable living conditions either in their own family, through adoption or in permanent foster care, avoiding changes within the protection system to ensure high quality care, and assessing the results of this.

The issue of when and how they return to their birth family is also controversial, this having a negative impact on children when it fails and they have to re-enter the system or stay at home in difficult conditions. According to this author [23] this happens because there is often a restricted view of the pathways children in care have: either to return home or be adopted, when these options do not generally meet the needs and wishes of many children.

Reviewing evidence on the effectiveness of child welfare intervention, these authors [24] showed that some evidence is available regarding the views of children as users of services, and that these are particularly relevant in areas relating to out-of-home care, providing understanding of both processes and outcomes; however, according to these authors, few of these studies also incorporated more objective measures. In the same publication, some authors stressed the value of contributions deriving from the views of children and young people living in situ ations of vulnerability.

\section{Method}

In our research team we conducted three studies in Catalonia between 2008 and 2013 which included the views of young care leavers regarding their passage through the protection system and the treatment they received. These studies were based on the following theoretical frameworks: (i) the perspective of quality-of-life research, where the views of all stakeholders are deemed important, including those of young people; (ii) the perspective of children's rights, in terms of their voice being heard on issues that affect their life; and (iii) eco-systemic theories that avoid linear causalities and share a multifactorial approach to the phenomenon.

Although these three studies were from three different research projects, as discussed below, the results give cause for us to draw up recommendations for improving the protection system in terms of childhood policies, professional practice and research. Thus, the aims of this article are to examine the treatment received by children in care based on the perceptions and opinions of young care leavers and to ascertain what suggestions they have for improvement.

The three studies had different goals but all shared a part where young people were asked to reflect on their passage through the protection system and give some advice in this respect. These studies had been reviewed focusing on the qualitative part of interviews and focus groups conducted with young people, and particularly on their assessment of the time they spent in residential homes, this being the common denominator that united them. The overall characteristics of each study are presented in Table 1. 
Table 1. Characteristics of the three studies analysed.

\begin{tabular}{|c|c|c|c|}
\hline $\begin{array}{l}\text { Acronym } \\
\text { \&Title }\end{array}$ & $\begin{array}{c}\text { YIPPEE-YP Leaving Care: } \\
\text { Pathways to Education in } \\
\text { Europe }\end{array}$ & $\begin{array}{c}\text { PE- Success Factors for } \\
\text { Children in Residential Care }\end{array}$ & $\begin{array}{c}\text { FEPA-Care Leavers: Evolution } \\
\text { and Future Challenges }\end{array}$ \\
\hline Year & $2008-2010$ & 2009 & 2012-2013 \\
\hline Funded by & 7FP-EU & $\begin{array}{c}\text { Private Foundation (Plataforma } \\
\text { Educativa) }\end{array}$ & $\begin{array}{c}\text { Private foundation (FEPA) and } \\
\text { Catalan Government }\end{array}$ \\
\hline Aims & $\begin{array}{l}\text { To investigate the educational } \\
\text { pathways of young men and } \\
\text { women from a public care } \\
\text { background in five EU countries }\end{array}$ & $\begin{array}{l}\text { To identify the success factors of } \\
\text { children and adolescents cared for } \\
\text { in residential homes }\end{array}$ & $\begin{array}{l}\text { To analyse the experiences while } \\
\text { YP were in care, their education, } \\
\text { family and social support received, } \\
\text { health, housing and leisure time. } \\
\text { To identify facilitators and } \\
\text { obstacles to transition to } \\
\text { adulthood. }\end{array}$ \\
\hline Method * & Qualitative method & Qualitative method & Qualitative method \\
\hline \multirow{2}{*}{$\begin{array}{l}\text { Sample* } \\
\quad(\text { In } \\
\text { Catalonia) }\end{array}$} & \multirow{2}{*}{ In-depth interviews (YP) $N=35$} & \multirow{2}{*}{$\begin{array}{l}\text { Semi-structured interview with } \\
\text { young people (aged 21-31) } N= \\
15\end{array}$} & $\begin{array}{c}4 \text { focus groups with care leavers } N \\
=49\end{array}$ \\
\hline & & & $\begin{array}{c}\text { In-depth interviews with care } \\
\text { leavers } N=15\end{array}$ \\
\hline Reference & {$[25,10]$} & {$[26]$} & {$[27]$} \\
\hline
\end{tabular}

* For the purpose of the article only qualitative samples of young people were listed.

The young people included in the three studies were aged between 18 and 22 in the Yippee and FEPA studies, and up to 31 in the PE study. They had all been in residential homes (the Spanish YIPPEE participants as well), although some of them had also been in foster families. They were all in a residential home while they were adolescents and a large number of them had used the care leavers support services. The YIPPEE sample $(N=35$, mean age $=19.5)$ were selected on the basis of their academic ability, a criterion which did not exist in the other two studies. In addition, requirements for being part of the YIPPEE project were that they had been in care a minimum of one year and in the protection system at the age of 16 . Regarding gender $68.6 \%$ of the sample were girls and $34.3 \%$ were born abroad.

In the PE study, the requirements for being interviewed were: that they had spent at least a year of their life in residential care; that at the time of the interview at least 5 years had already passed since they had left the residential home; and that they were adults at the time of the interview. Of the sample $(N=15$, mean age $=27.1), 26.6 \%$ were girls and $6.6 \%$ were born abroad.

In the FEPA study, the requirement for young people to participate in the study was that they had left the system at 18 . Of this sample ( $N=49$ participants for the focus groups and $N=15$ for the interviews, mean age $=20.5), 48.8 \%$ were girls and $67.2 \%$ were born abroad.

Regarding the qualitative analysis, in each of the three studies authorisations were obtained from the Catalan government, including an agreement to respect confidentiality. Focus groups and interviews were conducted with the free and informed consent of participants and were recorded. All the material was transcribed and a content analysis was conducted following the steps [28]: (1) pre-analysis; (2) exploration of the material; and (3) processing, inference and interpretation of 
results. A first reading of the material was done in order to familiarize with the content and establish operational criteria for the analysis (segmenting the text into comparable units and choosing a means of encoding for recording information). In a second phase, the categorical content analysis led us to use textual data to fragment text and group it into categories. To ensure the reliability of the categories - interjudge reliability - the process of categorizing the data was performed independently by two of the team's researchers [29]. We used the qualitative data analysis programme NVivo.

\section{Results}

In the analysis of the three studies, one common aspect that stands out is the way young people evaluate their experience in the protection system - they tend to establish two bases for comparison:

- The situation which they call "normal" children versus children in care

- The situation they were in when living with their birth family versus the situation when in care

Their evaluation therefore depends on the experience they have had with children from the general population, the severity of the situation experienced in their birth family and the quality of care in their placements. The comparative element is essential.

This means that we find two premises in the studies mentioned above:

- They value having been protected by the system and think that if they had stayed with their parents it would have been much worse (see quote), while also acknowledging that living in the system has its drawbacks and limitations, which children from the general population do not usually have.

"I'd rather be in a home than with my family" (FEPA, girl)

- They feel different in some aspects when compared with the general population but also similar because they are immersed in the same youth cultures, while some of them feel different from other children in care, seeing them as having more problems and conflicts than them.

Following on from this, below is a list of key themes drawn from the three studies:

- Entering the protection system

- Stability and emotional bonds in the protection system

- Their education

- The importance of having friends

- Labelling, stigmatization, rights and opportunities

- Autonomy and responsibility versus overprotection

- Contact with parents, siblings and extended family

- Maltreatment in care

- Leaving the system 
At the end of this section, I include some of the advice that young people give which match those given by children in residential homes and professionals who work there. In Table 2 we can observe the frequency and percentages for each theme among the three studies analyzed mainly from the individual interviews with young people with a care background, and also from focus groups. Despite some differences across studies, the most themes highlighted were related to pursuit of stability and emotional bonds, the importance of their education, the importance to be heard in the issue of contact with their family, and the support they need when leaving care. The other issues that stand out are the way they enter care, the importance of having friends, avoiding stigmatization and respecting their rights, and the importance of achieving autonomy and responsibility. Finally some of them mentioned the issue of maltreatment in care.

Table 2. Frequency and percentage for each theme within the 3 studies.

\begin{tabular}{|c|c|c|c|c|c|c|c|}
\hline & \multicolumn{2}{|c|}{ YIPPEE } & \multicolumn{2}{|c|}{$\mathbf{P E}$} & \multicolumn{3}{|c|}{ FEPA } \\
\hline & \multicolumn{6}{|c|}{ Interviews } & \multirow{3}{*}{$\begin{array}{l}3 \text { Focus } \\
\text { Groups }\end{array}$} \\
\hline & \multicolumn{2}{|c|}{$N=35$} & \multicolumn{2}{|c|}{$N=15$} & \multicolumn{2}{|c|}{$N=15$} & \\
\hline & $(f)$ & $\%$ & (f) & $\%$ & (f) & $\%$ & \\
\hline Entering the protection system & 26 & 74.3 & 11 & 73.3 & 10 & 66.7 & 1 \\
\hline $\begin{array}{l}\text { Stability and emotional bonds } \\
\text { in the protection system }\end{array}$ & 35 & 100 & 13 & 86.7 & 13 & 86.7 & 3 \\
\hline Their education & 35 & 100 & 12 & 80.0 & 13 & 86.7 & 3 \\
\hline The importance of having friends & 33 & 94.3 & 10 & 66.7 & 8 & 53.3 & 1 \\
\hline $\begin{array}{l}\text { Labelling, stigmatization, } \\
\text { rights and opportunities }\end{array}$ & 26 & 74.3 & 8 & 53.3 & 7 & 46.6 & 2 \\
\hline $\begin{array}{c}\text { Autonomy and responsibility } \\
\text { versus overprotection }\end{array}$ & 27 & 77.1 & 14 & 93.3 & 10 & 66.7 & 3 \\
\hline $\begin{array}{l}\text { Contact with parents, siblings } \\
\text { and extended family }\end{array}$ & 33 & 94.3 & 14 & 93.3 & 15 & 100 & 3 \\
\hline Maltreatment in care & 7 & 20.0 & 2 & 13.3 & 1 & 6.7 & 1 \\
\hline Leaving the system & 34 & 97.1 & 13 & 86.7 & 15 & 100 & 2 \\
\hline
\end{tabular}

\subsection{Entering the System}

Many of them (between $66.7 \%$ and $73.4 \%$, depending on the study) agree that entering the system was traumatic: happening suddenly, without being consulted and with very little information on where they were going, why and what would happen.

On the other hand, in all three studies there are those that complain about the delay and slowness of the services in intervening in their case and protecting them; they say they were suffering situations at home that could have been avoided.

The other issue is the negative experience of those who had to pass through emergency centres, which are enclosed, have very rigid, restrictive rules and are full of problematic children.

"I went to an emergency centre and was told it would not be for long, and not to worry, okay? 'You will be here only a very short time, don't worry' ... because it was horrifying! 
It was a jungle! Horrible! It was a jungle! There were really bad fights...! and I said:

'My God, where have I ended up?' For me it was a total shock”' (YIPPEE, boy)

But despite all the criticism regarding how they entered the system, they do value having been in it and are grateful towards the educators and carers they had and who gave them an opportunity in life; some of them - particularly young girls — think about returning this service by volunteering or studying a subject related to care (social education, nursing, teaching, etc.).

\subsection{Stability and Emotional Bonds in the Protection System}

Most (between $86.7 \%$ and $100 \%$ ) agree in stressing the importance of having a stable reference adult (a mentor, for example) involved in their upbringing; many of those who have lived in residential homes specifically complain about the lack of more stable reference adults and say it is difficult to establish a trusting relationship when they are in residential homes with numerous places, different educators and changes of shift. They also complain about changing residential home or foster family, and when their carers are not very involved in their work, have low or negative expectations of children in care and poor parenting skills.

What do they ask of their carers and the professionals who work with them? In the three focus groups they talked about patience, empathy, personalized care and flexibility, a strong commitment, trust, acceptance, support, that they love them and treat them as "if they were their own children", high expectations and demands.

"That they understand them, that they know that the kids need them. That they have a little empathy; that children need the mother or father figure they did not have. Educators need to be trained to be this figure" (FEPA, boy)

They also acknowledge the other adults (teachers, parents of friends, godparents, etc.) who during their childhood became key people on their life journey. Another aspect to highlight is that they do not complain about the number of years they were in care if they were stable; in fact they consider it fortunate.

"I got up, had breakfast, went to school, came back and, studied. I studied and had extracurricular activities, dancing and swimming, and that was all and it was fine, and I was very happy" (YIPPEE, girl)

\subsection{Their Education}

Between $80 \%$ and $100 \%$ of young people agree that they do not like changes of school, which makes them lose the pace of learning and their friends. They also mention the insufficient support they receive to continue studying, like when they need extra classes, a quiet place suitable for study, their carers having continued contact with the school, and confidence and expectations in their academic achievements; in some cases this is what made them reject the academic pathway. These young people agree that children living with their parents tend to have a lot more pressure to study and that this is a priority for parents, who want their children to go far in education. From what they say during the three focus groups, care placements clearly differ enormously in terms of 
compensating for their situation and the support given by tutors, as well as the type of school, where they are often stigmatized but also had some good experiences and results. They generally agree that school is not prioritized as much in care homes as it is by families, although more so than when they were living with their parents.

"They don't expect kids like us to have an academic career either, very few make it" (FEPA, boy)

"I think if I had been forced a little more in secondary education, now I would be very grateful." (FEPA, girl)

There was a clear difference between the young people in the first study in 2008 and those in the last in 2013, in that the former were working part or full-time and those from the 2013 study were mostly studying and almost none had work, either because they were continuing their studies or because they had no job and spent their time doing some form of training, in some cases non-formal. In the latter case, they currently considered this non-formal education to be a waste of time in that it did not respond to the labour market, as shown in the following example.

"They're short courses that are no use afterwards (the non-formal education track). Most of the kids from the residential homes are doing these courses and at 18 have problems finding work" (FEPA, boy)

Examples like going to visit their parents or psychologist during school hours are constant complaints by the young people, indicating that school is not prioritized in practice, and it was highlighted particularly for those much younger.

\subsection{The Importance of Having Friends}

Friends, when they can have them, represent a basic and major source of emotional and practical support. As many of them say (about $53.3 \%$ to $94.3 \%$ ), at times they replace their family, which is why changes in school and care placement cause so much harm.

"Friends take the place of siblings, it's the only family I have. They take the place of a family member." (FEPA, boy)

They also help them to continue with their studies because they often constitute the group with which they do school work and study for exams. Also, having friends allows them to meet their families, who are sometimes a direct source of support and learning. Finally, it is also with friends that they share free-time activities, including organized ones.

Another point highlighted is the dilemma of whether to make friends within the residential home or not. Some are clear that they should not, as it stigmatizes them and brings problems. Others, however, consider them fellow travellers, like siblings.

"At the home they always tell you, meet other people who are not from here..., but you get to spend so many hours with the girls that... well, for me, my best friend, is from the home, she's like a sister. But, of course, I also meet up with other friends" (YIPPEE, girl) 


\subsection{Labelling, Stigmatization, Rights and Opportunities}

Between $46.6 \%$ and $74.3 \%$ of young people interviewed recognize that entering the protection system represents either the start of feeling labelled as "conflictive" or as "poor thing" or a continuation or worsening of what they were labelled when they lived with their family. The weight of labelling is especially heavy when they live in a residential home, because although most of them try to hide it at school or at work, it is very difficult to keep it a secret: they have to carry a special permit to go to sleep at a friend's house, their educators - who are sometimes nuns - accompany them to school (see quote), they seldom invite friends to the home, they have little say in how they use their time and even less opportunity to improvise. They cannot appear in the class photo posted on the school website, and cannot ride a bike or prepare a snack in case they hurt themselves.

"Because you get in the van, and it has the name of the home on it... and your friends ask, "Whose van is that? ... Is it your dad's?"... They come to pick you up at the door, in front of the school, just when all the kids are coming out, ... no, we have a company" (PE, girl)

Everything that happens to children living in residential homes is an example of things that do not only lead to labelling but represent a significant loss of opportunity and individual freedom. On the other hand, those who experienced a situation of great suffering at home in particular acknowledge that the care system has given them opportunities they did not have and has given them back their rights.

Often they have to fight the label in order to show that although they are children from a home they are not going to be criminals, drug addicts or abusers, which is the message they receive from adults and the media.

They agree on the desire to prove that they will not be like their parents. They believe that when they are 18 they will be able to get rid of the label of "child in care" and be like anyone else. This is why most of them do not talk about this part of their past either where they study or at work.

\subsection{Autonomy and Responsibility versus Overprotection}

The issue of adolescents in care working towards personal and social autonomy stands out - between $66.7 \%$ and $93.3 \%$ of young people talked about that-, and it makes them very angry when they are not able to be responsible for and participate in their own process. They also agree that there is a large gap between being overprotected up to the age of 18 and then completely unprotected from this age onwards. Within the three focus groups, they all agree that they should start working towards autonomy in early adolescence.

"For example, autonomy was encouraged at my residential home, some days we cooked ourselves, we did our laundry, so in a home they get you prepared, if you are not prepared to do this kind of things then you might as well go back to your family because in supported housing for over-18s you are not going to survive." (FEPA, girl)

"In my residential home, for example, they gave us absolutely everything so afterwards when I left I was completely disoriented, the truth is I didn't know anything at all. They practically did everything for us..." (FEPA, boy) 


\subsection{Contact with Parents, Siblings and Extended Family}

Another issue that has also come up in all three studies and about almost $100 \%$ of interviews and focus groups is the young people demanding to be heard and have their opinion valued regarding the contact they want to have with different members of their birth family. One of the things they emphasize is that a negative consequence of there being limited time to see family members is that they stop seeing members of their extended family, as the short time they do have is sometimes taken up by only their parents. This also happens to those in non-kinship foster families. The other major complaint is a rupture in the relationship with siblings because the care system does not have a place for all of them together, particularly pointed out by young girls. Their relationship with their parents is also controversial, as they feel it is always the adults who decide.

"Every weekend I went home to my family. And then what did I do? Wasted time.

Actually you start a routine, you go there and if you're not alright, you know you're going to have a bad time, you waste time, I don't know" (YIPPEE, girl)

Once they have left the home they feel they can decide what contact to have with the family: for some of them family relationships then become more fluid and for others they become more distant or interrupted. The dilemma for them is often whether they need to show responsibility towards their family (financial support, especially among immigrants, emotional or practical support) or to end the relationship, generally feeling alone. This leads them to reiterate the feeling that they can only really rely on themselves.

"I rely on myself. I start something and even if I get tired of it and I feel like I can't go on, I carry on. Sometimes I cry because I want to do many things and I can't, I don't have the money, or I need someone to listen to me and who I can trust" (FEPA, girl)

\subsection{Maltreatment in Care}

Although this issue was a minor one in the three studies (between $6.7 \%$ and $20 \%$ of young people talked about that), it is worth noting that it appeared in all three, and both in residential care and with those who spent time in foster care. The point they agree on is that when a situation of abuse or neglect arises within the protection system, it is very difficult to get help because of the difficulty of getting the information to decision makers and being believed, and they are also slow to act.

"There was a monitor ... who dislocated my shoulder... he threw me on the floor and everything... very roughly, I had to be taken to the doctor's (...)" (YIPPEE, girl)

\subsection{Leaving Care}

There is much agreement (between $86.7 \%$ and $100 \%$ of young people interviewed) that leaving the care system provokes strong feelings of fear and insecurity, often worse than those experienced when entering it. They are forced to make decisions that most people of that age do not have to take: what to do about their family, school, work and where to live are all key issues that must be resolved. One of the most repeated phrases is you wait so long for the time to come that you can leave and 
when it arrives, you don't want to. It is in this sense that they request not to be left alone and to receive help with housing issues, education, economically and emotionally. The support services for care leavers are rated very positively, although they know they will have to work very hard and only have recourse to them until they are 21.

"I would be really bad if they had not given me the opportunity to have a flat. I hope they never close it down" (FEPA, girl)

"It's like a bridge, they prepare you. You have two years and you need to make progress and do something. If you are mature enough for this opportunity, you will take advantage of it. Otherwise, you'll lose everything" (FEPA, boy)

Young people are aware that there is a group that is left outside the aid available to care leavers and demand the range of services be diversified in order to reach more young people leaving the protection system: young care leavers with disabilities, mental illness, behavioural and other problems; and also that there be an increase in the supply of flats for young people aged 16 to 18 . The issue of leaving care is especially hard for young people who came to Spain without their families.

\subsection{Advice from Young Care-Leavers}

The advice these young people would give to adolescents who are still in a residential home is to take the opportunity to study, establish a positive relationship with educators, control their behaviour and learn to be responsible for themselves, and to take the opportunity to go to live in protected accommodation (post-care), if offered. The words take advantage of and opportunity stand out.

“That they don't be silly, don't run away and lose the opportunity to get a flat. And that they continue to study. There is time for everything, they can hang out with friends, but they must study. At first I didn't like the home at all, I wanted out, but in the first months of having a flat, I wanted to go back there... Because you can't take these girls into the future to see. If you could, they would realize" (FEPA, girl)

"That they make the most of their time, do everything they are told to do, take the opportunity to learn. That they make the most of everything to come out well-prepared." (FEPA, boy)

The advice they would give to educators in the residential homes is to have a lot of patience, listen to the adolescents and be empathetic, treating them differently, obliging them to study and not overprotecting them.

"The most useful thing is asking me how I am and helping me think about myself (...) encouraging me a lot and listening to me" (FEPA, boy)

"That at the residential home they try not to give them everything already done, that they have to earn it, because if they don't it's like a bubble, they don't know what's out there. Clothes don't come from heaven and don't wash themselves. That the children begin to value things earlier" (PE, girl) 


\section{Discussion}

Firstly, the most themes highlighted by young people with a care background were related to improvements needed in the pursuit of stability, the importance of their education, the importance to be heard in the issue of contact with their family, and support the leaving care process. Secondly, they also remarked improvements regarding the way they enter care, the importance of having friends, avoiding stigmatization and respecting their rights, and the importance of achieving autonomy and responsibility. Finally some of them mentioned the theme of maltreatment in care.

Listening to young people and learning from their experiences in order to try and improve the services that provide care for them is essential for professional practice and policy design, while also constituting a conceptual and methodological challenge for research. Young people continuously use comparison to evaluate the treatment they receive and to view their glass as half full or half empty. We also find this comparative element in authors who have studied child poverty and suggest that it is one of the factors that influences children when they display feelings of exclusion [30] and low levels of well-being [31], this perception of inequality being based on peer-group comparison.

The issue of stability in care and at school has taken on great significance in recent years in much of the research focusing on protection systems [20,22,23], but resolute policies are required to reverse the statistics. There is clear evidence that a lack of stability affects their school situation and social inclusion, leading to increased loss of control over their own lives. They are not able to plan aspects such as what they will do over the coming months with friends, their leisure activities, their holidays, resulting in a loss of trust in adults. Linked to this is the opportunity to have a key adult carrying out effective parental duties, and we have seen that what they are asking for coincides with that which appears in positive parenting recommendations $[11,12]$; they say treat us as you would your own children. This requires work in terms of awareness raising, training and commitment, which is not always well paid.

With regard to school, two ideas stand out; they repeat the idea: make and help us study like parents do with their children, don't abandon us as a lost cause. Some authors [25,10] emphasize the desirability of their completing compulsory education and being able to continue into post-compulsory education (not dead ends or pathways outside the education system), since only by ensuring equal educational opportunities will we be working towards their social inclusion.

The issue of contact with parents, siblings and extended family is paid particular attention by these young people, who think they are not consulted, are forced to go on visits they do not want to and are denied some contacts that would be beneficial to them. This is a complex issue, but one which will not be resolved by keeping them marginalized $[1,15]$. In addition, it is an issue that involves not only the subject of visits but also that of family reunification, which, if done at all, must be done properly [20,22,23]. In Spain, with the exception of one study [32], there are no official data on time spent in the system and percentages regarding where they go after leaving or success rates regarding family reunifications, making the work of professionals extremely difficult with regard to knowing the effects of their intervention.

In addition, leaving the system is a key period and all necessary support must be given to them during the following years, as if not all the prior work that has been done with the young person 
can be ruined, an issue that has been studied by authors [33]. Young care leavers highly value the support given to them and having a legal framework and public policies aimed at this group is a necessary step.

Numerous studies also argue that entry to the protection system is traumatic and that both the levels of information children receive and their direct participation must be improved in this respect $[1,17]$. This particularly calls for more training for social workers regarding which strategies to use to reach children, talk with them and have them participate in decision-making.

Reducing actions that lead to a greater number of stigmatization processes is an urgent and much debated task. These young people sense they have fewer rights and opportunities than other children, with overprotection often being the norm, although it is not known whether this is for the children or educators' benefit (if a child gets hurt, the parents can be accused). There is a difficult balance between protection and participation, particularly when it comes to children in care, and it should be debated thoroughly and solutions outlined [34].

In addition, these young people do not tire of saying that relationships with friends are very important to them, and it is clear this should be taken into account if we consider that studies on psychological well-being show the domain of interpersonal relationships to be the one which has the most influence on adolescent well-being [35].

Finally, on the issue of maltreatment in care, it should be noted that there is a complete lack of records and data on this phenomenon in Spain; we only know about it due to severe cases that appear in the press, which hinders both knowledge of the issue and decision-making by professionals.

The findings of the current paper should be interpreted with caution due to its limitations: it is not a systematic review; we used only three studies to describe and discuss the state of the art of the topic of improvements needed in the child protection system. Despite the above, the repetition and consistency of the issues highlighted across the three studies, do reinforce our findings in line with international research.

\section{Conclusions and Implications for Police, Practice and Research}

If we listen to young people regarding their passage through the protection system, according to the findings it would be recommended urgent improvements on the following points:

- It is necessary to promote positive parenting programs from carers and educators; that is, to improve the quality of care

- It is important to work towards the priority and support for education of children in care, involving and promoting stable and interconnected interventions between departments.

- It is necessary to increase the work done in residential homes towards children and adolescents' autonomy and their taking of responsibility, as well as the participation and central role of children and adolescents.

- Strengthen close and stable bonds i.e., reference adults and mentoring, is a key issue in the child protection systems, as well as to promote stability in their pathways.

- Be aware to avoid stigmatization processes as much as possible and to raise expectations towards this population group. 
- Regarding leaving care, it is important to provide more information for adolescents still in care homes regarding the type of support they will have when they leave, diversifying the supply of services to reach more young people leaving the protection system, and enhancing these young people's informal support networks.

- Provide support for professionals working with these young people regarding the work of managing emotions.

- Improve data collection and performance evaluation systems for young people. Quantitative studies and particularly longitudinal research should be developed in the future.

As we have seen, some of these issues are reflected in other research projects and some of them have long enjoyed consensus among researchers and professionals. The question, now that we have known them for some time, is what are the obstacles to addressing them? This in itself is the great challenge for the future.

\section{Acknowledgments}

Thanks are due to Barney Griffins for editing of the English text.

\section{Conflicts of Interest}

The author declares no conflict of interest.

\section{References}

1. Matthew Colton, Andrew Pithouse, Sue Roberts, and Harriet Ward. "The Fostering Literature." In Review of the Purpose and Future Shape of Fostering and Residential Care Services for Children and Young People in Wales. What Works in Practice: A Review of Research Evidence. Edited by National Assembly for Wales. Cardiff: National Assembly for Wales, 2004.

2. Paloma de Villota, and Susana Vázquez. "The Welfare State in Spain: Unfinished Business.” In The Handbook of European Welfare Systems. Edited by Klaus Schubert, Simon Hegelich and Ursula Bazant. London and New York: Routledge Taylor \& Francis Group, 2009.

3. Gosta Esping-Andersen. Three Worlds of Welfare Capitalism. Cambridge: Policy Press, 1990.

4. Maurizio Ferrera. Welfare State Reform in Southern Europe. London: Routledge, 2005.

5. Peter Taylor-Gooby. "Security, equality and opportunity: Attitudes and the sustainability of social protection." Journal of European Social Policy 21, no. 2 (2011): 150-63.

6. Mimi Ajzenstadt, and John Gal. Children, Gender and Families in Mediterranean Welfare States. New York: Springer, 2010.

7. Joseph Katan, and Ariela Lowenstein. "Privatization Trends in Welfare Services and Their Impact upon Israel as a Welfare State." In The Welfare State in Post-Industrial Society. Edited by Jason L. Powell and Jon Hendricks. New York: Springer, 2009, pp. 311-32.

8. Eurostat. Population and Social Conditions 2012. European Comission, 2012. Available online: http://epp.eurostat.ec.europa.eu/ (accessed on 1 October 2014). 
9. Consejo de la Juventud de España (CJE). El Observatorio de la Emnacipación Número 4. Madrid: CJE, 2014.

10. Carme Montserrat, Ferran Casas, and Sara Malo. "Delayed Educational Pathways and Risk of Social Exclusion: The Case of Young People from Public Care in Spain.” European Journal of Social Work 16, no. 1 (2013): 6-21.

11. Parenting in Contemporary Europe: A Positive Approach. Strasbourg: Council of Europe, 2007.

12. Maria Jose Rodrigo, María Luisa Máiquez, and Juan Carlos Martín. Parentalidad Positiva y Políticas Locales de Apoyo a las Familias. Madrid: Ministerio de Sanidad y Política Social, 2010.

13. Roger Bullock, Mark E. Courtney, Roy Parker, Ian Sinclair, and June Thoburn. "Can the corporate state parent?" Adoption and Fostering 30, no. 4 (2006): 6-19.

14. Hedy Cleaver, Ira Unell, and Jane Aldgate. Children's Needs-Parenting Capacity, 2nd ed. London: The Stationary Office, 2011.

15. Audrey Mullender, Gill Hague, Umme F. Imam, Liz Kelly, Ellen Malos, and Linda Regan. Children's Perspective on Domestic Violence. London: SAGE Publications, 2002.

16. Sarah Gorin. Understanding What Children Say. London: National Children's Bureau, 2004.

17. David Berridge. Foster Care: A Research Review. London: The Stationery Office, 1997.

18. Catherine Shaw. "Remember My Messages...The Experiences and Views of 2000 Children in Public Care in the UK." Who Cares? Trust, 1998.

19. Harriet Ward, Tricia Skuse, and Emily R. Munro. "The Best of Times, the Worst of Times": Young People's Views of Care and Accommodation." Adoption and Fostering 29, (2005): $8-17$.

20. Nina Biehal, Sarah Ellison, Claire Baker, and Ian Sinclair. Belonging and Permanence. Outcomes in Long-term Foster Care and Adoption. London: BAAF, 2010.

21. Tamar Dinisman, Carme Montserrat, and Ferran Casas. "The subjective well-being of Spanish adolescents: Variations according to different living arrangements." Children and Youth Services Review 34, no. 12 (2012): 2374-80.

22. Ian Sinclair, Claire Baker, Jenny Lee, and Ian Gibbs. The Pursuit of Permanency. A Study of the English Child Care System. London: Jessica Kingsley, 2007.

23. Jim Wade, Nina Biehal, Nicola Farrelly, and Ian Sinclair. Caring for Abused and Neglected Children. Making the Right Decisions for Reunification or Long-Term Care. London: Jessica Kingsley Publishers, 2011.

24. Colette McAuley, Peter Pecora, and Wendy Rose. "Effective Child Welfare Interventions: Evidence for Practice." In Enhancing the Well-being of Children and Families through Effective Interventions: International Evidence for Practice. London: Jessica Kingsley Publishers, 2006.

25. Sonia Jackson, and Claire Cameron. Improving the Participation of Young People in Care in Further and Higher Education. European Research and Practice. London: Jessica Kingsley Publishers, 2014. 
26. Letizia Araujo, and Carme Montserrat. "Jóvenes que estuvieron en el sistema de protección social a la infancia. Reflexiones a partir de una investigación realizada en Girona." Psicologia-Reflexao e Critica 27, no. 1 (2014): 198-206.

27. Carme Montserrat, Ferran Casas, and Clara Sisteró. Estudio Sobre la Atención a los Jóvenes Ex-tutelados: Evolución, Valoración y Retos de Futuro. Informe de Resultados. Barcelona: FEPA, 2014.

28. Laurence Bardin. Análisis de Contenido. Madrid: Ediciones Akal, 2002.

29. Kimberly Neuendorf. The Content Analysis Guidebook. Thousand Oaks: Sage, 2002.

30. Tess Ridge. Childhood Poverty and Social Erxclusion. Bristol: Policy Press, 2002.

31. Gill Main, and Kirsten Besemer. "Children's Material Living Standards in Rich Countries." In Handbook of Child Well-Being. Edited by Asher Ben-Arieh, Ferran Casas, Ivar Frønes and Jill E. Korbin. Springer Netherlands, 2014, pp. 1445-77.

32. Mónica López, Carme Montserrat, Amaia Bravo, and Jorge F. del Valle. "Factors associated with family reunification for children in foster care." Child \& Family Social Work 18, no. 2 (2013): 226-36.

33. Anat Zeira. "New initiatives in out-of-home placements in Israel." Child and Family Social Work 9 (2004): 307-9.

34. Jens Qvortrup. “Childhood Matters: An Introduction.” In Childhood Matters: Social Theory, Practice and Politics. Edited by Jens Qvortrup, Marjatta Bardy, Giovanni Sgritta and Helmut Wintersberg. Avenbury: Ashgate Publishing Company, 1994.

35. Ferran Casas. "Subjective Social Indicators and Child and Adolescent Well-being." Child Indicators Research 4 (2011): 555-75. 


\title{
Addressing the Clinical Burden of Child Physical Abuse and Neglect in a Large Metropolitan Region: Improving the Evidence-Base
}

\author{
Shanti Raman, Michelle Maiese, Katrina Hurley and David Greenfield
}

\begin{abstract}
Children at risk of abuse are more likely to be hospitalized and utilize health services according to international research. In a large metropolitan health region in New South Wales, Australia, there was little known of the clinical burden of child physical abuse and/or neglect (PAN), or of systems for clinical assessment of children presenting with abuse/neglect. We aimed to identify the number of children presenting with suspected PAN to emergency departments (EDs) and paediatric services in this region, to determine enablers and barriers to assessment for children with PAN presenting to frontline services, and to identify best practices to address gaps. We collated available data on children presenting to EDs and paediatric services with suspected PAN in 2007. We interviewed 36 health professionals from nine hospitals and 12 statutory child protection professionals, across the region before undertaking relevant document analysis. Of 64,700 paediatric ED presentations, a quarter were due to injury; $2 \%-5 \%$ of these were due to maltreatment. Clinician estimates and assessments of PAN varied widely; health and welfare workers identified major practice gaps, as well as good local practice. We identified feasible minimum standards for improving clinical assessment and follow-up for children presenting with PAN, given the right organizational support.
\end{abstract}

Reprinted from Soc. Sci. Cite as: Raman, S.; Maiese, M.; Hurley, K.; Greenfield, D. Addressing the Clinical Burden of Child Physical Abuse and Neglect in a Large Metropolitan Region: Improving the Evidence-Base. Soc. Sci. 2014, 3, 771-784.

\section{Introduction}

Child maltreatment (CM) is a major public health problem the world over [1-3]. In Australia, as with many nation states in the western world, CM is periodically the focus of sensationalist media attention and public outcry. In New South Wales (NSW), the state with the largest number of reported CM cases in Australia, a far-reaching review of child protection systems was carried out in 2008 and recommended major changes in the ways CM was responded to across agencies, including health services [4]. The NSW government's response to the child protection review, promised a greater shared responsibility for ensuring the wellbeing of children at risk, a major component of this responsibility resting on health services [5]. We know maltreated children are at risk of adverse health consequences [6], they are also more likely to be hospitalized and utilize more health services [7]. While systems to support the recognition of and response to CM are crucial, numerous studies in western countries have documented that $\mathrm{CM}$ is poorly reported and counted in healthcare administrative systems [8].

Several international studies have shown that children who have experienced abuse are often seen in an emergency department (ED) before the diagnosis of the abuse is made [9-11]. The authors of 
the six-country study on CM trends and policies which included Australian data, argue that there needs to be much better recording and analysis of CM data, including record linkages between hospital admissions and child protection services, as such data can provide valuable information about cumulative risk of maltreatment-related hospital admission, or contact with child protection agencies [12]. A seemingly obvious intervention would be effective screening for CM in EDs; however, the Cochrane review on interventions in EDs to increase detection of confirmed child abuse found that there was inconclusive evidence on effectiveness due to the scarcity of quality studies [13]. There have been many attempts to improve clinicians' performance in EDs with respect to CM [14,15]; Woodman et al.'s review suggested that none of the markers (infancy, type of injury, repeated attendance) were sufficiently accurate to screen injured children in the ED to identify those requiring paediatric assessment for possible PAN. They concluded that clinicians should be aware that among injured children at ED a high proportion of abused children will present without these characteristics and a high proportion of non-abused children will present with them, suggesting comprehensive assessment rather than screening as the appropriate modality [16]. A large-scale Dutch intervention study looking at improving detection rates among doctors and nurses in ED found that ED staff experienced many barriers, particularly communication with parents of children suspected of being abused [17]. Few studies have looked beyond systems of identification in acute health services to actually improving systems of care and follow-up of abused children in a holistic manner. While there are many studies reporting wide variations in reporting CM concerns by different professional groups [18], there has been little attention paid to the inter-disciplinary professional practice in clinical assessment of CM for example.

In a large metropolitan health region in NSW, with a substantial child and youth population that is culturally diverse and has significant sub-populations at social and economic risk within its boundaries [19], there were no epidemiological or health services data available on how many acute presentations of child physical abuse and/or neglect (PAN) were managed across hospital systems. Anecdotal reports suggest that there are high-risk localities within the region with disproportionately high numbers of child protection reports. In 2009, following directly the NSW government response to the child protection reforms, a quality improvement project was undertaken to determine the clinical burden of child PAN in this region, and to examine the assessment and care for children and young people presenting with suspected maltreatment to frontline clinical services. Prior to the project commencing, there was no clear understanding or documentation of what capacity there was within frontline clinical services to conduct or manage PAN assessments. Specifically, we aimed to quantify the number of suspected child PAN presentations to EDs and paediatric services, determine the current systems and processes for assessment and care of suspected PAN within frontline clinical services - including identifying enablers and barriers - and to develop feasible strategies to address the identified gaps.

\section{Methods}

This was a multi-method study; the data collection methods were secondary document analysis and semi-structured interviews allowing triangulation of findings [20]. 
From each of the nine hospitals in this health region with EDs where children and young people can be assessed and managed, we obtained estimates from the Clinical Information Departments, of children (under 16 years) seen with suspected PAN through 2007. These hospitals are all district level hospitals for paediatrics serving local populations that are quite distinct; three of them are tertiary teaching hospitals. All acute presentations are to EDs. We therefore analysed only data collected in EDs. Data was extracted by a data analyst from the Clinical Information Department of the largest hospital in that region, from the HASS EDIS database that was in use for ED clinical information throughout the hospitals in that region in 2007; this year was chosen as it was the last year in which consistent data was collected in ED and able to be extracted. The data analyst had been working extensively on the HASS EDIS dataset with the data entry clerks to ensure completeness of clinical information. A standardized data extraction form was used to extract data on the number of paediatric presentations to ED and the number of injury admissions to the paediatric ward. For paediatric ED admissions and injuries, we identified several ICD-10-AM clinical codes that may have been used for physical abuse and/or neglect. Codes included a child at risk, child abuse/non-accidental injury, physical abuse/assault, neglect/abandonment, and accidental ingestion/poisoning: these were identified following discussion with data entry clerks in ED and the Clinical Information Department.

We carried out in-depth semi-structured interviews with senior clinicians, i.e., doctors, nurses and social workers from EDs, paediatric wards and social work departments (as relevant) from each hospital that assesses children in the region. Participants were purposefully chosen; heads of the relevant departments were informed of the quality improvement project by email and were requested to nominate the most suitable clinicians for the in-depth interview. Questions covered estimates of numbers of suspected PAN cases seen, referral and assessment protocols and pathways, follow-up mechanisms, barriers and enablers to appropriate assessment and care. Interview schedules were pilot tested in two sites and subsequently modified. Interviews were conducted face to face by a doctor and a social worker from the project team. No clinician declined to participate; some had to reschedule their interviews due to other commitments. Each interview lasted between one and one and a half hours; all interviews with clinicians were conducted between August and December 2009.

Telephone interviews were carried out with the managers of the relevant statutory child protection authority, the departments of Family and Community Services (CS), in the early part of 2010. The managers of 12 local departments were provided information by email about the project and asked to nominate the most appropriate respondent; many were already aware of it via inter-agency meetings. Questions explored pathways and protocols used (if any) by caseworkers in arranging medical assessments for children with suspected PAN, barriers encountered, and suggestions for improvement. Representatives from one CS agency could not be interviewed despite numerous attempts. Transcription occurred as soon as possible after the interviews.

\section{Analysis}

Data from the Clinical Information Department on ED presentations was entered into an Excel spreadsheet and simple descriptive analysis of the data was carried out. We analysed the information from interviews using thematic content analysis [21], specifically searching across the content of 
interviews of clinicians and child protection workers to find repeated patterns of meaning. Paediatric presentations for suspected abuse and or neglect were compared to total paediatric presentations to ED and paediatric wards in 2007 and correlated with clinician estimates of PAN presentations, thus triangulating data analysis.

A multi-site ethics approval was obtained via the lead Human Research Ethics Committee at Royal Prince Alfred Hospital.

\section{Results}

In 2007, there were 64,700 paediatric (children under 16 years) presentations to EDs across hospitals in the region out of a total of 323,949 presentations $(20 \%) ; 15,573$ (24\%) of paediatric presentations were for injury. Table 1 lists the available data on children presenting to hospital sites with suspected PAN in 2007, hospitals are listed A-I in order of paediatric admissions, A being the busiest. Hospital A had the highest number of injuries presenting to ED, 125 with CM concerns, 4\% of injury presentations and $1 \%$ of all ED presentations. Hospital B had 118 paediatric injury presentations with CM concerns, $5 \%$ of injury presentations and $1 \%$ of all paediatric ED presentations followed by Hospital C and Hospital D with 3\% of injury presentations having identified CM concerns. All other hospital data had concerning injuries listed as $2 \%$ of paediatric injuries. In all hospitals except for Hospital E, paediatric injuries with CM concerns were approximately $1 \%$ of ED presentations.

Table 1. Correlation of paediatric injury presentations with clinician estimates of child maltreatment.

\begin{tabular}{ccccccc}
\hline Facility $^{\mathbf{1}}$ & $\begin{array}{c}\text { Total } \\
\text { Paediatric ED } \\
\text { Attendance }\end{array}$ & $\begin{array}{c}\text { Injury } \\
\text { Presentations } \\
\mathbf{n}(\%) * *\end{array}$ & $\begin{array}{c}\text { Injury } \\
\text { Admissions } \\
\mathbf{n}(\%) * *\end{array}$ & $\begin{array}{c}\text { ED Injury with } \\
\text { CM Concerns } \\
\mathbf{n}(\%) * *\end{array}$ & $\begin{array}{c}\text { Clinician } \\
\text { Estimate of } \\
\text { PAN }\end{array}$ & $\begin{array}{c}\text { Audit of } \\
\text { Paediatric ED } \\
\text { Presentations }\end{array}$ \\
\hline A & 12,989 & $3012(23)$ & $202(2)$ & $125(1)$ & $8-12 /$ month & Yes \\
B & 11,477 & $2538(22)$ & $389(3)$ & $118(1)$ & $30 /$ year to & No \\
C & 8112 & $1926(24)$ & $117(1)$ & $65(1)$ & $24-52 /$ year & No \\
D & 7850 & $1892(24)$ & $109(1)$ & $56(1)$ & $10-50 /$ year & No \\
E & 7431 & $993(13)$ & $51(1)$ & $19(0)$ & $60-70 /$ year & Yes \\
F & 6957 & $1521(22)$ & $85(1)$ & $37(1)$ & $12-50 /$ year & No \\
G & 4141 & $1528(37)$ & $1 *$ & $27(1)$ & $6-24 /$ year & Yes \\
H & 4052 & $1373(34)$ & $77(2)$ & $32(1)$ & $4-12 /$ year & No \\
I & 1691 & $790(47)$ & $12(1)$ & $18(1)$ & Minimal & Yes \\
\hline
\end{tabular}

Notes: ${ }^{1}$ Facilities A-I listed according to number of paediatric admissions, greatest to least. A, B, C, D, E, F, $\mathrm{H}$ are district-level paediatric services, Hospitals B, D and I are tertiary level services; * No in-patient paediatric ward available; ** Percentage presented in whole numbers only for clarity.

There were 36 clinicians across 9 hospitals that were interviewed (13 doctors, 13 nurses and 10 social workers), as well as 12 managers from the relevant statutory child protection agencies, see Table 2. Responses are reported against specific themes and categories below; direct quotes are not provided so as to preserve anonymity of respondents. 
Table 2. Respondents to in-depth interviews.

\begin{tabular}{llll}
\hline Facility $^{\mathbf{1}}$ & Medical & Nursing & Social work \\
\hline A & 1 Paediatric, 1 ED & 1 ED, 1 Paediatric & 1 Paediatric \\
B & 1 Paediatric, 1 ED & 1 ED, 1 Paediatric & 1 Paediatric \\
C & 1 Paediatric, 1 ED & 1 Paediatric & 1 Paediatric, 1 ED \\
D & 1 ED & $1 \mathrm{ED}, 1$ Paediatric & $1 \mathrm{ED}$ \\
E & 1 Paediatric & $1 \mathrm{ED}$ & 1 Paediatric \\
F & 2 Paediatric & 1 Paediatric & 1 paediatric \\
G & 1 ED & $1 \mathrm{ED}$ & $1 \mathrm{ED}$ \\
H & 1 Paediatric & $1 \mathrm{ED}, 1$ Paediatric & 1 Paediatric \\
I & 1 ED & $1 \mathrm{ED}$ & $1 \mathrm{ED}$ \\
CS & & & 12 \\
\hline
\end{tabular}

Note: ${ }^{1}$ Facilities A-I listed according to number of paediatric admissions, greatest to least.

\subsection{What is the Clinical Burden of Child Physical Abuse/Neglect in This Region?}

Clinician estimates of the burden of child PAN presentations ranged from very few per year to many per week (see Table 1). There was considerable variation in the estimated presentations of PAN even within hospitals between disciplines. No clinician or service had any data on CM or PAN presentations; this was felt to be a major drawback of data collection systems. Clinicians reported that the current electronic information system used in ED was not useful for auditing or estimating the numbers of presentations for a range of clinical concerns. Audits of paediatric presentations to ED were carried out by four hospitals in the region (Table 1). Managers from statutory agencies likewise had no recorded data on the number of medical assessments carried out for child PAN cases; their estimates ranged from three to 24 per year.

\subsection{How are Child Physical Abuse/Neglect Assessments Conducted?}

Table 3 lists the personnel involved in-hours for PAN assessments in ED. There were differing accounts on the personnel involved, including use of social workers. When clinicians were asked about whether there was a written procedure within their service for children with suspected PAN, of those who said yes $(n=14)$, six were outdated or could not be located. Three sites used a paediatric injury risk assessment process or protocol for identifying when injuries could be attributed to CM. Table 4 lists the procedures undertaken in hospitals in the region following the clinical assessment.

\subsection{What Child Protection Training Does Your Staff Get?}

As a response to the question "what sort of training does your staff get in child protection?", most $(32,89 \%$ of respondents) said that staff within their service had completed the two-hour mandatory training; 26 respondents (71\%), said their staff had completed one-day mandatory child protection training. Responses to this question did not vary between the clinical groups. Participants listed a range of other child protection training sessions they had attended; only one respondent (medical) was aware of and had attended a clinically oriented training session. 
Table 3. Who conducts child physical abuse/neglect assessments?

\begin{tabular}{|c|c|c|}
\hline Facility ${ }^{1}$ & In Hours & $\begin{array}{c}\text { Social } \\
\text { Worker } \\
\text { Involved }\end{array}$ \\
\hline A & Paediatric Registrar ${ }^{2}$ supported by paediatrician & Rarely \\
\hline B & Paediatric Registrar + paediatric SW * + Community paediatrician & Always \\
\hline $\mathrm{C}$ & Paediatric Registrar or junior doctor \pm Paediatrician support & Rarely \\
\hline $\mathrm{D}$ & $\begin{array}{c}\text { ED Doctor + Paediatric Registrar with ED Consultant Support } \\
\qquad \pm \mathrm{SW} \pm \mathrm{RN} * *\end{array}$ & Rarely \\
\hline $\mathrm{E}$ & Paediatric registrar or junior doctor & Always \\
\hline $\mathrm{F}$ & Paediatric registrar supported by paediatrician & Sometimes \\
\hline G & ED doctor & Never \\
\hline $\mathrm{H}$ & ED doctors or Paediatric junior or Paediatrician & Rarely \\
\hline I & $\mathrm{ED}$ registrar $+\mathrm{RN} * *+\mathrm{SW} *$ supported by ED Consultant & Rarely \\
\hline
\end{tabular}

Table 4. Procedures followed after child physical abuse/neglect clinical assessment.

\begin{tabular}{|c|c|c|c|c|}
\hline Facility $^{1}$ & $\begin{array}{l}\text { Medical } \\
\text { Report }\end{array}$ & $\begin{array}{l}\text { Follow-up } \\
\text { (Proportion) }\end{array}$ & Who follows up & CP Policy Used \\
\hline \multirow[t]{2}{*}{$\mathbf{A}$} & Yes & Yes $(75 \%)$ & Orthopaedic, Ambulatory & No (Doctors) \\
\hline & & & Paediatrics, Paediatrician & Yes (nurses) \\
\hline B & Yes & Yes $(100 \%)$ & Paediatrician, or child at risk clinic & Yes, not used clinically \\
\hline C & No & Yes $(100 \%)$ & Paediatrician, ED clinic & Yes, not used clinically \\
\hline D & No & Yes (don’t know) & Paediatrician, CPU, CS & No \\
\hline $\mathbf{E}$ & No & No & $\mathrm{CS}$ & Yes and helpful clinically \\
\hline $\mathbf{F}$ & No & Yes $(>50 \%)$ & Local paediatricians, CS & $\begin{array}{l}\text { Aware, not used } \\
\text { clinically }\end{array}$ \\
\hline G & No & Yes (if transferred) & All transferred to hospital A & Not aware \\
\hline $\mathbf{H}$ & No & Yes (most) & Paediatrician or GP & $\begin{array}{l}\text { Aware of policy not used } \\
\text { clinically }\end{array}$ \\
\hline I & No & Yes $(75 \%)$ & Hospital elsewhere & Aware, not used \\
\hline
\end{tabular}

Notes: ${ }^{1}$ Facilities A-I listed according to number of paediatric admissions, greatest to least. A, B, C, D, E, F, H are district level paediatric services; CP Policy: Child Protection policy; CS: Community Services; CPU: Child Protection Unit (forensic service based in a tertiary Children's Hospital).

\subsection{What is Working Well?}

- Team approach: Multidisciplinary teams with social worker involvement often had staff with a "passion" for child advocacy. Particular local teams with good working cultures were identified and commended on their collaborative working relationship.

- Availability of protocol and policy: Clinicians, who knew about the existing child protection policy, were able to find it and use it when required. Being able to locate the policy online was particularly useful. 
- Positive working relationship between health and statutory services: Some teams had established relationships with their local CS, this facilitated ease of reporting CM concerns and improved referral pathways between CS and hospitals.

- Good communication channels: These were reported in certain facilities or teams and included internal and external pathways. Teams with a culture of consultation with senior staff were acknowledged. For child protection managers, being able to consult a paediatrician and having a key contact person at each site to facilitate the referral process was a major bonus.

\subsection{What are the Gaps in Systems Currently?}

- Inadequate awareness, recognition and follow-up of CM among frontline clinicians: Social workers were more likely to point out that there was inadequate awareness and recognition of $\mathrm{CM}$ in the acute setting. While responses for whether some form of follow-up was provided varied (Table 3), most hospitals had inadequate psychosocial staff, i.e., social workers to provide appropriate follow-up for children identified as at risk.

- Children with CM concerns not prioritised in EDs: This was a frustration not just for child protection caseworkers but also for social workers. Caseworkers felt that children should not have to wait for a medical assessment, given their traumatic experiences.

- Poor communication between hospitals and CS: Busy clinicians, particularly doctors and nurses, pointed to poor information provided to clinicians by caseworkers, lack of feedback, and case coordination provided by $\mathrm{CS}$.

- Workforce issues: Lack of trained and qualified staff was a significant issue, particularly social workers in some hospitals and medical staff with paediatric experience. Workforce constraints contributed to the lack of multi-disciplinary assessments carried out. Limited after-hours availability of access to social work, radiology and paediatric expertise was a concern in the smaller district hospitals.

- Marked variability in quality: This was highlighted not just by child protection managers but also by clinicians. There were variations across hospital sites of quality of PAN assessments, timeliness and quality of medical reports.

\section{Discussion}

This clinical practice improvement project in metropolitan Sydney was carried out to inform planning and coordinate frontline clinical services to adequately respond to CM. Our study shows that children make up a sizable proportion of emergency presentations in metropolitan Sydney; a quarter of all presentations are for injury and a significant minority is attributable to CM. Clearly, the acute hospital setting is one where maltreated children do present to; data from the United States has shown that $10 \%$ of all children presenting to an ED are victims of CM and, without identification, a third will be injured again and 5\% will die from subsequent injuries [22]. In general, however, there is low-quality evidence on the accuracy of instruments for identifying abused children in the acute setting $[13,23]$. Beyond merely attempting to quantify the clinical burden of child PAN presenting to acute services, we also identified positive and negative interagency working practices and developed 
minimum clinical standards for assessment and care of this cohort of children in this region (see Box 1) [24]; from the results of this project and guided by the available international evidence.

Box 1. Minimum standards for the clinical assessment of children presenting with suspected physical abuse and/or neglect to frontline services.

- All paediatric injuries/poisoning presenting to ED are triaged using Paediatric Injury Sticker or equivalent ${ }^{1}$

- All children presenting with suspected significant PA/N or referred by $\mathrm{CS}$, are assessed by a paediatric trained doctor, social worker, \pm nurse as appropriate

- All clinical assessments to follow PA/N clinical protocol ${ }^{2}$

- Assessments to be discussed with most senior Consultant

- If child protection report is to be generated, it needs to be counter-signed by Consultant

- Child Protection Medical Report to follow standard format ${ }^{3}$

- Clinical photography if needed to be organised via the hospital audio-visual service

- $\mathrm{PA} / \mathrm{N}$ protocol and report to be filed in the medical record

- Clearly defined pathway in existence between child protection services and frontline health services in the region for children presenting with $\mathrm{PA} / \mathrm{N}$

- Paediatric and psychosocial follow-up to be available to all children identified with abuse and neglect, across the region

- All frontline clinical staff (i.e., doctors, nurses and social workers) working in ED and Paediatric Departments have completed core child protection training

- Clinically oriented child protection training to be scheduled annually in continuing education programs in all ED and Paediatric Departments across the region

Notes: ${ }^{1}$ The existing paediatric injury/poisoning risk assessment sticker has been incorporated into an online risk assessment tool in ED; ${ }^{2}$ The Suspected Child Abuse and Neglect (SCAN) clinical protocol is available on the intranet across the region; ${ }^{3}$ A template for the Child Protection Medical Report is available on the intranet across the region; ED: Emergency Department; PA/N: physical abuse and/or neglect; CS: Community Services, the State child protection service.

The obvious presence of children and families in our acute frontline services notwithstanding, the real burden of PAN presentations is still unclear. In 2007-2008, there were over 34,000 substantiated child protection reports made to the Child Protection Helpline in NSW; one-fifth of these reports were for physical abuse [25]. In our study, data from paediatric ED presentations coded with CM-type concerns in 2007 ranged from 20 per year in one facility (with low paediatric presentations) to 125 in the facility with the largest paediatric population. Clinician and child protection managers' estimates of PAN presentations to frontline services varied widely from four per year to one a day. From the available quantitative data on paediatric injury presentations, PAN-type concerns account for approximately $3 \%-5 \%$ of injury presentations and $1 \%$ of all paediatric ED presentations in our study. Early detection rates of child abuse in EDs vary widely among different countries (Netherlands: $0.2 \%$, Italy $2 \%$, the United Kingdom: $4 \%-6.4 \%$, United States: $10 \%$ ) due to varied screening tools, different settings and access to health services [9,14,26-29]. While our study suggests that in metropolitan Sydney, in busy district hospitals, physical abuse/neglect accounts for at least $1 \%$ of ED presentations; this is likely to be an underestimate and perhaps not the right question. 
This study showed that there was wide variation in response to children presenting with suspected PAN presentations to frontline services. There is variation in who assesses them, whether protocols are used, follow-up offered and medical reports done. Some of this reflects the resourcing of each facility in terms of trained paediatric staff, some of this reflects variation in clinical practice. Comprehensive guidelines do exist for clinicians responding to children with suspected maltreatment [30,31]. We know that a medical examination is an important component in the assessment of child abuse as it provides information to support or refute an allegation and helps to identify the health and welfare needs of vulnerable children [32]. The significant variation in paediatric and psychosocial follow-up offered to children with suspected maltreatment is of concern, given the high risk of recurrence of maltreatment, especially within the first month of the index event [33]. Clinician interviews matched well with the experiences of child protection managers, who also reported a great variability in the quality of assessments, timeliness of assessments and quality of reports. Only four facilities routinely audited paediatric presentations to ED; these included the busiest and the least busy ED with respect to paediatric presentations. We therefore identified critical problems not just in medical assessments of $\mathrm{CM}$ in the acute setting but also inter-agency responses. Much of the work done on inter-agency responses to $\mathrm{CM}$ have focused on improving professionals' abilities in information sharing and reporting of concerns $[18,34]$. Impressive work has also been done in the United Kingdom to standardize peer review processes for paediatricians as an essential component of the medical evaluation of CM [35]. The authors of these peer review standards acknowledged however that there was a role for making peer-review meetings both multidisciplinary and multi-agency [35].

Within the last two decades, there have been many attempts to improve clinicians' performance in EDs with respect to CM [14,15], including adapting guidelines from other national systems [29]. In this metropolitan region, Ziegler et al.'s review of children presenting with fractures in Hospital A, found poor identification of CM, poor documentation and follow-up of patients [11]. As a result of this review, the hospital ED put in place a paediatric injury-screening tool, subsequently adopted by two other hospitals. Two of the busiest hospitals use this screening tool and have higher proportions of children with injuries identified as being due to $\mathrm{CM}(4 \%-5 \%)$, thereby suggesting the tool improves risk identification. Leventhal et al.'s study of fractures in young children in the US does suggest that there has been a significant reduction in the proportion of abusive fractures from the 1980 s to the 2000 s, due to early recognition of less serious forms of CM and availability of family intervention [36]. A recent paediatric injury study from Queensland, Australia, using linked hospital and child protection service records, found a high proportion of children with unintentional injury codes had CM concerns, thus suggesting that hospital clinicians needed targeted training to ensure children at risk were being detected by the child protection system [37].

According to our respondents, most clinicians within their teams had completed their mandatory child protection training. In a previous study we conducted in this region on knowledge and practice of doctors and nurses, we found that although most clinicians reported some child protection training, more than $70 \%$ of ED nurses felt their training was inadequate, compared with $19 \%$ of ED doctors [38]. Studies have shown that child protection training improves the ability of clinicians to report suspected CM [39], whereas clinical experiences and training in CM improve the preparedness of doctors to identify and evaluate patients for abuse [40,41]. A systematic review of child protection 
training and interventions found evidence to support the use of procedural changes that improve documentation of suspected CM but an absence of rigorous evaluation of training programs and their impact [42]. We would suggest that mandatory training in child protection, such as is currently available, is not sufficient on its own to provide a quality response to children presenting with suspected abuse or neglect to frontline services.

In our study, several respondents were able to highlight good examples of local clinical practice, which involved good teamwork and good relationships with on the ground agencies. Health workers and child protection workers identified several gaps in practice and within their organisations and systems. The practice gaps identified were threefold, that is: inadequate awareness and recognition of physical abuse/neglect among frontline health staff; variations in assessments undertaken; and variation in use of procedures and protocols. A systematic review of effectiveness of professional and organizational interventions aimed at improving medical processes, such as documentation or clinical assessments by ED healthcare providers, found that moderate-quality observational studies suggested that education and reminder systems increase clinical knowledge and documentation but these findings were not supported by a multisite randomized trial [43]. System problems included a lack of priority given to suspected CM cases; different staffing arrangements across sites; ineffective data systems to capture PAN presentations to health services; inadequate follow-up systems for identified CM cases; unsatisfactory communication within and between agencies.

\section{Conclusions}

Tony Morrison promotes the idea of a "strategic leadership of complex practice"; i.e., collective forms of knowing and reflecting that learn from frontline staff accessing practice narratives as well as performance numbers, to achieve a systemic analysis of the state of practice and how it can be improved [44]. We believe that we have tried to do just that — arrive at an in-depth understanding of the pointy end of the complex inter-disciplinary practice involved with responding to child maltreatment within frontline clinical services. We described the clinical burden of child PAN presenting to frontline services in metropolitan Sydney, providing the best available estimate of numbers of children presenting with suspected abuse/neglect. We described professional practice with respect to $\mathrm{CM}$ across agency and professional boundaries, as it currently stands. We highlighted isolated examples of good practice but also pointed out areas for improvement. A twofold challenge exists: to improve service quality within the health system, and to enhance coordination across health and welfare agencies. Based on the findings and international guidelines, we formulated minimum standards for the clinical assessment and care of child PAN in our own region [24], which are currently feasible given the right leadership and organisational support. A vulnerable child and youth population is dependent upon these recommendations being addressed adequately.

\section{Acknowledgments}

We gratefully acknowledge the time and enthusiastic support provided by all the clinicians and statutory child welfare workers who were interviewed for this project. 


\section{Author Contributions}

All authors contributed to the conceptualization of this quality improvement project. Shanti Raman, Michelle Maiese, Katrina Hurley were involved carrying out fieldwork, data entry and analysis. Shanti Raman and David Greenfield were principally involved with writing up the manuscript.

\section{Abbreviations}

PAN: physical abuse and/or neglect;

ED: Emergency department;

CM: child maltreatment.

\section{Conflicts of Interest}

The authors declare no conflict of interest.

\section{References}

1. Gilbert, Ruth, Cathy Spatz Widom, Kevin Browne, David Fergusson, Elspeth Webb, and Staffan Janson. "Burden and Consequences of Child Maltreatment in High-Income Countries." The Lancet 373 (2009): 68-81.

2. Fang, Xiangming, Derek S. Brown, Curtis S. Florence, and James A. Mercy. "The Economic Burden of Child Maltreatment in the United States and Implications for Prevention." Child Abuse \& Neglect 36 (2012): 156-65.

3. Cuijpers, Pim, Filip Smit, Froukje Unger, Yvonne Stikkelbroek, Margreet ten Have, and Ron de Graaf. "The Disease Burden of Childhood Adversities in Adults: A Population-Based Study." Child Abuse \& Neglect 35 (2011): 937-45.

4. Wood, James. Report of the Special Commission of Inquiry into Child Protection Services in NSW. Sydney: State of NSW through the Special Commission of Inquiry into Child Protection Services in NSW, 2008.

5. Department of Premier and Cabinet. Keep Them Safe: A Shared Approach to Child Wellbeing 2009-2014. Sydney: Department of Premier and Cabinet, NSW Government, 2009.

6. Felitti, Vincent J., Robert F. Anda, Dale Nordenberg, David F. Williamson, Alison M. Spitz, Valerie Edwards, Mary P. Koss, and James S. Marks. "Relationship of Childhood Abuse and Household Dysfunction to Many of the Leading Causes of Death in Adults: The Adverse Childhood Experiences (Ace) Study." American Journal of Preventive Medicine 14 (1998): 245-58.

7. Flaherty, Emalee G., Richard Thompson, Alan J. Litrownik, Adrea Theodore, Diana J. English, Maureen M. Black, Traci Wike, Lakecia Whimper, Desmond K. Runyan, and Howard Dubowitz. "Effect of Early Childhood Adversity on Child Health." Archives of Pediatrics and Adolescent Medicine 160 (2006): 1232-38. 
8. Scott, Debbie, Lil Tonmyr, Jenny Fraser, Sue Walker, and Kirsten McKenzie. "The Utility and Challenges of Using Icd Codes in Child Maltreatment Research: A Review of Existing Literature." Child Abuse \& Neglect 33 (2009): 791-808.

9. Chang, David C., Vinita Knight, Susan Ziegfeld, Adil Haider, Dawn Warfield, and Charles Paidas. "The Tip of the Iceberg for Child Abuse: The Critical Roles of the Pediatric Trauma Service and Its Registry.” Journal of Trauma 57 (2004): 1189-98.

10. King, Wendalyn K., Eric L. Kiesel, and Harold K. Simon. "Child Abuse Fatalities: Are We Missing Opportunities for Intervention?” Pediatric Emergency Care 22 (2006): 211-14.

11. Ziegler, David S., John Sammut, and Anne C. Piper. "Assessment and Follow-up of Suspected Child Abuse in Preschool Children with Fractures Seen in a General Hospital Emergency Department." Journal of Paediatrics and Child Health 41 (2005): 251-55.

12. Gilbert, Ruth, John Fluke, Melissa O’Donnell, Arturo Gonzalez-Izquierdo, Marni Brownell, Pauline Gulliver, Staffan Janson, and Peter Sidebotham. "Child Maltreatment: Variation in Trends and Policies in Six Developed Countries.” The Lancet 379 (2011): 758-72.

13. Louwers, Eveline C. F. M., Maria J. Affourtit, Henriette A. Moll, Harry J. de Koning, and Ida J. Korfage. "Screening for Child Abuse at Emergency Departments: A Systematic Review." Archives of Disease in Childhood 95 (2009): 214-18.

14. Benger, Jonathan R., and Alison V. Pearce. "Quality Improvement Report: Simple Intervention to Improve Detection of Child Abuse in Emergency Departments." British Medical Journal 324 (2002): 780-82.

15. Smeekens, A. E. F. N., D. M. Broekhuijsen-van Henten, Judith S. Sittig, I. M. B. Russel, O. Th J. ten Cate, N. M. Turner, and Elise M. van de Putte. "Successful E-Learning Programme on the Detection of Child Abuse in Emergency Departments: A Randomised Controlled Trial." Archives of Disease in Childhood 96 (2011): 330-34.

16. Woodman, Jenny, Fiona Lecky, Deborah Hodes, Marion Pitt, Brent Taylor, and Ruth Gilbert. "Screening Injured Children for Physical Abuse or Neglect in Emergency Departments: A Systematic Review." Child: Care, Health and Development 36 (2009): 153-64.

17. Louwers, Eveline, Ida Korfage, Marjo Affourtit, Harry de Koning, and Henriette Moll. "Facilitators and Barriers to Screening for Child Abuse in the Emergency Department." BMC Pediatrics 12 (2012): 167.

18. Bunting, Lisa, Anne Lazenbatt, and Isla Wallace. "Information Sharing and Reporting Systems in the UK and Ireland: Professional Barriers to Reporting Child Maltreatment Concerns." Child Abuse Review 19 (2010): 187-202.

19. Morgan, Katie, John Eastwood, and Shola Faniran. Headline Population Indicators Data Report 2009: A Report for the South West Sydney Region on Key Statistics Relating to the Health and Wellbeing of Its Children and Families. Liverpool, Australia: Karitane and the Department of Community Paediatrics, Sydney South West Area Health Service, 2010.

20. Greene, Jennifer C., Valerie J. Caracelli, and Wendy F. Graham. "Toward a Conceptual Framework for Mixed-Method Evaluation Designs." Educational Evaluation and Policy Analysis 11 (1989): 255-74. 
21. Braun, Virginia, and Victoria Clarke. "Using Thematic Analysis in Psychology." Qualitative Research in Psychology 3 (2006): 77-101.

22. Mace, Sharon E., Michael J. Gerardi, Ann M. Dietrich, Stephen R. Knazik, Deborah Mulligan-Smith, Robert L. Sweeney, and Craig R. Warden. "Injury Prevention and Control in Children.” Annals of Emergency Medicine 38 (2001): 405-14.

23. Bailhache, Marion, Valeriane Leroy, Pascal Pillet, and Louis-Rachid Salmi. "Is Early Detection of Abused Children Possible?: A Systematic Review of the Diagnostic Accuracy of the Identification of Abused Children." BMC Pediatrics 13 (2013): 202.

24. Raman, Shanti, Michelle Maiese, and Katrina Hurley. Assessment and Care for Children Presenting with Suspected Physical Abuse and/or Neglect to Acute Services across Sydney South West Area Health Service: Clinical Practice Improvement Project. Sydney: Sydney South West Area Health Service, 2012.

25. Bromfield, Leah, and Briony Horsfall. Child Abuse and Neglect Statistics. Melbourne: Australian Institute of Family Studies, 2010.

26. Louwers, Eveline C. F. M., Ida J. Korfage, Marjo J. Affourtit, Dop J. H. Scheewe, Marjolijn H. van de Merwe, Francoise A. F. S. R. Vooijs-Moulaert, Claire M. C. Woltering, Mieke H. T. M. Jongejan, Madelon Ruige, Henriëtte A. Moll, and et al. "Detection of Child Abuse in Emergency Departments: A Multi-Centre Study." Archives of Disease in Childhood (2011): 422-25.

27. Palazzi, S., G. de Girolamo, and T. Liverani. "Observational Study of Suspected Maltreatment in Italian Paediatric Emergency Departments." Archives of Disease in Childhood 90 (2005): 406-10.

28. González-Izquierdo, Arturo, Jenny Woodman, Lynn Copley, Jan van der Meulen, Marian Brandon, Deborah Hodes, Fiona Lecky, and Ruth Gilbert. "Variation in Recording of Child Maltreatment in Administrative Records of Hospital Admissions for Injury in England, 1997-2009." Archives of Disease in Childhood 95 (2010): 918-25.

29. Sittig, Judith S., Erica D. M. Post, Ingrid M. B. Russel, Ingrid A. G. van Dijk, Edward E. S. Nieuwenhuis, and Elise M. van de Putte. "Evaluation of Suspected Child Abuse at the ED; Implementation of American Academy of Pediatrics Guidelines in the Netherlands." The American Journal of Emergency Medicine 32 (2013): 64-66.

30. National Collaborating Centre for Women's and Children's Health. When to Suspect Child Maltreatment. London: National Institute for Health and Clinical Excellence, 2009.

31. Royal College of Paediatrics and Child Health (RCPCH). Child Protection Companion. London: RCPCH, 2006.

32. Kirk, Charlotte B., Angela Lucas-Herald, and Jacqueline Mok. "Child Protection Medical Assessments: Why do We Do Them?” Archives of Disease in Childhood 95 (2010): 336-40.

33. Hindley, Nick, Paul Ramchandani, and David P. H. Jones. "Risk Factors for Recurrence of Maltreatment: A Systematic Review." Archives of Disease in Childhood 91 (2006): 744-52.

34. Goad, John. "Understanding Roles and Improving Reporting and Response Relationships across Professional Boundaries.” Pediatrics 122 (2008): S6-9. 
35. Thomas, Amanda, and Alison Mott. "Child Protection Peer Review for Paediatricians." Child Abuse Review 22 (2013): 60-66.

36. Leventhal, John M., Ilse A. Larson, Denise Abdoo, Sujatha Singaracharlu, Carolina Takizawa, Cindy Miller, Rob Goodman, Dana Schwartzc, Susanne Grassoc, and Katherine Ellingsond. "Are Abusive Fractures in Young Children Becoming Less Common?: Changes over 24 Years." Child Abuse \& Neglect 31 (2007): 311-22.

37. McKenzie, Kirsten, Debbie Scott, Jennifer A. Fraser, and Michael P. Dunne. "Assessing the Concordance of Health and Child Protection Data for 'Maltreated' and 'Unintentionally Injured' Children." Injury Prevention 18 (2012): 50-57.

38. Raman, Shanti, Anna Holdgate, and Rebecca Torrens. "Are Our Frontline Clinicians Equipped with the Ability and Confidence to Address Child Abuse and Neglect?" Child Abuse Review 21 (2012): 114-30.

39. Lawrence, Linda L., and Stephen J. Brannen. "The Impact of Physician Training on Child Maltreatment Reporting: A Multi-Specialty Study.” Military Medicine 165 (2000): 607-11.

40. Narayan, Aditee Pradhan, Rebecca R. S. Socolar, and Karen St. Claire. "Pediatric Residency Training in Child Abuse and Neglect in the United States.” Pediatrics 117 (2006): 2215-21.

41. Starling, Suzanne P., Kurt W. Heisler, James F. Paulson, and Eren Youmans. "Child Abuse Training and Knowledge: A National Survey of Emergency Medicine, Family Medicine, and Pediatric Residents and Program Directors.” Pediatrics 123 (2009): e595-602.

42. Carter, Yvonne H., Michael J. Bannon, Caroline Limbert, Andrea Docherty, and Jane Barlow. "Improving Child Protection: A Systematic Review of Training and Procedural Interventions." Archives of Disease in Childhood 91 (2006): 740-43.

43. Newton, Amanda S., Belle Zou, Michele P. Hamm, Janet Curran, Sahil Gupta, Celeste Dumonceaux, and Melanie Lewis. "Improving Child Protection in the Emergency Department: A Systematic Review of Professional Interventions for Health Care Providers." Academic Emergency Medicine 17 (2010): 117-25.

44. Morrison, Tony. "The Strategic Leadership of Complex Practice: Opportunities and Challenges." Child Abuse Review 19 (2010): 312-29. 


\title{
Child Welfare and Successful Reunification through the Socio-Educative Process: Training Needs among Biological Families in Spain
}

\author{
M. Angeles Balsells, Crescencia Pastor, Pere Amorós, Ainoa Mateos, Carmen Ponce \\ and Alicia Navajas
}

\begin{abstract}
In Spain, an average of 480 children per 100,000 is receiving some type of temporary care, and the reunification process is typically lengthy. Providing the biological family with specific training as part of the reunification process is key to solving this problem. Although previous research and social policy have emphasized the importance of such training to reunification, the training has not been fully implemented in Spain. This study investigates the specific training needs during the transition phase of the reunification process in which the child prepares to return home. The data were obtained from focus groups and through semi-structured interviews with 135 participants: 63 professionals from the Child Protection System and 42 parents and 30 children who have undergone or are currently undergoing reunification. A qualitative methodology and Atlas.ti software were used to analyze the interview content. The results indicate three specific training needs: (a) understanding the reasons for reunification and the reunification phases; (b) empowerment strategies; and (c) social support. These findings suggest the best practices for formulating specific support programs for this population during the reunification transition period.
\end{abstract}

Reprinted from Soc. Sci. Cite as: Balsells, M.A.; Pastor, C.; Amorós, P.; Mateos, A.; Ponce, C.; Navajas, A. Child Welfare and Successful Reunification through the Socio-Educative Process: Training Needs among Biological Families in Spain. Soc. Sci. 2014, 3, 809-826.

\section{Introduction: The Situation in Spain}

According to the official 2012 data, there are a total of 39,754 open cases of children receiving government protection in Spain or an average of 480 Spanish children per 100,000 [1]. These data indicate a slight downward trend since 2004, for both open cases and the number of guardianships. Unlike other countries, in Spain, residential care is used in $75 \%$ of placement cases and is the primary resource for children who are placed in out-of-home care. Another particular characteristic of Spain is the predominance of kinship foster care among foster care cases: kinship foster care is provided in $85 \%$ of family placement cases [2]. Additionally, foster care stays in Spanish residential institutions are typically lengthy. López and Del Valle [3] indicate that the children who stay the longest are primarily those between 9 and 12 years old who present emotional and/or behavioral problems ( $42 \%$ of the children under care receive psychological support) and whose parents have serious psycho-social problems.

Another factor that is evident from official statistics about measures for child protection in Spain is the absence of unified data about the number of minors who return to their nuclear family. This lack of uniformity in data is because each autonomous community is responsible for recording the 
information. Consequently, Spain lacks official data about the number of children in care who return home with their biological family, and little research about this topic exists.

Organic Law 1/1996 on the Legal Protection of Minors, passed on 15 January 1996 [4], calls for the prioritization of family reunification. It declares that children have a basic right to development in their family context and states that in the case of separation, the primary objective should be to facilitate reunification with the biological family. The Spanish autonomous communities were charged with implementing this law and are allowed use placement alternatives that accord with their own priorities [5]. In its report about Spain, the United Nations' Committee on the Rights of the Child [6] is also betting on the revaluation of the biological family and for interventions in child protection that support the preservation and reunification of families. Among other measures, it foresees providing parents with support mechanisms sufficient for fulfilling their responsibilities in raising their children and giving priority to the family itself for a process of reunification, despite the fact that legislation gives priority to family reunification. In fact, some studies have indicated that although family reunification is the most common idea among practitioners, it is not implemented in practice [7].

To encourage the reunification process, the Child Welfare Information Gateway [8] recommends training programs designed to empower families. Many researchers support this recommendation and tend to suggest the implementation of socio-educational programs for teaching parenting skills [8-10]. Other authors broaden this vision by also recommending training that addresses the specific needs relevant to each stage of the reunification process [11,12]. Spain is at the beginning stages with respect to training programs. The international tendencies and research undertaken by different teams at Spanish universities have enabled the production of programs called third generation $[13,14]$, where the main aim is to promote the quality of family functioning as a system through comprehensive long-lasting, multi-domain, multi-context interventions and through socio-educational group interventions with the whole family (parents and children) [15]. The Spanish parental education programs [16] are oriented towards promoting family communication that improves both the quality of the family system and parental skills. What predominates is the need to create an atmosphere that favors educating children in which organization is imposed over chaos [13] and in which the factors of protection that identify the capabilities are the best points of reference for a family intervention [11,16,17-19]. Nonetheless, in plans for family reunification, concrete objectives are addressed for the recovery of parents and improvement of the family context, but the introduction of specific training programs is not common practice.

This background situates reunification as one of the principal challenges for research and practice presently facing the Spanish system of protection.

\section{Literature Review}

In the Child Protection System, family reunification refers to the process through which children who have experienced abandonment, neglect or abuse return to the home of their birth families after a mandated separation period. It involves separating the child temporarily from the family and placing him or her in foster care and/or a residential placement. The reunification process begins the moment the child is separated from his or her parents. After the separation occurs, if reunification is 
the goal, the parents maintain contact with their children through visits in which they also receive training to become eligible for the child's return. Wade et al. [20] studied reunification in depth. Specifically, about the reunification decision and the consequences for maltreated and neglected children after four years of being away from home. In this study, there are some key points to highlight, such as: (a) the rates of admission, planning process, pathways and destinations of children to care vary by local authority; (b) the social workers based the decision to return home on improvements of problems that had led to the children's admission and on the level of risk to the safety of the children were considered to be acceptable, and (c) it observed more stability for those children who had been the entire time in foster care than those who had returned home; over half of the children who went home $(59 \%)$ had made at least one return to care. As Wade et al. [20] explain, stability is not the only factor to take into account to evaluate the reunification; we have to consider the well-being of the children at home. The return home of the children is more likely to be stable when decisions to reunify maltreated children are based on clear evidence of change in parenting capacity, the reunification has been well planned, and there is a strong provision of support services to assist parents and children. When this happens, the stability and well-being of the maltreated and neglected children is higher, and for this reason long-term care can be a positive option for maltreated and neglected children, contrary to common belief.

Previous studies indicate the need to support the biological family with the fundamental aspects of reunification in each stage of the process; specific needs vary by stage.

This paper studies the phase-months and days - during which the children prepare to return home. Once a decision has been reached that the children may return home based on the positive changes achieved by the family, specific needs arise that must be addressed for a satisfactory reunification.

Some family intervention or support processes were previously excessively structured from the perspective of deficit, based on the deficiencies or limitations of those involved. The perspective of potentialities that considers the possibilities of some factors of protection or simply of some personal resources that can and should be strengthened was not always considered. Professional work consists not only of reducing the limitations and weak points but also of increasing the capabilities and strengths that are found in most people, even those in negative situations [21].

The ecological-transactional model [22] allows for observation of both risk and protection factors that interact dynamically on the various ecological levels suggested by Bronfenbrenner [23]. From this model, one may analyze the paths of families overcoming challenges and developing in the face of adversity typical of a situation of mistreatment and abandonment. The identification of these protection factors allows an intervention to potentiate the resilience of families that must cope with a process of reunification and move from an "ideal" model of family functioning to a "resilient" model [14]. Parental capabilities; the economic, family and social context; and attention to childhood needs are three areas that entail protection factors for families capable of facing great adversity. The empowerment of families so that they can develop these protection factors is a trend in more recent interventions: "The relevance of the construct of family resilience for this sample supports the application of this theoretical material within family-centered practice" ([24], p. 209).

However, the scientific literature is also beginning to identify the specific needs of a process of reunification - those that are substantial for a family that is in the process of recovering guardianship of their children. From this perspective, the ecological-transactional model and resiliency theory may 
provide a deductive argument for the need to focus on the following key factors in successful reunification: understanding the motives for reunification and the reunification phases, empowerment strategies, and social support. These three needs must be considered throughout the reunification process. However, during the transition to the family context, they become particularly important due to their influence on the successful reunification.

\subsection{Understanding the Motives for and Process of Reunification}

Reunification becomes possible when the family has satisfactorily undergone the change process that enables the child to return home. The commitment, willingness and desire of the family to accept and make the necessary changes contribute the most to promoting reunification and family resilience during this process [24]. The British proposal "The Framework for the Assessment of Children in Need and Their Families" [25] identifies three areas in which these changes should occur: (a) the family context, social support received and environmental factors; (b) parental competence in providing adequately for the child's needs; and (c) improved quality of life and child welfare. This interpretative model suggests that adequate change during the reunification process should be measured in these three related areas. Parental recognition of these essential changes and requirements is the first step to reunification [26]. According to Balsells et al. [12], developing an awareness of these changes is a gradual process. Families initially see the reasons for the separation as contextual, but in the reunification phase, they begin to realize how their improved parental abilities make reunification possible. Therefore, awareness of the problem grows over time. However, according to the same authors, not all families are able to visualize how they will ensure the well-being and quality of life of their children at this stage of the process: they lack empathy and vision regarding the improved welfare of their children $[11,12]$.

Another factor identified in the literature as relevant to the success of reunification is knowledge about the reunification process. Parents should become familiar with the different adaptation situations that may arise after the child returns home. At first, parents may idealize living together, leading to a harmonious "honeymoon" phase $[15,26,27]$. This idyllic stage can deteriorate over time and be interrupted by unresolved reunification problems or other issues that may lead to a crisis. Therefore, Del Valle and Fuertes [28] argue that parents should be prepared by learning about these phases and obtaining adequate resources to resolve a potential crisis.

\subsection{Empowerment Strategies}

The scientific literature indicates that family empowerment, particularly through identity reinforcement and the development of a group identity, is necessary as families prepare to be reunified. When a family considers itself a group, it makes a greater effort to stay together [24,29,30]. As children prepare to return home from temporary care, several strategies are used to reinforce the feeling of connection, such as increasing visitations and parental involvement in important events [10] or providing parental capacities [31,32]. Other authors have identified positive intrafamily communication as an element that increases the success of the reunification process [32,33]. Similarly, the family's relationship with support professionals is also crucial, and the literature emphasizes the importance 
of promoting trust through exchange rather than creating a relationship informed by power dynamics [34,35]. Parents value honesty, consistency and respect from professionals [36].

Family members' ability to manage emotions also supports empowerment. Parents should recognize and address their children's contradictory feelings, which may include conflicts of loyalty or dissatisfaction with their return home [30]. Parents may also experience mixed feelings, including happiness and fear, before the child's arrival. They may therefore benefit from emotional management training [37]. Managing these specific emotions is necessary in this stage of the process.

Because of the novelty of living together as a family, parents should develop conflict resolution skills to help the entire family adapt to the habits and attitudes adopted by the children during their placement [30]. Festinger [38] adds that in such moments, it is crucial for parents to understand the evolution of their children's behavior and adapt to their new needs.

\subsection{Social Support}

Several authors have used the Bronfenbrenner [39] model to emphasize the importance of supporting families involved in child protection measures. The research indicates the importance of both formal and informal support during the reunification process.

Authors such as Lietz et al. [40] assert that formal support from child protection professionals is essential to making and maintaining the changes necessary for successful reunification. Cole and Caron [10] state that maintaining relations with professionals that are based on trust and respect helps families adequately adapt to the services and determine whether they are receiving sufficient support. Rodrigo et al. [41] add that all family members should be able to identify and apply the professional support offered by various institutions and maintain their earlier contacts.

Previous studies of informal support indicate that these families typically have weak social support networks. Therefore, many authors suggest that efforts be made to identify and maximize families' informal support resources $[42,43]$. Informal support facilitates reunification, as families rely on outside help to strengthen the family unit and prevent relapses [44]. Informal support can also help the family unit during the moments of stress and anxiety that occur during reunification, facilitate behavior change and prevent abuse and neglect in the family system [40].

Consistent with the literature reviewed above, the protection services that connect families to formal and informal support networks obtain better qualitative results in studies of the reunification process [41], leading many authors to recommend that professionals be involved in identifying and maximizing both informal $[42,43]$ and formal support resources $[24,34,45,46]$.

\section{Methodology}

\subsection{Objective}

This research aims to deepen the field's understanding of the specific needs of families undergoing the reunification process during the transition period prior to a child's return home from temporary care. It examines parents' various socio-educational needs during the months prior to reunification. 
The ultimate goal of the study is to contribute to the development of training programs designed to support the family reunification process.

\subsection{Participants}

The most important feature of the sample was its ability to provide a multi-informant perspective. Data were obtained from three population groups: professionals, parents and children.

The participants were contacted through child protection welfare services in four regions of Spain (Catalonia, the Balearic Islands, Galicia and Cantabria). The research team and the welfare staff selected the families to participate in the study.

To participate in the study, the participants were required to be (a) professionals working in various capacities within the Child Protection System who had experience with foster care or residential placement; (b) parents with varying characteristics (age, family structure, etc.) who had already been reunified with their children or would be reunified in the subsequent two months, were involved in a reunification plan and were willing to cooperate and collaborate with the professionals; or (c) children and young adults between 12 and 20 years old with no mental or physical disabilities who had left placement services (residential or foster care) more than one year ago. Only those children whose parents had also been selected could participate in the research.

The total number of participants was 135, of which 63 were professionals, 42 were parents and 30 were children.

The professionals had experience in residential placement or foster care (33 with birth families, 16 with residential care and 5 with kinship foster care). Thirty-three worked as social workers, 10 as educators and 20 as psychologists. The majority was women $(74.60 \%)$, and the remainder men (25.40\%). (See Table 1 for participant details).

Table 1. Characteristics of the participating professionals.

\begin{tabular}{ll}
\hline Characteristics & Professionals $(\boldsymbol{N}=\mathbf{6 3})$ \\
\hline Gender & \\
\hline Women & $47(74.60 \%)$ \\
\hline Men & $16(25.40 \%)$ \\
\hline Age & $16(25.80 \%)$ \\
\hline $25-35$ & $29(45.16 \%)$ \\
\hline $36-45$ & $18(29.04 \%)$ \\
\hline Over 46 & \\
\hline Training & $20(31.75 \%)$ \\
\hline Social educators & $10(15.87 \%)$ \\
\hline Pedagogues & $20(31.75 \%)$ \\
\hline Psychologists & $13(20.63 \%)$ \\
\hline Social workers & \\
\hline Biological family & $37(58.73 \%)$ \\
\hline Residential care & $16(25.40 \%)$ \\
\hline Family care & $10(15.87 \%)$ \\
\hline
\end{tabular}


Among the parents, 34 had been reunified and four were still involved in the reunification process; $76.19 \%$ were women, and $23.81 \%$ were men. (See Table 2 for participant details).

Table 2. Characteristics of the participating parents.

\begin{tabular}{ll}
\hline Characteristics & Parents $(\boldsymbol{N}=\mathbf{4 2})$ \\
\hline Gender & \\
\hline Women & $32(76.19 \%)$ \\
\hline Men & $10(23.81 \%)$ \\
\hline Family situation & \\
\hline Reunified & $37(88.09 \%)$ \\
\hline Undergoing reunification & $05(11.91 \%)$ \\
\hline
\end{tabular}

Among the children and young adults, 21 had been reunified and nine were still undergoing the reunification process. They ranged in age from 12 to $20 ; 53.33 \%$ were girls, and $46.67 \%$ were boys. (See Table 3 for participant details).

Table 3. Characteristics of the participating children and adolescents.

\begin{tabular}{ll}
\hline Characteristics & Children and Adolescents $(N=\mathbf{3 0})$ \\
\hline Gender & \\
\hline Girls & $16(53.33 \%)$ \\
\hline Boys & $14(46.67 \%)$ \\
\hline Age & \\
\hline $6-11$ & $05(16.66 \%)$ \\
\hline $12-17$ & $17(56.67 \%)$ \\
\hline Over 18 & $08(26.67 \%)$ \\
\hline Family situation & \\
\hline Reunified & $21(70.00 \%)$ \\
\hline Undergoing reunification & $09(30.00 \%)$ \\
\hline
\end{tabular}

\subsection{Tools}

A focus group and semi-structured interviews were used to gather the data. Three tools were developed: (a) a questionnaire for gathering participants' personal data (name, age, place of residence, names of children, type of placement, placement duration, etc.); (b) a guide for the focus group questions and semi-structured interviews; and (c) a form on which the development of the information acquisition process could be recorded (date, duration, place, motives, atmosphere, etc.).

The scripts were prepared based on a review of the scientific literature on the subject determining key elements to be investigated. The questions sought to provide opportunities for participants to present their experiences in processes of reunification, including how it occurred, their feelings and what assistance they received etc. from the perspectives of the parents, children and professionals involved. In the scripts for the discussion groups and the semi-structured interviews, the language of the questions was adapted to the contexts and the participants. The data were peer reviewed to maintain the reliability and credibility of the data. Thus, if there were some discrepancies in the 
selection of a word, it was reviewed, and an agreement was reached regarding which words would be culturally appropriate in context.

\subsection{Procedure and Analysis}

First, a comprehensive literature review was conducted on the topic to determine which factors influence successful reunification during the transition period. A field study was then conducted using 22 focus groups and 18 semi-structured interviews, which were recorded with the consent of the participants. The confidential nature of the recordings was ensured. For participants who were under age 18, authorization and consent were obtained from parents and the Public Administration if it had legal custody over them at that time.

All the information recorded was transcribed, and the literal transcription was analyzed using a system of coded categories that several researchers designed and developed by applying the "bottom-up" strategy. An exhaustive process of content analysis was conducted to define categories and subcategories. Bottom-up content analysis was applied in several stages. The first stage of analysis was textual, selecting paragraphs, fragments and significant quotes from the transcription papers. The second stage was conceptual, to identify categories and subcategories that could be interrelated. Both stages were conducted and subjected to peer review, and categories and subcategories were defined when data reached saturation. To achieve analytic reliability, three focus groups were initially analyzed by five judges (team researchers) to ensure that the categories were unambiguous and not mutually exclusive. Second, a system of double judges analyzed each hermeneutic unit. Each pair of judges had to read the analysis and codification individually, after which a consensus was found if any discrepancies surfaced. Finally, the codification was cleared using the software.

The Atlas.ti 6.1.1 software was used for the qualitative data processing. A Hermeneutic Unit Editor was created in which the literal transcriptions of the focus group (primary documents) were included, each category and subcategory was given a code (code) and textual notes were also included (memos). A conceptual network (network) was created to analyze the data as a basis for the connections established between the codes of the hermeneutic unit and the research.

The categories and codes included (a) understanding of the reunification process: (a.1) understanding reunification motives; (a.2) understanding the reunification process; (b) empowerment strategies: (b.1) active involvement; (b.2) communication; (b.3) emotional management; (b.4) adaptation; (c) social support: (c.1) formal support within the Child Protection System; (c.2) formal support outside of the Child Protection System; and (c.3) informal support.

\section{Findings}

\subsection{Understanding the Motives for Reunification and the Reunification Process}

The results indicate that parents' understanding of the difficulties involved in and the reasons behind the reunification with their children changed over time. When they are separated from their children, parents tend to blame environmental factors (i.e., lack of economic resources, inadequate housing, etc.). Nevertheless, as they anticipate their child's return, many of them state that both 
environmental factors and an improvement in their parenting skills contributed to the reunification. Therefore, the results revealed a gradual evolution in parents' understanding of the reasons for the separation, broadening their vision beyond contextual factors and adding parenting skills to the factors that they believe contributed to their situation. However, many parents fail to understand the factors related to the improved welfare of their children. According to Balsells et al. [12], few parents achieve this understanding, and even parents who have already been reunited with their children continue to focus on the contribution of environmental factors, as this quotation from one of the mothers participating in our study suggests:

"When they realized that they could not send them to another center, they said: So let them return to the mother." (Mother)

However, the professionals indicate that the majority of parents idealize their child's return home, requiring the professionals to underscore the importance of developing realistic expectations about their future lives together. They emphasize that establishing these expectations requires special attention and care because false expectations could lead to the reunification's failure. This description is consistent with the literature that identifies the "honeymoon" phase as a stage in which family members are optimistic and ignore the natural conflicts of daily life [27,29]. Despite the good relations established during this idyllic phase, an unresolved issue related to the separation-reunification process or some other type of issue eventually arises, resulting in a crisis that needs to be resolved. According to Del Valle and Fuertes [28], observations made by support professionals indicate that parents should be prepared by receiving education about the phases of the reunification process.

\subsection{Empowerment Strategies}

Previous studies have indicated the importance of empowering parents to face the situations that arise during the transition process. The results of this study suggest that reinforcing group identity within the family is a potent empowerment strategy. Identity, stability and the cohesion of the biological family [47-49] support family reunification, but research should determine how these characteristics can be achieved. Our results reveal that the active participation of parents in the entire process strengthens family identity. Parental participation can be achieved by encouraging parents to be present during their children's most important events (visits to the doctor, school meetings, etc.). Indeed, professionals particularly recommend such involvement in the later stages of the reunification process:

"If you do not make them participating parties with a right to voice their opinion, there comes a time when they stop believing that you are asking them, giving way to a sensation of being forced." (Professional)

This result is consistent with the literature. Del Valle et al. [30] demonstrate that the involvement of parents in their children's important events is crucial, particularly during the transition process. The parents participating in the research expressed that being treated as an active party and including all family members in important tasks facilitate the reunification process because they help them acquire new strength and unity as a family. This argument is consistent with the findings of 
Del Valle et al. [30], Osterling and Han [50] and Thomas et al. [49], who also detected associations between active participation, group identity and feelings.

Professionals, children and parents report that communication is an essential element of the reunification process. First, the parents and professionals interviewed indicated that communication with the spouse is a powerful strategy for overcoming difficulties and reuniting as a family. They also identify contact and good relationships with the children as factors that contribute to their desire to continue fighting for reunification. This result is consistent with previous studies. According to Wilson and Sinclair [32] and Farmer and Wijedasa [33], positive contact between family members is crucial because it increases the likelihood of family reunification.

Similarly, participants also consider communication between professionals and parents to be important because it provides the latter with support and an outlet. The narratives of the parents revealed what they considered to be the necessary content and characteristics of such communication. The content parents primarily desire is information about their children and their situation in the placement facility. They valued communication styles characterized by verbal language that accommodated their level of understanding and that expressed an attitude of trust and empathy for them. In the same context, Ghaffar et al. [36] found that honesty, consistency and respect from professionals were highly valued by parents.

Despite the importance of communication to all participants, the results revealed clear demands for improving this aspect of the reunification process. Parents request more regular follow-ups, including more personal contact, meetings, home visits and guidance.

"My child has a learning disability of $38 \%$, and I just found out now, when he is seven, that a report published five years ago indicates that my son has a disability." (Mother)

The professionals recognize that some information does not reach the parent and that it is necessary to conduct more direct work with the families. Milani [34] and Munro [35] found that the interaction between the family and the professional is a key factor in successful reunification, emphasizing the importance of communication based on mutual trust and not on unbalanced power relations.

Notably, differences were found in families' communication with the two specialized professional roles: family educators (professionals who conduct home visits and work directly with parents and children) and technical staff (administration professionals who perform the diagnosis, develop the work plan and perform the follow-up). Although the professionals claim that the families' relationship with the technical staff is crucial for reunification, the quality and quantity of their communication with the educators is usually better than that with the technical staff. The families report that the technical staff seems to have a more distant relationship with them, and they seem to be stricter and less flexible than the educators:

"I think I felt better with the center's educators. Yes, the technical woman came around, and she is a lovely woman, but my doubts, my headaches, my problems, all this has been addressed by the educators from the center and not the technical staff." (Mother)

During the transition phase of the reunification process, specific emotions, identified through research, begin to appear, including stress, pressure, nerves, pain, suffering, depression, fear, feelings 
of loneliness, aggression, impotence, lack of calm, insecurity, frustration or feelings of guilt. Prior to reunification, parents may experience desperation caused by the length of the placement, anxiety to finally recover their children, disappointment if the planned dates fall through, and anxiety about the lack of information. Parents also experience low self-esteem due to feelings of inadequacy, fear about the return of their children, and a sense of being overwhelmed by their responsibilities. As explained by Jiménez et al. [37], parents experience a range of feelings from joy to fear as they anticipate reunification. Content analysis confirms the ambivalence and contradictory feelings parents experience immediately prior to their child's return.

The results indicate the importance of acquiring abilities that allow family members to adapt to the difficulties accompanying reunification. Parents not only need the abilities necessary to resume their roles, but they must also adapt to the children's developmental stage and to the changes they underwent during placement. These two aspects must be prepared for during the transition phase. Parents should assume that the children have grown, that they are in a new developmental stage, and that their needs are therefore different. Participants stress the importance of having personal knowledge of family members and coming to terms with each family member's personal and developmental changes. This result is consistent with the literature [38] and is exemplified in the following quotation from a teenager:

"She still sees me as a little girl; when I was placed in a center, she obviously did not

follow the stage of 'now she goes to the park', 'now she is trying her first cigarette', 'now she is drinking her first alcoholic drink'; she did not go through these steps from...from little girl to teenager and an adult." (Teenager)

Parents must assume that new attitudes and routines have become part of their child's life. The adaptation of parental responses to their child's new lifestyle is an essential part of preparing for the child's return home, as stated by the following teenager:

"You are in a center, and you have your schedule. Now, you come home; all of a sudden, in a week, you are no longer in the center, so you do not go to sleep at nine-thirty; you are with your mother, who has never been with you, so you start saying: OK Mom, please let me go to sleep later..." [Teenager].

\subsection{Formal and Informal Support}

Formal support and informal support are two additional variables that facilitate family reunification [51]. The families themselves identify both as essential during the reunification process. Content analysis corroborates the importance of social support and differentiates between the contributions of formal support from specialized childcare services and the informal support of social services.

The results indicate that the support provided by the specialized social services of the Child Protection Service makes two primary contributions. Parents use these services to know what changes they should make and how to make them. Parents also state that support from professionals allows them to express their feelings and feel reassured. This finding confirms the results of 
Lietz et al. [40], who observed that formal support was a key factor in making and maintaining the changes necessary for successful reunification.

However, the quantity and quality of this support is questionable; participating families desire more dedication from support professionals and require more interaction with their children, family therapy, and parenting training:

"More visits, more home visits; I want them to say 'look, this should be like this, this should be taken in this way, this has to go'...” (Mother)

The professionals claim that they need more resources for their specialized work. The lack of experience in and resources for providing biological family support in Spain is reflected in the professionals' discourse:

"For addictions, child therapy and this type of thing, we do have resources, but the issue of the family, family therapy, parenting and these things: this is where we go wrong." (Professional)

Of the formal resources available outside the protection system, the one that is most sought after and appreciated by parents is psychological help. In fact, some believe that without professional psychological help, they would not have been able to follow through with the reunification process. Biehal [47] and Connell et al. [52] demonstrate that professionals must anticipate the recurrence of risk patterns and behaviors after families have been reunited. Therefore, support and follow-ups after reunification are essential to preventing the repetition of the events that led to the separation.

Finally, parents require different types of help from the formal help network, e.g., help in managing professional life alongside personal life, economic support, personal help and daily childcare. These resources are necessary to resolve serious difficulties, as explained by one mother:

"Economic support, associations or a place where they could be cared for so that you can go back to work." (Mother)

In addition to the importance of formal support received from protective institutions and services, the informal support received by family members and through social networks is also important [53,54]. According to Simard [55], this support is essential to achieving satisfactory reunification. Maluccio and Ainsworth [56] found that weak social and community support is an obstacle to family reunification. The results of this study confirm the results in the literature that most parents undergoing the reunification processes have little informal support $[42,43]$. Both the professionals and parents confirm this. One father states:

"I was alone, I have no family, I am alone, I was and am alone because, if I had a family, I would not have reached this situation.” (Father)

Those who report that they received informal support primarily received it from their spouse (considered a crucial supporter by married participants), family members (grandmothers, siblings, sisters-in-law, etc.) or friends. Few parents mention other types of informal support (e.g., religious groups and communication technology). The literature indicates that this informal support is important and that families with informal support networks obtain better qualitative results during 
the reunification process [41]. Therefore, many authors recommend that professionals work with families to identify and maximize their informal support resources [42,43].

\section{Conclusions}

This study represents the perspectives of all those involved in the reunification process. The combined perspective of parents, children and professionals contributes to a better understanding of the phenomenon and reaffirms the existence of specific educational needs during the transition phase of reunification. This study identifies further significant relevant needs and increases their specificity.

Prior research has emphasized the importance of understanding the reasons behind and the process of family reunification. This research indicates that parents desire more transparency about the needs and welfare of their children during the transition phase. Although parents gradually come to understand the reasons behind the separation and reunification, they are largely unaware of the improvement in the child's situation.

This research also indicates the clear need to develop strategies to help parents adapt to several significant changes, particularly developmental changes experienced by their children during the placement and changes in their routines and habits. Schofield et al. [57] and Thomas et al. [49] found that parental optimism, adaptability, flexibility, trust, security and autonomy were important reunification factors for their sons and daughters. They also observed that the adaptability of fathers and mothers, their openness to change, flexibility and the acquisition of trust, security and autonomy were necessary to overcome possible problems. This study identifies the areas that require further adaptation during the transition phase.

Finally, it is important to emphasize that one of the limitations in the study has been the small contribution of child participation. More recent policies and norms regarding childhood have moved significantly toward recognizing the right to participation of those involved in matters that concern them. This new view also includes research processes and child protection. Working from this perspective, children's voices have been collected in the proposed methodology for examining processes of family reunification. However, it can be seen in the content analysis that children have difficulty speaking about their experience, reporting little data regarding the information requested of them. This may be in part due to the scant tradition in our context of promoting experiments with child participation or investigative tools. Future investigations should find strategies that allow for greater expression for children and adolescents.

This study also contributes to the literature by revealing parents' desire to receive more formal support through the specialized network. The results indicate the necessity of meeting the specific needs that arise during the reunification process by providing specific support for families. These findings have important practical implications and underscore the practices that support family reunification and that can be incorporated into training programs. Both the results of this study and the literature reviewed lead to the conclusion that "providing adaptation and empowerment tools and strategies to parents and children for their return home" is fundamental in a training program for families. This general goal can be broken down into three specific objectives: (a) objectively planning, with the participation of all family members, the necessary adjustments for reconstructing the family unit and the return home; (b) being realistic about the changes undergone by providing 
reinforcement for all family members who consider themselves part of the family unit; and (c) understanding the characteristics of the reunification process.

To meet specific needs through training, the specific challenges of each stage mentioned by parents, professionals and children, in addition to parenting skills, must be addressed. The results of this study call for an approach that considers child welfare its primary discourse and objective.

\section{Acknowledgments}

This study was developed by the Research Group in Social-Educational Child Intervention (GRISIJ) and was financed by the Spanish Ministry of Science and Innovation (EDU2011-00144-C02-01), the Department of Universities, Research and Information Society of the Government of Catalonia (2009SGR 1392), the University of Barcelona and the University of Lleida.

\section{Author Contributions}

M. Àngels Balsells is the director researcher of the study, and Crescencia Pastor is the co-director. M. Àngels Balsells, Crescencia Pastor, Pere Amorós, Ainoa Mateos, Carmen Ponce and Alicia Navajas participated in the study design, carried out analyses, interpreted the data and wrote the manuscript.

\section{Conflicts of Interest}

The authors declare no conflict of interest.

\section{References}

1. Dirección General de Servicios para la Familia y la Infancia. Boletín de Datos Estadísticos de Medidas de Protección a la Infancia (Datos 2012). Madrid: Ministerio de Salud y Política Social, 2014.

2. Jesús Palacios, and Jesús Jiménez. "Kinship Foster Care: Protection or Risk?” Adoption \& Fostering 33 (2009): 64-75.

3. Mónica López, and Jorge F. del Valle. "The Waiting Children: Pathways (and Future) of Children in Long-Term Residential Care.” British Journal of Social Work 7 (2013): 1-17.

4. Boletín Oficial del Estado. Ley 1/1996, de 15 de enero, de Protección Jurídica del Menor, de modificación parcial del Código Civil y de la Ley de Enjuiciamiento Civil. Madrid: Ministerio de la Presidencia, 1996, pp. 1225-38. Available online: https://www.boe.es/boe/dias /1996/01/17/pdfs/A01225-01238.pdf (accessed on 23 February 2014).

5. Jesús Palacios, and Pere Amorós. "Recent Changes in Adoption and Fostering in Spain." British Journal of Social Work 36 (2006): 921-35.

6. Committee on the Rights of the Child. Examen de los Informes Presentados por los Estados Partes en Virtud del Artículo 44 de la Convención: Observaciones Finales: España. Ginebra: Naciones Unidas, 2010. 
7. Jorge F. del Valle, Mónica López, Carme Montserrat, and Amaia Bravo. "Twenty years of foster care in Spain: Profiles, patterns and outcomes." Children and Youth Services Review 31 (2009): 847-53.

8. Child Welfare Information Gateway. Family Reunification: What the Evidence Shows. Washington: Department of Health and Human Services Administration for Children and Families Administration on Children, Youth and Families Children's Bureau, 2011.

9. M. Àngels Balsells, Nuria Fuentes-Peláez, Ainoa Mateos, Maribel Mateos, and Verónica Violant, "Innovación socioeducativa para el apoyo de adolescentes en situación de acogimiento familiar." Educar 45 (2010): 133-44.

10. Mary Ann Cole, and Sandra L. Caron. "Exploring Factors which Lead to Successful Reunification in Domestic Violence Cases: Interviews with Caseworkers." Journal of Family Violence 25 (2010): 297-310.

11. M. Àngels Balsells, Pere Amorós, Nuria Fuentes-Peláez, and Ainoa Mateos. "Needs Analysis for a Parental Guidance Program for Biological Family: Spain's Current Situation.” Revista de Cercetare si Interventie Sociala 34 (2011): 21-37.

12. M. Àngels Balsells, Crescencia Pastor, M. Cruz Molina, Nuria Fuentes-Peláez, Eduard Vaquero, and Anna Mundet. "Child welfare and successful reunification understanding of the family difficulties during the socio-educative process." Revista de Cercetare si Interventie Sociala 42 (2013): 228-47.

13. Juan Carlos Martin-Quintana, M. Luisa Máiquez, M. José Rodrigo, Sonia Byrne, Beatriz Rodríguez, and Guacimara Rodríguez. "Programas de Educación Parental." Intervención Psicosocial 18 (2009): 121-33.

14. M. José Rodrigo, M. Luisa Máiquez, Juan Carlos Martín-Quintana, and Sonia Byrne. Preservación Familiar: Un Enfoque Positivo Para la Intervención con Familias. Madrid: Pirámide, 2008.

15. Pere Amorós, M. José Rodrigo, M. Àngels Balsells, Nuria Fuentes-Peláez, Ainoa Mateos, Crescencia Pastor, Sonia Byrne, Juan Carlos Martin-Quintana, and Mónica Guerra. Aprender Juntos, Crecer en Familia. Barcelona: Obra Social "La Caixa", 2011.

16. Pere Amorós, Nuria Fuentes-Peláez, Eva Kñallinsky, and Juan Carlos Martin-Quintana. "La formation et les recherches en éducation familiare en Espagne." In Les formations et Les Recherches en Éducation Familiare. Etat des Lieux en Europe et au Quebec. Edited by Enzo Catarsi and Jean-Pierre Pourtois. Paris: Harmatan, 2011, pp. 120-32.

17. Pere Amorós, Jesús Palacios, Núria Fuentes-Peláez, M. Esperanza León, and Alicia Mesas. Programa de Formación de Familias Acogedoras de Urgencia-Diagnóstico. Barcelona: Fundació "La Caixa", 2002.

18. M. Àngels Basells. Orientaciones Para Promover Acciones Socioeducativas con Familias en Situación de Riesgo Social. Barcelona: Praxis, 2007. Available online: http://www.guiasensenanzasmedias.es/pdf/fp/2_2_5.pdf (accessed on 7 February 2014).

19. Pere Amorós, M. Àngels Balsells, Montserrat Buisan, Sonia Byrne, and Nuria Fuentes-Peláez. "Implementation and evaluation of the Learning Together, Growing in Family Programme: The impact on the families." Revista de cercetare si Interventie Sociala 42 (2013): 120-44. 
20. Jim Wade, Nina Biehal, Nicola Farrelly, and Ian Sinclair. Caring for Abused and Neglected Children: Making the Right Decisions for Reunification or Long-Term Care. London: Jessica Kingsley Publishers, 2011.

21. Pere Amorós, and Jesús Palacios. El Acogimiento Familiar. Madrid: Alianza Editorial, 2004.

22. Dante Cicchetti, and Michael Lynch. "Toward an ecological/transactional model of community violence and child maltreatment: Consequences for children's development." Psychiatry Interpersonal and Biological Processes 56 (1993): 96-118.

23. Urie Bronfembrener. La Ecología del Desarrollo Humano. Barcelona: Paidós, 1987.

24. Cynthia A. Lietz, and Margaret Strength. "Stories of Successful Reunification: A Narrative Study of Family Resilience in Child Welfare." Families in Society: The Journal of Contemporary Social Services 2 (2011): 203-10.

25. Department of Health. Framework for the Assessment of Children in Need and their Families. London: The Stationery Office, 2000. Available online: https://www.the-stationery-office. co.uk/doh/ facn/facn.htm (accessed on 25 February 2014).

26. Amaia Bravo, and Jorge F. del Valle. Intervención Socioeducativa en Acogimiento Residencial. Cantabria: Gobierno de Cantabria, 2009.

27. Pere Amorós, Jesús Palacios, Nuria Fuentes-Peláez, M. Esperanza León, and Alicia Mesas. Familias Canguro. Una Experiencia de Protección a la Infancia. Barcelona: Fundación "La Caixa", 2003.

28. Jorge F. del Valle, and Jesús Fuertes. El Acogimiento Residencial en la Protección a la Infancia Madrid: Pirámide, 2007.

29. Roger Bullock, Michael Little, and Spencer Millham. Going Home: The Return of Children Separated from Their Families. Londres: Dartmuth, 1993, p. 263.

30. Jorge F. del Valle, Amaia Bravo, and Mónica López. "El acogimiento familiar en España: Implantación y retos actuales.” Papeles del Psicólogo 1 (2009): 33-41.

31. Richard P. Barth, Elizabeth C. Weigensberg, Philip A. Fisher, Becky Fetrow, and Rebecca L. Green. "Reentry of elementary aged children following reunification from foster care." Children and Youth Services Review 30 (2008): 353-64.

32. Kate Wilson, and Ian Sinclair. "Contact in foster care: Some dilemmas and opportunities." In Contact in Adoption and Permanent Foster Care. Edited by Elsbeth Neil and David Howe. London: British Association for Adoption and Fostering, 2004, pp. 165-83.

33. Elaine Farmer, and Dinithi Wijedasa. "The Reunification of Looked After Children with Their Parents: What Contributes to Return Stability?” British Journal of Social Work 43 (2013): 1611-29.

34. Paola Milani. Il Lavoro con le Famiglie: Relazione. Biennale Sulla Condizione Dell'infanzia e Dell'adolescenza in Italia. Firenze: Istituto degli Innocenti di Firenze, 2012.

35. Eileen Munro. The Munro Review of Child Protection: Final Report. London: The Stationery Office, 2011.

36. Wendy Ghaffar, Martin Manby, and Tracey Race. "Exploring the Experiences of Parents and Carers whose Children Have Been Subject to Child Protection Plans." British Journal of Social Work 42 (2012): 887-905. 
37. Jesús M. Jiménez Morago, Rocío Martínez, and Estefanía Mata. Guía Para Trabajar la Historia de Vida con Niños y Niñas, Acogimiento Familiar y Residencial. Sevilla: Junta de Andalucía, Consejería para la Igualdad and Bienestar Social, 2010.

38. Trudy Festinger. "Going Home and Returning to Foster Care." Children and Youth Services Review 5 (1996): 383-402.

39. Urie Bronfenbrenner. "Ecology of the family as a context for human development: Research perspectives." Developmental Psychology 22 (1986): 723-42.

40. Cynthia A. Lietz, Jeffrey R Lacasse, and Joanne Cacciatore. "Social Support in Family Reunification: A Qualitive Study." Journal of Social Work 1 (2011): 3-20.

41. M. José Rodrigo, Juan Carlos Martín, M. Luisa Máiquez, and Guacimara Rodríguez. "Informal and formal supports and maternal child-rearing practices in at-risk and non at-risk psychosocial contexts." Children and Youth Service Review 29 (2007): 329-47.

42. Jill D. Berrick, Edward Cohen, and Elizabeth Anthony. "Partnering with parents: Promising approaches to improve reunification outcomes for children in foster care." Journal of Family Strengths 11 (2011): 1-14. Available online: http://digitalcommons.library.tmc.edu/jfs/vol11/ iss $1 / 14 /$ ?utm_source=digitalcommons.library.tmc.edu\%2Fjfs $\% 2$ Fvol1 1\%2Fiss $1 \% 2 \mathrm{~F} 14 \& u t m$ medium=PDF\&utm_campaign=PDFCoverPages (accessed on 23 February 2014).

43. Amanda B. Nickerson, Sarah A. Colby, Jennifer L. Brooks, Jennifer M. Rickert, and Frank J. Salamone. "Transitioning youth from residential treatment to the community: A preliminary investigation." Child \& Youth Care Forum 36 (2007): 73-86.

44. Bethany R. Lee, Charlotte L. Bright, Deborah V. Svoboda, Sunday Fakunmoju, and Richard P. Barth. "Outcomes of group care for youth: A review of comparative studies." Research on Social Work Practice 21 (2011): 177-89.

45. M. José Rodrigo, M. Luisa Máiquez, and Juan Carlos Martín. Parentalidad Positiva Y Políticas Locales de Apoyo a las Familias: Orientaciones Para Favorecer el Ejercicio de las Responsabilidades Parentales Desde las Corporaciones Locales. Madrid: Federación Española de Municipios and Provincias, Ministerio de Sanidad y Política Social, 2010.

46. M. José Rodrigo, and Sonia Byrne. "Social Support and Personal Agency in At-Risk Mothers." Psychosocial Intervention 20 (2011): 13-24.

47. Nina Biehal. "Care or Control? Foster Care for Young People on Remand." Child \& Family Social Work 12 (2007): 439-40.

48. Ingunn T. Ellingsen, David Shemmings, and Ingunn Storksen. "The concept of family among Norwegian adolescents in long-term fostercare.” Child Adolescence Social Work Journal 28 (2011): 301-18.

49. M. Thomas, David Chenot, and Barbara Reifel. "A resilience-based model of reunification and reentry: Implications for out-of-home care services." Families in Society: The Journal of Contemporary Human Services 86 (2005): 235-43.

50. Kathy Lemon Osterling, and Meekyung Han. "Reunification outcomes among Mexican immigrant families in the child welfare system." Children and Youth Services Review 33 (2011): $1658-66$. 
51. Katherine Kortenkamp, Rob Geen, and Matthew Stagner. "The role of welfare and work in predicting fostercare reunification rates for children of welfare recipients." Children and Youth Services Review 26 (2004): 577-90.

52. Chirstian M. Connell, Jeffrey J. Vanderploeg, Karol H. Katz, Colleen Caron, Leon Saunders, and Jacob Kraemer. "Maltreatment following reunification: Predictors of subsequent child protective services contact after children return home." Child Abuse and Neglect 33 (2009): 218-28.

53. John Maluccio. Attrition in the Kwazulu Natal income dynamics study, 1993-1998. Washington: International Food Policy Research Institute (IFPRI), 2000.

54. Toni Terling. "The efficacy of family reunification practices: Reentry rates and correlates of reentry for abused and neglected children reunited with their families." Child Abuse and Neglect 23 (1999): 1359-79.

55. Marie-Claude Simard. "La riunificazionefamiliare di adolescenti in affidamento: Prospettive por i servizi e per la ricerca." In Conoscere. i Bisogni e Valutare L'efficacia Degli Interventi Bambini e Famiglie. Edited by Cinzia Canali, Tiziano Vecchiato and James K. Wittaker. Padova: Fondazione Emanuela Zancan, 2008, pp. 74-76.

56. Anthony N. Maluccio, and Frank Ainsworth. "Drug use by parents: A challenge for family reunification practice." Children and Youth Services Review 25 (2003): 511-13.

57. Gillian Schofield, Mary Beek, Emma Ward, and Clive Sellick. Care Planning for Permanence in Foster Care. Norwich: University of East Anglia, 2011. 


\title{
Assessment in Kinship Foster Care: A New Tool to Evaluate the Strengths and Weaknesses
}

\author{
Nuria Fuentes-Peláez, Pere Amorós, Crescencia Pastor, María Cruz Molina \\ and Maribel Mateo
}

\begin{abstract}
Placement in kinship family has existed informally throughout time. There are many countries in which kinship family care is the most common measure used for child protection. However, it is a subject of continuous debate. One of the major issues is that kinship foster care is relied upon without carrying out an evaluation study of the family; often the child is placed directly with grandparents and uncles simply because they are direct family. This article presents an assessment tool to evaluate extended families in order to ensure the welfare of the child. The tool was created as a result of the cooperative research of 126 professionals from seven regions of Spain. The tool can identify the strengths and weaknesses of families by considering six factors: personal characteristics, the coverage of basic needs, collaboration with professionals, the family structure and dynamics, the relationship between family, child, and biological family, and, finally, the attitude towards the placement. The assessment tool is innovative and introduces the opportunity to consider the skills of the kinship foster care family, the needs of support, and which families are unfit to take care of the child. To conclude, the tool tries to overcome one of the principal disadvantages of kinship foster care: the lack of knowledge about the kinship family.
\end{abstract}

Reprinted from Soc. Sci. Cite as: Fuentes-Peláez, N.; Amorós, P.; Pastor, C.; Molina, M.C. Mateo, M. Assessment in Kinship Foster Care: A New Tool to Evaluate the Strengths and Weaknesses. Soc. Sci. 2015, 4, 1-17.

\section{Introduction}

In Spain, extended family foster care has existed informally throughout history, but it did not become systematized and generalized until the Law 21/1987 [1]. Its development since then has been considerable.

As in other countries, kinship foster care in Spain has not been exempt from polemic. Many professionals perceived it to be an insufficient option, particularly because of the beliefs that mistreatment was transmitted intergenerationally [2-4] and that these are poorer quality foster care placements, as well as worries that kinship caregivers may collude with parents outside of the case planning [5]. Beginning with these ideas, foster care practice until the early 1990s in Spain attempted to avoid kinship foster care with grandparents [2].

The difficulties of recruiting unrelated foster families for foster care, the recognition that kinship foster care responds to a philosophy of family preservation, the benefits in terms of stability, the challenge of providing social support for families with difficulties, and the problem of economic compensation tied to other types of foster care are some of the factors that have led to a change in attitude, policy, and practice in some countries. This shift has allowed kinship foster care to spread and 
become more prevalent [6]. The increase has occurred in countries as diverse as Holland [7], Spain [8,9], Sweden [10], the United Kingdom [11,12], and the United States [13].

Testa and Slack [14] explain that demand for kinship foster care has developed because of the reduction in unrelated families willing to assume the challenge of foster care, combined with poor economic support and low quality of formal support [15]. Kinship care has evolved differently within different countries [5], but the situation of children is similar in all countries: many children and youths are in unprotected situations as a result of various parental crises, such as drug consumption and economic problems [16], or due to other circumstances such as imprisonment, mental illness, and health problems [17].

\subsection{The Current Situation}

The expansion of kinship foster care in Spain is due to a series of factors [2]. Legal factors, such as Law 21/1987 [1], which upgraded family foster care in general, and later Law 1/1995 [18] for legal protection of minors, in which Article 46.2 gives priority to family members when deciding on the best type of foster care for the minor, have contributed to the expansion. The recent bill for the child protection law approved in 2014 clearly explains in Article 20 the nature of foster care in unrelated families versus kinship foster care, how a foster family is evaluated (whichever type it may be) before formalizing foster care, and that family foster care should be given priority over residential care (Article 21). Among other rights of the child, the Law 1/1998 [19] on Rights and Attention to Minors states: "It should be prioritized that the minor remain in his or her own environment, such that foster care is created within the extended family unless this is not advisable in light of the minor's interests." This right has been considered by regional autonomous laws that determine the preference for kinship foster care over foster care in unrelated families (i.e., Law 14/2010, Rights and Opportunities of Childhood and Adolescence). Conversely, keeping the child in contact with his or her family, in a context where he or she is recognized and loved and in which maintaining contact with parents is easier, is considered to be a good practice. Moreover, the growth of kinship foster care in our country is also due to the regularization of de facto scenarios that are desired by extended families and save time and money for public administration. Therefore, it is not surprising that kinship foster care has become the first choice to consider when a child must be separated from his or her parents.

However, kinship foster care is not always a possibility (there must be family members interested in taking care of the children) or desirable (kinship foster care cannot be a second-rate foster arrangement in which families lack sufficient standards). The child protection system should be aware that this type of foster care also needs support, resources, and professional interventions similar to any other type of foster care. Thus, fostering family members should be prepared to provide safety to ensure wellbeing, afford all types of necessities, and manage contact and bonds with the biological family.

The study conducted by Del Valle and Bravo [20] in Spain reveals that $85 \%$ of family foster care is performed among extended family, which suggests much higher levels than in other countries. Regarding the characteristics of this foster care, Del Valle, López, Montserrat, and Bravo [21] find that $60 \%$ lived with grandparents, $32 \%$ with aunts and uncles, and the rest with cousins or brothers 
and sisters. The maternal line dominated in all cases (62\%). A total of $36 \%$ of foster care was performed by only one person, usually the grandmother. The median age of foster caregivers in this study was 52.2 years. A total of $59 \%$ of the foster caregivers had completed basic education, and $25 \%$ had no education. Finally, these foster caregivers had an average of 6.6 years as foster parents, and $34 \%$ had two or more foster children.

As we can see, kinship foster care should not be seen as the easiest type of foster care but as the most difficult for a variety of reasons. The characteristics found in Spain [9,20-22] are common to kinship caregivers from other countries: kinship foster caregivers tend to be older, have lower levels of education, more health problems, and low incomes [23]. Foster caregivers state that they feel stress about carrying out their role (raising their grandchildren as if they were their parents, facing everything related to biological parenthood) and receive less support than unrelated foster caregivers [24,25]. Despite all these characteristics, research shows that children living with kin have longer placements, experience fewer unplanned outcomes, and do not suffer from stunted emotional development compared to other children; in fact, their development can be even more positive [4].

On the other hand, in general, Spanish kinship foster caregivers have not completed a process of evaluation and training applied to candidates for foster care in unrelated families [19]. However, in recent years, a substantial increase in awareness has occurred among politicians and professionals of the need to introduce an assessment and training plan [2,26,27].

\subsection{Assessment in Foster Care}

There is unanimous agreement that assessment and foster caregiver training plans are key elements in ensuring quality fostering $[5,26,28]$. While it is established practice to evaluate non kin foster caregivers and there are clear guidelines, until recently there have been a lack of uniform guidelines in terms of service provision to kinship families [26]. The fact that progress is being made in the research of kinship foster care has enabled the development of specific guidelines for kin caregivers [5].

Due to these facts, specific assessment for kinship caregivers is a plausible option [29]. Reviewing research helps us identify the elements that are associated with disruptions in foster care and therefore could be explored in an assessment of kinship foster caregivers.

It is even less surprising that a large portion of the best or worst experiences in the adaptation process and later development of the foster care are due to the characteristics of the fostering family. Research offers some indicators for understanding which family characteristics and processes are most associated with continuity and which are more associated with the unforeseen interruption of foster care. The characteristics of foster caregivers that have demonstrated a relationship with good foster care development are relatively varied, which once again demonstrates that, as in other cases, there is not one magical element whose presence alone guarantees continuity and satisfaction regarding foster care. Moreover, factors associated with a good foster care process appear to repeat from some foster care modalities to others. For example, those modalities described by Redding, Fried, and Britner [30] regarding specialized family foster care are very similar to those described for foster care in general [31,32]. Here we review this evidence and try to explore whether these occur in kinship foster care. 
Among the characteristics of foster caregivers that should be mentioned are those related to motivation for foster care. The motivation to give affection to boys or girls who need it is associated with greater satisfaction with foster care [33], which in turn most likely means that the needs of the fostered child are considered an essential factor in foster caregiver decision making. This does not mean that they cannot also think about themselves and eventually about their children as beneficiaries of the experience but that the primary goal of foster care is seen in relation to everything that it will mean in the lives of the fostered children. It is important for foster caregivers to have clear roles and expectations. According to Triseliotis [32], foster caregivers should have clear motivations in order to understand that their role in fostering situations is not to simply substitute for the foster children's parents but to collaborate with them and help them in caring for their children and preparing for their eventual return. All of these expectations become very important starting points for the proper development of family foster care. Exploring the motivations behind kinship care is imperative. Research tells us that kinship foster caregivers usually initiate the demand for care when they encounter neglect or abuse and many of them step in to help in informal foster care situations [5]. However, although the motivation for fostering is a response to a crisis situation, known or reported by the protection system, it is still important to investigate the kinship family that will take the child to avoid, as Berridge said [31], children being placed with a kinship family based solely on availability.

Some sociodemographic factors appear to be significant in the proper development of foster care, whereas others appear irrelevant. For example, the age of foster caregivers is relevant; ages between 45 and 55 are associated with positive results [34]. This fact naturally does not mean that someone above or below these ages cannot foster successfully but that the proper development of foster care is somewhat less probable for young parents (who may be focused on raising their own children, for example) and for older parents (sometimes perhaps lacking the energy necessary to face the changing needs of the children). However, the educational level of the foster caregivers does not appear to be related to better or worse development of foster care, as there are positive and negative cases with parents at different cultural and professional levels [35]. What does appear to have an effect is the warmth of the foster caregivers, their orientation toward the child, and the positive interaction between both [36]. This is relevant in terms of the general characteristics of kinship foster care; most of them are grandparents and with low levels of education. Amongst other reasons, these factors justify many of the professionals' concerns regarding poor quality of kin placements [5]. By contrast, studies focusing on kinship foster care, e.g., the Farmer and Moyers study [37], show that this did not appear to have adverse effects on child emotional and behavioral development.

One of the traits of foster care families that has an important role in the fostering process is the presence of children in the fostering family. Logically, foster care is best in the simplest circumstances: when the children of foster caregivers no longer live in the family home or when those that live there are not of the same sex, and above all, not the same age as the fostered children [35]. As Triseliotis [32] has noted, when the behavior of the fostered children threatens the stability and the safety of the foster parents' children, the risk of interrupting foster care is high. In this type of situation, foster caregivers prioritize the needs of their own children. This aspect is not very developed in kinship care due to the characteristics of caregivers: most of them are grandparents. Research indicates the need to consider how crowded the home is and how this impacts on the children [5]. 
Another key trait established by research is inclusive attitudes regarding the child's biological family [28,38] and good cooperation between the biological family, foster family, agency, and authorities [35]. This finding is unsurprising if one considers the positive role that visits and contact between the foster child and his or her parents have on the wellbeing of the child and the quality of foster care [39]. Foster caregivers are in a privileged position to mediate between the child and his or her parents when preparing visits and in comments made later. Therefore, foster caregivers with positive attitudes and greater respect and consideration for the biological family will act as facilitators and help the foster children. Research stresses that children experience more problematic contact in kin homes than in non-kin due to different factors (same geographical area, less professional support, etc.) [5,39].

The task of fostering is very complex, and foster caregivers may not be intuitively prepared to adequately face the many highly complex demands they will encounter from the beginning of the experience. Conversely, the children arrive at foster care after having passed through a series of very negative personal experiences that have left them with behaviors, feelings, expectations, and ways to relate that affect their interactions with foster caregivers. To be able to adequately respond to a foster child's needs and problems, caregivers must combine a set of basic skills and receive training in how to interpret child behavior, educate and stimulate their foster children, and interact with services and professionals. This is clear when professionals talk about non-related foster care and should be the same for kinship caregivers. Specifically, kinship caregivers express their needs to manage behaviors and improve parental skills $[9,28,40]$.

With this in mind, we need to consider the level of support that foster caregivers receive from the child protection system. All research reviewed agrees that the level of support received during foster care is a key factor, strongly associated with the quality of foster care development [41,42]. The reality is that kinship foster placements receive less support $[9,24,25]$. However, it is not just a matter of the support services offered and availability (which is clearly insufficient and comparatively scarce); it is also about the kinship families' attitude towards support received and their efforts to collaborate with support offered [5,9].

\section{Objectives}

This study is based on the requirements of Child Protection Services professionals, whose objective is to create a useful and consensual instrument for evaluating extended families that are candidates for kinship foster care. The assessment tool attempts to unite criteria, to serve as a template for gathering information on aspects of family history and the current situation in the foster candidate family, and to determine whether it is necessary to develop a support plan for them.

\section{Methodology}

This project is part of an action-research study for transforming educational and social intervention in kinship foster care. It attempts to provide professionals with a new perspective on the topic and a new evaluation tool for foster families. 
From a methodological perspective, a cooperative action-research model has been chosen [43] in which university professors and child protection professionals become active research subjects. Cooperative research is one form of action research. In cooperative research, everyone involved makes a joint effort to create knowledge that contributes to the generation of new ideas.

Action-research is a participatory and democratic process aimed at developing practical knowledge in search of human objectives. It attempts to combine action, reflection, theory, and practice through participation with others in the search for practical solutions for improving individual and community wellbeing [44].

The procedure used established theories to develop an initial survey to act as an evaluation process for foster candidate families for kinship foster care. The survey was developed collaboratively by a team of 12 experts at the University of Barcelona and Seville based on their previous research used in an evaluation of foster care in Spain [45] and the literature review. The survey was composed of 33 items with which information was gathered and has open questions to add clarification to the items proposed in the survey.

This survey was evaluated by child protection professionals, who placed each item into one of the following categories:

- essential (in other words, totally essential to gather this information immediately for evaluating the case);

- necessary (allowing improvement of the knowledge of the case and helping to refine and better understand prior situations);

- convenient (aspects that could be necessary in some cases but that are usually not used as basic criteria), and

- irrelevant (information that could provide information but is irrelevant to decision-making).

The survey was built in three phases. First phase: the professionals answered the survey individually and later contrasted their opinions with those of their colleagues in the professional teams. Every team filled one overall survey as a consensus of the team discussion. This survey was sent to the research team. Later, the professional teams received feedback from the research team and added any other aspects to specify the items and evaluate them. In the second phase, they discussed the convenience of the survey structure and sent suggestions to the research team. Thirdly, the research team incorporated the contributions to build the final assessment tool and made an evaluation of the new contributions.

\section{Sample}

The sample that participated in the study included 126 child protection professionals grouped in 20 teams belonging to seven Autonomous Communities of the Spanish state which represent the southern, central, and northern regions of Spain: Andalusia, Baleares, Castilla León, Castilla La Mancha, Catalonia, La Rioja, and Valencia.

The professionals included psychologists (49\%), social workers (36\%), and social pedagogues (9\%), and the rest held social education and other degrees. All of them belonged to specialized Child Protection services. 


\section{Results}

The 20 professional teams agreed to maintain 32 items of the initial survey. The criterion of acceptance or inclusion of the different items was that they be seen by more than $50 \%$ of groups as essential, necessary, and convenient. There was only one item that more than $50 \%$ of the professionals deemed irrelevant and it was removed (item 29). Regarding the initial proposal and from a perspective of cooperative investigation, some groups suggested incorporating aspects to specify the items. These aspects went through an evaluation by the groups and those that met the above acceptance criteria for $50 \%$ of the professionals were added. There was only one aspect that more than $50 \%$ of the professionals deemed irrelevant and it was removed (religious intervention at item 13).

The analysis and frequency distribution for contributions from each of the groups regarding the evaluation of the items that could comprise the extended family evaluation instrument for the first phase can be seen in Table 1 .

Table 1. Level of consensus among child protection professionals during the first phase of instrument development.

\begin{tabular}{|c|c|c|c|c|c|}
\hline & Essential & Necessary & Convenient & Irrelevant & $\mathrm{NC} *$ \\
\hline \multicolumn{6}{|l|}{ A. Personal and Sociodemographic DATA } \\
\hline \multicolumn{6}{|l|}{ 1. Composition of nuclear family } \\
\hline Age of foster caregiver (male) & $46.15 \%$ & $38.46 \%$ & $7.69 \%$ & $7.69 \%$ & 0 \\
\hline Age of foster caregiver (female) & $46.15 \%$ & $38.46 \%$ & $7.69 \%$ & 0 & $7.7 \%$ \\
\hline Living in the same home with extended family & $15.38 \%$ & $38.46 \%$ & $30.77 \%$ & $7.69 \%$ & $7.7 \%$ \\
\hline $\begin{array}{l}\text { Relationship between parents and foster } \\
\text { family }\end{array}$ & $69.23 \%$ & $15.38 \%$ & $15.38 \%$ & 0 & 0 \\
\hline $\begin{array}{l}\text { 2. Current address and phone contacts } \\
\text { 3. Working situation of family members }\end{array}$ & $92.31 \%$ & 0 & 0 & $7.69 \%$ & 0 \\
\hline Current situation of caregiver (male) & $7.69 \%$ & $69.23 \%$ & $23.08 \%$ & 0 & 0 \\
\hline Current situation of caregiver (female) & $7.69 \%$ & $69.23 \%$ & $23.08 \%$ & 0 & 0 \\
\hline 4. Nuclear family economic sufficiency & $30.77 \%$ & $61.54 \%$ & $7.69 \%$ & 0 & 0 \\
\hline 5. Time adults have to dedicate to the family & $61.54 \%$ & $30.77 \%$ & $7.69 \%$ & 0 & 0 \\
\hline \multicolumn{6}{|c|}{ 7. Housing characteristics } \\
\hline \multicolumn{5}{|l|}{ 8. Characteristics of housing environment } & 0 \\
\hline Type of neighborhood & 0 & $15.38 \%$ & $61.54 \%$ & $23.08 \%$ & 0 \\
\hline Existence of nearby dangers & $7.69 \%$ & 0 & $61.54 \%$ & $23.08 \%$ & $7.69 \%$ \\
\hline \multicolumn{6}{|l|}{ B. Conflict Situations } \\
\hline \multicolumn{6}{|l|}{ 9. Coverage of foster child's basic needs } \\
\hline Food & $61.54 \%$ & $30.77 \%$ & 0 & 0 & $7.69 \%$ \\
\hline Clothing & $53.85 \%$ & $30.77 \%$ & $7.69 \%$ & 0 & $7.69 \%$ \\
\hline Health & $61.54 \%$ & $30.77 \%$ & 0 & 0 & $7.69 \%$ \\
\hline Education & $53.85 \%$ & $30.77 \%$ & $7.69 \%$ & 0 & $7.69 \%$ \\
\hline $\begin{array}{l}\text { C. Family Structure and Dynamics } \\
\text { 10. Relationship among extended } \\
\text { family members }\end{array}$ & & & & & \\
\hline
\end{tabular}


Table 1. Cont.

\begin{tabular}{|c|c|c|c|c|c|}
\hline & Essential & Necessary & Convenient & Irrelevant & $\mathrm{NC} *$ \\
\hline $\begin{array}{l}\text { Relationship between the members of } \\
\text { the couple }\end{array}$ & $76.92 \%$ & $15.38 \%$ & $7.69 \%$ & 0 & 0 \\
\hline \multicolumn{6}{|l|}{$\begin{array}{l}\text { 11. Coping styles for problems } \\
\text { and difficulty }\end{array}$} \\
\hline $\begin{array}{l}\text { Coping with difficulties and flexibility of } \\
\text { caregiver (male) }\end{array}$ & $30.77 \%$ & $30.77 \%$ & $30.77 \%$ & 0 & $7.69 \%$ \\
\hline $\begin{array}{l}\text { Coping with difficulties and flexibility of } \\
\text { caregiver (female) }\end{array}$ & $30.77 \%$ & $30.77 \%$ & $30.77 \%$ & 0 & $7.69 \%$ \\
\hline \multicolumn{6}{|l|}{ 12. History or record of abuse } \\
\hline Existence or record of abuse in family & $46.15 \%$ & $23.08 \%$ & $7.69 \%$ & 0 & $23.08 \%$ \\
\hline Abusing persons & $61.54 \%$ & $7.69 \%$ & $7.69 \%$ & 0 & $23.08 \%$ \\
\hline Abused persons & $46.15 \%$ & $23.08 \%$ & $7.69 \%$ & 0 & $23.08 \%$ \\
\hline Existence or record of personal abuse & $61.54 \%$ & 0 & 0 & 0 & $39.06 \%$ \\
\hline Existence or record of physical abuse & $61.54 \%$ & $7.69 \%$ & $7.69 \%$ & 0 & $23.08 \%$ \\
\hline Existence or record of emotional abuse & $61.54 \%$ & $7.69 \%$ & $7.69 \%$ & 0 & $23.08 \%$ \\
\hline $\begin{array}{l}\text { Existence or record of negligence } \\
\text { or abandonment }\end{array}$ & $61.54 \%$ & $7.69 \%$ & $7.69 \%$ & 0 & $23.08 \%$ \\
\hline Existence or record of sexual abuse & $61.54 \%$ & $7.69 \%$ & $7.69 \%$ & 0 & $23.08 \%$ \\
\hline Existence or record of labor exploitation & $53.85 \%$ & $15.38 \%$ & $7.69 \%$ & 0 & $23.08 \%$ \\
\hline Existence or record of corruption & $61.54 \%$ & $7.69 \%$ & $7.69 \%$ & 0 & $23.08 \%$ \\
\hline Existence or record of poverty & $46.15 \%$ & $23.08 \%$ & $7.69 \%$ & 0 & $23.08 \%$ \\
\hline $\begin{array}{l}\text { Existence or record of } \\
\text { institutional mistreatment }\end{array}$ & $46.15 \%$ & $15.38 \%$ & 0 & $15.38 \%$ & $23.08 \%$ \\
\hline \multicolumn{6}{|l|}{ 13. Intervention type } \\
\hline Social & $15.38 \%$ & $53.85 \%$ & $30.77 \%$ & 0 & 0 \\
\hline Educational & $7.69 \%$ & $61.54 \%$ & $15.38 \%$ & $7.69 \%$ & $7,7 \%$ \\
\hline Health & $38.46 \%$ & $46.15 \%$ & $15.38 \%$ & 0 & 0 \\
\hline Police/Legal & $53.85 \%$ & $38.46 \%$ & $7.69 \%$ & 0 & 0 \\
\hline Community Social Services & $15.38 \%$ & $46.15 \%$ & $15.38 \%$ & $7.69 \%$ & $15.40 \%$ \\
\hline Child Services or similar & $69.23 \%$ & $30.77 \%$ & 0 & 0 & 0 \\
\hline Specialized Centers & $69.23 \%$ & $30.77 \%$ & 0 & 0 & 0 \\
\hline Health Centers & $7.69 \%$ & $53.85 \%$ & $15.38 \%$ & $7.69 \%$ & $15.39 \%$ \\
\hline Educational Centers & $7.69 \%$ & $53.85 \%$ & $7.69 \%$ & $23.08 \%$ & $7.69 \%$ \\
\hline Religious Centers & 0 & $15.38 \%$ & $15.38 \%$ & $46.15 \%$ & $23.09 \%$ \\
\hline \multicolumn{6}{|l|}{$\begin{array}{l}\text { 14. Relationships between other members of } \\
\text { extended family }\end{array}$} \\
\hline $\begin{array}{l}\text { Relationship between members of extended } \\
\text { family living under the same roof }\end{array}$ & $46.15 \%$ & $46.15 \%$ & $7.69 \%$ & 0 & 0 \\
\hline \multicolumn{6}{|l|}{ 15. Capacity for organization and cohabitation. } \\
\hline \multicolumn{6}{|l|}{ Administration of resources } \\
\hline Administration of financial resources & $15.38 \%$ & $53.85 \%$ & $23.08 \%$ & 0 & $7.69 \%$ \\
\hline Stability in organizing daily life & $30.77 \%$ & $53.85 \%$ & $15.38 \%$ & 0 & 0 \\
\hline
\end{tabular}


Table 1. Cont.

\begin{tabular}{|c|c|c|c|c|c|}
\hline & Essential & Necessary & Convenient & Irrelevant & $\mathrm{NC} *$ \\
\hline \multicolumn{6}{|l|}{ 16. Parenting style of foster caregivers } \\
\hline Parenting style of caregiver (female) & $30.77 \%$ & $46.15 \%$ & $23.08 \%$ & 0 & 0 \\
\hline Parenting style of caregiver (male) & $30.77 \%$ & $46.15 \%$ & $23.08 \%$ & 0 & 0 \\
\hline \multicolumn{6}{|c|}{$\begin{array}{l}\text { 17. Communication ability between caregivers } \\
\text { and children }\end{array}$} \\
\hline $\begin{array}{l}\text { Ability to express affection, } \\
\text { caregiver (female) }\end{array}$ & $15.38 \%$ & $69.23 \%$ & $15.38 \%$ & 0 & 0 \\
\hline $\begin{array}{l}\text { Ability to express affection, } \\
\text { caregiver (male) }\end{array}$ & $15.38 \%$ & $69.23 \%$ & $15.38 \%$ & 0 & 0 \\
\hline Ability to communicate, caregiver (male) & $15.38 \%$ & $53.85 \%$ & $30.77 \%$ & 0 & 0 \\
\hline Ability to communicate, caregiver (female) & $15.38 \%$ & $53.85 \%$ & $30.77 \%$ & 0 & 0 \\
\hline \multicolumn{6}{|l|}{$\begin{array}{l}\text { 18. Ability of caregivers to set rules and have } \\
\text { them followed }\end{array}$} \\
\hline $\begin{array}{l}\text { Ability to set rules and have them followed, } \\
\text { caregiver (female) }\end{array}$ & $7.69 \%$ & $76.92 \%$ & $15.38 \%$ & 0 & 0 \\
\hline $\begin{array}{l}\text { Ability to set rules and have them followed, } \\
\text { caregiver (male) }\end{array}$ & $7.69 \%$ & $76.92 \%$ & $15.38 \%$ & 0 & 0 \\
\hline \multicolumn{6}{|l|}{$\begin{array}{l}\text { 19. Relationship with other family members } \\
\text { and child's parents }\end{array}$} \\
\hline Relationship with extended family & $7.69 \%$ & $38.46 \%$ & $46.15 \%$ & 0 & $7.69 \%$ \\
\hline 20. Relationship with surrounding people & 0 & $23.05 \%$ & $53.85 \%$ & $23.08 \%$ & 0 \\
\hline $\begin{array}{l}\text { 21. Level of social integration: community } \\
\text { participation }\end{array}$ & 0 & $15.38 \%$ & $53.85 \%$ & $23.08 \%$ & $7.69 \%$ \\
\hline \multicolumn{6}{|l|}{ D. Relationship between the Foster Family } \\
\hline \multicolumn{6}{|l|}{ And the Child's Parents } \\
\hline \multicolumn{6}{|l|}{ 22. Relationship level } \\
\hline $\begin{array}{l}\text { Affectionate relationship between foster } \\
\text { family and child's parents }\end{array}$ & $76.92 \%$ & $23.08 \%$ & 0 & 0 & 0 \\
\hline $\begin{array}{l}\text { Contact between foster family and } \\
\text { child's parents }\end{array}$ & $61.54 \%$ & $30.77 \%$ & $7.69 \%$ & 0 & 0 \\
\hline $\begin{array}{l}\text { Acceptance of situation involving } \\
\text { child's parents }\end{array}$ & $84.62 \%$ & 0 & $15.38 \%$ & 0 & 0 \\
\hline $\begin{array}{l}\text { Degree of collaboration between foster family } \\
\text { and child's parents }\end{array}$ & $69.23 \%$ & $15.38 \%$ & $15.38 \%$ & 0 & 0 \\
\hline \multicolumn{6}{|l|}{ E. Motivation, Attitude, and Knowledge of } \\
\hline \multicolumn{6}{|l|}{ Foster Care } \\
\hline \multicolumn{6}{|l|}{ 23. Family's knowledge regarding what } \\
\hline \multicolumn{6}{|l|}{$\begin{array}{l}\text { kinship foster care is and its types } \\
\text { and characteristics }\end{array}$} \\
\hline $\begin{array}{l}\text { Level of knowledge about the type of } \\
\text { foster care }\end{array}$ & $53.85 \%$ & $15.36 \%$ & $7.69 \%$ & $23.08 \%$ & 0 \\
\hline
\end{tabular}


Table 1. Cont.

\begin{tabular}{|c|c|c|c|c|c|}
\hline & Essential & Necessary & Convenient & Irrelevant & $\mathrm{NC} *$ \\
\hline \multicolumn{6}{|l|}{$\begin{array}{l}\text { 24. Aspects of foster care that the family } \\
\text { finds easy/has trouble assuming }\end{array}$} \\
\hline $\begin{array}{l}\text { Aspects of foster care seen as easy } \\
\text { to assume }\end{array}$ & $23.08 \%$ & $46.15 \%$ & $30.77 \%$ & 0 & 0 \\
\hline $\begin{array}{l}\text { Aspects of foster care seen as difficult } \\
\text { to assume }\end{array}$ & $46.15 \%$ & $36.45 \%$ & $15.38 \%$ & 0 & $2 \%$ \\
\hline \multicolumn{6}{|l|}{ F. Expectations for the Child and foster care } \\
\hline \multicolumn{6}{|l|}{ 25. Attitude toward possible parent visits } \\
\hline $\begin{array}{l}\text { Attitude of foster family toward visits or } \\
\text { contact with the child's parents }\end{array}$ & $84.62 \%$ & $15.38 \%$ & 0 & 0 & 0 \\
\hline \multicolumn{6}{|l|}{$\begin{array}{l}\text { 26. Attitude toward the departure of the } \\
\text { child from the home }\end{array}$} \\
\hline Attitude toward the farewell & $61.54 \%$ & $23.08 \%$ & $15.38 \%$ & 0 & 0 \\
\hline \multicolumn{6}{|l|}{$\begin{array}{l}\text { 27. Agreement of the couple } \\
\text { toward fostering }\end{array}$} \\
\hline $\begin{array}{l}\text { Level of agreement among the couple } \\
\text { toward fostering }\end{array}$ & $84.62 \%$ & $7.69 \%$ & $7.69 \%$ & 0 & 0 \\
\hline \multicolumn{6}{|l|}{ G. Collaboration with the Program } \\
\hline \multicolumn{6}{|l|}{ Technical Team } \\
\hline $\begin{array}{l}\text { 28. Acceptance by foster family of contact } \\
\text { with other foster families }\end{array}$ & 0 & 0 & $53.85 \%$ & $46.15 \%$ & 0 \\
\hline $\begin{array}{l}\text { 29. Level of acceptance regarding } \\
\text { participation in group follow-up }\end{array}$ & 0 & 0 & $30.77 \%$ & $46.15 \%$ & $23.08 \%$ \\
\hline \multicolumn{6}{|l|}{ H. Final Synthesis } \\
\hline 30. Global characterization of foster family & $69.23 \%$ & $23.08 \%$ & $7.69 \%$ & 0 & 0 \\
\hline $\begin{array}{l}\text { 31. Weak and critical points, limitations, } \\
\text { and disorders }\end{array}$ & $76.92 \%$ & $23.08 \%$ & 0 & 0 & 0 \\
\hline $\begin{array}{l}\text { 32. Positive aspects to highlight } \\
\text { 33. Possibility of improving with help }\end{array}$ & $53.85 \%$ & $30.77 \%$ & $15.38 \%$ & 0 & 0 \\
\hline Possibilities of improving & $53.85 \%$ & $23.08 \%$ & $23.07 \%$ & 0 & 0 \\
\hline Type of help or necessary interventions & $46.15 \%$ & $23.08 \%$ & $23.08 \%$ & 0 & $7.69 \%$ \\
\hline
\end{tabular}

* NC: Not considered by the $\%$ teams.

For the second phase, each professional team received the updated tool (including the added parts and omitting other parts) for a second qualitative review. In this review, the groups commented on the structure and composition of different sections, and the composition of questions. A content analysis was conducted using these comments, reorganizing the sections in a new order and using the results to create a definitive version of the instrument for evaluating extended families for kinship foster care.

As a result, we defined the evaluation instrument as a questionnaire comprising six sections of open questions to gather a wide range of information about families and their current personal, social, and familial situations, among other aspects, to be complemented by professionals working 
on the case. At the end, it included a section for synthesizing information for decision-making and the creation, if appropriate, of an individualized support plan for the case. The sections are as follows:

1. Personal and sociodemographic data: this section gathers information about the personal and sociodemographic characteristics of the families, such as age, the people living together, the composition of the nuclear family, the location of the home, and the level of economic sufficiency necessary to cover the child's basic needs.

2. Coverage of basic needs: this refers to the competence of foster caregivers to meet the basic needs of the fostered child (food, clothing, health, education, housing, affection, security); the availability of the caregivers to attend to the children's needs, whether due to health conditions or the time they have to offer the foster child; and finally, their integration into the community and the support (formal and informal) they have to help them respond to these needs.

3. Collaboration with foster program professional teams: this aspect concerns the level of acceptance by foster families toward professional follow-up, the attitude toward fostering, level of acceptance of support from the professional team, and, very importantly, the opinions and attitude of the child toward the fostering option.

4. Family structure and dynamics: information gathered in this section refers to relationships between foster family members; histories that could affect current relationships, communication, conflict resolution, and daily life organizing competencies; and the skills to establish rules and limits and have them followed. These aspects refer to parenting (educational) styles of each one of the caregivers.

5. Relationship between the foster family, the child, and the biological family: this section gathers information referring to the existing affective bonds, attitudes, predispositions, and expectations between the child and the foster family (parents and other family members). This also refers to the contact and relationships with their parents, other siblings, and other extended family members. It includes the acceptance of the situation facing the parents and siblings and the degree of collaboration offered by the foster family to the biological parents and family.

6. Motivation and attitude toward fostering: this section attempts to discern the motivation, attitudes, and knowledge of the foster caregivers regarding fostering as well as the aspects of fostering that the family sees as difficult and what position it takes regarding these.

7. Final synthesis: a global evaluation of the kinship foster family and considering the possibility of improving its situation with some type of adjustment or intervention.

Along with the instrument, a panel of favorable, risk, and high risk indicators for foster care are included. The professionals also agreed upon these levels of strength and risk. Next, Box 1 includes an example of how these indicators are used regarding the coverage of the basic need for food. 
Box 1. Example of favorable, risk, and high risk indicators for the item evaluating the coverage of needs.

\begin{tabular}{l}
\hline 2. Coverage of Basic Necessities \\
\hline Basic need: Food \\
Favorable Indicators: \\
Each member of the nuclear family has adequate organization to respond to the basic need for \\
food: varied and balanced food, appropriate for age and personal necessity. \\
The meal is a meeting time for foster family members, facilitating their communication. \\
Indicators of Risk: \\
The coverage of the basic need for food is insufficient and/or inadequate: poorly balanced and \\
unvaried food but caregivers are conscious of this difficulty and seek and accept help. \\
High Risk Indicators: \\
Inadequate and insufficient coverage of food needs: child only eats one time per day, record of \\
eating disorders in the family or physical evidence of poor nutrition: emaciated. \\
Caregivers are unaware of disorganization, and if they are aware, do not seek help to improve \\
the situation.
\end{tabular}

Finally, Box 2 indicates how the final evaluation of the foster family is made regarding its adequacy for providing foster care and in developing a support plan to help caregivers face fostering risks more securely.

Box 2. Synthesis of evaluation instrument for kinship foster care families.

\begin{tabular}{|l|}
\hline Final Synthesis \\
\hline Global characterization of the fostering family (evaluating the adequacy or non-adequacy \\
of the family) \\
Primary weak or critical points, disorders, or limitations (clear indicators of high risk and \\
non-adequacy for fostering) \\
Positive aspects and notable strengths \\
Possibility of improving the situation with support (specify if support is for the child or \\
for the fostering family) \\
Factors making change possible \\
Type of support or necessary intervention \\
\hline
\end{tabular}

\section{Conclusions}

Research demonstrates that kinship foster care has benefits for children in terms of stability, continuity, and the child's emotional development, despite its complexities such as the management of the relationship with parents, an environment of lower quality, and a greater need for support. Results indicate that despite everything, children in kinship foster care do as well or better than children who are in non-kinship foster care. It seems that the explanation lies in the stability and preexisting emotional relationships prior to placement [5].

Starting from this premise, from the perspective of the rights of children and in response to the norms that regulate the placement, the first option when there is a situation of neglect or abuse is to consider the extended family as a possible foster care option. However, the protection system is 
required to find out how capable this family is in meeting the child's needs and providing a safe environment. As already indicated at the beginning of this article, kinship foster caregivers in Spain until now have not typically completed the same evaluation and training process as unrelated foster families [22]. Fortunately, there has been interest in recent years on the part of public administrators and professionals in applying a rigorous methodology to the entire process of kinship foster care $[2,27]$. But, do the extended families need different assessment instruments than the unrelated foster families? A review of the literature and the results of our research reveal that there are certain features that must be incorporated when exploring the suitability of extended families and therefore we need specific assessment tools. Adequate assessment helps to guarantee that candidate families for these kinship foster care placements meet the necessary conditions for facilitating a process of family and social integration for the foster child.

The research presented has resulted in an action plan agreed upon between professionals in the child protection services. Having a structured and consensual plan helps professionals systematically gather data and use a common language for exchanging information based on the relevant findings.

However, collecting information from the most relevant areas is not enough. The discussion of evaluating the kinship foster families has pivoted on the standards that are to be measured. Do they have to be the same as those for non-kinship foster families? Have they been more lax? What is clear is that minimum standards must be met by both kin and non-kin [5,26]. However, it is not enough to know if they are adequate or not. Evaluating kinship caregivers requires a comprehensive assessment to establish the extent to which the family is appropriate and, more importantly, to help the family become aware of their competencies while recognizing their weaknesses. Therefore, using the action plan presented here helps obtain an indication of the level of risk. Thus, it can be shown that difficulties can be overcome if certain families have support. Conversely, studies may reveal a high risk family which is unable to carry out its protective functions and cannot be recommended for placement. When the assessment process is observed from this perspective it shows that evaluation is more than an end, it is a process of empowering families framed in the continuum of intervention. It is not only evaluation, it is also intervention.

At this moment, this assessment tool is being used by professionals in different Autonomous Communities. We do not have systematic data regarding its application, but initial evaluations by professionals let us predict that the tool's objectives, including systematic gathering of data, organization of information, and the use of an agreed-upon language among professionals and thus a rigorous evaluation of the foster family allowing for decision-making, can be met satisfactorily. The challenge now is to perform a systematic evaluation of the assessment tool. Furthermore, in the future it will be interesting to further explore the essential elements that contribute to the stability and quality of care in kinship foster care, and know whether they are those that obtained the greatest degree of consensus among professionals (shown in bold in Table 1).

Evidently, the methodological challenges of kinship foster care cannot be limited to the evaluation phase. One of the contributions of this study beyond those mentioned above is the possibility of identifying the support that the family needs to design a specific plan for each foster care arrangement. The need for support for kinship foster care, whether through training programs or some other type of support or supervision, has been demonstrated in several studies. These families 
desire support, and its provision represents a guarantee of the proper development and stability of foster care [23,45-47]. If the results are good despite the difficulties, we can ensure they are as successful as possible by providing suitable support. Perhaps a change of professional mentality is necessary: kinship foster care would not be seen as a second-rate foster care option, and would obtain resources commensurate with the complex demands of the tasks undertaken.

\section{Acknowledgments}

This article has been produced with the financial support of the Association for Research in Education Sciences (ARCE) of the University of Barcelona.

\section{Author Contributions}

All contributors were members of the research team and the two first authors of the article were responsible to lead the design and content of the paper. All contributors reviewed and made suggestions to the final document.

\section{Conflicts of Interest}

The authors declare no conflict of interest.

\section{References}

1. Modificación de determinados artículos del Código Civil y de la Ley de Enjuiciamiento Civil en materia de adopción Act of 21/1987, de 11 de noviembre, Pub. L. No.34158-34162 BOE no. 275 (1987).

2. Pere Amorós, and Jesús Palacios. Acogimiento Familiar. Madrid: Alianza Editorial, 2004.

3. Jay Belsky. "Child Maltreatment: An Ecological Integration." American Psychologist 35 (1980): 320-35.

4. Alfred Kadushin. Child Welfare Services. New York: Macmillan, 1980.

5. Lydia Brown, and Robin Sen. "Improving Outcomes for Looked after Children: A Critical Analysis of Kinship Care.” Practice 26 (2014): 161-80.

6. Jill Duerr Berrick, Richard P. Barth, and Barbara Needell. "A comparison of kinship foster homes and foster family homes: Implications for kinship foster care as family preservation." Children and Youth Services Review 16 (1994): 33-64.

7. Riet Portengen, and Bart van der Neut. "Foster care in family and social networks." In Journey through Fostering. Edited by Deirdre Mc Teigue. Dublin: Irish Foster Care Association, 1995, pp. 170-79.

8. Jorge Del Valle, Mónica López, Carme Montserrat, and Amaia Bravo. "Twenty Years of Foster Care in Spain: Profiles, Patterns and Outcomes." Children and Youth Services Review 31 (2009): 847-53. 
9. Nuria Fuentes-Peláez, Pere Amorós, Mà̀ngels Balsells, Josefina Fernández, and Eduard Vaquero. "The social support in kinship foster care: A way to enhance resilience." Child and Family Social Work, 2014. doi:10.1111/cfs.12182. Available online: http://onlinelibrary. wiley.com/doi/10.1111/cfs.12182/abstract (accessed on 11 December 2014).

10. Eva Bergerhed. "Kinship and network care in Sweden." In Foster Children in a Changing World. Edited by Hans Thelen. Berlin: Arbeitskreis Zur Forderung Von Pflegekindern E.V., 1995, pp. 236-43.

11. Mathew Colton, and Margaret Willians. "The nature of foster care: International trends." Adoption and Fostering 21 (1997): 44-49.

12. June Thoburn. Child Placement: Principles and Practice. Aldershot: Wildwood House, 1994.

13. Rob Geen. "Foster children placed with relatives often receive less government help." In New Federalism. Issues and Options for States. Washington: The Urban Institute, 2003, pp. 1-5.

14. Mark F. Testa, and Kristen Shook Slack. "The Gift of Kinship Foster Care." Children and Youth Services Review 24 (2002): 79-108

15. Rebecca Hegar, and Maria Scannapieco. Kinship Foster Care: Policy, Practice and Research. Oxford: University Press, 1999.

16. Peter J. Pecora, James K. Whittaker, Anthony N. Maluccio, and Richard P. Barth. Child Welfare Challenge, 2nd ed. New York: Aldine de Gruyter, 2000.

17. Roberta G. Sands, and Robin S. Goldberg-Glen. "Factors associated with stress among grandparents raising their grandchildren.” Family Relations 49 (2000): 97-105.

18. Protección del Menor Act 1/1995, de 27 de enero, Pub.L. No.1154-1164 BOPA 9-II-95 (1995).

19. Derechos y Atención al Menor Act 1/1998, de 20 de abril, Pub. L. No.20689-20702 BOE no. 150 (1998).

20. Jorge Del Valle, and Amaia Bravo. Situación Actual del Acogimiento de Menores en España. Oviedo: Universidad de Oviedo, 2003.

21. Jorge Del Valle, Mónica López, Carme Montserrat, and Amaia Bravo. El acogimiento Familiar en España. Una Evaluación de Resultados. Madrid: Ministerio de Educación, Política Social y Deporte, 2010.

22. Jorge Del Valle, Elvira Álvarez-Baz, and Amaia Bravo. "Acogimiento en familia extensa. Perfil descriptivo y evaluación de necesidades en una muestra del principado de Asturias." Bienestar y Protección Infantil 1 (2002): 33-55.

23. Rob Geen. "The evolution of kinship care policy and practice." Children, Families, and Foster Care 14 (2004): 130-49.

24. Susan J. Kelley, Deborah M. Whitley, and Peter E. Campos. "Grandmothers raising grandchildren: Results of an intervention to improve health outcomes." Journal of Nursing Scholarship 42 (2010): 379-86.

25. Youjung Lee, and Lisa V. Blitz. "We're GRAND: A qualitative design and development pilot project addressing the needs and strengths of grandparents raising grandchildren." Child and Family Social Work, 2014. doi:10.1111/cfs.12153. Available online: http://onlinelibrary.wiley. com/doi/10.1111/cfs.12153/abstract (accessed on 11 December 2014). 
26. Peter Gibbs, and Ulrich Müller. "Kinship Foster Care Moving to the Mainstream: Controversy, policy, and outcomes." Adoption Quarterly 4 (2000): 57-87.

27. Joan Llosada, Joan Mayoral, and Paquita Planas. "La meva família m'acull.” Available online: http://benestar.gencat.cat/web/.content/01departament/08publicacions/coleccions/papers_accio _social/num_26/papers_26_familia_acull.pdf (accessed on 30 September 2014).

28. Pere Amorós, Nuria Fuentes-Peláez, Maria Cruz Molina, and Crescencia Pastor. "Le soutien aux familles et aux adolescents bénéficiant d'une action centrée sur la promotion de la résilience." Bulletin de Psychologie 63 (2010): 429-33.

29. Bob Broad, and Alison Skinner. Relative Benefits: Placing Children in Kinship Care. London: British Association for Adoption and Fostering, 2005.

30. Richard E. Redding, Carrie Fried, and Preston A. Britner. "Predictors of placement outcomes in treatment foster care: Implications for foster parent selection and service delivery." Journal of Child and Family Studies 9 (2000): 425-47.

31. David Berridge. Foster Care. A Research Review. London: Her Majesty’s Stationery Office, 1997.

32. John Triseliotis. "Foster Care Outcomes: A Review of Key Research Findings." Adoption and Fostering 13 (1989): 5-17.

33. Ramona Denby, Nolan Rindfleisch, and Gerald Bean. "Predictors of foster parents' satisfaction and intent to continue to foster." Child Abuse and Neglect 23 (1999): 287-303.

34. Herbert W. Sanderson, and Margaret Crawley. "Characteristics of successful family-care parents." American Journal of Mental Deficiency 86 (1982): 519-25.

35. Mirjam Oosterman, Carlo Schuengel, Wim N. Slot, Ruud A. R. Bullens, and Theo A. H. Doreleijers. "Disruptions in foster care: A review and meta-analysis." Children and Youth Services Review 29 (2007): 53-76.

36. Ian Sinclair, and Kate Wilson. "Matches and mismatches: The contribution of carers and children to the success of foster placements." British Journal of Social Work 33 (2003): 871-84.

37. Elaine Farmer, and Sue Moyers. Kinship Care: Fostering Effective Family and Friends Placements. London: Jessica Kingsley, 2008.

38. David Berridge, and Hedy Cleaver. Foster Home Breakdown. Oxford: Blackwell, 1987.

39. Spencer Millham, Roger Bullock, Kenneth Hosie, and Martin Haak. Lost in Care: The Problems of Maintaining Links between Children in Care and Their Families. Aldershot: Gower, 1986.

40. Toni Terling-Watt. "Permanency in Kinship Care: An Exploration of Disruption Rates and Factors Associated with Placement Disruption." Children and Youth Services Review 23 (2001): 111-26.

41. Pere Amorós, Jesús Palacios, Nuria Fuentes, Esperanza León, and Alicia Mesas. "Familias Canguro. Una experiencia de protección a la infancia." Available online: http://obrasocial. lacaixa.es/deployedfiles/obrasocial/Estaticos/pdf/Estudios_sociales/vol13_es.pdf (accessed on 30 September 2014).

42. Child Welfare League of America. Kinship Care: A Natural Bridge. Washington: Child Welfare League of America, 1994. 
43. Margarita Bartolomé, and Maria Teresa Anguera. La Investigación Cooperativa: Vía Para la Innovación en la Universidad. Barcelona: PPU, 1990.

44. Peter Reason, and Hilary Bradbury. Handbook of Action Research. London: Sage, 2001.

45. Nuria Fuentes-Peláez, Pere Amorós, Mà̀ngels Balsells, Ainoa Mateos, and Verónica Violant. "The biological family from the perspective of kinship fostered adolescents." Psicothema 25 (2013): 349-54.

46. Ching-Hsuan Lin. "Evaluating Services for Kinship Care Families: A Systematic Review." Children and Youth Services Review 36 (2014): 32-41.

47. Kerry A. Littlewood, Anne L. Strozier, and Danielle Whittington. "Kin as Teachers: An early childhood education and support intervention for kinship families." Children and Youth Services Review 38 (2014): 1-9. 


\title{
Improving Pathways to Assessment and Care for Infants of Substance Abusing Mothers: Are We Getting It Right?
}

\author{
Joanna Alexander, Shanti Raman, Terence Yoong and Belinda Mawhinney
}

\begin{abstract}
There is documented correlation between parental substance abuse, child maltreatment, and poor outcomes. In two health districts in Sydney, Australia (Site A and B), specialised clinics were established to provide comprehensive assessments for infants of substance abusing mothers (ISAM). We aimed to determine whether there was a difference in outcomes between infants who attended clinic versus those who did not; and to identify differences in the pathways to care between sites. We analysed child protection reports and available health markers of all ISAM referrals in 2011. We held stakeholder meetings with services involved with ISAM in both sites; to describe service components; strengths and weaknesses of pathways. Fifty-five per cent $(11 / 20)$ attended clinic in Site A; 80\% (25/31) in Site B. Three-quarters of ISAM had at least one referral to child welfare; child protection service involvement was more common in those who attended. Immunisation status was lower than the national Australian average; approximately half were seen by community nursing services. Gaps in services, lack of database, and differences in pathways between sites were identified. Attending clinics correlates with child protection service involvement and may afford health protection. Transparent communication, service integration, and shared learning can improve outcomes for this vulnerable group.
\end{abstract}

Reprinted from Soc. Sci. Cite as: Alexander, J.; Raman, S.; Yoong, T.; Mawhinney, B. Improving Pathways to Assessment and Care for Infants of Substance Abusing Mothers: Are We Getting It Right? Soc. Sci. 2015, 4, 192-204.

\section{Introduction}

There is an extensive body of literature worldwide confirming the strong correlation between substance abuse and child maltreatment [1-3]. In keeping with the international research, a recent Australian study reported that maternal disclosure of substance use is greatly associated with increased rates of involvement with statutory child protection services [4]. Infants of substance abusing mothers (ISAM) have poorer developmental, behavioural, and social outcomes [3]. A number of variables coexist and influence the environment of the child in this situation, including parental effectiveness in providing nurturing care [5-8]. Engagement with health services can be a protective factor in maintaining child safety and child wellbeing, suggesting that child health engagement decreases child protection risk [9].

In two metropolitan health regions in Sydney, Australia (Site A and Site B), there has been more than a decade long program to support mothers with substance abuse concerns through the pregnancy and early childhood period. A multi-disciplinary service with Drug Health, Community Health, Maternity services and Social Work involvement was set up and operated in these health districts from 2005 onwards. In 2007, a specialised multi-disciplinary paediatric clinic, was set up to provide 
comprehensive paediatric, developmental and psychosocial assessment and support for ISAM. Referral to the clinic was primarily through perinatal identification of at risk families, by antenatal health care workers (social workers, drug health workers, neonatologists) and also through identification of children with child protection concerns, usually referred by Community Services (CS), the statutory child protection service. A previous audit looking at the cohort of patients attending this clinic suggested that despite early identification, uptake of services was not occurring in the early years of life [10]. Anecdotal reports suggested that there was poor attendance at clinic, across both sites, in spite of many reminders by administrative staff and others. There were also concerns voiced by clinicians that ISAM were falling through gaps within the system, and that various components of the hospital and community services working with this client group were not communicating effectively. Poor clinic attendance and ongoing child safety and wellbeing concerns prompted a clinical service improvement project to improve the quality of service provided to ISAM. Our overall aim was to examine the quality of the Community Paediatric service provided with a view to improving the quality of the service. Specifically we wanted:

(1) To determine if there was a difference in health and social outcomes, between those who attended clinic and those who did not;

(2) To determine if existing pathways translate to proactive engagement with the health service;

(3) To identify differences in robustness of pathways and functioning of services between the two sites;

(4) To identify service improvement recommendations that are feasible, appropriate and relevant to ISAM, their families and the stakeholders who provide health services to this vulnerable group.

\section{Methods}

This quality improvement project was a mixed methods study utilising both quantitative and qualitative components.

\subsection{Quantitative Component-Audit}

A retrospective analysis of the electronic medical record was undertaken of all referrals to clinic between January and December 2011, for both Site A and B. Available data was collected for ISAM who attended clinic as well as for those who did not attend. Clinical measures including immunisation status, attendance at hospital emergency departments (ED) and engagement with the child and family health nurse (CFHN); and child protection reports to Community Services (Risk of Significant Harm over the statutory threshold) and child wellbeing referrals to the Child Wellbeing Unit (Risk of Harm under statutory threshold) were determined. Immunisation status was identified as an important measure of a good health outcome and was verified using the Australian Childhood Immunisation Register (ACIR). Health service encounters including ED visits and CFHN encounters were sought using information available on the electronic medical record (CERNER) for the two local health districts covered by site A and B. Both child protection reports and wellbeing referral data was drawn from the Child Wellbeing Unit database, "Well Net", which contains information 
about children from across the state of NSW, enabling access to child protection reports even if the families have moved out of area. As this was an audit of the baby's medical records, information about what services the mother received for her substance abuse or mental health issues was not available.

\subsection{Qualitative Component-Stake Holder Engagement and Interviews}

A meeting of key stakeholders from Site A and B was held prior to and after the quantitative component (audit) of the study. Stakeholder membership included representatives from Drug Health, Community Health, Maternity, Neonatal, Paediatric services and Social Work services. Both individual and group interviews were conducted. The purpose of the Stake holder meetings was to describe the service components of the perinatal drug health and maternity service through to Community Paediatric pathway, to identify strengths and weaknesses of the current processes, and to develop and enhance those pathways following the results of the audit.

\subsection{Analysis}

\subsubsection{Quantitative}

Data collected from CERNER, ACIR and Well Net was entered onto an EXCEL database. A Pearson chi-squared test for two independent samples was used to calculate the difference in proportions between the sites and between patients who attended and those that did not ( $p$ value $=2$ sided significance).

\subsubsection{Qualitative}

Information was compiled from a series of stakeholder interviews held between March 2012 and August 2012. This included personnel from Site A (12 interviewees) and Site B (10 interviewees). The information from the key stakeholder interviews was analysed using thematic content analyses.

\subsection{Ethics}

A National Ethics Application proposal was developed describing both the quantitative and qualitative methodology of the project, which gained approval, by the lead Human Research Ethics Committee at Royal Prince Alfred Hospital.

\section{Results}

\subsection{Quantitative Component-Audit}

In Site A in 2011, a total number of 56 women were seen through the drugs in pregnancy coordinated care program (DAPCC); the women were being seen through three separate centres in the local health district. Similar data was not accessible for Site B. The last available database (2008) from Site B had 101 women identified through the Perinatal and Family Drug Health Service 
(PAFDHS); a significant majority of these were cannabis smokers. A total number of 51 ISAM were referred to ISAM clinic in the two sites. There were 20 appointments made for ISAM in Site A and 31 made for those in Site B. Of the appointments made $11(11 / 20-55 \%)$ were attended at Site A, and 25 were attended at Site B $(25 / 31-80 \%)$, significant difference between attendance at two sites ( $p=0.05$ ). Mother's ages ranged from 18 to 42 years at site A with a mean of 28 years and from 20 to 41 years at site B with a mean of 30 years.

The referrals to Site A were from a variety of sources, whereas referrals to the Site B clinic came entirely from the hospital neonatology team. Mothers of ISAM disclosed using a variety of substances in their antenatal visit, and approximately $30 \%$ of the infants referred to clinic had documented evidence of Neonatal Abstinence Syndrome (NAS) (Table 1). Three-quarters of ISAM had at least one child wellbeing unit referral at the time the study was being carried out (2012). Active involvement from Community Services was more common in those who attended clinics, at both sites (Table 2). Immunisation rates across both Sites were lower than the national Australian average, for those who did and those who did not attend clinic (Table 3). Half of ISAM, at both sites, had no documented electronic medical record evidence of a child and family health nurse visit. ISAM in Site A were more likely to be taken their local hospital emergency department (ED visits) for health related concerns, as compared to Site B (Table 4). The analysis of the data contained a count of less than five cases in various subgroups; therefore results of statistical significance were interpreted with caution. Table 5 shows demographic data across both sites.

Table 1. Drug use identified at Site A and B.

\begin{tabular}{lccc}
\hline Drug Use & & $\begin{array}{c}\text { Site } \mathbf{A} \\
\boldsymbol{n}=\mathbf{2 0}(\mathbf{\%})\end{array}$ & $\begin{array}{c}\text { Site B } \\
\boldsymbol{n}=\mathbf{3 1} \mathbf{( \% )}\end{array}$ \\
\hline Drug & Methadone & $8(40)$ & $9(30)$ \\
& Illicit/Methadone/Poly drug use & $7(35)$ & $8(25)$ \\
& THC & $3(15)$ & $4(13)$ \\
& Alcohol & $1(5)$ & $4(13)$ \\
& Unknown & $1(5)$ & $3(9.5)$ \\
NAS & Amphetamine & 0 & $3(9.5)$ \\
\hline
\end{tabular}

Table 2. Child protection concerns for clinic attendees versus non-attendees.

\begin{tabular}{lcccccc}
\hline CP Concerns & & Site A & & Site B & & $p$ value \\
\hline & & Attended & DNA & Attended & DNA & \\
& & $n=11(\%)$ & $n=9(\%)$ & $n=25(\%)$ & $n=6(\%)$ & \\
\hline Risk of harm reports & 0 & $3(27)$ & $2(23)$ & $6(24)$ & $2(33)$ & 0.8 \\
& $\geq 1$ & $8(73)$ & $7(77)$ & $10(40)$ & $2(33)$ & \\
& Unknown & 0 & 0 & $9(36)$ & $2(33)$ & \\
\hline CS involvement & Active & $6(54)$ & $4(44)$ & $15(60)$ & 0 & $0.02 *$ \\
& None & $4(37)$ & $4(44)$ & $3(16)$ & $4(67)$ & \\
& Unknown & $1(9)$ & $1(12)$ & $7(24)$ & $2(33)$ & \\
\hline OOHC placement & & $4(36)$ & $1(12)$ & $8(32)$ & 0 & $0.05 *$ \\
\hline
\end{tabular}

Notes: * significant; CP: Child Protection; CS: Community Services; OOHC: out of home care. 
Table 3. Immunisation status of clinic attendees versus non-attendees.

\begin{tabular}{ccccccc}
\hline Immunisation & & Site A & \multicolumn{3}{c}{ Site B } & p value \\
\hline & & Attended & DNA & Attended & DNA & \\
& & $n=11(\%)$ & $n=9(\%)$ & $n=25(\%)$ & $n=6(\%)$ & \\
\hline Immunised & Fully & $5(45)$ & $4(44.5)$ & $17(68)$ & $2(33)$ & 0.9 \\
& Partially & $5(45)$ & $3(33.5)$ & $6(24)$ & $3(50)$ & \\
& Not & $1(10)$ & $2(22)$ & $2(8)$ & $1(17)$ & \\
\hline
\end{tabular}

Table 4. Health encounters of clinic attendees versus non-attendees.

\begin{tabular}{lccccc}
\hline Health Encounter & \multicolumn{3}{c}{ Site A } & Site B & \\
\hline & & Attended & DNA & Attended & DNA \\
& & $n=11(\%)$ & $n=9(\%)$ & $n=25(\%)$ & $n=6(\%)$ \\
\hline CFHN involvement & Any visit & $4(36.5)$ & $6(66)$ & $15(60)$ & $2(33.5)$ \\
& 0 visits & $7(63.5)$ & $3(33.5)$ & $10(40)$ & $4(66.5)$ \\
& $<10$ visits & $4(36.5)$ & $4(44.5)$ & $9(36)$ & $2(33.5)$ \\
& $>10$ visits & 0 & $2(22)$ & $6(24)$ & 0 \\
\hline ED visit & 0 & $6(54.5)$ & $3(33)$ & 0 & 0 \\
& $\geq 1$ & $5(45.5)$ & $6(66)$ & 0 & $1(16)$ \\
\hline
\end{tabular}

CFHN: Child and Family Health Nurse.

Table 5. Demographic details of clients referred to clinic.

\begin{tabular}{llcc}
\hline Demographics & & $\begin{array}{c}\text { Site A } \\
\boldsymbol{n}=\mathbf{2 0}(\mathbf{\%})\end{array}$ & $\begin{array}{c}\text { Site B } \\
\boldsymbol{n}=\mathbf{3 1}(\mathbf{\%})\end{array}$ \\
\hline Attendance & & $11(52)$ & $25(80)$ \\
\hline Cultural background & Anglo & $12(60)$ & \\
& Indigenous & $5(25)$ & \\
& Culturally/linguistically diverse & $3(15)$ & \\
\hline Referral & Social Work & $13(65)$ & Neonatal team \\
& PAFDHS & $4(20)$ & \\
& CFHN & $1(5)$ & \\
& CS & $1(5)$ & \\
& Carer & $1(5)$ & \\
\hline
\end{tabular}

\subsection{Qualitative-Information Gathered from Stakeholder Meetings}

\subsubsection{Barriers to Pathways to Care for ISAM}

\section{Issues Common to Both Sites}

- Non-disclosure of substance use in pregnancy by mothers

- Substance abusing women reluctant to engage with services

- Lack of clear mechanism to monitor ISAM progress using current health records

- Overlap of risk categories such as mental health concerns, teen mother, intimate partner violence 
- Lack of clarity of case management responsibility for the infant between health and statutory child protection services

- Children placed in foster care outside the health district are likely to be lost to follow up

- Work force issues including recruitment and retention of skilled staff

Site A

- Lack of designated senior medical clinician involvement and leadership (especially for obstetrics and neonatal services)

- Limited involvement of child protection services with families at significant risk

- Lack of health services engagement with Indigenous Medical Service in the antenatal and postnatal period

- Discontinuation of multidisciplinary health and support service involvement after delivery of baby

- Poor linkages within Community Health services

Site B

- Multiplicity of meetings with risk of multiple care plans

- Lack of use of a unified database by all teams involved with ISAM families. This makes it difficult to capture the true extent of substance abuse in pregnancy and to track ISAM progress through the health system

- Senior drug health nursing position vacant

3.2.2. Facilitators to Pathways to Care for ISAM

For both Sites

- A skilled and committed workforce with a multidisciplinary model for perinatal psychosocial assessment and care

Site A

- The presence of senior Drug Health Nurse with access to database on drug health attendees

Site B

- Engagement of and leadership from senior clinicians (e.g., Obstetric and Neonatal Services)

- Involvement of neonatal medical staff through antenatal, perinatal and postnatal periods

- Strong engagement with Indigenous Medical Service

- Ongoing connection between neonatal team and ISAM Clinic

- Perinatal Family Conferencing: an innovative program involving a multi-disciplinary health team with CS engagement for pregnant women with substance abuse who are at risk of losing their infants to alternative care 


\section{Discussion}

Infants of substance using mothers are a particularly vulnerable group in our society [1]. Psychosocial factors surrounding mothers prior and throughout pregnancy, the intrauterine environment, the perinatal period and postnatal care are all times of potential risk of harm [8]. Targeted care and support for ISAM from conception into their first few years of life is required for this group to optimise health and well-being outcomes [10]. Our study focused on examining the quality of care provided by our health service to this vulnerable group given recent anecdotal reports of poor attendance to these clinics, with the aim of improving the quality of this service. We found that there were differences in pathways and a significant difference in engagement between sites for ISAM. Analysis of audit data suggested that child protection service involvement and being in out of home care $(\mathrm{OOHC})$ appears to increase clinic attendance; we saw no evidence to suggest that attending clinic resulted in babies being placed in $\mathrm{OOHC}$. Attending clinics may decrease hospital visits and provide some health protection. Importantly this project identified both facilitators and barriers to service delivery for ISAM, and also identified health indicators that can be improved for ISAM, such as immunisation status, community nurse engagement and acute hospital visits.

In conducting this project, we discovered that the true extent of substance abuse in pregnancy was not known, particularly in Site B. Data was available for the number of mothers in Site A in 2011 who attended the perinatal drug health service (total of 56), but similar data was not readily available for Site B. The Australian 2010 National Drug Strategy Household Survey found that $12.3 \%$ of females between 20-39 years of age, had used an illicit substance in the previous year [11]. Data from the United States suggest that illicit drug use is $7.4 \%$ among pregnant women aged 18-25 years [12]. When considering the birth rate at Site A for 2011 (approximately 2500 births), rate of substance abuse identified for our study would be placed at $0.2 \%$, likely to be a gross underestimate of the actual burden of the problem, with concerns of non-disclosure of drug use by women presenting for antenatal care.

Attendance rates at ISAM clinic were significantly greater at Site B, proving that anecdotal reports were indeed true and that engagement with the clinic was better at this site. Identification of the facilitators and barriers to care between both sites highlighted the differences in pathways to care and may shed light on the possible reasoning behind the differing attendance rates. Typically this group is difficult to engage in post-natal care [7]. Nehra's study found that, in the general neonatal population, factors that significantly improved compliance included having patient contact after discharge, and also giving early intervention referral. In that study patients that were referred to follow up clinic and contacted by a fellow after discharge, were $85 \%$ more likely to attend follow up appointments [13]. The families at site B were engaged early, with all ISAM being followed up by the hospital neonatal team even if they did not develop NAS. ISAM were then referred by the neonatal fellow to ISAM clinic, where they were seen within a few weeks of discharge from the neonatal team. At Site A, following discharge from hospital, referral was made for an assessment at six months of age to the ISAM clinic. Although at Site A there was earlier engagement with nursing and general paediatric teams, communication between these teams and ISAM clinic was not integrated 
or structured as at Site B, where the community clinic occurred on site at the NICU within a few weeks of discharge from the NICU team.

Powell discusses the issue of "did not attend", reported as a marker of the quality of the interface between primary and secondary health care (in our case between hospital services and community health), an important issue when establishing engagement with health care services for families. She also discussed that patient explanation including forgetfulness, fear, anxiety and a misunderstanding of the system compound non-attendance. The issue of being "lost to follow up" as opposed to "did not attend", would also need consideration for our group, with the possibility of mothers having difficulty navigating the system, or ISAM being placed in foster care out of area. Reports from key stakeholders did suggest that families at Site A were less knowledgeable about the community paediatric service than at Site B which may have added to the lack of early post-natal engagement with this group. Interviewing the families to gauge their understanding for the need and purpose of ISAM clinic would further clarify this question. Overall non-attendance carries a significant cost in terms of health care expenditure, but more importantly can veil child maltreatment particularly in the form of neglect for vulnerable families [14].

Neonatal abstinence syndrome is a syndrome of drug withdrawal with nonspecific signs and symptoms that may appear in babies following in-utero drug exposure. The risk is greatest with opioids although other drugs such as methamphetamines have been implicated [15]. The prevalence ranges from $40 \%-60 \%$ and appears to be increasing [16-18]. Risk factors for developing NAS in ISAM include mothers with a previous mental health admission, low skill levels, Indigenous status or smoking during pregnancy [19]. Our cohort showed a prevalence of $30 \%$ for NAS, lower than reported prevalence in the literature, although our group across both sites included mothers who did not report use of opiates (37\%). We are not able to account for this lower than expected rate by omitting mothers in the non-opioid group. Interestingly 9 of the 19 infants in our cohort who had documented NAS, had no documented evidence of opiate use by their mothers on electronic medical record (alcohol, cannabis and amphetamine use reported only), highlighting the issue of non-disclosure amongst this group, and/or the limitation in the use of the current electronic medical record to document drug use during pregnancy.

With respect to child protection concerns, our study findings correlate with the existing literature as to the association of this group with child maltreatment. O'Donnell reported that NAS infants were at greater risk for having a substantiated child maltreatment allegation and entering foster care with increased risk for maltreatment associated with mothers aged $<30$ years, having socially disadvantaged backgrounds, Indigenous status, and mental health or assault related admission [19]. O'Donnell's study concluded that there was a need for well-supported programs as well as the need for sustained long-term support after birth for this vulnerable group. Three quarters of the children in our study group had at least one documented report below the statutory risk for harm, this included infants with no documented evidence of NAS, highlighting the need to not use NAS as a marker for referral to clinic. Dawe reported on the high rates of child maltreatment in families with substance abuse concerns, reiterating that drug use alone does not correlate with child maltreatment and that the adverse outcomes are intertwined with other associated socioeconomic factors. She presented an intensive home based intervention, which targets multiple domains of family functioning with results 
showing reduction in child abuse potential, highlighting the need for extensive ongoing intervention for this group [20]. A project along similar lines is the Perinatal Family Conferencing project, which commenced mid-March 2012 at Site B, using a strengths-based model of care servicing women at risk of their infant entering $\mathrm{OOHC}$ at birth. The intervention includes the integration of skills from health and community services, and is already showing positive engagement with this vulnerable group [21]. A similar service at Site A may benefit this population in their navigation of the health system.

Being involved with child protection services in our group could be seen as a protective factor with respect to health engagement, as those involved with child protection services and those in OOHC were more likely to attend clinic. However, being known to or involved with child protection services did not correlate with other health indices such as improved immunisation rates. Health outcomes for our cohort provided a mixed picture; immunisation rates were lower than national average for both attendees and non-attendees ( $c f$. NSW children aged 12-17 months, 90\% fully vaccinated: [22]. Niccol's et al., carried out a systematic view of studies reporting on child outcomes for children with substance abusing parents in integrated health programs. They concluded that current evidence supports integrated programs as having benefits for the child with improvements in child development, growth, emotional and behavioural functioning. Integrated services were defined as caring, comprehensive, centralised services, which provided a "one stop shop". This would include on site pregnancy, parenting, child related and addiction services that would offer long-term (to 18 months) treatment [23]. This is important information in moving forward to providing an improved service model for our group.

Among our group, half had no documented record on electronic medical records of a CFHN visit, indicating poor engagement with CFHN services. The importance of the role of the child and family health nurse in engaging this particular group has been well documented. CFHN staffs are in a unique position to be able to build trusting relationships, offer continuity of care and assist in accessing health care systems [7,24,25]. In relation to hospital visits, these were higher in Site A, where attendance at clinic was lower and communication between hospital and community services specific to this vulnerable group was less structured. Improving integration of services between hospital and community-based services may remove access difficulties regarding seeking of health care for this population. This may in turn result in the decreased use of the hospital emergency department in seeking treatment of health care needs, although additional evidence would be required to substantiate this hypothesis.

Overall from the findings of our study and review of the literature, an integrated system with specific engagement of CFHN would be seen as critical in moving forward to providing improvement in the quality of service delivered to this population. Communication between all teams involved in the delivery of service including Child and Family Health Nurses, maternity, drug health, neonatology, paediatrics, and community health would assist in promoting service delivery. In addition this would allow for providing a service acceptable to mothers. There is evidence to suggest that longer-term multidisciplinary programs (beyond the first year of life), are of greater benefit for this group, although there is little in the way of documentation suggesting possible avenues to "track" these infants, or which of the many teams involved might be best placed to do this. 
A unified database with access to all teams involved in care for this group could allow for monitoring of progress. Longer term follow up of ISAM is required to determine how protective attending clinics are for these children, and in addition further evaluation of parental views of the current system would be highly beneficial in providing a user friendly service. These last two key components were seen as the main limitation of our study, and would be a direction for future research.

\section{Conclusions}

Key facilitators and barriers to care for ISAM were identified from this service improvement project. It was clearly noted that differences exist in pathways and engagement with health services for ISAM between sites; with child protection service involvement and being in foster care increasing clinic attendance. Overall transparent communication, service integration and shared learning can improve service provision for this population. Small service improvement strategies have already been put into place as a result of this project. Our fervent hope would be that this translates to positive and sustained health and social outcomes for this vulnerable group of infants and their families.

\section{Acknowledgments}

We gratefully acknowledge the time and experience provided by the key stakeholders and the commitment to improving services for this vulnerable group. We thank Alexandra Hendry for her support with analysis.

\section{Author Contributions}

All authors contributed to the designing and implementing of this project. Writing up was principally done by first author, with support from other three authors.

\section{Abbreviations}

ISAM: $\quad$ Infant of Substance Abusing Mother;

CS: $\quad$ Community Services;

CFHN: Child and Family Health Nurse;

ED: $\quad$ Emergency Department;

ACIR: Australian Immunisation Register;

DAPCC: $\quad$ Drugs and Pregnancy Coordinated Care Program;

PAFDHS: $\quad$ Perinatal and Family Drug Health Service;

NAS: $\quad$ Neonatal Abstinence Syndrome;

OOHC: $\quad$ Out of Home Care;

NICU: Neonatal Intensive Care Unit.

\section{Conflicts of Interest}

The authors declare no conflict of interest. 


\section{References}

1. Wells, Kathryn. "Substance Abuse and Child Maltreatment." Pediatric Clinics of North Amercia 56 (2009): 345-62.

2. Walsh, Christine, Harriet L. MacMillan, and Ellen Jamieson. "The Relationship between Parental Substance Abuse and Child Maltreatment: Findings from the Ontario Health Supplement." Child Abuse and Neglect 27 (2003): 1409-25.

3. Tomison, Adam M. "Child Maltreatment and Substance Abuse." National Child Protection Clearing House Discussion Paper No. 2, Australian Institute of Family Studies, Melbourne, Australia, September 1996. Available online: https://www3.aifs.gov. au/cfca/publications/child-maltreatment-and-substance-abuse (accessed on 1 June 2011).

4. McGlade, Andrea, Robert Ware, and Maree Crawford. "Child Protection Outcomes for Infants of Substance-Using Mothers: A Matched-Cohort Study.” Pediatrics 124 (2009): 285-93.

5. Ornoy, Asher, V. Michailevskaya, I. Lukashov, Rachel Bar-Hamburger, and S. Harel. "The Developmental Outcome of Children Born to Heroin-Dependent Mothers, Raised at Home or Adopted." Child Abuse \& Neglect 20 (1996): 385-96.

6. Ornoy, Asher, Jacob Segal, Rachel Bar-Hamburger, and Charles Greeenbaum. "Developmental Outcome of School Age Children Born to Mothers with Heroin Dependancy: Importance of Environmental Factors." Developmental Medicine and Child Neurology 43 (2001): 668-75.

7. Harvey, Susan R., Virginia Schmied, Daniel Nicholls, and Hannah Dahlen. "Key Components of a Service Model Providing Early Childhood Support for Women Attending Opioid Treatment Clinics: An Australian State Health Service Review." Journal of Clinical Nursing 21 (2012): 2528-37.

8. Nair, Prasanna, Maureen E. Schuler, Maureen M. Black, Laurie Kettinger, and Donna Harrington. "Cumulative Environmental Risk in Substance Abusing Women: Early Intervention, Parenting Stress, Child Abuse Potential and Child Development." Child Abuse and Neglect 27 (2003): 997-1017.

9. Callaghan, Tamra, Jennifer Crimmins, and Robert D. Schweitzer. "Children of Substance-Using Mothers: Child Health Engagement and Child Protection Outcomes." Journal of Paediatric Child Health 47 (2011): 223-27.

10. Mehta, Bhavesh K., and Shanti Raman. "How Early Is Early? Addressing the Health, Developmental and Social Outcomes of Children Exposed to Peri Natal Risks." Paper presented at Royal Australasian College of Physicians Annual Scientific Meeting, Darwin, Australia, May 2011.

11. Australian Institute of Health and Welfare. "2010 National Drug Stategy Household Survey Report.” 2011. Available online: http://www.aihw.gov.au/WorkArea/DownloadAsset. aspx?id=10737421314 (accessed on 3 March 2012). 
12. Patrick, Stephen W., Robert E. Schumacher, Brian D. Benneyworth, Elizabeth E. Krans, Jennifer M. McAllister, and Matthew M. Davis. "Neonatal Abstinence Syndrome and Associated Health Care Expenditures: United States, 2000-2009." The Journal of the American Medical Association 307 (2012): 1934-40.

13. Nehra, Vedika, Maria Pici, Paul Vinsintainer, and Jordan S. Kass. "Indicators of Compliance for Developmental Follow-up of Infants Discharged from a Regional NICU." Journal of Perinatal Medicine 37 (2009): 677-81.

14. Powell, Catherine, and Jane V. Appleton. "Children and Young People's Missed Health Care Appointments: Reconceptualising 'Did Not Attend' to 'Was Not Brought'-A Review of the Evidence for Practice.” Journal of Research in Nursing 17 (2012): 181-92.

15. Behnke, Marylou, Vincent C. Smith, Abuse Committee on Substance, and Fetus Committee on Newborn. "Prenatal Substance Abuse: Short- and Long-Term Effects on the Exposed Fetus." Pediatrics 131 (2013): e1009-24.

16. Buckley, Victoria, Adbalvahed Razaghi, and Paul Haber. "Predictors of Neonatal Outcomes amongst a Methadone and/or Heroin-Dependant Population Referred to a Multidisciplinary Perinatal and Family Drug Health Service." Australian and New Zealand Jurnal of Obstetrics and Gynaecology 53 (2013): 464-70.

17. McGlone, Laura, Helen Mactier, and Lawrence T. Weaver. "Drug Misuse in Pregnancy_Losing Sight of the Baby?” Archive of Disease in Childhood 94 (2009): 708-12.

18. Kelly, J., P. Davis, and Philip Henschke. "The Drug Epidemic: Effects on Newborn Infants and Health Resource Consumption at a Tertiary Perinatal Centre." Journal Paediatrics and Child Health 36 (2000): 262-64.

19. O’Donnell, Melissa, Natasha Nassar, Helen Leonard, Ronnie Hagan, Richard Mathews, Yvonne Patterson, and Fiona Stanley. "Increasing Prevalence of Neonatal Withdrawal Syndrome: Population Study of Maternal Factors and Child Protection Involvement." Pediatrics 123 (2009): e614-21.

20. Dawe, Sharon, and Paul Harnett. "Reducing Potential for Child Abuse among Methadone Maintained Parents: Results from a Randomised Controlled Trial." Journal of Substance Abuse Treatment 32 (2007): 381-90.

21. Mawhinney, Belinda. (Sydney Local Health District, Sydney, Australia.) Personal communication, 2014.

22. Australian Childhood Immunisation Register for Health Professionals (ACIR). Available online: http://www.humanservices.gov.au/health-professionals/services/australian -childhood-immunisation-register/ (accessed on 31 August 2013).

23. Niccols, Alison, Karen Milligan, Ainsley Smith, Wendy Sword, Lehana Thabane, and Joanna Henderson. "Integrated Programs for Mothers with Substance Abuse Issues and Their Children: A Systematic Review of Studies Reporting on Child Outcomes." Child Abuse Neglect 36 (2012): 308-22. 
24. Katz, Lynne, Saribel G. Ceballos, Keith Scott, and Gwen Wurm. "The Critical Role of a Paediatric Nurse Practitioner in an Early Intervention Programme for Children with Prenatal Drug Exposure." Jounral for Specialists in Paediatric Nursing 12 (2007): 123-27.

25. NSW Department of Health. "Supporting Families Early Package-Maternal and Child Health Primary Health Care Policy." 2009. Available online: http://www0.health.nsw.gov.au/ policies/pd/2010/pdf/PD2010_017.pdf (accessed on 3 March 2011). 


\title{
Current Debates on Variability in Child Welfare Decision-Making: A Selected Literature Review
}

\section{Emily Keddell}

\begin{abstract}
This article considers selected drivers of decision variability in child welfare decision-making and explores current debates in relation to these drivers. Covering the related influences of national orientation, risk and responsibility, inequality and poverty, evidence-based practice, constructions of abuse and its causes, domestic violence and cognitive processes, it discusses the literature in regards to how each of these influences decision variability. It situates these debates in relation to the ethical issue of variability and the equity issues that variability raises. I propose that despite the ecological complexity that drives decision variability, that improving internal (within-country) decision consistency is still a valid goal. It may be that the use of annotated case examples, kind learning systems, and continued commitments to the social justice issues of inequality and individualisation can contribute to this goal.
\end{abstract}

Reprinted from Soc. Sci. Cite as: Keddell, E. Current Debates on Variability in Child Welfare Decision-Making: A Selected Literature Review. Soc. Sci. 2014, 3, 916-940.

\section{Decision Variability in Child Welfare}

Decisions made in response to the problems facing families have considerable consequences in child welfare social work. The frameworks informing such decisions are essentially frameworks of social meaning and, as such, are highly influenced by the social contexts within which they occur. This context is far from monolithic, as many factors combine in a complex and contingent web of influences that converge and conflict. Thus, decisions are the outcome of highly situated categorisations of meaning sourced from available discourses in the national, political, organisational, professional, theoretical, technological, relational, material and personal environments. Such diverse and malleable social interpretations create a very complex context, and one outcome of this complexity is variability in decision outcomes. Drawing on a decision ecology approach, this article is a selected literature review of current research on several decision elements across the ecological spectrum. It discusses how they contribute to decision variability and why this matters [1,2]. It is not a systematic review in that it is not the result of a specific literature search and code technique; rather, the influences have been selected broadly based on current debates common in Anglophone contexts for their "reach" across the ecological spectrum. I argue that between-country variability is inevitable; nevertheless, it presents a major opportunity for critical examination of the impacts of various constructions of abuse, risk and family and their interactions with political contexts and policy orientations. In addition to this, within-country variability also exists. This represents an ethical problem, as general consistency at decision points across similar cases represents the universalist duties inherent in human rights and duty-based ethics. 
This article outlines the occurrence of decision variability, considers the ethical questions such variability provokes, then discusses a selected range of known contributors to variable decision outcomes. Inevitably, this leads to political considerations. Decision variability in child welfare social work ultimately reflects inherent tensions in the normative versus radical traditions of social work, conflicting methods of risk assessments and perceptions, differing attitudes on child welfare outcomes and epistemological conflicts about the nature of child abuse [3,4]. All of these aspects - ecological, ethical, psychological and political - are reflected in decision outcomes that can vary widely in terms of access to services, recommendations for statutory assessment and decisions to remove children and place them in foster care. Why does such variability exist, even within countries that have the same policy orientation to child welfare [5]? Is it a problem, and for whom? If it is, can it be resolved? This article addresses these questions. It begins by introducing decision-making concepts, outlines variability and discusses the ethical consequence of this. It then covers a range of selected issues impacting variability broadly organized ranging from the macro to the micro: policy orientations, risk, inequality and poverty, evidence-based practice, constructions of abuse and its causes and cognitive processes.

\section{Decision-Making: Rational and Consistent?}

Decision-making is not necessarily rational. Kemshall ([6], p. 216) suggests the rational actor paradigm, "... fails to acknowledge the importance of macrosociological and historical forces on the one hand, and non-rational, individual forces on the other". She argues instead that all decision makers are "situated", that their decisions are contingent upon the meaning making resources and priorities of their social context. Many studies seek to elucidate the complexities and lack of consistency in child welfare decision-making in practice. Such studies illustrate decisions at a range of points on the continuum from notification to a child protection service, substantiation, decisions to assess, to intervene, to remove and to return children. A range of studies show that many countries have variable placement or substantiation decision outcomes in response to the same or similar cases [1,7-11]. These differences have variously been related to ethnicity, risk perceptions, professional background, poverty, worker attitudes towards removal, the specific site office and family wishes, while others note that the presence of alternative care resources is also implicated in variable decisions [12-17].

For example, Forkby and Hojer [18] found that decisions to place children in residential care were shaped by several factors. Firstly, it was viewed by practitioners as a last resort option, and as the outcomes of it were unknown, this resulted in a "damned if you do, damned if you don't" position for the social worker. Removal as containing significant risk of harm has been shown elsewhere to result in a "weighing up of harms" by social workers, rather than a simple assumption of removal equates to safety position. This is especially so if the underpinning cultural preference is for family maintenance rather than removal [19]. Rossi et al. [20] compared the decisions of experts (academics, agency leaders, etc., $n=27)$ and frontline workers $(n=103)$ in response to real case summaries. They found that although all emphasised the same characteristics in the cases, these did not lead to uniform or consistent decisions. Instead, there was significant variability between both experts and workers spread across the spectrum from: close the case, offer ordinary services, offer family preservation 
services or remove. Experts were slightly more weighted towards the family preservation options, and the most influential case characteristic for removal was a prior record of abuse. Characteristics of the decision makers, such as gender or age, had little effect on decision outcomes [20].

Britner and Mossler [21] compared different professionals' responses to the same case using vignettes. These included judges, guardians, court advocates, social workers and mental health workers. They found that the professional discipline determined the decision outcome more than the content of the complaint. Social workers and mental health providers relied on information about the severity and pattern of abuse, information about services offered in the past and parental responses to those services. Judges and guardians ad litem tended to emphasise information about "the likelihood of a reoccurrence of abuse and the child's ability to recount the abuse, whereas CASA (court advocate) volunteers rely on information about the stability of the family" ([21], p. 317). Arad-Davidson et al. [9] asked social workers about real decisions they had made via a questionnaire. They questioned them at two points in time and found that $21 \%$ of decisions, mostly to remove, had not been implemented in the six-month time period between the questionnaires. The reasons given were mostly either parental or child objections, particularly if the child was older or the worker was more experienced; however, all children whose mothers were drug or alcohol addicts were removed.

Arad-Davison and BenBenishty [3] in another decision-making study of 200 social workers in Israel examined case worker attitudes via a questionnaire and compared them to responses to a vignette. Workers' attitudes towards issues in child welfare (removal from the home of a children at risk, the ability of alternative care to foster children's development, the optimal duration of alternative care and parent's and children's participation in the intervention recommendation) were compared with their risk assessments and intervention recommendations. They found that workers could be organized into "pro-removal" and "anti-removal" groups, via the questionnaire. They found that the former pro-removal group rated risk more highly and was more likely to recommend removal in response to the vignette family. They found that mother and child wishes had no effect on decisions and that social worker variables (such as experience) had no effect on which attitudinal group into which they could be categorised. Jergeby and Soydan [22] found that when comparing social workers' responses to a vignette between and within countries, that even within countries, there was no evidence of standardised responses to the same situation.

In Aotearoa/NZ, the rate of notification to substantiation ranges from $5 \%$ to $48 \%$, depending on the location of the site office [23], and a recent qualitative workforce review of child protection services noted the difficulties of establishing a clear and consistent threshold between NGO family support and statutory child protection intervention [24]. This review concluded that despite the assistance of assessment frameworks, decision-making protocols and legislation, that "...these sources were open for interpretation when determining whether or not the needs of a child or young person met the threshold for Child, Youth and Family assessment and intervention" ([24], p. 34). Also noted are the various impacts on social worker's decision-making in a complex context, including public perceptions of the social worker role, the nature and duration of the actual concerns for the child, the practitioner's own skill level and experience, the interface with other agencies providing services in local areas and the clarity of organisational messages and drivers ([24], p. 49). 
Thus, variability in decision outcomes reflects a range of influences across the ecological spectrum, far beyond individual characteristics [16]. These include site locations, professional discipline, attitudes toward family maintenance, underpinning beliefs about the possible harm of foster care and the organizational contexts of practice. These aspects highlight the situated actor Kemshall [6] speaks of in contrast to the rational actor, as these factors highlight the contingent and socially-influenced aspects of decision-making in real-life contexts.

\section{The Ethical Consequences of Variability}

Thus, decision outcomes are variable and influenced by cultural variations, some of which are to be expected. As child abuse is ultimately socially constructed, it is unsurprising that reactions to it are also variable in line with differing national contexts $[4,25]$. However, comparing why variations exist between countries is valuable. It draws our attention to connections between the macro and micro realms and enables critical examination of the taken for granted [26,27]. Examining internal variability is even more important. Internal variability in decision outcomes represents an ethical difficulty that is not easily resolved. Platt and Turney [28] offer a cogent critique of attempts to standardise threshold decisions on several counts: firstly, that the complex decision-making context involves numerous factors beyond the actual case characteristics or agency decision-making tool; secondly, that the worker's own sense-making processes contain numerous aspects to do with cognitive processes, intuition emotion and values; thirdly, that neither linear, rational decision-making nor the use of heuristics and biases as "defective" are realistic appraisals of real-life decision-making. They also point out that the various types of abuse and varied circumstances it occurs in make comparing them in order to make a distinct "line in the sand" impossible. However, all of these critiques are directed at the difficulties of standardising decisions in terms of the real-world context, but do not address the ethical issues inherent in variability. Certainly, descriptive theories of decision-making should be complex and situated, rather than linear and "rational", yet pointing this out does not resolve the ethical issues raised by decision variability.

I contend that some kind of consistency in decision-making in regards to child protection decision-making should be attempted, however imperfectly, despite complexity. Why is consistency important ethically? As a statutory agency, the level of protection extended to children and the level of respect accorded to the parental rights of parents should not intersect at a line so malleable as to make the response of a statutory social work unreliable and arbitrary. If the macro factors (orientation) are held equal and the case facts are similar, deontological ethics (that is, that the same duties are accorded to all clients based on their existence as humans with intrinsic value) would suggest that outcomes should be consistent [29]. Thus, either a child does or does not reach a threshold for out-of-home care or access to a therapeutic service. The home is or is not safe enough to warrant return. Decisions such as these should have some level of transferability within a nation state, as an expression of the commitment to maintaining both the duty of care to protect children equally and to respect the autonomy and guardianship rights of parents. Otherwise, the law is arbitrary.

However, close studies of substantiation and other decision points do not conform to this expectation. As explained above and below, this issue is evident in many countries and represents several contributing influences. However, first, is this issue the ethical problem I have posed it as? It 
may be that variability, even within countries, is not quite the ethical problem I have posited. It could be argued that the research methods and ethical theories relied on to reach such a conclusion are inadequate. For example, most decision-making research is quantitative research limited to variables that are measurable and able to be manipulated, for example recorded case data or factors derived from factorial surveys using case vignettes. Many real-life variables that impact on decisions are not captured in either types of data, for example the in-depth, contingent and case-specific aspects, such as the social worker-client relationship, the reactions of both parents and children to the social worker, the perceived trustworthiness and caring attitude of the social worker toward the client and compliance. These variables are all found in qualitative studies to impact case decisions, albeit indirectly [30-32]. From an ethics of care perspective, some decision variability may not necessarily be negative, as such variability may reflect the type of relationship a worker and client family have. According to an ethics of care perspective (as opposed to a "duty" perspective), ethical decisions should not be determined solely by identifying one's duties, but also by the context-dependent nature of the case and the relational or caring obligations that derive from it [33-36].

An ethical decision in child protection, therefore, could be considered not only one that reflects the weighing up of universal duties to protect children and respect the self-determination rights of parents or the costs and benefits of possible courses of action (traditional justice approaches), but one that is contingent upon the nature of obligations derived from a caring and supportive relationship with the family. Thus, it may be that some variability reflects the different relational qualities in a case that are not captured by research methods comparing the surface facts of a case, but are ethically defensible. This conclusion may have some merit, yet it is not a complete resolution, as the fairness question remains, as do concerns regarding transparency. However, it does lend us a more nuanced understanding of the ethical component of this issue and leads beyond the more straightforward question of what drives decision outcome variability, to when is decision variability ethically justified and when is it not.

\section{Policy Orientations}

Therefore, what drives these decision differences? One driver in between-country differences is the policy orientation of the nation state. At the macro level, differences abound in the historical development of services; for example, Duffy and Collins [26] note that the historical contexts of the U.S. and Northern Ireland have led to differing emphases on legal, cultural and political aspects of child welfare. Gilbert et al. [5] outline the differences between the policy orientations of nation states, deriving three main types: child protection, child welfare and child focussed. Others have examined the interrelationship between these orientations and decision reasoning, noting that the first leads to a focus on specific acts of abuse, the second locates the cause of problems in family needs, while the final one can result in a 'child-centric' practice that protects children's individual rights and wellbeing, but may downplay family relationships [37-41].

Policy orientations can be described as broad "flavour differences" in overall policy directions [5,37-39,42]. Within a child welfare orientation, the best interests of the child are closely linked to the interests of the family as a whole, and assessments include strengths, as well as difficulties. Its purpose is preventive, and the focus within this approach is to "...create those 
material and social conditions within which all children are given sufficient opportunities to reach their full potential" ([43], p. 2; [44]). Thus, a child welfare orientation offers a broad-based prevention policy framework, based on a long-term understanding of epidemiology, rather than focussing on a single risky event [45].

Gilbert et al. [5] conversely characterise a "child protection" orientation as one that frames problems in individualistic and moralistic ways, directs legalistic and investigatory intervention types, promotes adversarial state-parent relationships and results in the use of mostly involuntary out-of-home placement. Fargion [43] adds to this description, stating that child protection orientations define children's best interests narrowly in terms of children's protection, reify 'abuse' as something objectively apprehendable and utilise standardised assessment tools. Significantly, she claims this approach "treats difficulties as signals of risks" ([43], p. 2). A further emerging direction is a "child focussed" orientation, one that directs policy focussed on promoting the rights and wellbeing of individual children; however, a significant downside of this orientation is that children can become viewed as entirely separate from the context of their social relationships [41].

These three orientations thus shape policy frameworks, but the application of these orientations is not straightforward, with "mixed" orientations increasingly common [5,39]. Kriz and Skivenes [46] provide an example of this contrast, stating that "the American and English welfare systems provide social assistance to the most destitute, with a child welfare system that focuses on risks for children. This type of welfare system stands in contrast to the Norwegian social democratic welfare state, which provides universal services related to health and social welfare, many of which are aimed at families, and with a child welfare system that focuses on children's needs as well as risks" ([47], p. 1867).

Orientation frameworks shape decision-making by setting out the preferred aims and functions of a child protection system within national contexts. Variability often relates to clashes between these orientations, not only between nation states, but also within them. Kriz and Skivenes [47] for example, found that people in different national contexts, namely California, England and Norway, evaluated risk in the same case vignette differently, with Californians evaluating risk the lowest, then England and Norway. They found that the child welfare orientation in Norway could be attributed to an increase in perceptions of risk by Norwegian social workers, as the threshold for intervention is much lower when prevention is framed as a family support service provision aimed at preventing out-of-home placement. Of note were significant differences in the perceptions of which factors created risk for the children involved, as well as interesting findings that showed that the least regulated environment, Norway, produced the most homogenous types of reasoning around risk, while the other two contexts were more internally heterogeneous. They argue that this reflects not only different risk assessment tools, but also the policy orientations and type of welfare state of each nation. Other studies have also tracked the congruence between policy orientations and decision-making, for example Khoo et al.'s study of Canadian and Swedish approaches to child abuse and Skivenes and Stenberg's study of social worker responses to domestic violence [38,47-49]. Internal variability can also reflect these broad frameworks, as the study by Arad-Davidson and Benbenishty (described below) shows that internal variation along these same lines (child welfare/child protection orientations) impacts on decision variability about out-of-home care. 
Another aspect of decision variability is the disjuncture between official policy frameworks and how social work is actually practised. As Buckley argues, the two can be quite disparate, with real practice differing so markedly from espoused policy guidelines, that she questions whether it is an "ungovernable enterprise" [50]. Kriz and Skivenes [51] compared the ways that social workers in Norway, the U.K. and England responded as "street level bureaucrats" to their policy contexts, that is, they managed the demands made of them by official policy and legal frameworks given institutional and financial limitations. This study highlighted that although many countries share similar commitments to the principles of the best interests and/or wellbeing of the child, family preservation, permanence and safety, that nevertheless, the degree to which governments focus on individual principles differs, and importantly, how social workers deal with the sometimes conflicting nature of those principles is quite a different matter. Such a high level of discretion can contribute to differences in decision outcomes. Pendulum swings in reaction to media reports can also shape practitioner responses in a manner that may diverge from official policies, as public opinion that swings from criticising too much removal to criticising family preservation attempts can drive decisions based on fear of public opinion, rather than in line with stated policy [12,52].

\section{Orientations, Risk and Neo-Liberalism}

Such studies highlight the culturally-defined nature of responses to child protection issues across national contexts, patterned by policy frameworks. These orientations clearly have some influence on across-country variability and internal variability as more countries adopt mixed orientations. Mixed orientations can be seen in conflicting legal imperatives, such as family preservation and children's "best interests", but other influences fuelling the fragmentation of ways of approaching decision-making may be the influence of neo-liberal ideologies and the impact of risk thinking. Risk hyper-sensitivity is particularly likely within a "risk society". Beck's [53] analysis of a risk society proposed that risk is increasingly perceived as ubiquitous, as people are more aware of risks than ever before. Whatsmore, risk is viewed as widespread and potentially catastrophic, and simultaneously, people are expected to guard against all possible risks to themselves [54]. Within a neo-liberal political system, this expectation is heightened. Neo-liberal ideologies focus broadly on reducing the role of government, individualising social problems and "responsibilising" both professionals and individuals $[55,56]$. This results in the spreading of responsibility for child welfare across NGOs and statutory services, common in neo-liberal environments focussed on economic efficiency and devolution of responsibility. As rates of referral to child protection services increase dramatically, intense pressure on child protection systems have led many countries to significantly reconstruct their service systems in these ways, particularly in the wake of the fiscal constraints imposed by the worldwide recession. Such changes commonly focus on spreading the responsibility for child abuse responses beyond statutory agencies and introducing new technologies in attempts to make practice responses more systematised and targeted to those most at risk [57,58]. The state's role moves from being a "social state" to a "facilitating state", merely a coordinator of services, rather than a body responsible for their existence, functioning or resourcing [59]. This spreading of responsibility among multiple agencies may multiply the various logics and beliefs relating to the correct or proper role of statutory social work with children, as agencies have their own cultural 
beliefs, practices and tools to assess families. It may also produce an uneven impact on the practitioner's level of risk aversion, as an increasingly accountable workforce reacts to the pressure to manage risks to the self in different ways, with some workers complying and others resisting [60]. Within such a system, the possibility is that social workers become focussed on lowering their own risk of future accusations of poor practice, rather than building durable and humane solutions for children and their families. Decision-making becomes framed as avoidance of risk rather than promotion of wellbeing or self-determination.

Further, the professional knowledge and relationship focus of social workers are downplayed within a context driven by managerial and technical discourses, as are the radical traditions of social work [61]. One effect of this is that "this framing of social problems encourages those professions working on social problems to adopt an 'inward-looking' perspective that minimizes the connections between structural change and the manifestation of individual problems" ([62], p. 1023). Another is that targeting of "programmes" is considered the only solution to abuse, and universal, supportive services are eroded. Abuse itself becomes considered as an individual problem, to which the correct and proper response is the correction of parenting practices, rather than considering the ways that parent's interactions with their children are shaped by their material and social resources. It can be reasonably concluded that where a social worker is positioned along the radical-normative continuum will drive decision variability in responses to risk in the context of neo-liberal states.

\section{Risk and Safety in a Risk Society}

Thus, how risk is conceptualised is another major driver of decision-making in Anglophone countries [6,63]. Indeed, risk assessment and its associated "risk logics" have become the focus of child protection systems nearly worldwide and, with it, an economic-rationalist assumption that risks are measurable, predictable and avoidable [57,64]. Considering risk assessment highlights two debates in decision-making: how risk assessment tools are derived and used and whether they include strengths or safety perspectives. Houston [65] states differences in ways of conceptualizing risk reflect objectivist, subjectivist and critical meta-theoretical paradigms, each with their own epistemology, ontology and axiology in relation to risk. One expression of an objectivist approach to risk, for example, has been in the development of risk factor science and related risk assessment tools. A concern about risk and a perceived need to identify and reduce risk has led to increasing research into risk factors, using longitudinal and quasi-experimental methods, to measure the effect sizes of different variables. These have been incorporated into risk assessment tools, often termed "actuarial" approaches to risk assessment work. While providing valuable information about patterns across populations and successful in some studies to predict future abuse, on their own, such methods have significant limitations for decision-making [65,66].

Limitations of decision tools exist for two related reasons - the method of quantification and the way they are used in the practice of decision-reasoning. Firstly, in terms of the production of risk factors via statistical correlations, they are neither "necessary nor sufficient" to predict abuse in the future [67], thus producing a high rate of "false positives" [68]. Secondly humans as decision makers are notoriously imperfect at incorporating accurate assessments of probability and effect sizes into decision-making [69]. France et al. [70] note this in social work when they state that while 
statisticians might understand the level of surety or otherwise are able to be infer it from statistical correlation, nevertheless, risk factors are often treated as if they can give certainty about future outcomes in practice [70]. Gillingham [12] and others have noted that practitioners may subvert the intention of structured decision-making tools to get the outcome they desire or use the language of risk to legitimate decisions they have already made on other grounds [71]. However, if used correctly, actuarial approaches can be combined with consensus or discretionary approaches to produce a more complete method of risk assessment than one or the other would alone, with some research demonstrating that actuarial approaches are more accurate in terms of the actual risk of future notification than professional discretion approaches only [72]. However, using them alone to decrease decision variability is undesirable, as many other factors in addition to future risk must be considered.

Either way, in addition to actuarial knowledge, case-specific knowledge, a relationship with the family, understanding how risks change over time, theoretical underpinnings and ethical commitments are required to be able to make decisions related to particular families [72,73]. This is particularly true given that estimations of future harm are just one aspect of decision-making about children's lives. While preferred within modernist economic rationalist paradigms that attempt to predict and control uncertain outcomes, the use of risk-factor approaches can fuel practice dominated by risk aversion and forensic investigatory-type approaches $[64,74]$. The development of strengths and safety-oriented perspectives have attempted to counter this deficit approach to risk assessment, arguing that searching for risk factors alone is neither accurate, fair, nor useful in a context of unequal power relations and where the ongoing relationship is the best hope for actual change in the family [75-77]. These approaches attempt to resist risk saturation by actively searching for and including aspects related to client safety and strengths. Initial research notes the impact on decision-making of the Signs of Safety approach as producing knowledge about clients in ways that retain moral subject positions for parental clients to occupy. This contributes to shared power and parental engagement, creates the opportunities for personal change and leads to decisions that are likely to be less risk averse [78]. In terms of decision variability, which tools are specifically adopted by different agencies is therefore a significant driver of differences in decision outcomes, as those using traditional risk assessment formats and those utilising strengths or safety-oriented tools may reach very different conclusions about the level of risk and, thus, the need for intervention. Safety-oriented tools are also more likely to open up different pathways for intervention, as they focus on creating an intensely collaborative relationship with families and utilising their own networks and resources, whereas traditional risk assessment methods, used in the context of targeting and resource efficiency, tend to use the assessment to determine who should receive evidence-based standardised programmes delivered by a third party.

\section{Inequality and Poverty}

This leads us to consider the role of poverty in family lives, as how the impact of poverty is constructed by decision-makers is another major driver of differences in decision outcomes. An individualised focus can lead to a narrow evaluation of quantifiable and individualised risks, obscuring a major concern with the pervasive over-representation of those most socio-economically 
disadvantaged in child protection systems. An enduring correlation between poverty and abuse, while not deterministic, nevertheless raises questions about the relationship between poverty and abuse in terms of causality and ethical questions about child welfare intervention as a reflection of inequality [41,79-82]. Paxson and Waldfogel [83] in a large study found that an increase from 10\% to $15 \%$ of children living in extreme poverty was associated with a $22 \%$ increase in child abuse. Many others have found similar results [84]. However, interpreting these findings in decision-making contexts requires careful examination: "The experiences of those trying to parent in a profoundly unequal society are not interrogated rigorously enough in current responses, with causation and correlation confused in a highly abstract language that renders real people and their lives invisible and/or unintelligible" ([41], p. 5).

In terms of decision-making, the connections between poverty, inequality and abuse are important for practitioners to grasp. However, how does one incorporate them in decision-reasoning? There is some evidence that social workers can become de-sensitised to poverty as an integral and seriously damaging aspect of client's lives [85]. Other studies have found that poverty made no impact on social worker's decision-making, although other markers of poverty, such as substandard housing, did [14]. While Stokes and Schmidt [14] point out that social workers should be considering the impact of poverty on the ability of families to care for children, particularly from an anti-oppressive standpoint that recognises the impact of macro-structural conditions on families' lives, Moraes et al.'s study [86], while investigating a similar question and with similar findings, came to quite a different conclusion. Moraes et al. [86] used a representative sample drawn from the Canadian Incidence Study of reported child abuse and neglect. They found that over five indicators (case substantiation, provision of ongoing child welfare services, referrals to child and family support programmes, out-of-home placement, applications to child welfare court and police involvement), poverty had an extremely minimal impact (6\%) on the variance in decision outcomes. Nor did a poverty index of the family's circumstances, although, again, living in unsafe housing (perhaps a proxy for poverty) had some impact on substantiation of abuse, particularly in cases where there was no physical injury. They conclude that there is no evidence in this study that social workers act in a 'discriminatory' manner in relation to families living in poverty and posit this as a positive finding.

As Keddell [87] notes, this contrasting interpretation of findings in relation to poverty in decision-reasoning is indicative of the intensely contestable nature of the definition of the social work role and the tensions practitioners must navigate: one must be aware of the oppressive nature of poverty and its impacts on parenting, but at the same time, resist judgemental and negative assumptions about parents in poverty. This dichotomy reflects the difference between reflection and critical reflection: the former encourages self-examination with a view toward eradicating discriminatory stereotypes, while critical reflection moves beyond this to include structural awareness of social problems in one's assessment of a family, so as to recognise the interconnections between family practices and structural conditions [88]. These two types of reflection have significant implications for decisions where poverty and child welfare concerns converge, as decisions reflect, at least partly, the practitioner's evaluation of the culpability for, or source of, the problems facing the family. Without at least some inclusion of structural impacts, culpability lies only with parents. Decision variability may reflect these tensions. 
Despite the radical and critical traditions implicit in social work education, political changes in many countries (particularly Australia, New Zealand and the U.K.) towards the individualisation of social problems in both welfare reform and child protection systems reconfigurations constantly cast social work as a micro-level profession sent to maintain control and regulation of the masses, rather than advocate for them [89]. Marston and McDonald [62] bemoan the de-politicisation of social work, arguing that recent neo-liberal developments of policy in many Western countries have resulted in a significant reconstruction of the social work role and, with it, the replacement of “...sociological and political-economy approaches to problems like poverty, and have instead opted for behavioural-economic understandings of human behaviour. The combined effect of these changes is to cast doubt on the knowledge and actions of social workers as political actors, particularly those social workers directly engaged in work that seeks to redress social injustice and to influence public policy" ([63], p. 1023). Interestingly, Moraes et al. also draw a link between attitudes toward poverty and decision reasoning, hypothesising that in "...nations where poverty is viewed as primarily an individual responsibility and income inequality is pronounced, child welfare measures may be more intrusive among poor than non-poor families. On the other hand, in nations where poverty is viewed largely a societal responsibility and income inequality is more moderate, child welfare professionals may be more egalitarian in their decision-making" ([87], p. 167). Thus, the challenge for social workers in increasingly neo-liberal climes is to incorporate poverty in decision-making beyond simply eliminating negative stereotypes towards poor families, but must continue to remain resistant to pervasive social discourses that cast the poor as primarily responsible for their own demise [90].

\section{Evidence-Based Practice}

Likewise, while including known risk factors in decision processes is important background knowledge, current exhortations to make "better use of research" can result in a deterministic use of risk factors or an inappropriate weighting of them in decision reasoning. Many effect sizes are tiny or the relationships between factors indeterminate. For example, Appleyard et al. [91] found in their study examining the relationship between childhood abuse, adult substance abuse and victimisation of one's own children that there were traceable relationships, but the effect size was small $(0.26 / 0.19)$. Studies of the impact of young parental age at first birth, a commonly relied on risk factor, actually show that effects are mixed. Some show a clear correlation with maltreatment, but these effects are also influenced by lower economic status, lack of social support and high stress levels [92]. This means that the age at first birth may not be as influential as first thought, or, all of the above factors combine for the effect. However, when research is translated for practitioners, it is often oversimplified, so that the nuances involved are lost [41]. Thus, the use of research in practice can be used inappropriately, as when over-simplification is combined with natural tendencies to over-estimate effect sizes, the result can be too much emphasis on negative attributes [92]. These issues led Munro et al. [67] to conclude: "The repeated exhortations to child protection services to predict and prevent maltreatment, and the associated blame when they fail to do so, should be replaced with more modest expectations" ([68], p. 70). Thus, while understanding broad population 
patterns in relation to risk factors is certainly important background knowledge, its use in ways that assume they confer certainty in any specific situation is misguided and may contribute to variability [93].

\section{Constructions of Abuse and Its Causes}

Alongside these macro influences of national orientation and changing conceptualisations of risk and evidence, other changes are also occurring in regards to child abuse definitions and understandings of the causes and consequences of abuse. Definitions of abuse are played out at the micro level, as the idiosyncratic nature of family circumstances and behaviour is often difficult to fit into formal definitions of abuse, or if it does, deciding at what point or threshold it is 'bad enough' for intervention is a slippery fish. As noted, child abuse is a socially-constructed phenomenon in terms of its meanings, definitions and social responses [94]. This is reflected in the changing definition of abuse for differing purposes, such as for research, practice or legal purposes [95], differences in social worker's responses to the same cases, intense public debate as to the boundary line between physical punishment and abuse and beliefs about what constitutes reasonable care or "good enough" parenting [15,96-98]. Modern definitions of abuse cover a variety of types, and establishing their parameters in real-life situations remains difficult.

Considering definitions and constructions of abuse leads to a serious consideration of the causes of abuse. Many system's responses, drawing on a neo-liberal paradigm, propose that abuse is caused by psychological or criminal tendencies and, thus, prescribe systems of surveillance, control and sanction as ways of reducing and preventing abuse [99]. These changes, without responding to a wider range of abuse causes, risk factors and effects of abuse, remain partial, only targeting one aspect of abuse prevention (surveillance and prediction) and only the most severe types of abuse. Such responses assume that definitions of abuse are obvious, straightforward and its solutions are self-evident [100]. In turn, decision-making itself is conceived of as correctly "recognising" abuse and categorising a family as "abusive" or "non-abusive", rather than the more difficult holistic assessment of child and family needs, opinions and wishes.

Risk factors, as discussed, cannot predict abuse with any accuracy. Profiling of the most serious offenders can result in effective prevention of secondary abuse and sometimes primary. However, the vast majority of families referred to child abuse services, as well as those for whom abuse is substantiated, have much more complex, diffuse and chronic issues, with strong relationships to structural conditions, rather than the innate pathology of individuals [67,101-103]. What is more, child deaths are extremely rare events that are not predictable, even when considering a high-risk population [93]. In the use of the predictive risk model in Aotearoa/New Zealand that tracked babies from birth over their first five years, the top two deciles of risk were $66 \%$ accurate; in other words, it also identified $34 \%$ of those deciles as a "high risk" population that did not go on to become abusive [104]. Pritchard and colleagues found that those who killed children had several identifiable salient features, such as having a history of violence and being not biologically related to the children they killed. They conclude that: "The juxtaposed results indicate that the assailants' problems are essentially psycho-criminological, especially violence, rather than socio-economic, although poverty worsens most situations" ([101], p. 1403). However, such cases make up a tiny proportion of those referred to child protection services, even of the substantiated cases. In Aotearoa/New Zealand in 
2012, for example, emotional abuse and neglect made up around $80 \%$ of substantiated cases, with the remainder physical and sexual abuse [105]. However, substantiated cases (18,595 distinct children) were, in turn, a tiny proportion of the total of 148,659 notifications (of which 57,766 were police notifications for domestic violence) [24,105]. In Canada, $85 \%$ of referrals to their child protection service can be categorised as chronic needs, while the remainder are urgent protection cases [106]. Thus, practice responses attempt to respond to both high-end perpetrators, who may well have individual psychological risk markers for serious physical or sexual abuse, as well as the much more common diffuse, chronic situations of a combination of mental illness, poverty, drug and alcohol addiction, discrimination and domestic violence [24,107]. Based on an assumption that the former type of abuse is what most abuse "is" (influenced strongly by media representations), there is a substantial mismatch between systems and services and the actual phenomena of child abuse [52]. Wolfe et al. [107] state the problem thus: "Child abuse is an event, not a uniform disorder, and therefore it is necessary to consider multiple causes that interact unpredictably. Notwithstanding the critical role of the adult offender, child abuse is rarely caused by a single risk factor. Although risk signs and indicators are present, it is still very difficult to predict who will become abusive and who will not — child abuse may emerge in any given family if the 'right' conditions exist. These causal conditions stem largely from the interaction of child, familial, and cultural influences, but it is not possible to predict with precision when they will occur" ([108], p. 35).

The variety of psychological and social work theories, as well as theories of human development, constructions of childhood and what might constitute children's best interests also impact on decisions about what counts as abuse and harm across the lifespan [108]. For example, conflicts arise when considering the line between punishment and physical abuse, which despite being criminalized in a number of countries, remains a contested areas as to what amount of force, with what intention, to what age child, over what period of time and combined with what other family factors constitute abuse; and if so, is it to the level of harm such that statutory intervention is required [3]? Likewise, the impact on neglect, particularly of poverty and mental illness, can make a finding of neglect difficult if the parent is considered not in reasonable control over the contributing circumstances. Each of these (definitions of neglect and physical abuse) may have considerable cultural dimensions, with child rearing practices differing markedly across ethnic and cultural groups. This leads to a consideration of the way that a variety of types of abuse impacts on decision variability. It is only in recent times that the vast array of harms to children have been categorized as "abuse": neglect, physical abuse, sexual abuse and emotional abuse. Some of these are clearer than others in terms of the degree of social consensus on harm, including the research evidence. For example, Chan et al. [109] found that despite an assumption that professionals would have some kind of common, professional view on abuse and its consequences, it was found instead that their attitudes towards child abuse reflected their cultural backgrounds rather than a professional consensus. Such differences in the interpretation of child abuse illustrate the contested nature of child abuse. This must refract through the varied decisions of social workers. 
Domestic Violence as the New Child Abuse

A further major recent change in the construction of the child abuse definition has been the inclusion of domestic violence as a type of emotional abuse of children [110]. Increasingly, convincing research on the harm to children from exposure to or witnessing of domestic violence has led to its transformation from an issue primarily affecting adult victims, most commonly women, to also having child victims [111-114]. There is also evidence that in addition to exposure, domestic violence also has a high co-occurrence with direct abuse of children, with some estimates between $30 \%-60 \%$ [115]. This has led to interesting developments in the responses of child protection systems. In Aotearoa/New Zealand, for example, police callouts for domestic violence where children were present prompted a now-mandatory referral to child protection services. Due to this change, one third of families referred to child protection services each year come directly from Police (see above). As in other countries, this represents a challenge to child protection services, where the reconstruction of domestic violence as a new type of child abuse leaves a service more familiar with traditional types of abuse ill-prepared to intervene effectively [110,116,117], with either excessive criminalization or child removal having significant drawbacks [118-120].

Considerable collaboration across services is needed to respond in ways that effectively protect children from harm (and women) [121,122]. However as Hester [121] notes, this is difficult when child protection systems and women's protection systems operate within very different paradigms, leading to conflict about the most urgent problem faced by families and, thus, how to intervene successfully [119]. Simply educating child protection workers about domestic violence, while a good start, is insufficient in establishing an effective and systematic response to this phenomenon, where both the values and knowledge of child protection and women's advocacy services are needed to be included, combined with case-specific consultation in order for collaboration to be successful $[123,124]$. This issue presents considerable tensions for social workers, for whom the definitions and conceptualisation of domestic violence presents challenges for establishing decision consistency. How it should be coded (as emotional abuse or neglect), if it should be considered a risk to children at all and who is assigned responsibility for protecting children from it, all impact on decisions in relation to it. Skivenes and Stenberg [49] compared responses to two vignettes, one a neglect case and one a domestic violence case. They note that in response to a domestic violence case, that responses between the U.S. and the U.K. were similarly concerned with risk, and this may be due to the U.K. swinging towards a child protection orientation; although, in another type of vignette offered (neglect), they found much more of an emphasis in the U.K. on a family service or child welfare-type approach. They contend that this is due to the type of case and that this may show the impact of evidence-informed practice, as knowledge about the effect of domestic violence has a more established cross-national consensus than other types [49]. However, they found that despite the uniformity of views on domestic violence as constituting a risk factor, that marked heterogeneity again appeared in the reports of what action social workers would actually take in response to this risk.

Another issue in responding to domestic violence in case decision-making relates to who is perceived as responsible for it. As other research shows, where parents are viewed as culpable, more 
intrusive decisions follow. A variety of studies show that women are perceived as "bad mothers" when they are faced with domestic violence in the child protection system, and this results in a deficit mothering discourse that blames them for their predicament. In terms of decision-making, this can result in an ultimatum approach from child protection services of requiring women to separate from their partners or remove the children [125]. Where women are viewed as both responsible, yet holding little real control over the risk presented by their partner to both themselves and their children, intrusive decisions become constructed as justified [126]. In a study examining the ways child protection workers attributed blame in domestic violence cases [127] found that the presence of domestic violence increased worker's perception of risk to children. Every construct they used in a factorial vignette approach showed that workers were more likely to view women as more culpable for exposing their children to harm than their partner, even though in every case, their male partner was the violence perpetrator. Thus, understanding how domestic violence is affecting decision variability requires an understanding of the ways blame, culpability and risk are understood in relation to domestic violence, as well as how child protection systems interact with other services in particular locations.

\section{Cognitive Processes and Group Decision-Making}

Finally, the variable ways in which all of these factors are used in decision-making highlight the known cognitive problems with decision-making. For example, the tendency of humans to make decisions based on the most vivid or recent piece of information [128], the lack of the computational ability of humans to consider and weigh up all relevant information, the effect of "frames" (the implicit contextual parameters of decisions) satisficing - taking the best available option rather than the ideal - and the use of heuristics and biases, particularly the tendency to have a confirmation bias. Many of these dynamics can lead to an overconfidence in human judgement, particularly when people are forced to make decisions quickly, or the "latent conditions" under which they are forced to operate lead to negative decision "shapers" such as incomplete information and high uncertainty, systemic feedback errors, improper drivers (such as technical tasks rewarded, rather than family outcomes) or a lack of training $[69,92,129,130]$. However, slower consideration of relevant issues, combined with education about cognitive biases, can help reduce their impact [92,131]. Others argue that heuristics (short-hand rules of thumb derived from practice experience) are not necessarily problematic, but the complex use of short cuts in response to recognised patterns that are often correct when used in their specific environmental contexts. It is this proposition on which proponents of ecological rationality and naturalistic decision-making essentially rely [28,132,133]. Hogarth [134] extends these ideas to consider heuristics as an aspect of the intuitive components of decision-making, which together with analytic reasoning, make up decision processes [73]. He argues that the learning of "correct" heuristics as one part of developing sound intuitive reasoning must take place in "kind", as opposed to "wicked" learning environments. A "kind" environment is one that "...provides timely feedback and allows the tacit or experiential system to shape practitioner responses. In contrast, 'wicked' learning environments provide misleading, or no, feedback resulting in unfounded practitioner confidence" ([134], p. 4).

In terms of decision-making variability, therefore, a reliance on either individual practitioners or

the immediate ecological context presents challenges for national consistency in decision-making, as 
individual differences in perceptions, as well as site differences and their varieties of latent conditions, frames and whether there is a kind or wicked immediate environment for the learning of intuitive heuristics (very similar to "practice wisdom" concepts in social work), may produce inconsistency between locations. A child in one town, with its particular mix of available resources and site office systems and cultures, should not be afforded a different level of protection than the same child in similar circumstances in a different location, nor should the rights of parents be impinged upon differently. For example, one reason for the interaction between inequalities and child protection involvement may be the lack of supportive family resources in poorer neighbourhoods that leave few choices open to both NGO and statutory social workers than to use legal intervention; an understandable response and one entirely consistent with naturalistic decision-making, but not an equitable one. Establishing a fairer response to threshold decisions would highlight the increased need in some neighbourhoods for more family support services, rather than involve statutory services that are unwarranted and can be harmful (in terms of intrusive and stressful interventions and the uncertain outcomes of foster care) [135-137]. Furthermore, while many social work processes use groups to attempt to include a range of stakeholders, the influence of "group think" can also be negative, wherein group process can lead to a decision that reflects a desire for consensus rather than the best or most accurate decision. Current studies tend to ignore these cognitive processing issues, with many practitioners forced by working conditions to make decisions based on scanty information, under time pressure and in unstructured group decision-making contexts [24]. This impacts on decision variability, as without considered decisions and well-structured systems that support them, the internal variables of biases and values, the impact of a "wicked" learning environment, or "group think", can become primary decision drivers, leading to increased variability.

\section{Conclusions}

This conceptual article discusses selected research as it applies to decision-making variability in the child protection realm. There are some omissions, as to discuss decision-reasoning is to discuss the entirety of the social context, and this is impossible to cover in an article. Nevertheless, this article raises many issues currently driving both between-country and within-country decision variation in response to child abuse and neglect. It highlights factors ranging from the macro to the micro, showing that orientations shape both external and internal variability. They contribute to variations in the ways that the causes of abuse are framed and highlight that child abuse remains subject to intense contestation as to its nature, consequences and best interventions. The impact of responsibilisation in neo-liberal environments, constructions of risk, responses to poverty and inequality, evidence-based practice, contestable views on abuse definitions and its causes and cognitive and systemic decision-making processes present intense challenges to decision consistency. I argue that despite this complex ecological context, finding ways to establish realistic decision systems and direct guidance is more desirable than ever. While concepts from either the "situated actor" of sociology or the naturalistic decision-maker from cognitive psychology are both useful ways to describe how decisions are made in context, neither offers guidance on how decisions should be made. To simply say that the environmental and cognitive issues at play are too complex brushes over the social justice issues at stake. One idea for developing realistic decision guides may be to 
develop complex case exemplars with annotation to highlight decision principles that would apply at each decision point and provide such exemplars for each type of child abuse, for each age of child. Attention to systems to ensure "kind" learning environments that enhance the development of sound professional discretion for practitioners, as well as logical decision pathways embedded in organisational structures are also imperative. Continuing to emphasise critical reflection in social work education and practice is another important aspect of increasing consistency in decision-making, as is addressing the numerous organizational systems, cultural and processual elements of decision-making. However, in addition to these micro-meso solutions, settling the macro framing of child abuse and its ideological dimensions is crucial to improving decision variability. This must include the ongoing commitment of social work to address political and macro issues of access to resources and the harmful effects of neo-liberal individualisation. Ideally, this commitment would result in establishing decision-reasoning processes that acknowledge influences from all levels of the ecological approach on problem causation, as well as the ethical commitments that social work espouses.

\section{Conflicts of Interest}

The author declares no conflict of interest.

\section{References}

1. Fallon, Barbara, Martin Chabot, John Fluke, Cindy Blackstock, Bruce MacLaurin, and Lil Tonmyr. "Placement decisions and disparities among aboriginal children: Further analysis of the canadian incidence study of reported child abuse and neglect part A: Comparisons of the 1998 and 2003 surveys." Child Abuse \& Neglect 37 (2013): 47-60.

2. Baumann, Donald J., L. Dalgleish, John Fluke, and Homer Kern. The Decision-Making Ecology. Washington, DC: American Humane Association, 2011.

3. Arad-Davidzon, Bilhah, and Rumi Benbenishty. "The role of workers' attitudes and parent and child wishes in child protection workers' assessments and recommendation regarding removal and reunification." Children and Youth Services Review 30 (2008): 107-21.

4. Cradock, Gerald. "Thinking goudge: Fatal child abuse and the problem of uncertainty." Current Sociology 59 (2011): 362-78.

5. Gilbert, Neil, Nigel Parton, and Marit Skivenes. Child Protection Systems: International Trends and Orientations. Oxford, UK: Oxford University Press, 2011.

6. Kemshall, Hazel. "Risk rationalities in contemporary social work practice." British Journal of Social Work 40 (2010): 1247-62.

7. Arruabarrena, Ignacia, and Joaquín De Paúl. "Improving accuracy and consistency in child maltreatment severity assessment in child protection services in spain: New set of criteria to help caseworkers in substantiation decisions." Children and Youth Services Review 34 (2012): 666-74.

8. Drake, Brett, and Melissa Jonson-Reid. "Substantiation and early decision points in public child welfare: A conceptual reconsideration." Child Maltreatment 5 (2000): 227-35. 
9. Davidson-Arad, Bilha, Dorit Englechin-Segal, Yochanan Wozner, and Rosy Gabriel. "Why social workers do not implement decisions to remove children at risk from home." Child Abuse \& Neglect 27 (2003): 687-97.

10. Everson, Mark D., and Jose Miguel Sandoval. "Forensic child sexual abuse evaluations: Assessing subjectivity and bias in professional judgements." Child Abuse \& Neglect 35 (2011): 287-98.

11. Davidson-Arad, Bilha, and Rumi Benbenishty. "Contribution of child protection workers' attitudes to their risk assessments and intervention recommendations: A study in Israel." Health \& Social Care in the Community 18 (2010): 1-9.

12. Gillingham, Philip. "Child protection practitioners and decision-making tools: Observations and reflections from the front line." Brisith Journal of Social Work 40 (2010): 2598-616.

13. Mandel, David R., Darrin R. Lehman, and John C. Yuille. "Should this child be removed from home? Hypothesis generation and information seeking as predictors of case decisions." Child Abuse and Neglect 18 (1994): 1051-62.

14. Stokes, Jacqueline, and Glen Schmidt. "Child protection decision making: A factorial analysis using case vignettes.” Social Work 57 (2012): 83-90.

15. Williams, Charlotte, and Haluk Soydan. "When and how does ethnicity matter? A cross-national study of social work responses to ethnicity in child protection cases." British Journal of Social Work 35 (2005): 901-20.

16. Wells, Susan J., Peter Lyons, Howard J. Doueck, C. Hendricks Brown, and Judy Thomas. "Ecological factors and screening in child protective services." Children and Youth Services Review 26 (2004): 981-97.

17. DePanfilis, Diane, and Heather Girvin. "Investigating child maltreatment in out-of-home care: Barriers to effective decision-making." Children and Youth Services Review 27 (2005): 353-74.

18. Forkby, Torbjörn, and Staffan Höjer. "Navigations between regulations and gut instinct: The unveiling of collective memory in decision-making processes where teenagers are placed in residential care." Child \& Family Social Work 16 (2011): 159-68.

19. Keddell, Emily. "Weighing it up: Family maintenance and children's best interests discourses in child protection decision-making." Child \& Family Social Work, 2014. doi:10.1111/cfs.12168.

20. Rossi, Peter H., John Schuerman, and Stephen Budde. "Understanding decisions about child maltreatment.” Evaluation Review 23 (1999): 579-98.

21. Britner, Preston A., and Daniel G. Mossler. "Professionals' decision-making about out-of-home placements following instances of child abuse." Child Abuse \& Neglect 26 (2002): 317-32.

22. Jergeby, Ulla, and Haluk Soydan. "Assessment processes in social work practice when children are at risk.” Journal of Social Work Research and Evaluation 3 (2002): 127-44.

23. Wynd, Donna. Child Abuse: An Analysis of Child Youth and Family Data. Auckland: Child Poverty Action Group, 2013, 
24. Office of the Chief Social Worker. Workload and Casework Review: Qualitative Review of Social Worker Caseload, Casework and Workload Management. Wellington: Child, Youth and Family, 2014,

25. Munro, Eileen. Child Protection. London: Sage, 2007.

26. Duffy, Joe, and Mary Elizabeth Collins. "Macro impacts on caseworker decision-making in child welfare: A cross-national comparison." European Journal of Social Work 13 (2010): 35-54.

27. Cameron, Gary, Marshall Fine, Sarah Maiter, Karen Frensch, and Nancy Freymond. Creating Positive Systems of Child and Family Welfare: Congruence with the Everyday Lives of Children and Parents. Toronto: University of Toronto Press, 2013.

28. Platt, Dendy, and Danielle Turney. "Making threshold decisions in child protection: A conceptual analysis.” British Journal of Social Work 44 (2014): 1472-90.

29. Banks, Sarah. Ethics and Values in Social Work. Basingstoke: Palgrave Macmillan, 2006.

30. Keddell, Emily. "Going home: Managing 'risk' through relationship in returning children from foster care to their families of origin.” Qualitative Social Work 11 (2011): 604-20.

31. Healy, Karen, Yvonne Darlington, and Judith A. Feeney. "Parents' participation in child protection practice: Toward respect and inclusion." Families in Society: The Journal of Contemporary Social Services 92 (2011): 282-88.

32. Spratt, Trevor, and James Callan. "Parents' views on social work interventions in child welfare cases." British Journal of Social Work 34 (2004): 199-224.

33. Tronto, Jane. Moral Boundaries: A Political Argument for an Ethic of Care. New York: Routledge, 1994.

34. Parton, Nigel. "Rethinking professional practice: The contributions of social constructionism and the feminist "ethics of care'." British Journal of Social Work 33 (2003): 1-16.

35. Gray, Mel. "Moral sources and emergent ethical theories in social work." British Journal of Social Work 40 (2010): 1794-811.

36. Holland, Sally. "Looked after children and the ethic of care." British Journal of Social Work 40 (2010): 1664-80.

37. Križ, Katrin, and Marit Skivenes. "Systemic differences in views on risk: A comparative case vignette study of risk assessment in england, norway and the united states (california)." Children and Youth Services Review 35 (2013): 1862-70.

38. Khoo, Evelyn G., Ulf Hyvönen, and Lennart Nygren. "Child welfare or child protection: Uncovering swedish and canadian orientations to social intervention in child maltreatment." Qualitative Social Work 1 (2002): 451-71.

39. Spratt, Trevor. "The influence of child protection orientation on child welfare practice." British Journal of Social Work 31 (2001): 933-54.

40. Hall, Christopher, Nigel Parton, Sue Peckover, and Sue White. "Child-Centric Information and Communication Technology (ICT) and the Fragmentation of Child Welfare Practice in England.” Journal of Social Policy 39 (2010): 393-413.

41. Featherstone, Brid, Sue White and Kate Morris. Re-Imagining Child Protection: Towards Humane Social Work with Families. Bristol: Policy Press, 2014. 
42. Connolly, Marie. Child and Family Welfare: Statutory Responses to Children at Risk. Christchurch: Te Awatea Press, 2004.

43. Fargion, Sylvia. "Synergies and tensions in child protection and parent support: Policy lines and practitioners' cultures." Child and Family Social Work 19 (2014): 24-33.

44. Cradock, Gerald. "Risk, morality and child protection: Risk calculation as guides to practice." Science Technology Human Values 29 (2004): 314-31.

45. Spratt, Trevor. "Possible futures for social work with children and families in Australia, the United Kingdom and the United States." Child Care in Practice 14 (2008): 413-27.

46. Križ, Katrin, and Marit Skivenes. "How child welfare workers view their work with racial and ethnic minority families: The united states in contrast to england and norway." Children and Youth Services Review 33 (2011): 1866-74.

47. Darlington, Yvonne, Karen Healy, and Judith A. Feeney. "Approaches to assessment and intervention across four types of child and family welfare services." Children and Youth Services Review 32 (2010): 356-64.

48. Križ, Katrin, and Marit Skivenes. “We have very different positions on some issues': How child welfare workers in norway and england bridge cultural differences when communicating with ethnic minority families." European Journal of Social Work 13 (2009): 3-18.

49. Skivenes, Marit, and Hanne Stenberg. "Risk assessment and domestic violence- - how do child welfare workers in three countries assess and substantiate the risk level of a 5-year-old girl?" Child and Family Social Work, 2013. doi:10.1111/cfs.12092.

50. Buckley, Helen. Child Protection Practice: Beyond the Rhetoric. London: Jessica Kingsley Publishers, 2003.

51. Križ, Katrin, and Marit Skivenes. "Street-level policy aims of child welfare workers in england, norway and the united states: An exploratory study." Children and Youth Services Review 40 (2014): 71-78.

52. Lonne, Bob, and Nigel Parton. "Portrayals of child abuse scandals in the media in Australia and England: Impacts on practice, policy, and systems: Most media coverage distorts the public understandings of the nature of child maltreatment." Child Abuse Negl 38 (2014): 822-36.

53. Beck, Ulrich. World Risk Society. Cambridge, UK: Polity Press, 1992.

54. Alaszewski, Andy, and Adam Burgess. "Risk, time and reason." Health, Risk \& Society 9 (2007): 349-58.

55. Rose, Nikolas. "Governing 'advanced' liberal democracies." In Foucault and Political Reason: Liberalism, Neo-Liberalism and Rationalities of Government. Edited by Andrew Barry, Thomas Osborne and Nikolas S. Rose. London: UCL Press, 1996.

56. Gillingham, Philip. "Risk assessment in child protection: Problem rather than solution?" Australian Social Work 59 (2006): 86-98.

57. Broadhurst, Karen, Chris Hall, David Wastell, Sue White, and Andy Pithouse. "Risk, instrumentalism and the humane project in social work: Identifying the informal logics of risk management in children's statutory services." British Journal of Social Work 40 (2010): $1046-64$. 
58. Vaithianathan, Rhema, Tim Maloney, Emily Putnam-Hornstein, and Nan Jiang. "Children in the public benefit system at risk of maltreatment: Identification via predictive modeling." American Journal of Preventive Medicine 45 (2013): 354-59.

59. Rose, Nikolas. Powers of Freedom. Cambridge, UK: Cambridge University Press, 1999.

60. Stanford, Sonya. "'Speaking back' to fear: Responding to the moral dilemmas of risk in social work practice.” British Journal of Social Work 40 (2010): 1065-80.

61. Munro, Eileen. "Improving practice: Child protection as a systems problem." Children and Youth Services Review 27 (2005): 375-91.

62. Marston, Greg, and Catherine McDonald. "Getting beyond 'heroic agency' in conceptualising social workers as policy actors in the twenty-first century." British Journal of Social Work 42 (2012): 1022-38.

63. Parton, Nigel. "Child protection and safeguarding in England: Changing and competing conceptions of risk and their implications for social work." British Journal of Social Work 41 (2011): 854-75.

64. Houston, Stan, and Huw Griffiths. "Reflections on risk in child protection: Is it time for a shift in paradigms?" Child and Family Social Work 5 (2000): 1-10.

65. Houston, Stan. "Meta-theoretical paradigms underpinning risk in child welfare: Towards a position of methodological pragmatism." Children and Youth Services Review 47 (2013): 55-60.

66. Schwalbe, Craig S. "Strengthening the integration of actuarial risk assessment with clinical judgement in an evidence based practice framework." Children and Youth Service Review 30 (2008): 1458-64.

67. Munro, Eileen, Julie Taylor, and Caroline Bradbury-Jones. "Understanding the causal pathways to child maltreatment: Implications for health and social care policy and practice." Child Abuse Review 23 (2014): 61-74.

68. Munro, Eileen. "Confidentiality in a preventive child welfare system." Ethics and Social Welfare 1 (2007): 41-55.

69. Kahneman, Daniel, Paul Slovic, and Amos Tversky. Judgments under Uncertainty: Heuristics and Biases. Cambridge, UK: Cambridge University Press, 1990.

70. France, Alan, Kate Freiburg, and Ross Homel. "Beyond risk factors: Towards a holistic prevention paradigm for Children and Young People." British Journal of Social Work 40 (2010): 1192-210.

71. Stanley, Tony. "Risky work: Child protection practice." Social Policy Journal of New Zealand 30 (2007): 163-93.

72. Shlonsky, Aron, and David Wagner. "The next step: Integrating actuarial risk assessment and clinical judgment into an evidence-based practice framework in cps case management." Children and Youth Services Review 27 (2005): 409-27.

73. Munro, Eileen. The Munro Review of Child Protection: Final Report, a Child-Centred System. London: The Stationary Office Limited, 2011.

74. Gillingham, Philip, and Leah Bromfield. "Child protection, risk assessment and blame ideology." Children Australia 33 (2008): 18-24. 
75. Turnell, Andrew. Adoption of Signs of Safety as the Department for Child Protection's Child Protection Practice Framework. Perth: Government of Western Australia, 2008.

76. Saleebey, Dennis. The Strengths Perspective. Kansas: Strengths Institute, University of Kansas, School of Social Welfare, 2010.

77. Turnell, Andrew, and Steve Edwards. Signs of Safety: A Solution and Safety Oriented Approach to Child Protection Casework. London: W.W. Norton and Company, 1999.

78. Keddell, Emily. "Theorising the signs of safety approach to child protection social work: Positioning, codes and power." Children and Youth Services Review 47 (2014): 70-77.

79. Bywaters, Paul, Geraldine Brady, Tim Sparks, and Elizabeth Bos. "Child welfare inequalities: New evidence, further questions." Child \& Family Social Work, 2014. doi:10.1111/cfs.12154.

80. Bywaters, Paul, Geraldine Brady, Tim Sparks, and Elizabeth Bos. "Inequalities in child welfare intervention rates: The intersection of deprivation and identity." Child \& Family Social Work, 2014. doi:10.1111/cfs. 12161.

81. Stokes, Jacqueline, and Glen Schmidt. "Race, poverty and child protection decison making." Brisith Journal of Social Work 41 (2011): 1105-21.

82. Cancian, Maria, Kristen Shook Slack, and Mi Y. Yang. The Effect of Family Income on Risk of Child Maltreatment. Wisconsin: Institute for Research on Poverty, 2010.

83. Paxson, Christina, and Jane Waldfogel. "Welfare reforms, family resources, and child maltreatment." Journal of Policy Analysis and Management 22 (2003): 85-113.

84. Slack, Kristen Shook, Jane L. Holl, Bong Joo Lee, Marla McDaniel, Lisa Altenbernd, and Amy Bush Stevens. "Child protective intervention in the context of welfare reform: The effects of work and welfare on maltreatment reports." Journal of Policy Analysis and Management 22 (2003): 517-36.

85. Bywaters, Paul, Geraldine Brady, Tim Sparks, and Elizabeth Bos. Deprivation and Inequalities in Children's Services-Research Briefing Paper 1. Coventry: Coventry University, 2014, pp. 1-4.

86. Moraes, Sabrina, Joan E. Durrant, Douglas Brownridge, and Grant Reid. "Professionals' decision-making in cases of physical punishment reported to child welfare authorities: Does family poverty matter?" Child and Family Social Work 11 (2006): 157-69.

87. Keddell, Emily. "Beyond care versus control: Decision-making discourses and their functions in child protection social work." Ph.D. Thesis, University of Otago, Dunedin, New Zealand, 2013, p. 517.

88. Fook, Jan, Sue White, and Fiona Gardener. Critical Reflection in Health and Social Care. Maidenhead: Open University Press, 2006.

89. Keddell, Emily. "The white paper on vulnerable children and welfare reform in aotearoa new zealand: Two sides of the same coin?" Paper presented at Social Work, Social Development Conference, Melbourne, Australia, 13 July 2014. 
90. Lopez, Monica, Cilia Witteman, Rumi Benbenishty, Bilha Davidson-Arad, Jorge F. del Valle, and Trevor Spratt. "Cross-national comparison of caseworker's attitudes towards child welfare issues and their impact in assessments and decisions to place a child out of home." Paper presented at 7th International Foster Care Research Netwpork Meeting-Foster care in Europe: What do we know about outcomes and evidence, Padova, Italy, 9-11 September 2013.

91. Appleyard, Karen, Lisa Berlin, Katherine Rosanbalm, and Kenneth Dodge. "Preventing early child maltreatment: Implications from a longitudinal study of maternal abuse history, substance use problems, and offspring victimization." Prevention Science 12 (2011): 139-49.

92. Kahneman, David. Thinking: Fast and Slow. New York: Farrar, Strauss and Giroux, 2011.

93. Kearney, Jeremy. "Perceptions of non-accidental child deaths as preventable events: The impact of probability heuristics and biases on child protection work." Health, Risk \& Society 15 (2013): 51-66.

94. Munro, Eileen. Effective Child Protection. London: Sage, 2002.

95. National Research Council. Understanding Child Abuse and Neglect. Washington, DC: Research Council, 1993.

96. Herrenkohl, Roy C. "The definition of child maltreatment: From case study to construct." Child Abuse \& Neglect 29 (2005): 413-24.

97. D'Cruz, Heather. "The social construction of child maltreatment." Journal of Social Work 4 (2004): 99-123.

98. White, Anne. Assessment of Parenting Capacity: Literature Review. NSW: Centre for Parenting and Research, 2005.

99. Waquant, Loiz. Prisons of Poverty. Minneapolis: University of Minnesota Press, 2009.

100. Cradock, Gerald. "Who owns child abuse?" Social Sciences 3 (2014): 854-70.

101. Pritchard, Colin, Jill Davey, and Richard Williams. "Who kills children? Re-examining the evidence." British Journal of Social Work 43 (2013): 1403-38.

102. Macdonald, Geraldine, and Kenneth Macdonald. "Safeguarding: A case for intelligent risk management." British Journal of Social Work 40 (2010): 1174-91.

103. Parton, Nigel. "Social work, child protection and politics: Some critical and constructive reflections." British Journal of Social Work 44 (2014): 2042-56.

104. Vaithianathan, Rhema. Can Administrative Data Be Used to Identify Children at Risk of Adverse Outcomes? Auckland: Business Shcool, Department of Economics, University of Auckland, 2012.

105. Child Youth and Family Service. "Key statistics and information for media." 2014. Available online: http://www.cyf.govt.nz/about-us/who-we-are-what-we-do/information-for-media-backup. html (accessed on 8 August 2014).

106. Trocmé, Nico, Alicia Kyte, Vandna Sinha, and Barbara Fallon. "Urgent protection versus chronic need: Clarifying the dual mandate of child welfare services across canada." Social Sciences 3 (2014): 483-98. 
107. Wolfe, David. "Risk factors for child abuse perpetration." In Violence against Women and Children, Vol 1: Mapping the Terrain. Edited by Jacquelyn W. White, Mary Koss and Alan Kazdin. Washington, DC: American Psychological Association, 2011.

108. Daniel, Brigid, and Alison Bowes. "Re-thinking harm and abuse: Insights from a lifespan perspective." British Journal of Social Work 41 (2011): 820-36.

109. Chan, Jasmine S., John M. Elliott, Yvonne Chow, and Joyce I. Thomas. "Does professional and public opinion in child abuse differ? An issue of cross-cultural policy implementation." Child Abuse Review 11 (2002): 359-79.

110. Friend, Colleen, Aron Shlonsky, and Liz Lambert. "From evolving discourses to new practice approaches in domestic violence and child protective services." Children and Youth Services Review 30 (2008): 689-98.

111. Fantuzzo, John, Robert Boruch, Abdullahi Beriama, Marc Atkins, and Susan Marcus. "Domestic violence and children: Prevalence and risk in five major U.S. Cities." Journal of the American Academy of Child and Adolescent Psychiatry 36 (1997): 116-22.

112. Cross, Theodore P., Ben Mathews, Lil Tonmyr, Debbie Scott, and Catherine Ouimet. "Child welfare policy and practice on children's exposure to domestic violence." Child Abuse \& Neglect 36 (2012): 210-16.

113. Humphreys, Cathy. Issues Paper 13: Domestic Violence and Child Protection: Challenging Directions for Practice. Sydney: Australian Domestic and Family Violence Clearing House, University of New South Wales, 2007.

114. McGuigan, William M., and Clara C. Pratt. "The predictive impact of domestic violence on three types of child maltreatment." Child Abuse \& Neglect 25 (2001): 869-83.

115. Edleson, Jeffrey L. "The overlap between child maltreatment and woman battering." Violence Against Women 5 (1999): 134-54.

116. Kohl, Patricia L., Richard P. Barth, Andrea L. Hazen, and John A. Landsverk. "Child welfare as a gateway to domestic violence services." Children and Youth Services Review 27 (2005): 1203-21.

117. Moles, Kerry. "Bridging the divide between child welfare and domestic violence services: Deconstructing the change process." Children and Youth Services Review 30 (2008): 674-88.

118. Kim, Mimi E. "Challenging the pursuit of criminalisation in an era of mass incarceration: The limitations of social work responses to domestic violence in the USA." British Journal of Social Work 43 (2013): 1276-93.

119. Hester, Marianne. "The three planet model: Towards an understanding of contradictions in approaches to women and children's safety in contexts of domestic violence." British Journal of Social Work 41 (2011): 837-53.

120. Keeling, June, and Katherine van Wormer. "Social worker interventions in situations of domestic violence: What we can learn from survivors' personal narratives?" British Journal of Social Work 42 (2012): 1354-70. 
121. Banks, Duren, Andrea L. Hazen, Jeffrey H. Coben, Kathleen Wang, and Janet D. Griffith. "Collaboration between child welfare agencies and domestic violence service providers: Relationship with child welfare policies and practices for addressing domestic violence." Children and Youth Services Review 31 (2009): 497-505.

122. Cleaver, Hedy, Deborah Nicholson, Sukey Tarr. Child Protection, Domestic Violence and Parental Substance Misuse: Family Experiences and Effective Practice. London: Jessica Kingsley Publishers, 2007.

123. Fleck-Henderson, Ann. "Domestic violence in the child protection system: Seeing double." Children and Youth Services Review 22 (2000): 333-54.

124. Stanley, Nicky, Pam Miller, Helen Richardson Foster, and Gill Thomson. "A stop-start response: Social services' interventions with children and families notified following domestic violence incidents.” British Journal of Social Work 41 (2011): 296-313.

125. Lapierre, Simon. "Mothering in the context of domestic violence: The pervasiveness of a deficit model of mothering." Child and Family Social Work 13 (2008): 434-63.

126. Lapierre, Simon. "More responsibilities, less control: Understanding the challenges and difficulties involved in mothering in the context of domestic violence." British Journal of Social Work 40 (2010): 1434-51.

127. Landsman, Miriam J., and Carolyn Copps Hartley. "Attributing responsibility for child maltreatment when domestic violence is present." Child Abuse \& Neglect 31 (2007): 445-61.

128. Munro, Eileen. "Common errors of reasoning in child protection work." Child Abuse and Neglect 23 (1999): 745-58.

129. Van de Luitgaarden, Guido M. J. "Evidence-based practice in social work: Lessons from judgement and decision theory." British Journal of Social Work 39 (2007): 1-18.

130. De Bortoli, Lillian, and Mairead Dolan. "Decision making in social work with families and children: Developing decision-aids compatible with cognition." British Journal of Social Work, 2014. doi:10.1093/bjsw/bcu087.

131. Munro, Eileen. "Learning to reduce risk in child protection." British Journal of Social Work 40 (2010): 1135-51.

132. Schraagen, Jan Maarten, Gary Klein, and Robert R. Hoffman. "The macrocognition framework of naturalistic decision making." In Naturalistic Decision Making and Macrocognition. Edited by Jan Maarten Schraagen, Laura G. Militello, Tom Ormerod and Raanan Lipshitz. Hampshire: Ashgate, 2008, pp. 3-26.

133. Klein, Gary, and Robert R. Hoffman. "Macrocognition, mental models and cognitive task analysis." In Naturalistic Decision Making and Macrocognition. Edited by Jan Maarten Schraagen, Laura G. Militello, Tom Ormerod and Raanan Lipshitz. Hampshire: Ashgate, 2008, pp. $57-80$.

134. Hogarth, R. Deciding Analytically or Trusting Your Intuition? The Advantages and Disadvantages of Analytic and Intuitive Thought. Barcelona: Departament d'Economia i Empresa, Universitat Pompeu Fabra, 2002.

135. Scott, Dorothy, and Di O'Neil. Beyond Child Rescue: Developing Family Centred Practice at St Lukes, 2nd ed. St Leonards: Allen \& Unwin, 2003. 
136. Pritchett, Rachel, Christopher Gillberg, and Helen Minnis. "What do child characteristics contribute to outcomes from care: A prisma review." Children and Youth Services Review 35 (2013): 1333-41.

137. Doyle, Joseph J. “Causal effects of foster care: An instrumental-variables approach.” 2011. Available online: http://www.mit.edu/ jjdoyle/doyle_cysr.pdf (accessed on 28 July 2014). 


\title{
The Productive Uses of Conflict in Child Protection
}

\section{Doug Magnuson}

\begin{abstract}
Some child protection cases exemplify a certain kind of cooperative interdependence, a consequence of the ways in which practitioners and clients are entangled. Client and practitioner are "stuck" with each other and need each other to succeed. There is also an intrinsic power imbalance that technique, ideology, and skill cannot hide and that has risks for the well-being and success of the practitioner-client relationship. There is also a risk to the practitioner of biases caused by successful influence. "Productive conflict," defined as conflict under conditions of cooperative interdependence, may compensate for these challenges and lead to "integrative solutions." In these cases the conflict itself is a kind of collaboration.
\end{abstract}

Reprinted from Soc. Sci. Cite as: Magnuson, D. The Productive Uses of Conflict in Child Protection. Soc. Sci. 2014, 3, 672-686.

\section{Introduction}

Child protection practitioners go to great lengths to mitigate conflict with clients, even though the context makes conflict probable. Most researchers do not include conflict between practitioners and parents as a variable, even though conflict is a frequent occurrence in everyday practice. In recent years solution-focused [1], response-based [2], relationship-based practice [3,4], and similar frameworks have been adopted by policy-makers, trainers, and practitioners with the aim of making collaboration more likely, and a background assumption is that collaboration and conflict are inversely related. That is, as collaboration increases, conflict should decrease.

Perhaps, but the benefits of conflict are under-theorized in the child protection research literature. Practitioners know a lot about it, but they do not receive much help, and in everyday practice they may receive the message that conflict is bad; still, experienced practitioners know many cases of good outcomes coexisting with serious conflict. Collaboration is a laudable goal, yet most practitioner-client relationships are unpredictable, and the emphasis on collaboration, partnership, and participation suggest a kind of stability and predictability that does not always fit the everyday practice.

Some researchers over the years have documented these gaps between our ideals of collaboration and participation and everyday practice. Bell cited Thoburn, Lewis, and Shemmings, who found that only 16 percent of parents described having a "full partnership" ([5], p. 439) with the caseworkers, and Bell suggests that the promise of partnership can have the risk of raising parental expectations that are often disappointed. Corby, Millar and Young [6] found that professionals and parents disagreed widely about the experience of parental participation, with professionals being overwhelming positive, while only 18 percent of parents thought it was positive. Parents approved of the idea of participation, but they did not feel as if they influenced the process. 
Trotter said that parents and practitioners disagreed about the frequency of practitioners' use of collaborative skills. "...the clients felt that their practitioners used the skills about half the time, whereas the practitioners believed that they used the skills most of the time..." ([7], p. 46). Platt [8] summarized several studies of congruence and similarity of perception and reported rates of congruence between practitioners and clients from fair to high, although one study that found a high rating also found that parents' expectations of relief from stress were higher than that of practitioners. Another study cited by Platt found that half of the mothers in the child protection sample disagreed with the findings in the early stages of an investigation.

Dumbrill says that "Parents reported responding to intervention in three ways: (1) 'fighting' through openly challenging and opposing practitioners in court; (2) 'playing the game' by feigning co-operation; and (3) working with services in what appeared to be genuine and collaborative relationships" ([9], p. 33). Altman found that professionals had difficulty being honest with clients about their true feelings and were afraid of confrontation. In contrast, clients said, "Come out and tell me, don't beat around the bush just tell me. You know, don't sit there and worry about my feelings. Just tell me. You know I might not like what I hear, you know, but I'd rather somebody be honest with me" ([10], p. 49). It is easy to misread compliance as cooperation, even seeing it as the first step on the way. An additional risk of the differences in role and perception is the gap between how services are intended to be used and how they are implemented: "fidelity to practice". For example, Vesneski [11] described how family group decision-making models are too often used without private time for the family, the most important feature.

Rather than seeing these differences as issues of inadequate skill and training, some have argued that they are consequences of the structure of the situation and that it is unrealistic to expect them to go away. Mayer [12] says that the child protection situation is such that "...the power of the family has to be circumscribed and enhanced at the same time". Similarly, Maiter, Palmer, and Manji [13] said that "The imbalance of power in the CPS (Child Protection System)-parent relationship is a central aspect of the relationship." Their parent participants described the positive aspects of professionals as caring, genuine, empathetic, exceptionally helpful, listening, non-judgmental, and accepting. They did not like practitioners who were "judgmental, cold and uncaring, poor listeners, critical and insincere".

These are not surprising lists, and they are often presented as "should". Yet it is possible that these are post hoc descriptions rather than causes of good outcomes, a kind of tautology. Another example of this tautological conclusion comes from Dore and Alexander who said that the "helping alliance" ([14], p. 182) was characteristic of success. But this is a post hoc judgment: It's a helping alliance when it helps, and it begs the question how that success is achieved when a relationship modeled on therapeutic ideals is not possible. There may be fewer cases where "helping alliances"-in the counseling sense of the phrase-are possible and more cases where other interpretations are needed.

As Reich said, a practitioner's implicit message to clients is: "We work for the government. We're here to help." ([15], p. 22). Also Trotter [7] said that practitioners act in the legalistic/surveillance helping/therapeutic/problem-solving roles at the same time. This is an uneasy alliance and suggests that an easy integration of principles adopted from other kinds of practices, like therapy, is not 
always possible. Practitioners and theorists have made progress in reconceptualizing collaboration and in integrating collaboration into child protection practice. Family group conferencing is one good example. Still, in most practice the unequal power relationship will persist, not all relationships will be rosy and, especially, imposing the expectations of a warm relationship, at least initially, is not always realistic even if it is desirable. As well, some of the research cited above suggests that some warm relationships may be characterized by "feigning cooperation" and compliance rather than true collaboration. Yet the uneasiness with unequal power relationships is legitimate and well-intentioned. One reason to be concerned has to do with what Kipnis [16] called the "metamorphic" effects of power.

\section{How Power Affects the Powerholder}

In a series of studies Kipnis [16,17] and his colleagues studied the "metamorphic" effects of power on the powerholder, and their findings can help us interpret the particular and unusual characteristics of the practitioner-client relationship in child protection. Kipnis [18] says there are two main elements of the metamorphic effects of power: (1) the strength of the influence tactics used to persuade, and (2) the subsequent attributions of the influencing agent concerning who controls behavior - the target or external forces. The stronger the tactic the more the influencer attributes change to him- or herself [19,20].

Kipnis studied these effects in a wide variety of settings, including counseling, where therapists who used more behavioral technology and more technique were found to (a) distance themselves from their clients; (b) attribute changes in clients to their own abilities; and (c) attribute a lack of change to the client's inabilities. Moreover, Kipnis says, “...the very act of successfully influencing causes devaluation of the target person" ([16], p. 177). In this dynamic is the potential for metamorphic effects in child protection. Even convincing a family to participate in a collaborative method such as mediation or family group conferencing is an act of influence.

I suggest here two additional metamorphic effects that warrant further study. One is that the use of empathy in child protection, when aligned with standard interpretations and ideologies, is subject to metamorphic effects. Kipnis argued that the use of technique, such as cognitive-behavioral therapy, increases the chances of influencers attributing change to the technique and their own skill rather than to the competence of the target [21-24]. Empathy, as an attitude, skill, and value in child protection, may have a similar effect in that in an odd way it risks mechanizing the work such that the practitioner comes to view the client as a victim of poverty, of oppression, of violence, of the system, and the client's own abilities are unintentionally devalued and the practitioner's abilities to free the client from oppression are overrated. This interpretation has been suggested by practitioners.

It is consistent with Trotter's [25] work, where he suggests that empathy in non-voluntary work has risks of giving approval to client behavior. There is also an intriguing, if undocumented, application of the theory to the ways in which organizations attempt to monitor and supervise child protection practitioners. There is substantial literature these days [26] debating how much discretion professionals do or should have. Of interest to this discussion is that one of the implications of the social psychology of power is that organizations themselves, when they manage by rules, may be subject to metamorphic effects, attributing success to the organization and blaming professionals for failures. Yet again, even when practitioners adopt collaborative practices, the context makes more 
likely over-confidence in one's own abilities and the devaluing of clients' agency. Kipnis' studies, described above, suggest that it is not easily escaped.

In the light of these challenges of and to child protection practice, is it possible that there is some proportion of practice that results in successful outcomes despite few of our preferred characteristics of collaborative practice? For example, Rooney [27] cites Cingolani who believed that practitioners have been taught to value the therapeutic relationship as the good relationship. Everything else gets defined as "not-good". Perhaps a collaborative relationship understood as a therapeutic relationship is not always necessary - even if it would be fantastic if it were possible - and perhaps there is at least a substantial minority of child protection cases in which conflict is not a barrier but an impetus to better outcomes, in part by compensating for metamorphic effects. Perhaps conflict of a certain type is evidence of a different kind of collaboration. In the studies from which this argument is drawn professionals and clients reported in interviews and casual conversations some cases in which there was a successful outcome, as measured by both client and professional satisfaction, in which there was neither much congruence of understanding nor much warmth, augmented by serious and sometimes intense conflict. Moreover, this conflict seemed - by all accounts - to have a beneficiary effect on the outcome. How can we understand these cases?

It is possible that some literature on the social psychology of conflict and the metamorphic effects of power may help us understand the psychological and phenomenological experience of conflict in child protection. More strongly, I argue that in certain cases conflict may be a practical and ethical necessity for serving the client well. Conflict, at least of a certain type, may make integrative solutions possible.

\section{Background}

Child protection in Canada is a legally mandated profession with the responsibility to investigate possible cases of child abuse and neglect. In the Anglo-Canadian liberal political model [28] the right of government to intrude on individual and family life is limited, and child protection is a boundary-crossing profession: It has a legal mandate to investigate the most private acts of family life within a political system where such acts are usually prohibited [29]. Not surprisingly, in this context the majority of initial contact with families involves some explicit and implicit conflict. It is shocking to be visited by a child protection practitioner.

The cases that are cited here are from two different but related studies. For a year, the offices of two child protection teams were the location of an ethnographic study using observation and interviews. Two researchers participated in team meetings and meetings with community partners, listened to phone calls, observed case conferences between practitioners, and conducted several interviews each day with practitioners about cases and about their thought processes and work strategies. In the second study, a researcher selected domestic violence cases from one of the teams and then interviewed the practitioners and the clients and collected data from the case files. In each setting there were several cases that resulted in successful outcomes but that began with intense disagreement and conflict. The theory and observations here are from both studies, although in the case of the ethnographies we have data only from practitioners. 
Fine [30] distinguished between ethnographies that are peopled, postulated and personal. Although the ethnography from which these case are drawn was peopled, with extensive, detailed data, the format of this essay is postulated, focusing on theory development, supported by a small amount of empirical data about cases in which collaborative expectations for how practitioners and clients should or do behave were not present but whose outcomes were positive and acceptable to client and practitioner.

\section{An Example}

This extended quotation is from a woman who was the victim of domestic violence. The police called child protection because the children witnessed the violence-which in British Columbia is considered a risk of emotional harm - and because no family member was willing to take in the children. Familial reasons for reluctance to take children are often complicated and may be as simple as availability but can also be a result of the threat of having to cope with the violent father or it may be because cooperating with the child protection authorities is perceived by some to be a betrayal. This woman was not the target of the intervention: The perpetrator of the problem was the father, who beat her badly in front of the children. The situation would seem to invite a collaborative, participative approach. Yet the mother initially rejected the very terms of the relationship.

It was kind of hard at first actually because I wasn't in the greatest state, physically or in any way really. And I know that, here specifically, a lot of the Native people have problems with that-with their families and their children and they like to...I don't know, they pretty much stereotyped me. I specifically said "Do not stereotype me, I'm not like the other Native people in this town. I'm not like that, and I have to tell you that." Because of the way she was talking to me, I knew what she was doing and I knew what she was trying to put upon me. I told her, "Don't do that, because I'm not like that. I've gotten myself into a really bad situation but...." I just told her not to. That was a really big thing was that she did stereotype at the beginning me along with the other families that she has dealt with in the Native community...

So can you give me an idea of how she stereotyped you?

It was - she actually, just the certain terms that she used. She said "Native people" and I knew what she said and I said "What do you mean by that?" I asked her about it and I asked her to explain it to me and she was like "Oh, it's not like that." And I said "You just said that." And I was mad and I knew what she was doing and she knew it. I said "Yeah, I may be messed up but you can't look at me like this. Because she wanted to take my kids away from me. And I told her "no." And they did actually take away my kids for like a week and it was really hard for my kids and myself. Like my kids will never forget that... I thought that they would be with family but they were actually with mandated people. I don't know how it works out like that or why it works out like that but that's just what happened. And that didn't bother me because I told her that I was going to get my kids back and they're maybe not with me right now, but I'm going to get them back as soon as I can. And I think that it took less than a week for me to get 
my kids back from them. They didn't think that was okay, that's how bad it was, they didn't think that I was okay enough to take care of my kids. But I didn't care. I didn't want anyone taking care of my kids.

How did you get your kids back so quickly? That's a pretty quick turnaround time.

I told them I was going to take care of my kids and that's all I told them. I told them, I don't want anyone else watching my kids. I said, "I know I'm not in the greatest state but I want to take care of my kids." and they let me...When we were all done with her she apologized to me. And she said sorry to me for doing it.

And in terms of the violence how did they respond to that?

...they were really good with that part. They really made sure that we did what we needed to do and got where we needed to go and got what we needed done done and everything was thoroughly taken care of when it came to that.

So how did that work?

I was really mad at her. I told her that I was going to do what I needed to do. And they told me that if I was to go to-because I kept saying that I wanted to have my children - they said that I would have to go into a transition house to have my kids back and I did.

And so would you have done that anyways do you think or was that something...?

I don't know. I don't think that I would have done that. They made me do it and it was a good thing that I did it; it helped a lot. I learned a lot and I got a lot of help with my kids. I got a lot of help. Well the whole thing was that it happened and it was going to happen again, is what she said....I mean I was pretty messed up. And she told him that he needed to get the help that he needed to get and told him what he could do and he went and did all of it because he wanted to change. And it all-I guess, with their system, it helped things smooth out in that area.

The client's portrayal of the situation is fascinating because her children were not removed under a mandated protection order; the Ministry provided temporary care because no one else was available. The mother was not a suspect. On the face of it, there was no obvious reason for a conflict between practitioner and client; they ought to be allies. But this did not happen. One source of conflict in cases like this is disagreement about how to protect the children from witnessing further violence, and another is how to protect the victim from further assaults - and these were certainly concerns.

Most fundamentally, though, the mother initially rejected the definition of the situation, including the terms of the relationship and any suggestion that she was a typical "Native" or a typical protective services client. She insisted that she wanted to reunite with her husband. She rejected sympathy and empathy as patronizing and perceived attempts to help as stereotyping. The argument here, based on interviews with the client and the practitioner, is that the client's forceful rejection of the terms and the initiation of a conflict is not adequately accounted for by ordinary ways of conceiving collaboration and client participation. 
Her position led to almost everything being negotiated. At this point it was a bargaining relationship. Client and practitioner are not allied around mutual goals and collaborative processes. For example, even though the children were under a voluntary care order and mom had rights to see them and have them back, she says they made her go to a transition house before she could have her children back. Whether they "made her" or not, she felt pressured, and she reports that it was a good thing. The immediate outcome, important to the practitioner, was that the children and mom were safe. An immediate outcome, important to mom, was that she be perceived as being in charge of her children. Eventually her husband completed treatment for alcohol addiction, stopped being violent, and they reunited.

\section{Influence, Resistance, and Bargaining: Persuasion in Child Protection}

In social psychological studies, the target of a powerholder's influence is usually in a situation where they can leave if it is too uncomfortable. Employees are an example [31]. Families, though, who are the target of child protection cannot usually flee, and while they do have available to them methods like feigning cooperation, as described above, they also do in fact quite frequently resist and bargain in somewhat surprising situations. They may resist because they feel they have no other choice. They may resist because they are aggrieved, offended, and sense the loss of dignity. They may resist because they are innocent. Power operates in a unique way, because families cannot usually escape and the powerholder has an interest in a resolution of the situation.

In these studies families used compliance, which can mislead practitioners and slow down their progress. They make the professional life of practitioners uncomfortable. They try to embarrass practitioners for using their authority. They befriend and "warm up to" as an ingratiation strategy. They work to delegitimize the practitioner and the Ministry by portraying them in unflattering ways. They may charge the practitioner with unethical practices. It can be punishing to practitioners to remove a child. Reder, Duncan, and Gray [32] documented some of these strategies, and they also described "disguised noncompliance" and "feigned compliance". On the one hand, clients pretend to comply, and on the other they also offer capitulation as a way to get rid of the practitioner. Families manage their availability. They move to make it harder to track them. They move activities out of public view. Without a doubt, clients have less power. Still, because of their interdependence with practitioners, they have a forum for both active and passive resistance.

The choice of influence strategy by practitioners may indicate something interesting about how the ambivalence practitioners feel about their own authority. O’Neal, Kipnis, and Craig [33] describes several influence strategies such as foot-in-the-door, door-in-the-face, collegial decision-making, one or two-sided arguments, communicator credibility, and dissonance arousal. They say that these strategies are typically used by the less powerful to influence powerholders. Practitioners commonly use these strategies. They have an incentive to use the least aggressive approaches, sometimes because they perceive more direct approaches as raising the possibility of retaliation by clients, using strategies noted above. It also reflects the perception by many practitioners that while they have ultimate authority, this authority is somewhat dichotomous, with softer approaches on one side and more aggressive approaches on the other. 
This is the location of one kind of gap between practitioners' viewpoint and families' viewpoint. Under conditions of unequal power, families may perceive weak influence methods as less as an offer of collaboration than as a kind of ingratiation strategy on the part of practitioners to gain influence to find out what they want to know. Altman [10] reports that clients preferred practitioners to be direct and honest and come to the point, for example - the language of partnership and cooperation can be deceptive and dishonest. To build relationship, one practitioner in this study reported lying about having children. In the dynamics between practitioners and some families, it is likely that - in some cases - the offer of assistance will be perceived as disingenuous, and this may be a realistic assessment on the part of families.

These types of persuasion and the context in which it occurs is conflictual, a "negotiated relationship" ([27], p. 176), and are better characterized as bargaining than as therapy. However, conflict can be constructive or destructive.

\section{Productive and Destructive Conflict}

A key to whether conflict is helpful to the relationship and to the outcome in child protection hinges on whether practitioners and clients share a common fate. Morton Deutsch [34] said that conflict can be either destructive or constructive, and whether it is destructive or constructive depends on whether the structure of social interdependence is cooperative, competitive, or individualistic. Cooperative interdependence is present when my success depends upon your success and my failure results in your failure. Competitive interdependence is present when one can succeed only when the other party fails. Individualistic interdependence is present when my failure or success does not depend on your failure or success. In sum, conflict is more likely to be productive and helpful under conditions of cooperative interdependence and destructive under conditions of competitive interdependence.

On the face of it, a child protection case appears to be a competitive situation. If I am the client who is being investigated, the practitioner — and the State - have far more power, and because of that power I may perceive that I have fewer options and that doing what the practitioner-and the State - wants is my only option, even when I disagree. I may feel forced to comply, hardly a cooperative relationship. Also, the presence of conflict suggests a competitive interpretation. Yet it is not the presence of conflict that matters: It is the reward structure, that is, whether the reward structure is such that practitioners and families succeed or fail together.

One of the symptoms of an unusual reward structure in child protection is that families and practitioners do not always respond to each other in the way we would expect: Conflict is likely, yet there are interesting elements of an interdependence, although of an unusual kind. Second, coupled with this interdependence is a situation where an imbalance of power is intrinsic to the context, and the stark reality of this imbalance of power may bias our interpretation.

The child protection relationship with families may need to be reinterpreted with social interdependence in mind. From the point of view of the parent, most of the perceived, possible outcomes of the investigation are bad. The issue is emotional, often embarrassing, associated with other life conditions of which he or she is often not proud, including poverty, drug or alcohol abuse, or poor parenting. An audience of neighbors and relatives waits for the drama. From the point of 
view of the practitioner the situation is no better. It is an investigation, not a counseling visit, and she is legally required to look for evidence of bad behavior. There is always the potential to be required to remove the child or to demand that the parent change behavior. It is painful to find harm to a child. She faces a family that is not happy to see her. She is expected by her agency to "collaborate" with the family, but she is expected by the law and society to protect the child at all costs.

Therefore, we have a practitioner and a family in a difficult position. The practitioner has to act. The family may feel "up against it", and so they resist because they cannot walk way and for the sake of their own dignity, it would seem that the parents would want to resist cooperating, to deny any problems, and to stake their claim to the right to raise their children as they see fit. Thus families and practitioners are stuck with each other. This "stuckness" is a kind of interdependence from which neither party can easily extricate themselves and that usually requires them to work together, even if that working together is conflictual. As Ansell and Gash say, “...deadlock itself imposes a serious cost on both sides of dispute... high conflict per se is not necessarily a barrier to collaborating" ([35], p. 553).

\section{Reframing Success}

I have described some child protection cases as being characterized by a certain kind of cooperative interdependence, a consequence of the ways in which practitioners and clients are entangled. Client and practitioner are "stuck" with each other and need each other to succeed. There is also an intrinsic power imbalance that technique, ideology, and skill cannot hide and that has risks for the well-being and productivity of the practitioner-client relationship. The power imbalance is intrinsic, and the solution is not to take away the practitioner's power but to recognize the consequences of that imbalance for practice. "Productive conflict", defined as conflict under conditions of cooperative interdependence, can lead to good outcomes and "integrative solutions" that leave both parties satisfied with the result. In these cases the conflict itself is a kind of collaboration.

In this interpretation, the meaning of conflict depends on the underlying goal structure of interdependence, as described by Deutsch [34], and whether the practitioner is skillful enough to recognize the nature of her interdependence with the family. When the goal structure is cooperative, even when created by negative interdependence, there are very good chances that the conflict can result in good outcomes that are satisfactory to both parties. Experienced practitioners are often not threatened by conflict or afraid of it. They recognize the inevitability of conflict in practice and recognize the long-term possibilities that might be enhanced by conflict. One has to be aware that the weaker party in the relationship, the family, will feel threatened, and that conflict might serve the interests of the family and the interests of a long-term, sustainable integrative outcome.

How does this happen? The observations and interviews in this study provide a narrative but not an explanation, and for this Pruitt and Syna [36] and Deutsch [34] suggest that there are successful strategies for capitalizing on conflict and reinforcing cooperative goal structures while seeking an "integrative solution" (not simply compromise). If the practitioner recognizes this and does not foreclose by making an early decision, which happens fairly often, conflict is a means for buying enough time and negotiating the terms of the relationship such that an integrative solution is possible. A period of conflict can be useful in preparation for bargaining in these ways: 
$A$ It provides a period of "posturing" for the purpose of face-saving and establishing credibility. Being investigated is threatening, and marshalling resources in one's own defense is an element of defending one's dignity. This is a point that has been taken up lately by some solution-focused theorists. Clients rally their informal support networks around them, and they can be skillful at preparing counter arguments and explanations for the events under question. Consistent with these principles, conflict may demonstrate to the practitioner the parents' care for and commitment to their family. Parents' defense of their right to parent may be instructive to practitioners. If the practitioner is able to avoid feeling under attack and threatened by conflict, and if she is able to allow the family time and space to defend itself, good things may result. We have also seen practitioners, as in the example above, tolerate unfair portrayals of themselves and accept unfair blame in the long-term interest of sustaining the relationship.

$B$ Helping each party to clarify their own goals and impressing them on the other party. Occasionally it takes time for the client to take seriously the intentions of the practitioner. But this principle is most important for the weaker party. A period of conflict makes it more likely that the strong party will listen to the weaker party. This is crucial to success, because it interrupts the clock-time, linear process of the unfolding of a case. The unpredictability of the client may invite - or force - the practitioner to pay attention in a different way and to look for new data. In the case cited above, the client and victim of violence refused to accept the assumption of the professional that ending the relationship with the perpetrator was the ultimate goal. She described the practitioners' interventions as based on an Aboriginal stereotype, and she insisted that her views be taken into account. It may have been a coincidence, but the outcome was that her husband successfully completed addiction treatment, she began taking classes at a local college, and parents and children were reunited in short order.

Clarification of goals is crucial here. Practitioners aim to keep children safe, of course, but the particulars of "what safety looks like," in their phrase, take time to work out and investigate in the context of a family's daily life: rhythms, available extended family, material resources, capacities, and each party's assumptions get tested. Clients' negotiation, in conflict, may require practitioners to take a second look.

$C$ Testing how far the other party can be pushed and impressing on each party that a dead end accomplishes little. This is a risky strategy for both parties in child protection, and it is probably not recommended. Yet in one case we saw that its use by a family helped it grasp the difference between the practitioner's negotiable and non-negotiable interests.

$D$ Demonstrating firmness. Interestingly, the bargaining literature suggests that "If one party refuses to engage in early competitive behavior, the other will often conclude that the first is quite flexible and hence will gain greater faith in competitive tactics." ([34], p. 76). Responding to disagreement and to bargaining positions by being "nice" or giving way too soon may backfire by unintentionally encouraging more competitive behavior. An early, firm response and careful explication of one's position may increase the likelihood of later collaboration. 
$E$ Conflict can be enjoyable and satisfying, and we have seen families and practitioners being drawn into the drama that results. It motivates clients and practitioners, although only a few practitioners will admit it. It is easily heard in any professional office, and it is often easily heard in the waiting area of child welfare offices, as families talk to each other and to receptionists, and it is seen and heard in interviews.

$F$ Conflict demarcates groups from one another and establishes group and personal identities. It bonds family members to each other. External conflict fosters internal cohesiveness. Deutsch [34] calls this "enemy interdependence". This is quite common among clients, where extended family and friends may rally to the defense of the client. Practitioners play the role of "enemy" when it can lead to a family rallying to the care of a child and advocating for themselves.

$G$ Conflict allows for adjustment to new norms, and once the respective power of the contenders has been ascertained through disagreement, a new equilibrium can be established and the relationship can proceed on this new basis. This is one reason why interpreting conflict with the family as "resistance" might be a limited understanding. This is a wide-spread view in perspectives adopted from therapy, such as response-based and solution-focused perspectives. These characterize resistance as a psychological strategy of preserving dignity. However, resistance is not just a psychological dynamic: It is a bargaining and negotiating tool, and interpreting it as resistance underestimates the context of bargaining and diminishes the client.

$H$ "Conflict arouses motivation to solve problems that might otherwise go unattended" ([34], p. 361). We have seen this especially with experienced professionals, for whom a conflict may help invoke their expertise and experience in helpful ways or help them respond in less autonomic ways. Conflict encourages effort to overcome tension and frustration, and it inspires a search for creative solutions.

I Conflict facilitates honesty between professionals and client. Earlier I described how some parents report that when professionals make nice at the beginning of the relationship, they are more suspicious, not less, and want the practitioner to "get on with it". The professional is less likely to obscure what she wants.

\section{Conclusions}

The woman in the case cited earlier raged against the practitioner and the Ministry, embarrassed by their presence in her life, afraid of her husband, and afraid to lose her children. She was abusive to the practitioner and libeled the practitioner in the community. She fought hard against the service even after her husband beat her so badly in front of her children that her friends did not recognize her. Yet she and the practitioner were stuck with each other, and the practitioner was undeterred. The practitioner later acknowledged that she did not handle everything as well as she would like, but she was honest and direct, and if she erred she erred on the side of being too honest. She told the client the bottom line and, most importantly, the client's battle for herself allowed the practitioner to take the time to listen to the possibility that everything could work out, despite the addiction and the violence. In the end, the client said, "The practitioner was terrible and also did everything possible to help." 
The case is over and has been closed, and the client calls the practitioner occasionally to say hello and report how things are going. In spite of the client's verbal abuse of her, the practitioner came to like and respect the client. This is a small miracle.

The conflict and renegotiation of goals is a kind of collaboration, although not a kind of collaboration modeled after any other helping relationship, especially counseling. Conflict in child protection seems to disrupt the dynamics of unequal power, temporarily, and it gains for the client a space and some time to regroup, to marshal arguments on one's own behalf, and that process may also help the client to come to understand better the practitioner's point of view.

Child protection practice has trouble when it only circumscribes the power of the family-being too controlling - and when it only enhances the power of the family, ceding authority and putting children's safety at risk. Corby, Millar, and Young said “...there is a need for an approach which more explicitly acknowledges the power differentials involved in child protection work, but which operates within these constraints of power to more genuinely give parents a voice, even if this leads to more open disagreement between parents and professionals. Disagreement can actually be construed as a positive part of the process, something to be facilitated..." ([6], p. 489).

Conflict may engage families with practitioners in such a way that capitalizes on this central dynamic. Mayer says that family group conferencing and mediation are two methods that enhance the power of the client within the context of child protection. These are wonderful tools, and they require serious commitment of time and resources. Conflict between child protection practitioners and clients is an everyday activity that enacts, in part, some of the empowerment while not pretending that practitioners do not have much authority. It is the interdependence that allows conflict to flourish and that takes the sharp edges off the worst consequences of unequal power. Clients have real power in these settings; at the same time, practitioners have no intention-nor should they - of giving up their mandated authority. Both coexist, and conflict may be a part of enacting this collaborative dynamic in productive ways.

This theoretical exploration is reporting on ethnographic data in a postulated way, with an extended discussion of theory about a limited amount of data. Extended study of many additional cases in great detail is demanded to better understand this dynamic. Further, this interpretation is based on the assumption that child protection relationships are accurately characterized as a kind of cooperative interdependence, and this needs verification. Such verification requires data about whether or not there really is a common fate shared by practitioners and clients and whether the reward structure really does operate in the way described here.

A further need is to examine the nature of integrative solutions, that is, solutions that meet the needs and interests of both the family members and the practitioner and the system he or she represents. It would be useful to study how these come about and the kinds of agreements to which they come.

\section{Conflicts of Interest}

The author declares no conflict of interest. 


\section{References}

1. Andrew Turnell. "Constructive Child Protection Practice: An Oxymoron or News of Difference.” Journal of Systemic Therapies 25 (2006): 3-12.

2. Alan Wade. "Despair, Resistance, Hope: Response-Based Therapy with Victims of Violence." In Hope and Despair in Narrative and Family Therapy. Edited by Imelda McCarthy, Jim Sheehan and Carmel Flaskas. New York: Routledge, 2007, pp. 63-74.

3. Gillian Ruch. "The Contemporary Context of Relationship-based Practice." In Relationship-Based Social Work: Getting to the Heart of Practice. Edited by Gillian Ruch, Danielle Turney and Adrian Ward. Philadelphia: Jessica Kingsley Publishers, 2010, pp. 13-28.

4. Gillian Ruch. "Relationship-based Practice and Reflective Practice: Holistic Approaches to Contemporary Child Care Social Work." Child and Family Social Worker 10 (2005): 111-23.

5. Margaret Bell. "Working in Partnership in Child Protection: The Conflicts." British Journal of Social Work 29 (1999): 437-55.

6. Brian Corby, Malcolm Millar, and Lee Young. "Parental Participation in Child Protection Work: Rethinking the Rhetoric.” British Journal of Social Work 26 (1996): 475-92.

7. Chris Trotter. Working with Involuntary Clients. Thousand Oaks: Sage, 2006.

8. Dendy Platt. "Congruence and Cooperation in Social Workers' Assessments of Children in Need." Child \& Family Social Work 12 (2007): 326-35.

9. Gary C. Dumbrill. "Parental Experience of Child Protection Intervention: A Qualitative Study." Child Abuse \& Neglect 30 (2006): 27-37.

10. Julie C. Altman. "Engaging Families in Child Welfare Services: Workers versus Client Perspectives.” Child Welfare 87 (2008): 41-61.

11. William Vesneski. "Street-level Bureaucracy and Family Group Decision Making in the USA." Child \& Family Social Work 14 (2009): 1-5.

12. Bernie Mayer. "Reflections on the State of Consensus-Based Decision Making in Child Welfare." Family Court Review 47 (2009): 10-20.

13. Sarah Maiter, Sally Palmer, and Shehenaz Manji. "Strengthening Social Worker-Client Relationships in Child Protective Services: Addressing Power Imbalances and 'Ruptured' Relationships.” Qualitative Social Work 5 (2006): 167-86.

14. Martha Morrison Dore, and Leslie B Alexander. "Preserving Families at Risk of Child Abuse and Neglect: The Role of the Helping Alliance." Child Abuse \& Neglect 20 (1996): 349-61.

15. Jennifer A. Reich. Fixing Families: Parents, Power, and the Child Welfare System. New York: Routledge, 2005.

16. David Kipnis. The Powerholders. Chicago: University of Chicago Press, 1976.

17. David Kipnis. "Accounting for the use of Behavior Technologies in Social Psychology." American Psychologist 49 (1994): 165-72.

18. David Kipnis. "Using Power: Newton's Second Law." In The Use and Abuse of Power: Multiple Perspectives on the Causes of Corruption. Edited by Annette Y. Lee-Chai and John A. Bargh. New York: Psychology Press, 2001, pp. 3-17. 
19. Bruce Rind, and David Kipnis. "Changes in Self-Perceptions as a Result of Successfully Persuading Others." Journal of Social Issues 55 (1999): 141-56.

20. David Kipnis. "Can Social Behavior Be Influenced by Events That We Are Unaware of?" American Psychologist (1998): 1079-180.

21. Philip C. Kendall, David Kipnis, and Laura Otto-Salaj. "When Clients Don't Progress: Influences on and Explanations for Lack of Therapeutic Progress." Cognitive Therapy and Research 16 (1992): 269-81.

22. David Kipnis. "Technology, Power, and Control." Research in the Sociology of Organizations 3 (1984): 125-56.

23. David Kipnis. "Psychology and Behavioral Technology." American Psychologist 42 (1987): 30-36.

24. David Kipnis. "The Consequences of Technological Control." In Recent Advances in Social Psychology: An International Perspective. Edited by Joseph P Forgas and J. Michael Innes. North-Holland: Elsevier Science, 1989.

25. Chris Trotter. "Worker Skill and Client Outcome in Child Protection." Child Abuse Review 11 (2002): 38-50.

26. Eva Hjorne, Kirsi Juhila, and Carolus van Hijnatten. "Negotiating Dilemmas in the Practices of Street-level Welfare Work." International Journal of Social Welfare 19 (2010): 303-09.

27. Ronald H. Rooney. Strategies for Work with Involuntary Clients. New York: Columbia University Press, 1992.

28. Evelyn G. Khoo, Lennart Nygren, and Ulf Hyvonen. "Resilient Society or Resilient Children? A Comparison of Child Welfare Service Orientations in Sweden and Ontario, Canada." In Promoting Resilience in Child Welfare. Edited by Robert F. Flynn, Peter M. Dudding and James G. Barber. Ottawa: University of Ottawa Press, 2006, pp. 72-93.

29. Harry Ferguson. Protecting Children in Time: Child Abuse, Child Protection, and the Consequences of Modernity. London: Palgrave MacMillan, 2004.

30. Gary Alan Fine. "Towards a Peopled Ethnography: Developing Theory from Group Life." Ethnography 4 (2003): 41-60.

31. David Kipnis. "The Use of Power in Organizations and Interpersonal Settings." Applied Social Psychology Annual 5 (1984): 179-10.

32. Peter Reder, Sylvia Duncan, and Moria Gray. Beyond Blame: Child Abuse Tragedies Revisited. London: Routledge, 1993.

33. Edgar C. O’Neal, David Kipnis, and K.M. Craig. "Effects on the Persuader of Employing a Coercive Influence Technique.” Basic and Applied Social Psychology 15 (1994): 225-38.

34. Morton Deutsch. The Resolution of Conflict: Constructive and Destructive Processes. New Haven: Yale University Press, 1973.

35. Chris Ansell, and Alison Gash. "Collaborative Governance in Theory and Practice." Journal of Public Administration, Research, and Theory 18 (2007): 543-71.

36. Dean G. Pruitt, and Helena Syna. "Successful Problem Solving." In Productive Conflict Management: Perspectives for Organizations. Edited by Dean G. Tjosvold and David W. Johnson. Edina: Interaction Book Company, 1989, pp. 69-90. 


\section{MDPI AG}

Klybeckstrasse 64 4057 Basel, Switzerland Tel. +4161683 7734 Fax +41613028918

http://www.mdpi.com/

Social Sciences Editorial Office

E-mail: socsci@mdpi.com

http://www.mdpi.com/journal/socsci 

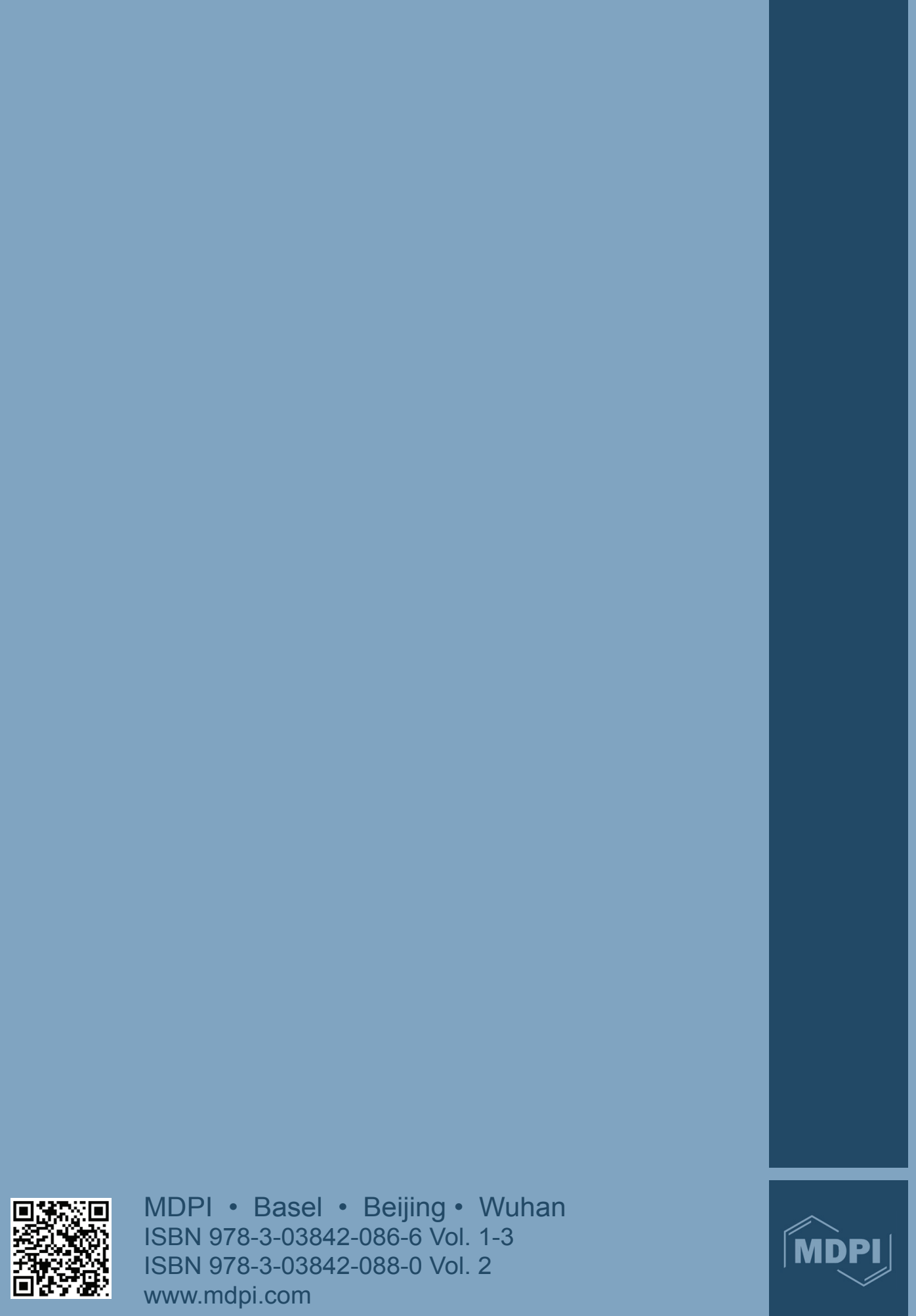